\title{
DESIGN OF A BORON NEUTRON CAPTURE ENHANCED FAST NEUTRON THERAPY ASSEMBLY
}

\author{
A Dissertation \\ Presented to \\ The Academic Faculty
}

by

Zhonglu Wang

In Partial Fulfillment of the Requirements for the Degree Doctor of Philosophy in Health Physics

in the G.W. Woodruff School of Mechanical Engineering

Georgia Institute of Technology

December 2006

COPYRIGHT @ 2006 BY ZHONGLU WANG 


\section{DESIGN OF A BORON NEUTRON CAPTURE ENHANCED FAST NEUTRON THERAPY ASSEMBLY}

Approved by:

Dr. Nolan E. Hertel, Advisor

School of Mechanical Engineering

Georgia Institute of Technology

Dr. C-K Chris Wang

School of Mechanical Engineering

Georgia Institute of Technology

Dr. Ratib Karam

School of Mechanical Engineering

Georgia Institute of Technology
Dr. Eva K. Lee

School of Industrial \& Systems

Engineering

Georgia Institute of Technology

Dr. Arlene J. Lennox

Fermilab Neutron Therapy Facility Fermi National Accelerator Laboratory

Dr. Rebecca Howell

Department Oncology

Emory University

Date Approved: July 19, 2006 
In the memory of my grandparents, Junwen and Shi Wang 


\section{ACKNOWLEDGEMENTS}

I wish to thank all those who have helped me with this work, both directly and indirectly. I am deeply grateful to my advisor Dr. Nolan E. Hertel for giving me the opportunity to work with him on so many interesting projects. He has been a great advisor and friend to me through the years. Without his guidance, support, patience and inspiration I would not have come through my graduate life this way. I would like to thank Dr. C-K Chris Wang for his assistance and advice.

I thank Dr. Arlene Lennox for her support, assistance and insights for this project. I am grateful to her for spending the weekend helping me with the experiments when she was supposed to be with her family.

I would like to thank Dr. Ratib Karam, Dr. Eva Lee and Dr. Rebecca Howell for serving on my reading committee and for providing advice on this research.

I have benefited from the work of Dr. Jeremy E. Sweezy. His work has provided me a sound basis for this research. He also provided me assistance on MCNP and MCNPX problems.

I also want to thank Dr. Tom Kroc, Dr. Erik Ramberg and Mr. Mark Austin for their help. Dr. Kroc helped me with foil activation and depth-dose distribution measurements. Dr. Ramberg prepared most of the materials for the experiment. He stayed until midnight to run the LINAC and also provided insightful suggestions for the experiment. Mr. Martin provided the drawings of the head phantom based on which I performed the MCNP simulation. 
I have to say a big thank to Eric Burgett for helping me with my experiments. Without his help there would be quite a few data points missing. Thanks to Dwayne Blaylock for his help with the hot cell operation.

I would like to thank Dr. John Valentine for recruiting me into the Nuclear Radiological Engineering and Health Physics program and thank Dr. Rodney Ice for hiring me as a Graduate Research Assistant in the Radiological Safety Office (ORS). Thanks to Jeremiah Sauber and Nazia Zaker for their help while I was working in the ORS.

To Yufen, my wife, I am grateful for her support, encouragement and motivation through the endeavors in the last fifteen years. To Xiaoyu and Xiaolei, I am so lucky to have them as my sons.

To my parents, Tongzhen and Yuhua, my brothers, Zhongfu and Zhongzheng, my sisters, Zhongxiang and Zhongling, my aunt, Tonglian, I appreciate all the support and love that you have given me through every endeavor. 


\section{TABLE OF CONTENTS}

$\begin{array}{lr} & \text { Page } \\ \text { DEDICATION } & \text { iii } \\ \text { ACKNOWLEDGEMENTS } & \text { iv } \\ \text { LIST OF TABLES } & \text { ix } \\ \text { LIST OF FIGURES } & \text { xii } \\ \text { LIST OF ABBREVIATIONS } & \text { xvii } \\ \text { SUMMARY } & \text { xix }\end{array}$

\section{$\underline{\text { CHAPTER }}$}

1 INTRODUCTION 1

$\begin{array}{ll}1.1 \text { Objective } & 2\end{array}$

1.2 Organization 2

2 BACKGROUND 4

2.1 Boron Neutron Capture Therapy 4

$\begin{array}{ll}\text { 2.2 Fast Neutron Therapy } & 8\end{array}$

2.3 Boron Neutron Capture Enhanced Fast Neutron Therapy 9

3 DOSE MEASUREMENTS 13

3.1 Measurements of the Absorbed Dose 13

3.2 Borated Ion Chamber Thermal Neutron Response 16

3.3 Dose Enhancement Due to Boron Neutron Capture 19

3.4 Calibration of the TE Ion Chambers 19

3.4.1 Gamma-ray calibration 19

$\begin{array}{ll}\text { 3.4.2 Thermal neutron calibration } & 21\end{array}$ 
4 CALCULATION AND MEASUREMENTS OF THE NEUTRON SPECTRAL FLUENCE RATE 26

4.1 Activation Foils and Activation Products 27

4.2 HPGe Detector Calibration 29

4.2.1 Modeling of the HPGe detector 29

4.2.2 Calculation of the efficiencies for gamma rays emitted by ${ }^{24} \mathrm{Na}$

4.3 Neutron Spectrum Unfolding 33

4.4 Calculation of the Response Matrices 34

4.5 Foil Activation and Counting 37

$\begin{array}{ll}4.6 \text { Results } & 38\end{array}$

5 DESIGN OF THE BNCEFNT ASSEMBLY 42

5.1 Selection of Material for the Filter and Collimator 42

5.2 Characterization of the Designed Assembly using MCNP Simulations

5.3 Validation of the Design 56

5.4 Dose Enhancement Calculation in a Hypothetic Tumor 74

$\begin{array}{ll}5.5 \text { Discussion } & 80\end{array}$

6 EVALUATION OF THE ABSORBED DOSE IN OTHER ORGANS 83

7 RADIOACTIVITIES GENERATED IN THE BNCEFNT ASSEMBLY AND THEIR DOSE CALCULATIONS 85

7.1 Calculation of the Activities of the Activation Products 86

7.1.1 Activities of the Activation Products in Tungsten Filter 86

7.1.2 Activities of the Activation Products in Lead collimator 89

7.2 Calculation of the Dose Rate for Unit Activity of the Activation Products $\quad 89$

8 CONCLUSIONS AND FUTURE WORK 94 
8.1 Conclusions $\quad 94$

8.2 Future Work 95

APPENDIX A: TABLES OF NTF NEUTRON SPECTRUM AND RESPONSE MATRICES 97

APPENDIX B: MEASUREMENTS AND CALCULATIONS OF THE ABSORBED DOSE, BORON DOSE AND PDE 104

APPENDIX C: TABLES RAW DATA OF MEASUREMENTS 112

APPENDIX D: SELECTED MCNPX AND MCNP5 INPUT FILES 123

$\begin{array}{lr}\text { REFERENCES } & 160\end{array}$ 


\section{LIST OF TABLES}

Page

Table 1: AAPM recommend values and uncertainties [44] of the constants in Equation (3.5).

Table 2: Gamma calibration results of the borated and non-borated ion chambers 20

Table 3: Decay data of the Activation Products [52,53] 28

Table 4: MCNP5 calculated peak efficiencies for gamma rays from the aluminum and copper foil activation products

Table 5: Production rates $(\mathrm{Bq} / \mathrm{g} / \mathrm{sec})$ for foils behind different moderation thickness 39

Table 6: Doses in other organs relative to brain dose.

Table 7: Number of nuclei of the activation products generated in 1 gram of tungsten per unit neutron fluence

Table 8: Total activities $(\mathrm{Bq})$ produced in 5-cm tungsten filter for 12, 20 and 100 minutes

Table 9: Total activities $(\mathrm{Bq})$ produced in the lead collimator for 21, 20 and 100 minute irradiation

Table 10: Calculated Dose rate by different conversion factors at $50 \mathrm{~cm}$ from back, front and side of the BNCEFNT assembly due to unit activity of the activation products in tungsten filter.

Table 11: Calculated Dose rate by different conversion factors at $50 \mathrm{~cm}$ from back, front and side of the BNCEFNT assembly due to unit activity of the activation products in lead collimator.

Table 12: Total air kerma rate $(\mathrm{Rad} / \mathrm{h})$ due to activation products in the tungsten filter and lead collimator at the end of 12, 20, and 100-minute irradiation

Table 13: Measured and MCNPX calculated NTF neutron spectrum at isocenter $\quad 98$

Table 14: Al-28 response matrix ( $\mathrm{Bq} / \mathrm{g}$ per $\left.\mathrm{n} / \mathrm{cm}^{2}\right)$

Table 15: Mg-27 response matrix Bq/g per $\mathrm{n} / \mathrm{cm}^{2}$

Table 16: Na-24 response matrix $\mathrm{Bq} / \mathrm{g}$ per $\mathrm{n} / \mathrm{cm}^{2}$

Table 17: Cu-66 response matrix $\mathrm{Bq} / \mathrm{g}$ per $\mathrm{n} / \mathrm{cm}^{2}$ 
Table 18: Cu-62 response matrix Bq/g per $\mathrm{n} / \mathrm{cm}^{2}$

Table 19: MCNP5 calculated absorbed dose (neutrons and gamms) distributions in the simplified water filled head phantom for different thickness of tungsten filter

Table 20: MCNP5 calculated PDE distribution for different thickness of tungsten filter

Table 21: MCNP5 calculated gamma dose percentage in the total absorbed dose for different thickness of tungsten filter

Table 22: Calculated absorbed dose distribution (Gy/MU) for different thick tungsten filter as in the measurements

Table 23: Calculated boron dose per 100-ppm ${ }^{10} \mathrm{~B}$

Table 24: Calculated PDE distribution for different thick tungsten filter as in the measurements

Table 25: Measurements of the absorbed dose in the water-filled head phantom using non-borated ion chamber (SN:445)

Table 26: Measured boron-10 dose using the borated (SN\#446) and the non-borated ion chambers and Equation (3.22)

Table 27: Measured PDE Normalized to $100-\mathrm{ppm}{ }^{10} \mathrm{~B}$ using the borated and non-borated ion chambers and Equation (3.23)

Table 28: Non-borated ion chamber measurement data for the simplified BNCEFNT assembly: $5 \times 5 \mathrm{~cm}^{2}$ collimator with no-filter using the $20 \times 20 \mathrm{~cm}^{2}$ standard therapy beam. Measurements made May, 2006.

Table 29: Non-borated ion chamber measurement data for the simplified BNCEFNT assembly: $5 \times 5 \mathrm{~cm}^{2}$ collimator with $1.0-\mathrm{cm}$ tungsten filter using the $20 \times 20 \mathrm{~cm}^{2}$ standard therapy beam. Measurements made May, 2006.

Table 30: Non-borated ion chamber measurement data for the simplified BNCEFNT assembly: $5 \times 5 \mathrm{~cm}^{2}$ collimator with $2.0-\mathrm{cm}$ tungsten filter using the $20 \times 20 \mathrm{~cm}^{2}$ standard therapy beam. Measurements made May, 2006.

Table 31: Non-borated ion chamber measurement data for the simplified BNCEFNT assembly: $5 \times 5 \mathrm{~cm}^{2}$ collimator with $3.0-\mathrm{cm}$ tungsten filter using the $20 \times 20 \mathrm{~cm}^{2}$ standard therapy beam. Measurements made May, 2006.

Table 32: Non-borated ion chamber measurement data for the simplified BNCEFNT assembly: $5 \times 5 \mathrm{~cm}^{2}$ collimator with $4.0-\mathrm{cm}$ tungsten filter using the $20 \times 20 \mathrm{~cm}^{2}$ standard therapy beam. Measurements made May, 2006. 
Table 33: Non-borated ion chamber measurement data for the simplified BNCEFNT assembly: $5 \times 5 \mathrm{~cm}^{2}$ collimator with $5.0-\mathrm{cm}$ tungsten filter using the $20 \times 20 \mathrm{~cm}^{2}$ standard therapy beam. Measurements made May, 2006.

Table 34: Borated ion chamber measurement data for the simplified BNCEFNT assembly: $5 \times 5 \mathrm{~cm}^{2}$ collimator with no-filter using the $20 \times 20 \mathrm{~cm}^{2}$ standard therapy beam. Measurements made May, 2006.

Table 35: Borated ion chamber measurement data for the simplified BNCEFNT assembly: $5 \times 5 \mathrm{~cm}^{2}$ collimator with 1.0 -cm tungsten filter using the $20 \times 20 \mathrm{~cm}^{2}$ standard therapy beam. Measurements made May, 2006.

Table 36: Borated ion chamber measurement data for the simplified BNCEFNT assembly: $5 \times 5 \mathrm{~cm}^{2}$ collimator with $2.0-\mathrm{cm}$ tungsten filter using the $20 \times 20 \mathrm{~cm}^{2}$ standard therapy beam. Measurements made May, 2006.

Table 37: Borated ion chamber measurement data for the simplified BNCEFNT assembly: $5 \times 5 \mathrm{~cm}^{2}$ collimator with $3.0-\mathrm{cm}$ tungsten filter using the $20 \times 20 \mathrm{~cm}^{2}$ standard therapy beam. Measurements made May, 2006.

Table 38: Borated ion chamber measurement data for the simplified BNCEFNT assembly: $5 \times 5 \mathrm{~cm}^{2}$ collimator with $4.0-\mathrm{cm}$ tungsten filter using the $20 \times 20 \mathrm{~cm}^{2}$ standard therapy beam. Measurements made May, 2006.

Table 39: Borated ion chamber measurement data for the simplified BNCEFNT assembly: $5 \times 5 \mathrm{~cm}^{2}$ collimator with $5.0-\mathrm{cm}$ tungsten filter using the $20 \times 20 \mathrm{~cm}^{2}$ standard therapy beam. Measurements made May, 2006. 


\section{LIST OF FIGURES}

Page

Figure 1: Demonstration of boron neutron capture reaction in tissue 4

Figure 2: Diagram of the MCNP5 modeled HPGe detector. (drawing not to scale) 30

Figure 3: Peak efficiency curves calibrated with a standard point source placed on the surface center of the detector cap and modeled using MCNP5 for the same geometry. 30

Figure 4: Simplified decay scheme of ${ }^{24} \mathrm{Na}$.

Figure 5: Observed peak efficiencies for a ${ }^{24} \mathrm{Na}$ point source moving along radial direction.

Figure 6: ${ }^{27} \mathrm{Al}(\mathrm{n}, \gamma){ }^{28} \mathrm{Al}$ Response functions behind various moderator thicknesses 35

Figure 7: ${ }^{27} \mathrm{Al}(\mathrm{n}, \mathrm{p}){ }^{27} \mathrm{Mg}$ Response functions behind various moderator thicknesses 35

Figure 8: ${ }^{27} \mathrm{Al}(\mathrm{n}, \alpha)^{24} \mathrm{Na}$ Response functions behind various moderator thicknesses 36

Figure 9: ${ }^{65} \mathrm{Cu}(\mathrm{n}, \gamma){ }^{66} \mathrm{Cu}$ Response functions behind various moderator thicknesses 36

Figure 10: ${ }^{63} \mathrm{Cu}(\mathrm{n}, 2 \mathrm{n}){ }^{62} \mathrm{Cu}$ Response functions behind various moderator thicknesses 37

Figure 11: Fermilab NTF neutron spectrum at isocenter for a $10 \times 10 \mathrm{~cm}^{2}$ standard treatment beam. The fluence rate is corresponding to a proton current of $1.5 \times 10^{14} \mathrm{p} / \mathrm{s}$

Figure 12: Fermilab NTF neutron spectrum at isocenter for a $10 \times 10 \mathrm{~cm}^{2}$ standard treatment beam displayed in lethargy.

Figure 13: Comparison of the Fermilab NTF neutron spectra determined by Cupps et al. and this work

Figure 14: Diagram of the MCNP5 model of graphite moderator/reflector, iron, lead and tungsten filter and collimator combinations, and the simplified RSVP head phantom. 43

Figure 15: PDE at 5-cm depth in the head phantom for various filter and collimator combinations.

Figure 16: Total dose rate at 5-cm depth in the head phantom for various filter and collimator combinations.

Figure 17: Relationship between PDE and total dose rate at 5-cm depth in the head phantom for various filter and collimator combinations. 
Figure 18: Diagram of the MCNP model of a tungsten filter, tungsten collimator and graphite reflector.

Figure 19: Calculated isodose curve of the neutron and gamma dose for 5.64-cm diameter and $7.0-\mathrm{cm}$ thick tungsten collimator, $4.0-\mathrm{cm}$ tungsten filter and $10-\mathrm{cm}$ thick graphite reflector as shown in Figure 18.

Figure 20: Calculated isodose curve of the boron dose $\left({ }^{10} \mathrm{~B}\right.$ concentration is uniformly distributed through the head) for 5.64- $\mathrm{cm}$ diameter and $7.0-\mathrm{cm}$ thick tungsten collimator, 4.0-cm tungsten filter and 10-cm thick graphite reflector as shown in Figure 18.

Figure 21: The MCNP calculated (a) depth-kerma distribution $\left(1.7 \times 10^{14}\right.$ protons $\left./ \mathrm{sec}\right)$ and (b) depth-PDE distribution of the 5.64-cm collimator along the centerline for various thick filters.

Figure 22: MCNP5 calculated depth-boron capture dose distribution of the 5.64-cm collimator along the centerline for various thick filters.

Figure 23: The MCNP5 calculated (a) depth-kerma distribution $\left(1.7 \times 10^{14}\right.$ protons $\left./ \mathrm{sec}\right)$ and (b) depth-PDE distribution of the 11.29-cm collimator along the centerline for various thick filters.

Figure 24: Relationship between PDE and total kerma rate as a function of filter thickness for the $5.64-\mathrm{cm}$ collimator at $5.7-\mathrm{cm}$ depth in the water filled head phantom.

Figure 25: The percentage of gamma kerma in the total dose as a function of depth in the water-filled head phantom for various tungsten filter thickness.

Figure 26: Total kerma rate off-axis profile at various depths in the water-filled head phantom in the designed BNCEFNT assembly with $5 \times 5 \mathrm{~cm}^{2}$ equivalent collimator and no-filter.

Figure 27: Total kerma rate off-axis profile at various depths in the water-filled head phantom in the designed BNCEFNT assembly with $5 \times 5 \mathrm{~cm}^{2}$ equivalent collimator and 4.0-cm thick tungsten filter.

Figure 28: Boron dose rate off-axis profile per $100-\mathrm{ppm}{ }^{10} \mathrm{~B}$ uniformly distributed in a water-filled head phantom in the designed BNCEFNT assembly with no-filter

Figure 29: Boron dose rate off-axis profile per $100-\mathrm{ppm}{ }^{10} \mathrm{~B}$ uniformly distributed in a water-filled head phantom in the designed BNCEFNT assembly with 4.0-cm tungsten filter

Figure 30: Drawings of the moderator, frame, collimator, and filter of the designed system

Figure 31: The $5 \mathrm{~cm}$ x $5 \mathrm{~cm}$ collimator made of four lead bricks (the brown colored in the center). 
Figure 32: Picture of the simplified moderator/collimator assembly.

Figure 33: The standard $20 \mathrm{~cm}$ x $20 \mathrm{~cm}$ beam collimator used in the experiment. 61

Figure 34: Head phantom used in the experiment. 61

Figure 35: The head phantom filled with deionized water inside the assembly. $\quad 62$

Figure 36: MCNP5 calculated and measured depth-dose distribution in the water filled head phantom for 0 -cm filter.

Figure 37: MCNP5 calculated and measured depth-dose distribution in the water filled head phantom for $1.0-\mathrm{cm}$ filter.

Figure 38: MCNP5 calculated and measured depth-dose distribution in the water filled head phantom for $2.0-\mathrm{cm}$ filter.

Figure 39: MCNP5 calculated and measured depth-dose distribution in the water filled head phantom for 3.0 -cm filter.

Figure 40: MCNP5 calculated and measured depth-dose distribution in the water filled head phantom for $4.0-\mathrm{cm}$ filter.

Figure 41: MCNP5 calculated and measured depth-dose distribution in the water filled head phantom for $5.0-\mathrm{cm}$ filter.

Figure 42: PDE for $100-\mathrm{ppm}{ }^{10} \mathrm{~B}$ in the water filled head phantom for $0.0-\mathrm{cm}$ filter. The measured PDE is obtained using Equation (3.23) and the borated and non-borated ion chamber readings.

Figure 43: PDE for $100-\mathrm{ppm}{ }^{10} \mathrm{~B}$ in the water filled head phantom for $1.0-\mathrm{cm}$ filter. $\quad 68$

Figure 44: PDE for 100-ppm ${ }^{10} \mathrm{~B}$ in the water filled head phantom for $2.0-\mathrm{cm}$ filter. $\quad 68$

Figure 45: PDE for $100-\mathrm{ppm}{ }^{10} \mathrm{~B}$ in the water filled head phantom for 3.0-cm filter. 69

Figure 46: PDE for 100-ppm ${ }^{10} \mathrm{~B}$ in the water filled head phantom for 4.0-cm filter. 69

Figure 47: PDE for 100-ppm ${ }^{10} \mathrm{~B}$ in the water filled head phantom for 5.0-cm filter. $\quad 70$

Figure 48: Comparison of the calculation and measurements of the boron dose distribution for $5.0-\mathrm{cm}$ thick tungsten filter.

Figure 49: Comparison of the calculation and measurements of the boron dose distribution for $4.0-\mathrm{cm}$ thick tungsten filter.

Figure 50: Comparison of the calculation and measurements of the boron dose distribution for 5.0-cm thick tungsten filter with adjusted data. 
Figure 51: PDE for 100-ppm ${ }^{10} \mathrm{~B}$ in the water filled head phantom for 5.0-cm filter after adjustment (a re-plot of Figure 47).

Figure 52: Comparison of the off-axis total dose rate profiles between MCNP calculations and the experiment at $8.8-\mathrm{cm}$ depth in a water-filled head phantom in the simplified BNCEFNT assembly with no-filter.

Figure 53: Comparison of the off-axis total dose rate profiles between MCNP calculations and the experiment at $8.8-\mathrm{cm}$ depth in a water-filled head phantom in the simplified BNCEFNT assembly with 5.0 -cm tungsten filter.

Figure 54: Relative dose due to boron neutron capture reaction in a water-filled head phantom inserted in the BNCEFNT assembly with $5 \times 5 \mathrm{~cm}^{2}$ tungsten collimator and no filter.

Figure 55: Calculated isodose curves for $(a)(n+\gamma)$ and (b) $(n+\gamma+$ BNC) in a waterfilled head phantom for a BNCEFNT assembly with 5.64-cm diameter tungsten collimator and no filter.

Figure 56: Calculated isodose curves for $(a)(n+\gamma)$ and $(b)(n+\gamma+B N C)$ in a waterfilled head phantom for a BNCEFNT assembly with 5.64-cm diameter tungsten collimator and $5.0-\mathrm{cm}$ tungsten filter.

Figure 57: PDE for the water-filled head phantom inserted in the BNCEFNT assembly with 5.65-cm diameter tungsten collimator and no-filter.

Figure 58: PDE for the water-filled head phantom inserted in the BNCEFNT assembly with 5.65-cm diameter tungsten collimator and 5.0-cm tungsten filter.

Figure 59: Absorbed dose rate and PDE-depth distribution in the head phantom in a BNCEFNT assembly with a 5.64-cm diameter collimator and a 7.5-cm tungsten filter. 79

Figure 60: Relative kerma $(n+\gamma)$ distributions in a water-filled head phantom in the BNCEFNT assembly with $5.64-\mathrm{cm}$ diameter collimator for no-filter and $5.0-\mathrm{cm}$ tungsten filter.

Figure 61: Relative measured absorbed dose $(n+\gamma)$ distributions in the water-filled head phantom using the simplified BNCEFNT assembly for no-filter and 5.0-cm filter.

Figure 62: Demonstration of dose enhancement in tumor for the simplified BNCEFNT assembly with no-filter and 5.0-cm tungsten filter.

Figure 63: Cross-sectional view (a) from front and (b) from side, of an anthropomorphic phantom in a sitting posture with its head in the BNCEFNT reflective assembly for the computation of organ doses.

Figure 64: Number of absorption, (n, 2n) and (n, 3n) interactions in each 20x20x1 cm tungsten filter per unit fluence in a $20 \times 20 \mathrm{~cm}^{2}$ standard neutron therapy beam. 
Figure 65: Comparison of source neutron spectrum and neutron spectrum after $5.0-\mathrm{cm}$ tungsten filter in the simplified BNCEFNT assembly (lethargy).

Figure 66: Comparison of source neutron spectrum and neutron spectrum after $5.0-\mathrm{cm}$ tungsten filter in the simplified BNCEFNT assembly (linear). 


\section{LIST OF ABBREVIATIONS}

\begin{tabular}{|c|c|}
\hline AAPM & American Association of Physicists in Medicine \\
\hline $\mathrm{Be}$ & Beryllium \\
\hline BMRR & Brookhaven Medical Research Reactor \\
\hline $\mathrm{BNCT}$ & Boron Neutron Capture therapy \\
\hline BNCEFNT & Boron Neutron Capture Enhanced Fast Neutron Therapy \\
\hline BNL & Brookhaven National Laboratory \\
\hline BPA-F & Boron Phenylalanine-Fructose \\
\hline $\mathrm{BSH}$ & Sodium borocaptate \\
\hline CAB & Cellulose Acetate Butyrate \\
\hline ENDF & Evaluated Nuclear Data File \\
\hline FNT & Fast Neutron Therapy \\
\hline GBM & Glioblastoma Multiforme \\
\hline HPGe & High-Purity Germanium \\
\hline ICRP & International Commission on Radiological Protection \\
\hline ICRU & International Commission on Radiation Units and Measurements \\
\hline Linac & Linear Accelerator \\
\hline LET & Linear Energy Transfer \\
\hline MCNP & Monte Carlo N-Particle Transport Code \\
\hline MIT & Massachusetts Institute of Technology \\
\hline MU & Monitor Units \\
\hline NIST & National Institute of Standards and Technology \\
\hline PDE & Percent Dose Enhancement \\
\hline ppm & Parts per million \\
\hline
\end{tabular}




$\begin{array}{ll}\text { RBE } & \text { Relative Biological Effectiveness } \\ \text { STP } & \text { Standard Temperature-Pressure }\left(0{ }^{\circ} \mathrm{C} \text { and } 1000 \mathrm{kPa}\right) \\ \text { TE } & \text { Tissue Equivalent } \\ \text { UW } & \text { University of Washington }\end{array}$




\section{SUMMARY}

The use of boron neutron capture to boost tumor dose in fast neutron therapy has been investigated at several fast neutron therapy centers worldwide. This treatment is termed boron neutron capture enhanced fast neutron therapy (BNCEFNT). It is a combination of boron neutron capture therapy (BNCT) and fast neutron therapy (FNT). It is believed that BNCEFNT may be useful in the treatment of some radioresistant brain tumors, such as glioblastoma multiforme (GBM).

A boron neutron capture enhanced fast neutron therapy assembly has been designed for the Fermilab Neutron Therapy Facility (NTF). This assembly uses a tungsten filter and collimator near the patient's head, with a graphite reflector surrounding the head to significantly increase the dose due to boron neutron capture reactions. The assembly was designed using Monte Carlo radiation transport code MCNP version 5 for a standard $20 \times 20 \mathrm{~cm}^{2}$ treatment beam. The calculated boron dose enhancement at $5.7-\mathrm{cm}$ depth in a water-filled head phantom in the assembly with a $5 \times 5$

$\mathrm{cm}^{2}$ collimation was $21.9 \%$ per $100-\mathrm{ppm}{ }^{10} \mathrm{~B}$ for a $5.0-\mathrm{cm}$ tungsten filter and $29.8 \%$ for a $8.5-\mathrm{cm}$ tungsten filter. The corresponding dose rate for the $5.0-\mathrm{cm}$ and $8.5-\mathrm{cm}$ thick filters were 0.221 and $0.127 \mathrm{~Gy} / \mathrm{min}$, respectively; about $48.5 \%$ and $27.9 \%$ of the dose rate of the standard $10 \times 10 \mathrm{~cm}^{2}$ fast neutron treatment beam.

To validate the design calculations, a simplified BNCEFNT assembly was built using four lead bricks to form a $5 \times 5 \mathrm{~cm}^{2}$ collimator. Five $1.0-\mathrm{cm}$ thick $20 \times 20 \mathrm{~cm}^{2}$ tungsten plates were used to obtain different filter thicknesses and graphite bricks/blocks were used to form a reflector. Measurements of the dose enhancement of the simplified 
assembly in a water-filled head phantom were performed using a pair of tissue-equivalent ion chambers. One of the ion chambers is loaded with 1000-ppm natural boron (184-ppm $\left.{ }^{10} \mathrm{~B}\right)$ to measure dose due to boron neutron capture. The measured dose enhancement at 5.0-cm depth in the head phantom for the 5.0-cm thick tungsten filter is $(16.6 \pm 1.8) \%$, which agrees well with the MCNP simulation of the simplified BNCEFNT assembly, $(16.4 \pm 0.5) \%$. The error in the calculated dose enhancement only considers the statistical uncertainties. The total dose rate measured at $5.0-\mathrm{cm}$ depth using the non-borated ion chamber is $(0.765 \pm 0.076) \mathrm{Gy} / \mathrm{MU}$, about $61 \%$ of the fast neutron standard dose rate $(1.255 \mathrm{~Gy} / \mathrm{MU})$ at $5.0-\mathrm{cm}$ depth for the standard $10 \times 10 \mathrm{~cm}^{2}$ treatment beam.

The increased doses to other organs due to the use of the BNCEFNT assembly were calculated using MCNP5 and a MIRD phantom. The activities of the activation products produced in the BNCEFNT assembly after neutron beam delivery were computed. The photon ambient dose rate due to the radioactive activation products was also estimated. 


\section{CHAPTER 1}

\section{INTRODUCTION}

Of the estimated 17,000 primary brain tumors diagnosed in the United States each year, approximately $60 \%$ are gliomas [1]. Glioblastoma multiforme (GBM), a primary, grade IV brain tumor, is by far the most common and most malignant of the glial tumors. This type of tumor is very difficult to remove completely by surgery due to its finger-like extensions that infiltrate the surrounding normal brain tissue. Patients diagnosed with GBM normally die within three months without treatment, and the mean survival time of the treated GBM patients is about one year.

GBM is radioresistant and the trials of photon therapy and fast neutron therapy have failed to provide a cure. However, the use of postoperative radiotherapy has shown to increase the median survival rate [2]. Studies reported by Catterall et al. has shown that the anti-tumor effects for patients receiving fast neutron therapy are greater than for patients receiving megavoltage $\mathrm{x}$-ray photon therapy [3].

Interest in the use of boron neutron capture therapy (BNCT) to treat giloblastoma started in the early 1950s. A ${ }^{10} \mathrm{~B}$ containing drug would be administered to the GBM patient and the ${ }^{10} \mathrm{~B}$ would be preferentially accumulated in the tumor volume. Then the tumor is irradiated with a thermal or epithermal neutron beam from a nuclear reactor or other neutron source. Boron-10 has a large thermal neutron capture cross section, and the highly ionizing alpha particle and lithium ion emitted from the reaction releases 2.34 $\mathrm{MeV} /$ interaction. Subsequently, the high linear energy transfer (LET) alpha particle and lithium ion give a large localized dose to the tumor cells. Despite the high tumor doses, the success of BNCT for GBM patients is quite limited, and it is still at the trial stage today. 
Waterman proposed the combination of boron neutron capture therapy and fast neutron therapy in 1978 [4], often called boron neutron capture enhanced fast neutron therapy (BNCEFNT), or neutron capture augment FNT. This therapy takes the advantage of fast neutron therapy (better penetration) and the dose enhancement at the tumor volume from BNCT. Studies have been focused on the improvement of physical dose enhancement for the BNCEFNT. No patients have ever been treated with BNCEFNT.

\subsection{Objective}

The objective of this work was to design a reflected BNCEFNT assembly around the patient's head with the goal of providing a greater than $15 \%$ dose enhancement for a 100 ppm ${ }^{10} \mathrm{~B}$ concentration. As a constraint on the BNCEFNT assembly, the total dose rate delivered to the patient should not decrease substantially. The design should not require any change in the structure of the standard treatment beam assembly.

The absorbed dose to other organs of the patient using the BNCEFNT assembly should be evaluated.

\subsection{Organization}

A brief review of boron neutron capture therapy (BNCT), fast neutron therapy (FNT) and boron neutron capture enhanced fast neutron therapy(BNCEFNT) is given in Chapter 2. The methods to measure fast neutron therapy dose and boron neutron capture dose are presented in Chapter 3. The calibration of the paired ion chambers used in this work, with an emphasis on the thermal neutron calibration, are also reported in Chapter 3. The measurements of spectral fluence rate of the Fermilab NTF neutron beam are presented in Chapter 4. In Chapter 5, the design of the BNCEFNT assembly using MCNP5 code is described and the calculated boron dose enhancements and total dose rate for various settings are given. The measurements and simulation of dose enhancement and total dose rate in a water-filled head phantom using a simplified BNCEFNT are also reported in 
Chapter 5. The calculation of dose to other organs of the patient using the BNCEFNT assembly for treatment is reported in Chapter 6. The activities of the most common activation products in the filter and collimator of the BNCEFNT assembly and dose rate due to these activities are reported in Chapter 7. Conclusions and recommendations for future investigations are presented in Chapter 8 .

Measurements and MCNPX calculations of the Fermilab NTF neutron spectral fluence rate are tabulated in Appendix A as are the responses of the foil activations ${ }^{28} \mathrm{Al}$, ${ }^{27} \mathrm{Mg},{ }^{24} \mathrm{Na},{ }^{62} \mathrm{Cu}$ and ${ }^{66} \mathrm{Cu}$ used to construct the spectrum. The measurements and calculations of dose enhancement and total dose rate are tabulated in Appendix B. The raw data from the BNCEFNT design validation are given in Appendix C. Selected MCNPX and MCNP5 input files are listed in Appendix D. 


\section{CHAPTER 2}

\section{BACKGROUND}

\subsection{Boron Neutron Capture Therapy}

The advantage of ${ }^{10} \mathrm{~B}$ in neutron capture therapy over other isotopes is its large reaction cross section, 3839 barns for $0.0253 \mathrm{eV}$ neutrons, its high natural abundance $19.8 \%$, and its high-LET reaction products. ${ }^{10} \mathrm{~B}$ is also available enriched to greater than $90 \%$. The boron neutron capture reaction for BNCT is shown in Figure 1. The lithium ion and alpha particle lose their energy over distances less than $10 \mu \mathrm{m}$, which is less than the diameter of a cell nucleus. The $1.47-\mathrm{MeV}$ alpha particle has a stopping power of 150 $\mathrm{MeV} / \mathrm{mm}$ and the $0.84-\mathrm{MeV}$ lithium ion has a stopping power of $52 \mathrm{MeV} / \mathrm{mm}$.

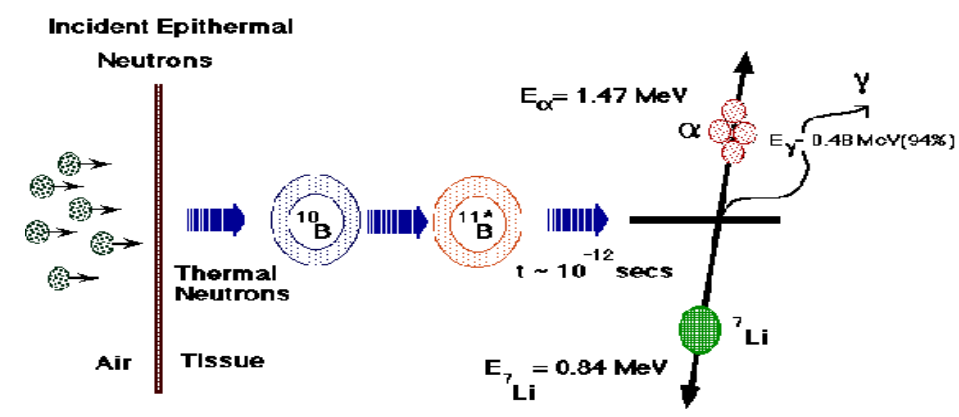

Figure 1: Demonstration of boron neutron capture reaction in tissue

William Sweet was the first to apply boron neutron capture therapy (BNCT) to the treatment of brain tumors. Sweet found that the blood-brain barrier prevented "first generation" borated compound from reaching normal tissue [5] and thus boron would be preferentially accumulated in the tumor volume where the blood-brain barrier was broken.

In the United States, the first clinical trial of boron neutron capture therapy (BNCT) for patients with GBM was initiated at Brookhaven National Laboratory's Graphite Research Reactor (BGRR) in 1951 [6]. From 1959 to 1961 a series of patients 
with intracranial tumors received BNCT at the Brookhaven Medical Research Reactor (BMRR). Another group of patients with malignant gliomas was treated at a reactor at the Massachusetts Institute of Technology (MIT) during 1959 1961. Results from these trials were disappointing and all clinical trials in the US were stopped. The disappointing results were attributed to the inadequate penetration of thermal neutron beams and poor localization of boron in tumor.

In the 1980's, improvements in neutron beams and boron compounds allowed reconsideration of BNCT. Clinical trials re-started in 1994 in the United States. The treatments were given with a closed skull using epithermal beams. Both boron phenylalanine-fructose (BPA-F) and sodium borocaptate $\left(\mathrm{Na}_{2} \mathrm{~B}_{12} \mathrm{H}_{11} \mathrm{SH}\right.$ : $\left.\mathrm{BSH}\right)$ boron compounds were used in these trials. The primary objective of the protocols was to evaluate the safety of BPA-F mediated BNCT in patients with GBM. As a second objective, the palliation of GBM by BPA-F mediated BNCT was assessed. Between September 1994 and June 1999, 54 patients were treated with BPA-F based BNCT at the BMRR. Of the 28 patients treated under protocol 4 (the most recent data available) at Brookhaven National Laboratory, 11 received single field therapy with a median survival of 14 months while the 17 patients with larger tumor volumes ( $37 \mathrm{cc}$ versus $18 \mathrm{cc}$ ) treated with two fields had a median survival of 10.5 months [7].

At Harvard-MIT, a phase I trial was conducted between July 1996 and May 1999 and 24 patients with primary or metastatic brain tumors were entered into the trial (22 patients were irradiated at the MIT Nuclear reactor laboratory) [8]. Neutron irradiation was delivered with a $15-\mathrm{cm}$ diameter epithermal beam. The treatment plans varied from 1 to 3 fields depending upon the size and location of the tumor. The ${ }^{10} \mathrm{~B}$ carrier, amino acid boron phenylalanine-fructose (BPA-F) compound was infused through a central venous catheter at doses of $250 \mathrm{mg} / \mathrm{kg}$ over $1 \mathrm{~h}$ (10 subjects), $300 \mathrm{mg} / \mathrm{kg}$ over $1.5 \mathrm{~h}$ (2 subjects), or $350 \mathrm{mg} / \mathrm{kg}$ over $1.5-2 \mathrm{~h}$ (10 subjects). The pharmacokinetic profile of ${ }^{10} \mathrm{~B}$ in blood was very reproducible and permitted a predictable model to be developed. A more recent 
phase I/II clinical trial was conducted at Harvard-MIT using a fission converter epithermal neutron beam [9]. Six GBM patients were treated with NCT by infusion of the BPA-F boron carrier at a dose of $14.0 \mathrm{~g} / \mathrm{m}^{2}$ body surface area over 90 min followed by irradiation by epithermal neutrons. The reported doses (in RBE Gy) were biologically weighted by applying the relative biologic effectiveness (RBE) factors for fast neutrons (3.2), thermal neutrons (3.2) and the compound biologic effectiveness factor (CBE) for the boron compound (3.8 for tumor and 1.3 for normal tissue). A dose reduction factor of 0.5 was applied for photon dose. Estimates of average tumor dose ranged from 33.7 to 83.4 RBE Gy (median 57.8 RBE Gy), a substantial improvement over the previous trials where the median value of the average tumor dose was $25.8 \mathrm{RBE}$ Gy.

Between August 1968 and July 2001, 183 patients with different kinds of brain tumors were treated by BNCT using 6 different reactors in Japan. In the retrospective analysis of appropriate radiation dose of boron n-alpha reactions, 105 patients with glial tumors treated in Japan between 1978 and 1997 were included [10]. Only the absorbed doses from boron $n$-alpha reactions were considered important to clinical outcomes. The RBE of the heavy charged particles was not evaluated. Gamma and fast neutron doses were not estimated. When 105 patients were divided according to whether they survived for more (group 1; $\mathrm{n}=29$ ) or less (Group 2; $\mathrm{n}=76$ ) than 3 years, it was found that those with longer survival times had received a significantly higher tumor volume dose. In patients with grade 2 giloma, the dose was 11.4 Gy (Group 1) versus 7.1 Gy (Group2), in those with grade 3 it was 15.3 Gy (Group 1) versus 10.5 Gy (Group 2), and in patients with glioblastoma (grade 4) it was 15.6 Gy (group1) versus 9.5 (group 2). Yamamoto et al. [11] reported on the latest BNCT trial at the Japan Research Reactor 4 (JRR-4) which has a mixed thermal/epithermal neutron beam. Nine patients with high-grade gliomas (5 glioblastoma and 4 anaplastic astrocytomas) were treated with BSH-based intraoperative boron neutron capture therapy. The blood boron level at the time of irradiation averaged $29.9(18.8-39.5) \mu \mathrm{g} / \mathrm{g}$. The minimum boron dose for the tumor and target volume 
averaged 15.9 Gy (7.5-24.6 Gy) and 7.3 Gy (3.7-11.9Gy), respectively. At the time of the report, 7 (4 glioblastoma and 3 anaplastic astrocytoma) of the 9 patients had died. The median survival time was 23.3 months for glioblastoma and 25.9 months for anaplastic astrocytoma.

In Europe, a phase I clinical trial testing the tolerance of the central nervous system (CNS) to BSH-mediated BNCT was undertaken and 10 patients have been treated [12]. In the European clinical trial, photon therapy is replaced by BNCT which is administered 2-6 weeks after debulking surgery. The boronated drug used is sodium borocaptate (BSH). The radiations are performed using the epithermal neutron beam of the High Flux Reactor at the Joint Research Center (JRC) in Petten/The Netherlands. The clinical trial is based on extensive preclinical dog studies as well as on distribution studies of the BSH in tumor cells.

The reports from both the Harvard-MIT and BNL studies indicate that the use of BNCT on residual tumor volumes greater than $60 \mathrm{~cm}^{3}$ leads to a greater incidence of neurological toxicity associated with increased intracranial pressure $[8,13]$. This is an acute effect related to tumor cell killing and associated edema. Other than side effects related to the residual tumor volume, the most commonly observed neurological side effect was a somnolence syndrome. The combined data for 68 evaluated patients from the Harvard-MIT and BNL BNCT clinical studies indicated that the doses associated with a $50 \%$ incidence of the effect $\left(\mathrm{ED}_{50} \pm \mathrm{SE}\right)$ were $6.2 \pm 1.0$ and $14.1 \pm 1.8 \mathrm{~Gy}(\mathrm{w})$ for average whole-brain doses and peak brain doses, respectively [14]. The brain doses are expressed in weighted $(\mathrm{Gy}(\mathrm{w}))$ units using $\mathrm{RBE}$ and compound biological effectiveness (CBE) [15,16] factors reported by Coderre and Morris [17] and Coderre et al. [18].

Kageji et al. [19] concluded from their study that the maximum vascular dose should not exceed 12 Gy to avoid the delayed radiation injury. In particular, it should be less than $10 \mathrm{~Gy}$ if the tumor exists in the speech center. The doses here are expressed in boron neutron capture physical dose (Gy). 
In clinical BNCT dosimetry, estimates of ${ }^{10} \mathrm{~B}$ dose in normal healthy tissue are generally based on the ${ }^{10} \mathrm{~B}$ concentration in blood as a surrogate for normal tissue [2022]. Furthermore, in the trials using the BPA-F complex as the boron delivery agent, a temporally constant tumor-to-blood concentration ratio of approximately $3.5-4$ to 1 is assumed for GBM [23-25]. These tumor-to-blood uptake ratios were measured by Coderre et al. $0.5-1.5 \mathrm{~h}$ after the end of infusion [26, 27]. A pharmacokinetic model to

predict ${ }^{10} \mathrm{~B}$ concentration in blood following the infusion of BPA-F, a schedule currently employed for BNCT treatment by Harvard-MIT group, has been developed by Kiger et al. $[28,29]$.

\subsection{Fast Neutron Therapy}

The study of biological effectiveness of neutrons started after the discovery of the neutron by Chadwick in 1932 [30]. In 1936 Lawrence et al. demonstrated that neutrons had a "selectively effect" in killing tumor tissue as opposed to health tissue when compared to x-rays [31]. In 1939, Stone began to treat patients using a neutron beam produced by $16-\mathrm{MeV}$ deuterons on a beryllium target. He reported that the neutrons produced a beneficial tumor response, but the treatment resulted in unacceptable late skin and subcutaneous radiation changes. In 1948, Stone concluded that neutrons had no place in cancer treatment because the side effects he observed outweighed the clinical benefits [32]. Ten years later researchers reopened this question and found out that Stone had severely overdosed the early patients [33]. New clinical studies [34] were begun in 1966 and their encouraging results led to the development of neutron therapy clinical trials throughout the world.

Fast neutron beams are considered the treatment of choice for inoperable salivary gland tumors. Fast neutron therapy has demonstrated advantage over conventional photon therapy [35] for the treatments resulting in long-term survival in advanced prostate cancer, inoperable squamous-cell lung cancer, soft-tissue sarcoma and osteosarcoma. It is 
estimated that $10-20 \%$ [36] of all oncology radiation patients would benefit from fast neutron therapy.

It was presumed that the fast neutrons may be beneficial for the treatment of brain tumors due to the presence of hypoxic cells. The clinical trials on fast neutron therapy for brain tumors did not show any advantage over photon therapy [36, 37] considering the life quality and survival time of the patients. Autopsy studies revealed considerably greater tumor destruction in the neutron-treated patients compared with those receiving photon treatments, but survival was limited by the onset of fatal postirradiation gliosis. This implied that no therapeutic window existed at which tumor control could be achieved without serious side effects.

\subsection{Boron Neutron Capture Enhanced Fast Neutron Therapy}

Boron neutron capture enhanced fast neutron therapy (BNCEFNT) was first proposed by Waterman et al. in 1978 [4]. In their proposal a boron containing drug would be used to selectively load the tumor cells with boron. Instead of irradiating the tumor with thermal or epithermal neutron beam, the tumor is irradiated with a fast neutron therapy beam. As a fast neutron beam penetrates the tissue some of the particles are degraded to thermal energies which can be captured by ${ }^{10} \mathrm{~B}$ resulting in a highly-localized release of additional energy during a course of fast neutron therapy. The percent dose enhancement (PDE) of a neutron beam generated by bombarding a $50-\mathrm{MeV}$ proton beam on a beryllium target is about $0.1 \%$ per ppm of boron concentration [39]. Since the fast neutron therapy beams are designed to minimize the thermal neutron spectral component, it needs to be modified to have a larger fraction of thermal/epithermal neutrons to enhance the boron neutron capture dose in the tumor and thus to set up a therapeutic window for the treatment of radiation-resistant tumors.

Several fast neutron therapy facilities worldwide, including the University of Washington (UW), Harper Hospital Fast Neutron Therapy facility, the Fermilab Neutron 
Therapy Facility (NTF), National Accelerator Centre (iThemba), and the Biomedical Cyclotron of Nice, are investigating ways of increasing the boron neutron capture dose.

In the UW FNT facility protons are accelerated in a cyclotron to an energy of 50.5 $\mathrm{MeV}$. The resulting proton beam is directed by a series of magnets and focusing devices onto the target. The standard target is a $10.5 \mathrm{~mm}$ beryllium target. The spectral character of the fast neutron beam was determined using activation foil technique [40]. A modified target specifically designed for BNCEFNT studies has been installed. The new target is composed of a $5-\mathrm{mm}$ layer of beryllium, followed by a $2.5-\mathrm{mm}$ layer of tungsten. The new target design produces essentially the same neutron flux above $40-\mathrm{MeV}$ as the standard target, per unit proton current, but leads to a decreased fluence rate in the 10 to $40-\mathrm{MeV}$ range and an increased fluence rate below $10 \mathrm{MeV}$. The new target produces a boron dose enhancement of $13 \%$ to $14 \%$ at a depth of about $6 \mathrm{~cm}$ for a $100 \mathrm{ppm}$ boron- 10 concentration and a 10x10 $\mathrm{cm}^{2}$ beam. The standard target resulted in a boron dose enhancement of about $7 \%$ at the 6 -cm depth $[41,42]$.

The Harper Hospital Fast Neutron Therapy Facility uses a superconducting cyclotron which accelerates deuterons to an energy of $48.5 \mathrm{MeV}$. The deuteron beam is incident on a beryllium target $(14.9 \times 20.1 \times 3.1 \mathrm{~mm})$ brazed to a channeled copper backing plate which is cooled with water [43]. The unmodified beam at this facility has a boron dose enhancement of $2.5 \%$ to $5 \%$ per $100-\mathrm{ppm}{ }^{10} \mathrm{~B}$ [44]. Studies at this facility have investigated the use of steel, tungsten, lead, and aluminum as possible filter materials for a BNCEFNT beam [45]. They found that the steel and tungsten provided the highest dose enhancements. Burmeister et al. [46] used a $25-\mathrm{cm}$ thick steel filter upstream of the beam to obtain a therapeutic gain factor (defined as the ratio of RBE-weighted tumor dose to RBE-weighted normal tissue dose) greater than $50 \%$ for a $15 \times 15 \mathrm{~cm}^{2}$ field at depths required to treat brain lesions. The modification of the beam resulted in RBE-weighted tumor dose rate of approximately $4 \mathrm{cGy} / \mathrm{min}$ at the depth of $2.5 \mathrm{~cm}$, which is too low for clinical applications. 
The Nice Biomedical cyclotron produces $60-\mathrm{MeV}$ protons that are incident on a laminated target of $15-\mathrm{mm}$ of beryllium followed by $9-\mathrm{mm}$ of graphite. A percent dose enhancement of $4.6 \%$ per $100-\mathrm{ppm}{ }^{10} \mathrm{~B}$ for a $10 \times 10 \mathrm{~cm}^{2}$ field and $10.4 \%$ for a $20 \times 20 \mathrm{~cm}^{2}$ field [47] has been calculated using FLUKA/MCNP-4A codes. Further studies to increase the PDE for the Nice Biomedical Cyclotron have focused on the addition of high atomic number material collimation near the patients head which is surrounded by a block of graphite. These studies concluded that a lead collimator placed near the head can produce PDE of $22 \%$ per $100-$ ppm ${ }^{10} \mathrm{~B}[48]$.

The Fermilab Neutron Therapy Facility produces neutrons by bombarding a 2.21cm-thick beryllium target with $66-\mathrm{MeV}$ protons. The protons lose $49 \mathrm{MeV}$ in the beryllium target and are stopped by a $0.5-\mathrm{mm}$ gold backing $[49,50]$. The percent dose enhancement (PDE) of the Fermilab NTF has been measured by Katja Langen using tissue-equivalent proportional counter loaded with 200-ppm ${ }^{10} \mathrm{~B}$ [51]. These measurements were performed in a head-shaped Lucite phantom filled with water at a depth of $5 \mathrm{~cm}$. A PDE of $1.5 \%$ per $100-\mathrm{ppm}{ }^{10} \mathrm{~B}$ for the $10 \times 10 \mathrm{~cm}^{2}$ field of the standard treatment beam was measured. Langen also attempted to modify the beam to increase the dose enhancement by using $9.0 \mathrm{~cm}$ of tungsten filtration. The tungsten filter was placed near the head phantom and produced a dose enhancement of $(2.5 \pm 0.1) \%$ for $100-\mathrm{ppm}$ ${ }^{10} \mathrm{~B}$. She reduced the proton energy to $37-\mathrm{MeV}$, and thus obtained a dose enhancement of (6.0 0.2$) \%$ using 20 -cm thick steel blocks to form a $12 \times 12 \mathrm{~cm}^{2}$ beam and using the 9.0 thick tungsten filter.

Jeremy Sweezy investigated the modification of the standard fast neutron beam at Fermilab NTF to increase PDE by using different collimation and filter materials with the MCNPX code [52]. He chose iron from 86 materials studied for use as collimation and filter materials. He measured a boron dose enhancement of $16.3 \%$ per $100-\mathrm{ppm}{ }^{10} \mathrm{~B}$ for a $20-\mathrm{cm}$ diameter beam and $10.0 \%$ per $100-\mathrm{ppm}$ of ${ }^{10} \mathrm{~B}$ for a $10-\mathrm{cm}$ diameter beam for this system. The dose rate of the modified beam was reduced to $4.4 \%$ of the dose rate of the 
standard treatment beam [53]. Sweezy also proposed the use of tungsten filter, tungsten collimator and graphite reflector around the head instead of using a filter and collimator up stream of the beam to increase the boron percent dose enhancement (PDE). He calculated a PDE of about $30 \%$ per $100 \mathrm{ppm}{ }^{10} \mathrm{~B}$ with a $5-\mathrm{cm}$ thick tungsten filter, a 10$\mathrm{cm}$-thick by $5.64-\mathrm{cm}$-inner-diameter tungsten collimator and a partial graphite reflector placed around a mathematical head phantom [53]. 


\section{CHAPTER 3}

\section{DOSE MEASUREMENTS}

Two tissue-equivalent ionization chambers manufactured by Exradin, now the Standard Image, Inc. [54], were available for the measurement of the fast neutron, photon and boron dose in the head phantom at Fermilab NTF. The chambers are $0.5-\mathrm{cm}^{3}$ Spokas thimble chambers composed of A-150 tissue-equivalent plastic. The two ion chambers are identical except that one of them is borated with 1000-ppm of natural boron in the tissue equivalent (TE) material. Since ${ }^{10} \mathrm{~B}$ comprises 18.4 weight percent of natural boron, the borated detector contains 184-ppm of ${ }^{10} \mathrm{~B}$. For all measurements and calibrations in this work, the ionization chambers are filled with air.

\subsection{Measurements of the absorbed dose}

The technique of using ionization chamber to measure the absorbed dose is based on the application of the Bragg-Gray Principle, which states that the absorbed dose in a given material can be deduced from the ionization produced in a small gas-filled cavity within the material. This relationship is based on the assumption that the charged particles produced by the radiation in the wall material of an ionization chamber lose a negligible fraction of the energy in traversing the gas cavity. This requires the use of a small cavity or alternatively the use of a homogeneous chamber, i.e., a chamber with wall and gas of the same composition. Ion chambers collect charges liberated in the fill gas, chamber wall, and surrounding media. The charge collected for radiation type $\mathrm{x}, Q_{x}$, is proportional to the absorbed dose in the chamber gas, which is in turn proportional to the absorbed dose in the chamber wall, $D_{w, x}$. The absorbed dose can be expressed as

$$
D_{w, x}=Q_{x} \cdot \frac{\bar{W}_{x}}{e} \cdot\left(S_{w, g}\right)_{x} \cdot \frac{1}{M_{g}}
$$


where $M_{g} \quad=$ the mass of the gas in the cavity

$\left(S_{w, g}\right)_{x}=$ ratio of stopping powers of wall to gas for secondary charged particles

$\bar{W}_{x} / e=$ the average energy required to produce an ion pair in the gas

$e \quad=$ the charge of the electron $\left(1.6 \times 10^{-19}\right.$ Coulomb $)$

The subscript $x$ denotes the type of radiation. If the ion chamber is calibrated in a ${ }^{60} \mathrm{Co}$ field the subscript is $C$. If the ion chamber is used to measure a mixed radiation beam the subscript is $T$, for total. The subscript $N$ is often used in place of $T$ when the neutron component predominates the radiation field.

For determination of the absorbed dose in tissue or tissue-equivalent phantom, $D_{t, x}$, the ratio of the mass-energy absorption coefficient of muscle tissue to that of the material of the chamber wall (A-150), $K_{x}$, must be applied.

$$
D_{t, x}=K_{x} \cdot D_{w, x}
$$

For measuring the absorbed dose of tissue in a mixed fast neutron and gamma radiation beam, $D_{t, T}$, the following equation should be used.

$$
D_{t, T}=Q_{T} \cdot \frac{1}{M_{g}} \cdot \frac{\bar{W}_{N}}{e} \cdot\left(S_{w, g}\right)_{N} \cdot K_{N} \cdot d_{N G}
$$

where $K_{N}=K_{t} / K_{w}$ is ratio of neutron kerma factor for tissue to that of A-150, $d_{N G}$ is the chamber displacement correction factor which accounts for the perturbation of the radiation field by the displacement of the phantom material by the ion chamber, $\bar{W}_{N} / e$ is the average energy $(\mathrm{J} / \mathrm{C})$ required to produce an ion pair in the chamber gas by secondary charged particles created by neutrons, and $Q_{T}$ is the charge collected by the detector. In this work, the absorbed dose due to fast neutron and gammas is measured with the nonborated ion chamber and $Q_{T}$ is replaced by $Q_{N B}$.

As seen in Equations (3.1) and (3.3), the mass of the gas, $M_{g}$, in the sensitive volume of the chamber is required. Generally, the sensitive volume of a chamber can not be computed with the designed accuracy from drawings. Therefore, the ion chamber is 
normally placed in a ${ }^{60} \mathrm{Co}$ field of known exposure for calibration. The absorbed dose of tissue from the known exposure to ${ }^{60} \mathrm{Co}$ is obtained by

$$
D_{t, C}=X_{c} \cdot f_{t, C} \cdot A_{w, C}=Q_{C} \cdot \frac{1}{M_{g}} \cdot \frac{\bar{W}_{C}}{\boldsymbol{e}}\left(\boldsymbol{S}_{w, g}\right)_{C} \cdot \boldsymbol{K}_{C}
$$

where $X_{c}$ is the known exposure (R) from the ${ }^{60} \mathrm{Co}$ source, $f_{t, C}$ is the tissue-dose-toexposure conversion coefficient $(\mathrm{Gy} / \mathrm{R}), A_{w, C}$ is the photon attenuation and scattering correction factor for the chamber(unitless), and $\bar{W}_{C} / e$ is the average energy $(\mathrm{J} / \mathrm{C})$ required to produce an ion pair in the chamber gas by secondary electrons created by ${ }^{60} \mathrm{Co}$ gamma rays. Combining equation 3.3 and 3.4, Equation 3.5 is obtained

$$
D_{t, T}=Q_{T} \cdot f_{t, C} \cdot A_{w, C} \cdot d_{N G} \cdot N_{C} \cdot \frac{\bar{W}_{N}}{\bar{W}_{C}} \cdot \frac{\left(S_{w, g}\right)_{N}}{\left(S_{w, g}\right)_{C}} \cdot \frac{K_{N}}{K_{C}}
$$

where $N_{c}=X_{C} / Q_{C}$ is the ion chamber ${ }^{60}$ Co calibration factor, $(\mathrm{R} / \mathrm{nC})$. The AAPM Report No. 7 recommended values and uncertainties [55] for these factors in Equation (3.5) are shown in Table 1. The value of the displacement correction factor, $d_{N G}$, shown in Table 1 for 0.5 -cc chamber is the linear interpolation of 0.970 (1.0-cc chamber) and $0.989(0.1-\mathrm{cc}$ chamber). These parameters are used in this experiment. Using these values, Equation (3.5) becomes

$$
\begin{aligned}
& \boldsymbol{D}_{t, T}=\boldsymbol{N}_{\boldsymbol{C}}(\boldsymbol{R} / \mathbf{n C}) \cdot 0.985 \cdot 0.00957(\mathbf{G y} / \mathbf{R}) \cdot 0.981 \cdot \frac{1.157}{1.142} \cdot \frac{35.8(\mathrm{~J} / \mathrm{C})}{33.7(\mathrm{~J} / \mathrm{C})} \cdot \frac{0.952}{1.004} \cdot \boldsymbol{Q}_{T}(\boldsymbol{n C}) \\
& =9.437 \times 10^{-3}(\mathbf{G y} / \mathbf{R}) \cdot \boldsymbol{N}_{\boldsymbol{C}}(\boldsymbol{R} / \mathbf{n C}) \cdot \mathbf{Q}_{\boldsymbol{T}}(\boldsymbol{n C})
\end{aligned}
$$

The charge measured in mixed radiation, $Q_{T}$, should be corrected to the same temperature-pressure condition as that of the ion chamber ${ }^{60} \mathrm{Co}$ calibration factor, $N_{c}$. The uncertainty of the coefficient in Equation (3.7), $9.437 \times 10^{-3}(\mathrm{~Gy} / \mathrm{R})$, is about $9 \%$, which is the combination of the uncertainties listed in Table 1.

The response of the ion chamber is a function of the mass of the gas in the chamber volume. The mass of the air inside the chamber changes with the change of temperature and pressure, so a correction of the temperature and pressure must be applied 
to the measurement. The temperature and pressure correction factor, TPC, corrected to the standard condition, $0{ }^{\circ} \mathrm{C}$ and $1000 \mathrm{kPa}$ is

$$
T P C_{x}=\frac{273.15+T_{x}}{273.15} \cdot \frac{1000 \mathrm{kPa}}{P_{x}}
$$

where $T_{x}$ is the temperature $\left({ }^{\circ} \mathrm{C}\right)$ and $P_{x}$ is the pressure $(\mathrm{kPa})$, the subscript $x$ denotes the environment of the measurement.

Table 1: AAPM recommend values and uncertainties [55] of the constants in Equation (3.5).

\begin{tabular}{cccc}
\hline Constant & AAPM value & Uncertainty $(\%)$ & Unit \\
\hline$A_{w, C}$ & 0.985 & 0.5 & unitless \\
$f_{t, C}$ & 0.00957 & 0.2 & Gy/R \\
$d_{N G}$ & 0.981 & 1 & unitless \\
$\left(S_{w, g}\right)_{N}$ & 1.157 & $4-5$ & unitless \\
$\left(S_{w, g}\right)_{C}$ & 1.142 & 1.0 & unitless \\
$\bar{W}_{N} / e$ & 35.8 & $6-8$ & $\mathrm{~J} / \mathrm{C}$ \\
$\bar{W}_{C} / e$ & 33.7 & 0.4 & $\mathrm{~J} / \mathrm{C}$ \\
$K_{N}$ & 0.952 & 2 & Unitless \\
$K_{C}$ & 1.004 & 0.2 & unitless \\
\hline
\end{tabular}

\subsection{Borated Ion Chamber Thermal Neutron Response}

The dose due to the boron capture reaction is a function of the ${ }^{10} \mathrm{~B}$ concentration and the thermal neutron flux. It can be measured using the borated and non-borated TE ion chamber. Because the alpha particles and lithium ions have a very short range in air the Bragg-Gray principle may not be satisfied for ion chambers with dimensions larger than the range of alpha particles and lithium ions. To overcome this problem the two ion chambers should be calibrated in a thermal neutron beam of known thermal neutron fluence rate.

The thermal neutron fluence is proportional to the difference of collected charges in the borated and non-borated ion chamber multiplied with a calibration factor. 


$$
\phi_{t h}=N_{t h} \cdot\left[Q_{B}-Q_{N B}\left(\frac{N_{C}^{N B}}{N_{C}^{B}}\right)\right]
$$

where $\phi_{t h}=$ the thermal neutron fluence $\left(\mathrm{n} / \mathrm{cm}^{2}\right)$.

$N_{t h}=$ the ion chamber thermal neutron calibration factor $\left(\mathrm{n} / \mathrm{cm}^{2} / \mathrm{nC}\right)$

$Q_{B}=$ the charge collected by the borated chamber (nC)

$Q_{N B}=$ the charge collected by the non-borated chamber (nC)

$N_{C}{ }^{B}={ }^{60}$ Co calibration factor of the borated ion chamber $(\mathrm{R} / \mathrm{nC})$

$N_{C}{ }^{N-B}={ }^{60}$ Co calibration factor of the non-borated ion $(\mathrm{R} / \mathrm{nC})$

If the thermal neutron fluence is known, the thermal neutron calibration factor can be calculated

$$
N_{t h}=\frac{\phi_{t h}}{\left[Q_{B}-Q_{N B}\left(\frac{N_{C}^{N B}}{N_{C}^{B}}\right)\right]}
$$

The boron capture dose, or the boron neutron capture rate per unit mass, is proportional to the thermal neutron fluence rate. The boron capture dose can be calculated from the boron capture rate:

$$
D_{B-10}(G y)=\frac{\phi_{t h} \sigma_{a_{t h}}^{B-10} N_{B-10} Q}{\rho_{\text {wall }}}
$$

where $\sigma_{a_{t h}}^{B-10}=$ the average microscopic $(\mathrm{n}, \alpha)$ cross section for thermal neutrons $\left(\mathrm{cm}^{2}\right)$.

$N_{B-10}=$ the atomic density of ${ }^{10} \mathrm{~B}\left(\right.$ atoms $\left./ \mathrm{cm}^{3}\right)$.

$\mathrm{Q}=$ the energy imparted to the alpha and lithium ions from the $(n, \alpha)$ reaction $(2.34 \mathrm{MeV})$.

$\rho_{\text {wall }}=$ density of the wall material $\left(\mathrm{g} / \mathrm{cm}^{3}\right)$.

The $(\mathrm{n}, \alpha)$ cross section of the ${ }^{10} \mathrm{~B}$ nuclide has a $1 / v$-behavior in thermal neutron region and the thermal reaction cross section, $\sigma_{a_{t h}}^{B-10}$ can be related to the $(\mathrm{n}, \alpha)$ cross section of $2200 \mathrm{~m} / \mathrm{s}$ neutrons $(0.0253 \mathrm{eV})$ by 


$$
\sigma_{a_{t h}}^{B-10}=\frac{\sqrt{\pi}}{2} \cdot \sqrt{\frac{T_{0}}{T_{n}}} \cdot \sigma_{a}^{B-10}\left(E_{0}\right)
$$

where $T_{0}$ and $T_{\mathrm{n}}$ are temperatures of the tabulated cross section (typically 293.46K) and the moderator for the measurement, respectively. $\sigma_{a}^{B-10}\left(E_{0}\right)$ is the microscopic $(\mathrm{n}, \alpha)$ cross section for neutrons of energy $E_{0}(0.0253 \mathrm{eV})$. From the ENDF-VI [56] evaluation for ${ }^{10} \mathrm{~B}, \sigma_{a}^{B-10}(0.0253 \mathrm{eV})=3839 \pm 6$ barns, therefore $\sigma_{a_{t h}}^{B-10}=3402 \pm 6$ barns if $T_{\mathrm{n}}=T_{0}$.

The ${ }^{10} \mathrm{~B}$ atomic density of the borated ion chamber can be calculated from

$$
N_{B-10}=\frac{w_{B-10} \rho_{\text {wall }} N_{a}}{A_{B-10}}
$$

where $w_{B-10}=$ weight percent of ${ }^{10} \mathrm{~B}, 184$ ppm for the borated ion chamber used.

$$
\begin{aligned}
& N_{a}=\text { Avogadro's number, } 6.022 \times 10^{23} \text { atoms } / \text { mole. } \\
& A_{B-10}=\text { atomic weight of }{ }^{10} \mathrm{~B}, 10.01293 \mathrm{~g} / \mathrm{mole} .
\end{aligned}
$$

Combining Equations (3.8), (3.10), and (3.12), we have

$$
\begin{aligned}
D_{B-10}(G y) & =N_{t h} \cdot\left[Q_{B}-Q_{N B}\left(\frac{N_{C}^{N B}}{N_{C}^{B}}\right)\right] \cdot \sigma_{a_{\text {th }}}^{B-10} \cdot \frac{Q}{\rho_{\text {wall }}} \cdot \frac{w_{B-10} \rho_{\text {wall }} N_{a}}{A_{B-10}} \\
& =N_{t h} \cdot\left[Q_{B}-Q_{N B}\left(\frac{N_{C}^{N B}}{N_{C}^{B}}\right)\right] \cdot Q \cdot \sigma_{a_{t h}}^{B-10} \cdot \frac{w_{B-10} N_{a}}{A_{B-10}}
\end{aligned}
$$

Substituting the parameters in Equation 3.13, for the 184-ppm ${ }^{10} \mathrm{~B}$ ion chamber, Equation (3.13) becomes

$$
\begin{aligned}
& D_{B-10}(G y)=N_{t h}\left(\frac{\mathrm{n}}{\mathrm{cm}^{2} \cdot \mathrm{nC}}\right) \cdot\left[Q_{B}(\mathrm{nC})-Q_{N B}(n C)\left(\frac{6.709(R / n C)}{7.055(R / n C}\right)\right] \cdot\left(3402 \times 10^{-24} \mathrm{~cm}^{2}\right) \times \\
& \frac{\left(184 \times 10^{-6}\right)\left(6.022 \times 10^{23} \text { atoms } / \mathrm{mole}\right)}{\left(10.01293 \mathrm{~g} / \mathrm{cm}^{3}\right)}(2.34 \mathrm{MeV})\left(1.602 \times 10^{-13} \frac{\mathrm{J}}{\mathrm{MeV}}\right)\left(1000 \frac{\mathrm{g}}{\mathrm{kg}}\right) \\
& =1.411 \times 10^{-11}\left(\frac{\mathrm{Gy}}{\mathrm{n} / \mathrm{cm}^{2}}\right) \cdot N_{t h}\left(\frac{\mathbf{n} / \mathbf{c m}^{2}}{n C}\right) \cdot\left[\boldsymbol{Q}_{B}(\mathrm{nC})-Q_{N B}(n C)\left(\frac{N_{C}^{N B}}{N_{C}^{B}}\right)\right]
\end{aligned}
$$




\subsection{Dose Enhancement Due to Boron Neutron Capture}

The percent dose enhancement (PDE) is defined as

$$
P D E=\frac{D_{B-10}}{D_{n+\gamma}} \times 100(\%)
$$

where $D_{n+\gamma}$ is the dose due to fast neutrons and gamma rays, which is the same as $D_{t, T}$ defined in Equation (3.7). Substituting Equations (3.7) and (3.14) into Equation (3.15), yields,

$$
\boldsymbol{P D E}=1.495 \times 10^{-9}\left(\frac{\mathrm{R}}{\mathrm{n} / \mathrm{cm}^{2}}\right)\left(\frac{N_{t h}\left(\frac{\mathrm{n} / \mathrm{cm}^{2}}{\mathrm{nC}}\right)}{N_{C}^{N B}\left(\frac{\mathrm{R}}{\mathrm{nC}}\right)}\right)\left[\frac{\boldsymbol{Q}_{B}(\mathrm{nC})-\boldsymbol{Q}_{N B}(\mathrm{nC})\left(\frac{N_{C}^{N B}}{N_{C}^{B}}\right)}{\boldsymbol{Q}_{N B}(\mathrm{nC})}\right] \times 100 \%
$$

\subsection{Calibration of the TE Ionization Chambers}

\subsubsection{Gamma-ray Calibration}

The TE ion chambers used in this project were calibrated in NIST traceable ${ }^{60} \mathrm{Co}$ source field on several occasions and the calibration factors are consistent. The borated and non-borated ion chambers were calibrated at the University of Wisconsin-Madison Radiation Calibration Laboratory. The radiation Calibration Laboratory is a National Institute of Standards and Technology (NIST) accredited secondary standards laboratory and is also accredited by the American Association of Physicists in Medicine (AAPM). The ion chambers were calibrated against a NIST traceable source to determine the ${ }^{60} \mathrm{Co}$ calibration factor, $N_{C}(\mathrm{R} / \mathrm{nC})$. The borated ion chamber ( $\left.\mathrm{SN} \# 446\right)$ had a calibration factor of $7.055 \mathrm{R} / \mathrm{nC} \pm 2 \%$. And the non-borated TE ion chamber ( $\mathrm{SN} \# 445$ ) had a calibration factor of $6.709 \mathrm{R} / \mathrm{nC} \pm 2 \%$.

The two ion chambers were also calibrated against a NIST traceable ${ }^{60} \mathrm{Co}$ source at the Georgia Institute of Techmology (Georgia Tech) ${ }^{60} \mathrm{Co}$ Irradiation Facility. The exposure rate of the Georgia Tech ${ }^{60} \mathrm{Co}$ source had an uncertainty of $3.4 \%$. The 
calibration factors for the borated and non-borated ion chamber were determined to be $6.972(\mathrm{R} / \mathrm{nC}) \pm 4 \%$ and $6.591(\mathrm{R} / \mathrm{nC}) \pm 4 \%$, respectively. The calibration factors obtained in the two calibration facilities agreed within uncertainty.

Table 2: Gamma calibration results of the borated and non-borated ion chambers

\begin{tabular}{cccccc}
\hline $\begin{array}{c}\text { Calibration } \\
\text { Source }\end{array}$ & $\begin{array}{c}\text { Calibration } \\
\text { Facility }\end{array}$ & $\begin{array}{c}\text { Calibration } \\
\text { Date }\end{array}$ & $\begin{array}{c}\text { NB-IC } \\
(\text { SN\#445) }\end{array}$ & $\begin{array}{c}\text { B-IC } \\
(\text { SN\#446) }\end{array}$ & $\begin{array}{c}\text { Ratio } \\
\text { NB-IC/B-IC }\end{array}$ \\
\hline \multirow{3}{*}{${ }^{60}$ Co } & UW & $04 / 06 / 2001$ & 6.709 & 7.055 & 0.9510 \\
& GIT & $07 / 07 / 2004$ & 6.552 & 6.978 & 0.9390 \\
& GIT & $08 / 19 / 2004$ & 6.630 & 6.966 & 0.9518 \\
& & & & & \\
& NTF & $05 / 06 / 1996$ & 6.743 & 7.072 & 0.9535 \\
${ }^{137} \mathrm{Cs}$ & NTF & $01 / 21 / 2001$ & 6.885 & 7.279 & 0.9459 \\
& UW & $04 / 06 / 2001$ & 6.846 & 7.180 & 0.9535 \\
& NTF & $11 / 30 / 2001$ & 6.714 & 7.097 & 0.9460 \\
& NTF & $05 / 19 / 2006$ & 6.808 & 7.101 & 0.9587 \\
\hline \multirow{6}{*}{} & Average & & 6.736 & 7.091 & 0.9499 \\
& St. Dev. & 0.111 & 0.102 & 0.0061 \\
& Percent Error & $1.6 \%$ & $1.4 \%$ & $0.6 \%$ \\
\hline
\end{tabular}

UW - University of Wisconsin-Madison Radiation Calibration Laboratory

NTF - Fermilab Neutron Therapy Facility

GIT - Georgia Tech Irradiation Facility

Before each set of measurements, the detectors were checked with a ${ }^{137} \mathrm{Cs}$ source located in the treatment room of the Fermilab Neutron Therapy Facility. The calibration factors from the ${ }^{60} \mathrm{Co}$ and ${ }^{137} \mathrm{Cs}$ sources are shown in Table 2. It shows that the responses of the detectors have been very stable over a long period of time. Since the calibrations performed at the University of Wisconsin-Madison Radiation Calibration Laboratory had the smallest uncertainty, the calibration factors for the borated $\left(N_{C}^{B}\right)$ and the non-borated $\left(N_{C}^{N B}\right)$ ion chambers, namely $7.055 \mathrm{R} / \mathrm{nC} \pm 2 \%$ and $6.709 \mathrm{R} / \mathrm{nC} \pm 2 \%$, were used in the late measurements. The different responses of the two detectors implies that the gas volume of the borated ion chamber is smaller than that of the non-borated ion chamber by the following ratio

$$
\frac{N_{C}^{N B}}{N_{C}^{B}}=\frac{6.709(\boldsymbol{R} / n \boldsymbol{C})}{7.055(\boldsymbol{R} / \mathbf{n C})}=0.951
$$


This correction factor needs to be applied to the charge measured by the non-borated ion chamber before it is subtracted from the charge measured by the borated ion chamber to determine the charge due to boron capture reactions.

\subsubsection{Thermal Neutron Calibration}

Since alpha particles and lithium ions from the ${ }^{10} \mathrm{~B}(\mathrm{n}, \alpha)^{7} \mathrm{Li}$ reactions have very short ranges in air, the Bragg-Gray principle may not be satisfied for the borated TE ion chamber. So this chamber has to be calibrated in a thermal neutron beam of known fluence rate.

Both the borated and non-borated ion chambers were calibrated in the thermal column of Oregon State University (OSU) research reactor in 2001. The thermal neutron fluence rate was determined to be $1.39 \times 10^{8} \mathrm{n} / \mathrm{cm}^{2} / \mathrm{sec} \pm 13 \%$ using gold foil activation method. The calibration factor of the borated ion chamber was determined to be $1.76 \mathrm{x}$ $10^{9} \mathrm{n} / \mathrm{cm}^{2}$ per $\mathrm{nC} \pm 13 \%$. The large uncertainty associated with this calibration factor resulted in a large uncertainty of the boron dose enhancements reported by Sweezy [52, 57].

In order to reduce the uncertainty of the thermal neutron calibration factor of the borated ion chamber, the responses of the two ion chambers to thermal neutrons were calibrated again in the National Institute of Standards and Technology (NIST) reactor thermal column in 2004. The NIST thermal column has a very high fraction of thermal neutrons with a cadmium ratio greater than 400 determined by gold foil activation. The calibration of the borated TE ion chamber was performed at the center of the beam. The thermal neutron fluence rate was determined by a dual fission ion chamber [59] provided by NIST. The thermal neutron component of the beam can be substantially attenuated by placing an optically thick lithium slab at the opening of the beam port.

The conversion factor $\left(\mathrm{n} / \mathrm{cm}^{2}\right.$ per count) of the dual fission ion chamber is

calculated using the number of ${ }^{235} \mathrm{U}$ nuclei, the thermal neutron fission cross section and 
a series of corrections. The fission cross section of ${ }^{235} \mathrm{U}$ for thermal neutrons can be calculated by

$$
\sigma_{t h}=\frac{\sqrt{\pi}}{2} \cdot g(T) \cdot \sqrt{\frac{T_{0}}{T}} \cdot \sigma_{f}\left(E_{0}\right)
$$

where $\sigma_{f}\left(E_{0}\right)$ is the microscopic fission cross section for neutrons of energy $E_{0}$, typically $0.0253 \mathrm{eV}$ or $2200 \mathrm{~m} / \mathrm{s}, \sigma_{f}(0.0253 \mathrm{eV})=584 \mathrm{barn} ; T_{0}$ is the temperature of the tabulated cross section, $294.61 \mathrm{~K}$; $\mathrm{T}$ is the temperature of the moderator for the measurement, 303 $\mathrm{K} ; g(T)$ is the empirical correction factor of the departure from $1 / \mathrm{v}$ behavior of ${ }^{235} \mathrm{U}$. At $303 \mathrm{~K}, g(T)$ is 0.974 . Substituting the values of the parameters in equation (3.18), $\sigma_{t h}=496 \mathrm{~b}$ is obtained.

The upper chamber of the dual fission chamber has $378.5 \pm 1 \% \mu \mathrm{g}$ of ${ }^{235} \mathrm{U}$ uniformly deposited over an area of $1.2668 \mathrm{~cm}^{2}$, corresponding to $9.655 \times 10^{17}{ }^{235} \mathrm{U}$ nuclei per $\mathrm{cm}^{2}$. The bottom chamber was not used in the measurements. The detection of the fission fragments is essentially $100 \%$ and the conversion factor (CF) of the fission chamber counts to thermal neutron fluence rate is

$$
C F=\frac{1}{\sigma_{t h} \cdot N}=2079 \mathrm{~cm}^{-2} / \text { count }
$$

The counter reading is the integral of the pulses above the low level discriminator threshold and the integral must be extrapolated to include count down to zero pulseheight. The extrapolation-to-zero correction is 1.0368 , self-absorption correction is 1.0206 , inscatter from substrate correction is $1 / 1.034$, in-scatter correction from chamber is $1 / 1.023$, out-scatter by chamber bottom and anode correction is 1.009 . The total correction factor is the combination of the above, i.e. $(1.0368)(1.0206)\left(\frac{1}{1.034}\right)\left(\frac{1}{1.023}\right)(1.009)=1.009$, so the corrected count-to-fluence conversion factor for the fission chamber is $(2079)(1.009)=2099 \mathrm{~cm}^{-2} /$ count. 
A correction for the dead time of the electronics must also be made. The width of each pulse is $2 \mu$ s and the fraction of count loss due to dead time is $(2 \mu \mathrm{s} / \mathrm{pulse})(\#$ pulses/s). The count rate of the fission chamber at low neutron fluence rate was 2417 counts per second and at high neutron fluence rate were 20,426 counts per second, leading to a dead time losses of 0.005 and 0.0407 , respectively. The conversion factor corrected for dead time, $C F_{f}$, are $2109.5 \pm 5 \% \mathrm{n} / \mathrm{cm}^{2}$ per count at the lower neutron fluence rate and $2184.4 \pm 5 \% \mathrm{n} / \mathrm{cm}^{2}$ per count at the higher neutron fluence rate. The thermal neutron fluence rate, $\phi_{t h}$, is determined by

$$
\phi_{t h}=C \cdot C F_{f}
$$

where $\mathrm{C}$ is the count rate (cps) of the fission chamber for thermal neutrons. Substituting Equation (3.20) into Equation (3.9), the borated ion chamber thermal neutron calibration factor is obtained

$$
N_{t h}=\frac{C \cdot C F_{f}}{Q_{T}^{B}-Q_{T}^{N B}\left(\frac{N_{C}^{N B}}{N_{C}^{B}}\right)}
$$

The subscript $T$ in equation (3.21) stands for the total, including thermal neutrons, fast neutrons and gamma rays. All readings from the ion chambers are corrected to standard temperature and pressure of $273.15 \mathrm{~K}$ and $100 \mathrm{kPa}$ using Equation (3.6).

The ion chambers, the electrometer, and the high voltage unit were placed near the NIST thermal column beam. Since they are filled with ambient air, the ion chambers have the same temperature and pressure as the experimental environment. The temperature and the pressure in the room were recorded. The fission chamber was placed at the center of the neutron beam with its front surface perpendicular to the neutron beam. The position of the chamber stem was marked to ensure that the placement of the fission chamber was repeatable. The fission chamber was replaced with the ion chamber and the ion chamber was centered at the same location as the fission chamber. 
The boron curtain on the thermal column beam was lifted until the thermal neutron fluence rate was around $5 \times 10^{6} \mathrm{n} / \mathrm{cm}^{2}$ based on the fission chamber readings. The readings of the fission chamber were recorded several times to reduce statistical uncertainties in the count rate. The fission chamber was then replaced with the borated ion chamber (446B). An electrometer was used in charge mode, and readings for integration times of 1 second, 10 seconds and 1 minute were taken at least six times. After the measurements the optically thick lithium plate was placed in the front of the neutron beam port to stop the thermal neutrons and the responses of the borated ion chamber to fast neutrons and gamma rays were recorded. The procedure was repeated for the non-borated chamber (445).

The boron curtain in the reactor was lifted higher to obtain a larger neutron fluence rate and the calibration procedure was repeated. When the measurements with the two TE ion chambers were finished, measurements were performed with the fission chamber at three positions along the neutron beam axis and three positions about the center line of the beam perpendicular to the neutron beam. These data were used to evaluate the uncertainties caused by positioning of the chambers.

The chambers were calibrated at the thermal neutron fluence rates of $5.10 \times 10^{6}$ and $4.46 \times 10^{7} \mathrm{n} \mathrm{cm}^{-2} \mathrm{~s}^{-1}$. The calibration factors of the borated ion chamber obtained from the lower and higher neutron fluence rates are $1.86 \times 10^{9}$ and $1.81 \times 10^{9} \mathrm{n} / \mathrm{cm}^{2}$ per $\mathrm{nC}$, respectively. The final calibration factor is the average, which is $1.83 \times 10^{9} \pm 5.5 \% \mathrm{n} / \mathrm{cm}^{2}$ per $\mathrm{nC}$ at $\mathrm{STP}\left(0{ }^{\circ} \mathrm{C}\right.$ and $\left.1000 \mathrm{kPa}\right)$ conditions. This result agrees with Sweezy's result within the uncertainty.

The dose due to the 184-ppm ${ }^{10} \mathrm{~B}$ in the borated ion chamber Equation (3.14) can now be calculated as

$$
\boldsymbol{D}_{\boldsymbol{B}-10}(\boldsymbol{G} \boldsymbol{y})=1.411 \times 10^{-11}\left(\frac{\mathrm{Gy}}{\mathrm{n} / \mathrm{cm}^{2}}\right) \cdot 1.83 \times 10^{9}\left(\frac{\mathrm{n} / \mathrm{cm}^{2}}{\mathrm{nC}}\right) \cdot\left[\boldsymbol{Q}_{\boldsymbol{B}}(\mathrm{nC})-0.951 \cdot \boldsymbol{Q}_{N \boldsymbol{B}}(\mathrm{nC})\right]
$$




$$
=0.0258\left(\frac{\mathrm{Gy}}{\mathrm{nC}}\right) \cdot\left[\boldsymbol{Q}_{\boldsymbol{B}}(\mathrm{nC})-0.951 \cdot \boldsymbol{Q}_{N B}(\mathrm{nC})\right]
$$

And the PDE can be determined from Equation (3.16) as

$$
\begin{aligned}
\boldsymbol{P D} \boldsymbol{E} & =1.495 \times 10^{-9}\left(\frac{\mathrm{R}}{\mathrm{n} / \mathrm{cm}^{2}}\right)\left(\frac{1.83 \times 10^{9}\left(\frac{\mathrm{n} / \mathrm{cm}^{2}}{\mathrm{nC}}\right)}{6.705\left(\frac{\mathrm{R}}{\mathrm{nC}}\right)}\right)\left[\frac{\boldsymbol{Q}_{B}(\mathrm{nC})-(0.951) \boldsymbol{Q}_{N B}(\mathrm{nC})}{\boldsymbol{Q}_{N B}(\mathrm{nC})}\right] \times 100 \% \\
& =0.4080 \cdot\left[\frac{\boldsymbol{Q}_{B}(\mathrm{nC})-(0.951) \boldsymbol{Q}_{N B}(\mathrm{nC})}{\boldsymbol{Q}_{N B}(\mathrm{nC})}\right] \times 100 \%
\end{aligned}
$$

The error associated with the PDE correction factor in Equation (3.23), 0.4080, is about $11 \%$. It comes from two major sources, the thermal neutron calibration factor, $N_{t h}$ $(5.5 \%)$ and $\bar{W}_{N} / e(6-8 \%)$. The latter is the greatest error contributor to the error associated with the Bragg-Gray equation (9\%). Substituting $N^{N B}{ }_{C}=6.709 \mathrm{R} / \mathrm{nC} \pm 2 \%$ into Equation (3.7), the Bragg-Gray equation for the TE ion chamber ( $\mathrm{SN} \# 445)$ is

$$
\begin{aligned}
\boldsymbol{D}_{n+\gamma}(\mathrm{Gy}) & =9.437 \times 10^{-3}\left(\frac{\mathrm{Gy}}{\mathrm{R}}\right) \cdot 6.705\left(\frac{\mathrm{R}}{\mathrm{nC}}\right) \cdot \boldsymbol{Q}_{T}^{N B}(\mathrm{nC}) \\
& =0.0633(\mathrm{~Gy} / \mathrm{nC}) \cdot \boldsymbol{Q}_{T}^{N B}(\mathrm{nC})
\end{aligned}
$$

The coefficient in Equation (3.24), $0.0633(\mathrm{~Gy} / \mathrm{nC}$ ) has an uncertainty of about $9 \%$ which comes mainly from $\bar{W}_{N} / e(6-8 \%)$. 


\section{CHAPTER 4}

\section{CALCULATION AND MEASUREMENTS OF THE NEUTRON SPECTRAL FLUENCE RATE}

The Fermilab Neutron Therapy Facility (NTF) produces neutrons by bombarding a 2.21 -cm-thick beryllium target with $66-\mathrm{MeV}$ protons. The protons lose $49 \mathrm{MeV}$ in the beryllium target and are stopped by a $0.5-\mathrm{mm}$ gold backing [53]. The neutron beam is collimated to produce different field sizes by using different collimators. The neutron fluence rate is monitored by dual parallel plate ionization chambers during experiments and therapy. The ionization chambers are calibrated such that one monitor unit (MU) produces a dose of one gray at $10-\mathrm{cm}$ deep in tissue for a $10 \times 10 \mathrm{~cm}^{2}$ collimator (standard treatment field size) at $190 \mathrm{~cm}$ source to axis distance (SAD).

The knowledge of the neutron spectral fluence rate is essential for Monte Carlo simulations. So a relationship between proton current or charge measured by the dual parallel plate ion chamber and the neutron fluence rate or fluence at the isocenter is required. Cupps et al. [57] measured the neutron fluence rate spectrum of the Fermilab NTF using gold and indium foil activations in 1996. Ross et al. [60] calculated the neutron spectrum using the LAHET and MCNP codes in 1997. The shapes of the calculated and measured neutron spectrum were in reasonable agreement. Since Ross et al. also calculated the neutron spectrum of the neutron therapy facility at the National Accelerator Centre (NAC) in South Africa, and their calculation agreed well with the extensive time-of-flight measurements of Jones et al. [61], the shape of the Fermilab NTF neutron spectra measured by Cupps et al. and calculated by Ross et al. should be reasonable. 
J. Sweezy [53] modeled the Fermilab NTF neutron beam using MCNPX and the LA-150 neutron libraries [62]. A total of $6.0 \times 10^{9}$ source protons were tracked resulting in $9.0 \times 10^{6}$ neutrons incident on the face of the collimator, which were written to a surface source file for subsequent calculations. Sweezy calculated a total fluence of $2.58 \times 10^{-7}$ neutrons $/ \mathrm{cm}^{2}$ per proton at the $190 \mathrm{~cm}$ isocenter of the Fermilab Fast Neutron Therapy facility using the MCNPX Bertini intranuclear cascade (INC) model and the LA-150 neutron library. Comparison of depth-dose measurements to the calculation indicated that MCNPX underestimated the total absorbed dose by approximately a factor of three. This discrepancy needed to be addressed before further simulations of BNCEFNT design could be conducted using the MCNPX code.

Due to the space limitation in the treatment room, the time-of-flight technique can not be used to measure the neutron spectral fluence rate at the Fermilab FNT facility. An active detector placed in the neutron beam will be saturated due to the intensity of the neutron beam. So foil activation techniques were used to measure the neutron spectral fluence rate for the neutron beam at the Fermilab NTF facility.

\subsection{Activation Foils and Activation Products}

Aluminum and copper foils were chosen to be the activation detectors because they have well evaluated neutron cross section data up to $150 \mathrm{MeV}$ in the MCNPX library and their activation products have appropriate half-lives and gamma ray lines for counting. The Fermilab NTF neutron beam was moderated by polymethylmethachrylate (PMMA) slabs of various thicknesses before reaching the foils. The foils were attached to the center of the downstream wall of a moderator box made of PMMA material with dimensions of $30 \mathrm{~cm} \times 30 \mathrm{~cm} \times 15 \mathrm{~cm}$. The thickness of the box walls was $0.6 \mathrm{~cm}$. Up to 12 PMMA slabs of various thicknesses were inserted into the box. The thickness of the moderator was varied from $1.2 \mathrm{~cm}$ (empty) to $14.5 \mathrm{~cm}$ (all slabs inserted) in these 
measurements. The center of the front surface of the moderator box was placed at the isocenter $(\mathrm{SAD}=190 \mathrm{~cm})$.

Five reactions are considered for the experiment: ${ }^{27} \mathrm{Al}(\mathrm{n}, \gamma){ }^{28} \mathrm{Al},{ }^{27} \mathrm{Al}(\mathrm{n}, \mathrm{p}){ }^{27} \mathrm{Mg}$, ${ }^{27} \mathrm{Al}(\mathrm{n}, \alpha){ }^{24} \mathrm{Na},{ }^{65} \mathrm{Cu}(\mathrm{n}, \gamma){ }^{66} \mathrm{Cu}$ and ${ }^{63} \mathrm{Cu}(\mathrm{n}, 2 \mathrm{n}){ }^{62} \mathrm{Cu}$. The decay data (half-life, gamma-ray energy and emission probability) of these activation products are shown in Table 3.

Table 3: Decay data of the Activation Products [63, 64]

\begin{tabular}{|c|c|c|c|c|}
\hline Reactions & Radionuclide & $\mathrm{T}_{1 / 2}$ & $\mathrm{E}_{\gamma}(\mathrm{keV})$ & $\mathrm{P}_{\gamma}(\%)$ \\
\hline${ }^{27} \mathrm{Al}(\mathrm{n}, \gamma){ }^{28} \mathrm{Al}$ & ${ }^{28} \mathrm{Al}$ & $2.2414 \mathrm{~min}$ & 1778.9 & 100 \\
\hline \multirow{2}{*}{${ }^{27} \mathrm{Al}(\mathrm{n}, \mathrm{p}){ }^{27} \mathrm{Mg}$} & \multirow{2}{*}{${ }^{27} \mathrm{Mg}$} & \multirow{2}{*}{$9.458 \mathrm{~min}$} & 843.76 & 71.0 \\
\hline & & & 1014.4 & 28.0 \\
\hline \multirow{2}{*}{${ }^{27} \mathrm{Al}(\mathrm{n}, \alpha){ }^{24} \mathrm{Na}$} & \multirow{2}{*}{${ }^{24} \mathrm{Na}$} & \multirow{2}{*}{$14.9512 \mathrm{~h}$} & 1368.5 & 100 \\
\hline & & & 2754.1 & 99.9 \\
\hline${ }^{65} \mathrm{Cu}(\mathrm{n}, \gamma){ }^{66} \mathrm{Cu}$ & ${ }^{66} \mathrm{Cu}$ & $9.67 \mathrm{~min}$ & 875.71 & 0.15 \\
\hline${ }^{63} \mathrm{Cu}(\mathrm{n}, 2 \mathrm{n}){ }^{62} \mathrm{Cu}$ & ${ }^{62} \mathrm{Cu}$ & $5.12 \mathrm{~min}$ & 1039.2 & 7.4 \\
\hline
\end{tabular}

Each irradiated foil was counted using an HPGe detector-based spectrometer and the activities of the activation products, ${ }^{28} \mathrm{Al},{ }^{27} \mathrm{Mg},{ }^{24} \mathrm{Na},{ }^{66} \mathrm{Cu}$ and ${ }^{62} \mathrm{Cu}$, at the end of each irradiation were determined. The beam fluctuation was small and was assumed to be constant during the irradiation, the production rates of the activation products are also constant, the production rate was obtained by

$$
\dot{P}_{j}=\frac{A_{j}(0) \lambda_{j}}{1-e^{-\lambda_{j} T}} \frac{1}{m}
$$

where $\dot{P}_{j}$ is the production rate of radionuclide $j(\mathrm{~Bq} / \mathrm{s} / \mathrm{g}), \lambda_{j}$ is its decay constant $\left(\mathrm{s}^{-1}\right), T$ (s) is the irradiation time, $m$ is the mass of the foil $(\mathrm{g})$ and $A_{j}(0)$ is the activity of radionuclide $j$ at the end of irradiation $(\mathrm{Bq})$, which is calculated by

$$
A_{j}(0)=\frac{C_{i j}}{P_{i j} \varepsilon_{i}} \frac{\lambda_{j}}{1-e^{-\lambda_{j} T_{R}}} \frac{T_{R}}{T_{L}} \cdot e^{\lambda_{j} T_{D}}
$$

where $C_{i j}$ is the net full-energy peak counts for the gamma-ray line of energy $E_{i}$ of radionuclide $j, P_{i j}$ is the gamma-ray emission probability, $\varepsilon_{i}$ is the detection efficiency, $T_{R}$ 
is the real time (s), $T_{L}$ is the live time (s) and $T_{D}$ (s) is the decay time (from the end of irradiation to the start of the counting).

\subsection{HPGe Detector Calibration}

The HPGe detector is calibrated using a NIST-traceable mixed gamma-ray point source. The foils must be counted on the surface of the detector because of the low activity in the foil. So the efficiencies for this geometry must be determined. Due to the cascading emission of two gamma rays from both ${ }^{60} \mathrm{Co}$ and ${ }^{88} \mathrm{Y}$, summing effects were unavoidable in counting the standard point source. Thus the high energy part (above 889 $\mathrm{keV}$ ) of the efficiency curve for the short source-to-detector distance geometry needs to be corrected for the summing effect. The MCNP code was used in the calculation of the true efficiency and the correction factor for the summing effects [65].

\subsubsection{Modeling of the HPGe detector}

The detector used in this work is an EG \& G Ortec manufactured p-type HPGe detector (Model No. GEM-15190-P). For the $1.332 \mathrm{MeV}{ }^{60} \mathrm{Co}$ gamma rays, it has a relative efficiency of about $18.8 \%$ and has a $1.83-\mathrm{keV}$ full width half-maximum (FWHM) at the full-energy peak. The detector was modeled using MCNP5 code based on the detector drawing provided by the manufacturer. A diagram of the MCNP5 modeled detector is displayed in Figure 2. The germanium dead layer and the distance between the surface of the crystal and the aluminum housing cap was adjusted to make the calculated full-energy peak efficiencies at 88, 122 and $662 \mathrm{keV}$ to match the efficiencies of the three peaks calibrated using a NIST traceable mixed point source within 3.0\%. After that, the efficiencies for other gamma rays were calculated and compared with the calibration obtained using the point source standard. Figure 3 shows the efficiency curves for the standard point source calibration and MCNP5 simulations. It is obvious that the summing effect is significant for the ${ }^{60} \mathrm{Co}$ and ${ }^{88} \mathrm{Y}$ gamma rays in this geometry. The peak 
efficiencies of gamma rays above $898 \mathrm{keV}$ calibrated using ${ }^{60} \mathrm{Co}$ and ${ }^{88} \mathrm{Y}$ would be more than $20 \%$ lower if the correction were not applied than the true efficiencies.

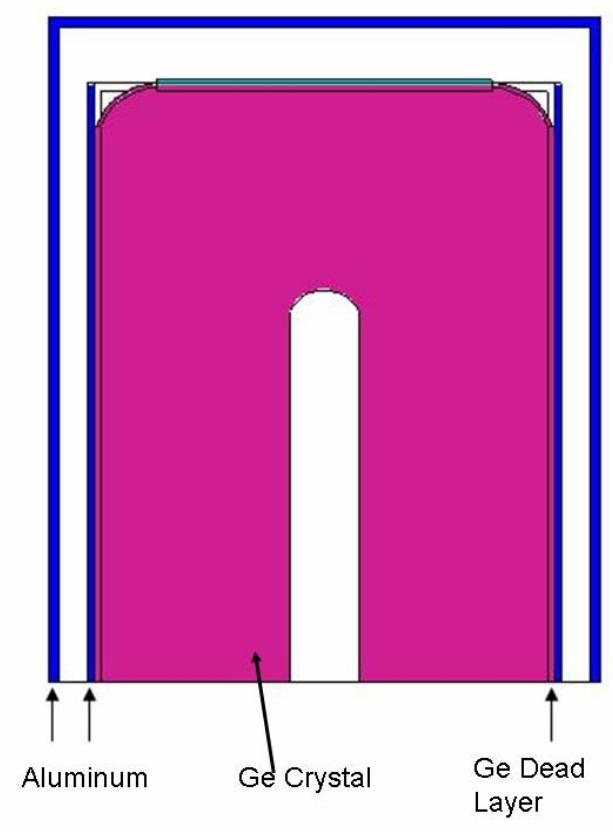

Figure 2: Diagram of the MCNP5 modeled HPGe detector. (drawing not to scale)

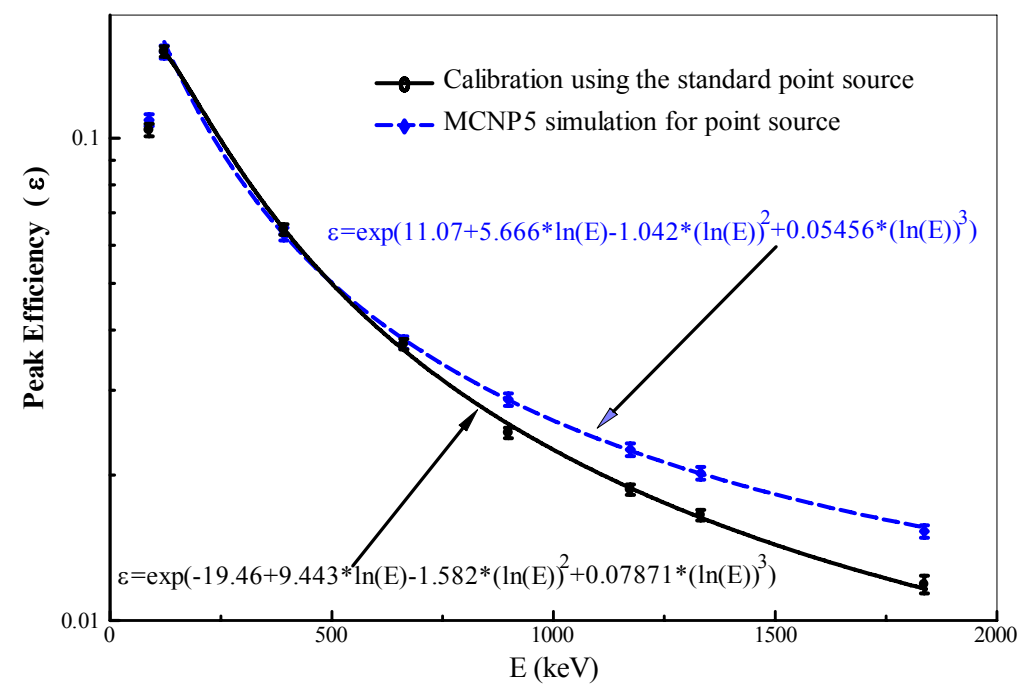

Figure 3: Peak efficiency curves calibrated with a standard point source placed on the surface center of the detector cap and modeled using MCNP5 for the same geometry. The lines are fit curves without the $88-\mathrm{keV}$ data point.

Once the MCNP5 Model is validated, the detection efficiencies for gamma rays from the five activation products of interest were calculated. Radioisotopes were assumed 
uniformly distributed in the foils. Self-absorption is automatically corrected for in the calculation. The calculated peak efficiencies for the interested gamma rays are listed in Table 4. The efficiencies of the two ${ }^{24} \mathrm{Na}$ gamma rays were obtained using different methods from others because these two gamma rays have coincidence summing effect in the same way as gamma rays emitted by ${ }^{60} \mathrm{Co}$ and ${ }^{88} \mathrm{Y}$.

Table 4: MCNP5 calculated peak efficiencies for gamma rays from the aluminum and copper foil activation products

\begin{tabular}{ccccc}
\hline Foil & $\mathrm{E}_{\gamma}(\mathrm{keV})$ & $\begin{array}{c}\text { Peak } \\
\text { efficiency }(\%)\end{array}$ & Error (\%) & \\
\hline \multirow{3}{*}{ aluminum } & 1778.9 & 1.45 & 4.0 & ${ }^{28} \mathrm{Al}$ \\
& 843.76 & 2.79 & 3.5 & ${ }^{27} \mathrm{Mg}$ \\
& 1014.4 & 2.37 & 3.5 & ${ }^{27} \mathrm{Mg}$ \\
copper & 1368.5 & 1.69 & 5.0 & ${ }^{24} \mathrm{Na}$ \\
& 2754.1 & 0.847 & 5.0 & ${ }^{24} \mathrm{Na}$ \\
& 875.71 & 2.72 & 3.5 & ${ }^{66} \mathrm{Cu}$ \\
\hline
\end{tabular}

4.2.2 Calculation of the efficiencies for gamma rays emitted by ${ }^{24} \mathrm{Na}$

The simplified ${ }^{24} \mathrm{Na}$ decay scheme from Table of Isotopes [66] is shown in Figure 4. There is a chance that while the $2754-\mathrm{keV}$ gamma ray is detected by the detector, the $1369-\mathrm{keV}$ gamma ray may also interact in the detector. The signal processing inside the detector takes much longer time than $1.35 \mathrm{ps}$, so the detector can not differentiate the signals from the two gamma rays. The two gamma rays will result in a larger energy signal and either gamma ray line could lose a count in its full-energy peak if it happens to be a full energy event. If either gamma-ray peak gains a count from coincident summing of Compton scattering events of the two gamma rays, this count only contributes to the background of the peak and will be subtracted in peak analysis. 


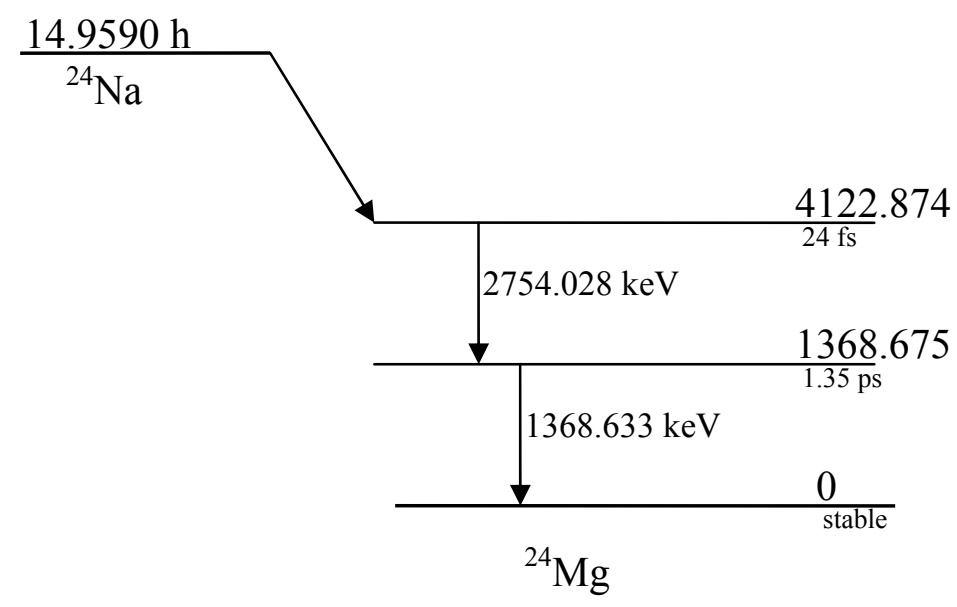

Figure 4: Simplified decay scheme of ${ }^{24} \mathrm{Na}$.

If the total efficiencies of the $2754-\mathrm{keV}$ and $1369-\mathrm{keV}$ gamma rays are $\varepsilon_{t, h}$ and $\varepsilon_{t, l}$, respectively, their true (no-summing) full-energy peak efficiencies are designated as $\varepsilon_{p, h}$ and $\varepsilon_{p, l}$, the observed full-energy peak efficiencies of the 2754-keV and $1369-\mathrm{keV}$ gamma rays emitted from ${ }^{24} \mathrm{Na}$ decay can be obtained from the following equations

$$
\begin{aligned}
& \varepsilon_{p}(2754 k e V)=\varepsilon_{p, h}\left(1-\varepsilon_{t, l}\right) \\
& \varepsilon_{p}(1369 k e V)=\varepsilon_{p, l}\left(1-\varepsilon_{t, h}\right)
\end{aligned}
$$

Equations (4.3) and (4.4) are only valid for point sources. The efficiency for a disc source can be obtained in two steps. First, a set of total and peak efficiencies of 2754-keV and $1369-\mathrm{keV}$ point sources placed on the detector surface moving along radial direction ( from 0 to $0.85 \mathrm{~cm}$ ) were calculated using MCNP5. The point source is actually a small cylinder with $1-\mathrm{mm}$ diameter and $0.5-\mathrm{mm}$ thickness because the aluminum foil used in this project is $0.5-\mathrm{mm}$ thick. The observed peak efficiencies for $2754-\mathrm{keV}$ and $1369-\mathrm{keV}$ gamma rays at each point were computed using Equations (4.3) and (4.4). Then the observed peak efficiencies were plotted against the radial distance, $r$, and these data points were fitted using a quadratic equation, $\varepsilon(\mathrm{r})=\mathrm{a}+\mathrm{br}+\mathrm{cr}^{2}$, as shown in Figure 5. The observed peak efficiency for a disc source with radius $\mathrm{R}$ is calculated by integrating $\varepsilon(\mathrm{r}) \mathrm{dr}$ from 0 to $\mathrm{R}$ and then divided by $\mathrm{R}$, which is 


$$
\varepsilon_{\text {disc }}=\frac{\int_{0}^{\mathrm{R}} \varepsilon(\boldsymbol{r}) \boldsymbol{d} \boldsymbol{r}}{\mathrm{R}}=\frac{\int_{0}^{\mathrm{R}}\left(\boldsymbol{a}+\boldsymbol{b} \boldsymbol{r}+\boldsymbol{c} \boldsymbol{r}^{2}\right) \boldsymbol{d} \boldsymbol{r}}{\mathrm{R}}=\boldsymbol{a}+\frac{\boldsymbol{b}}{2} \mathrm{R}+\frac{2 \boldsymbol{c}}{3} \mathrm{R}^{2}
$$

Substituting the radius of the aluminum foil $\mathrm{R}=0.85 \mathrm{~cm}$ and the fitted parameters (in Figure 5) into equation (4.5), the peak efficiencies for the $2754-\mathrm{keV}$ and $1369-\mathrm{keV}$ gamma rays emitted from ${ }^{24} \mathrm{Na}$ decay were obtained to be $(0.847 \pm 0.042) \%$ and $(1.69 \pm 0.08) \%$, respectively.

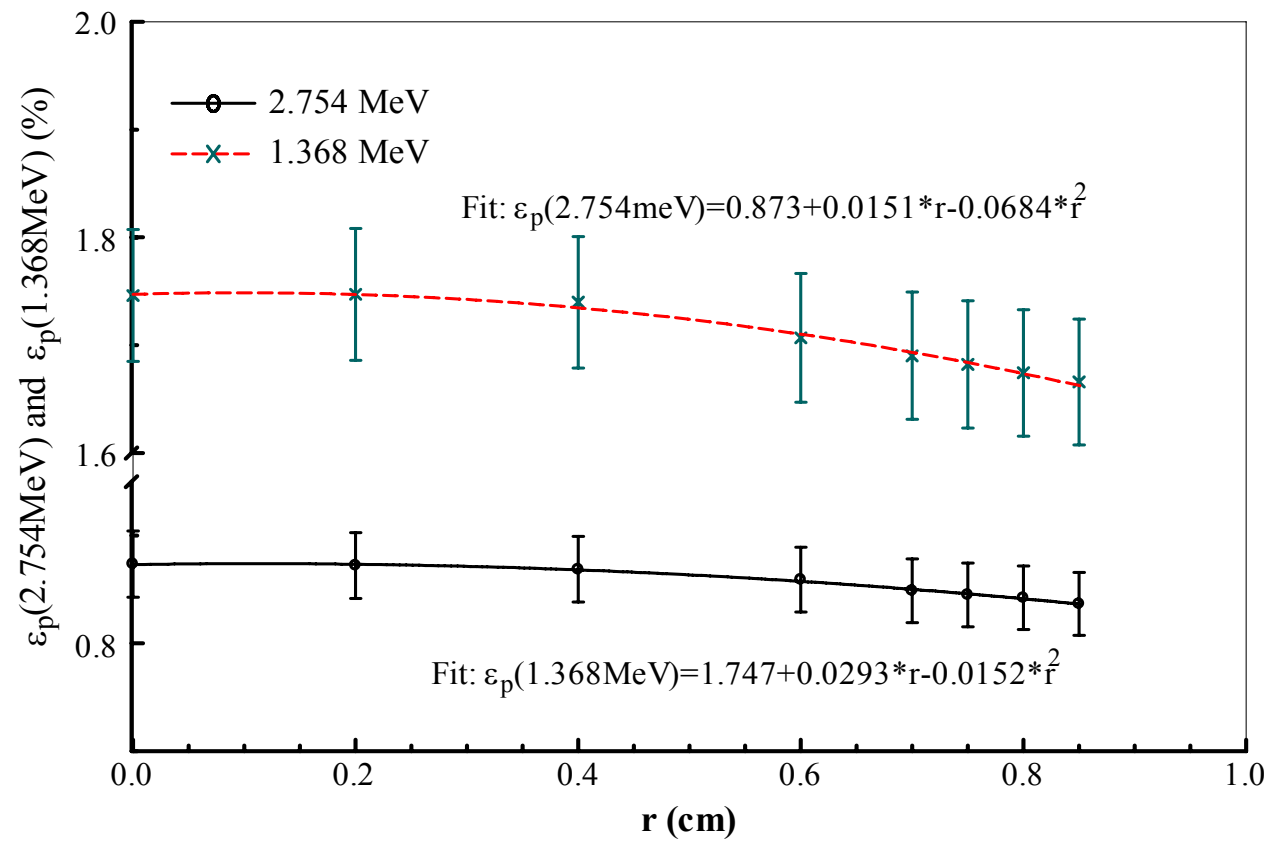

Figure 5: Observed peak efficiencies for a ${ }^{24} \mathrm{Na}$ point source moving along radial direction.

\subsection{Neutron Spectrum Unfolding}

The unfolding of neutron spectra is performed by using MXD_FC33 code [67]. The MAXED algorithm [68-70] used in the code is the maximum entropy algorithm. In principle, the spectral neutron flux rate desired can be solved from the following equations:

$$
\dot{P}_{j}(k)+\varepsilon_{j}(k)=\sum_{l=1}^{n} \phi_{l} R_{l j}(k)
$$




$$
\sum_{k} \sum_{j} \frac{\varepsilon_{j}(k)^{2}}{\sigma_{j}(k)^{2}}=\Omega
$$

where $\dot{P}_{j}(k)$ is the production rate of the radionuclide $\mathrm{j}$ of moderation $\mathrm{k}$ in unit of $\mathrm{Bq} / \mathrm{s} / \mathrm{g}$, $\phi_{l}$ is the neutron flux rate of energy group $l$ in unit of $1 / \mathrm{cm}^{2} / \mathrm{s}, R_{l j}(k)$ is the response matrix for radionuclide $j$ of moderation $k$ over energy group $l$ in unit of $\mathrm{Bq} / \mathrm{g}$ per $\mathrm{n} / \mathrm{cm}^{2}$ and $\Omega$ is a parameter set by the user (typically, $\Omega$ is set to the number of detectors) [57].

There are fewer equations than unknowns in equation (4.3) and no unique solution can be obtained. An initial guess for the spectrum is provided to the MXD_FC33 code for the unfolding process.

\subsection{Calculation of the Response Matrices}

The response matrices, $R_{l j}(k)$, for $j={ }^{28} \mathrm{Al},{ }^{27} \mathrm{Mg},{ }^{24} \mathrm{Na},{ }^{66} \mathrm{Cu}$ and ${ }^{62} \mathrm{Cu}$ are calculated using MCNPX with the LA150N neutron cross section library. The energy scale is divided into 49 groups from $10^{-10} \mathrm{MeV}$ to $70 \mathrm{MeV}$. The response functions for ${ }^{28} \mathrm{Al},{ }^{27} \mathrm{Mg},{ }^{24} \mathrm{Na},{ }^{66} \mathrm{Cu}$ and ${ }^{62} \mathrm{Cu}$ are shown in Figure 6 to 10 , respectively. Only the responses for 6 different moderator thicknesses are shown in each figure.

The MCNPX input files modeled the experimental setup as exactly as possible. A $10 \times 10 \mathrm{~cm}^{2}$ field size of a parallel neutron beam is directed perpendicularly on the center of the front face of the PMMA box with the copper and aluminum foils mounted on the back face of the box. The density of the PMMA $\left(\mathrm{C}_{5} \mathrm{H}_{8} \mathrm{O}_{2}\right)_{\mathrm{n}}$ is $1.19 \mathrm{~g} / \mathrm{cm}^{3}$. The tally multiplication card (FM) and special treatment card (SCX) were used to tally the responses of neutrons for each incident energy bin in one MCNPX run. 


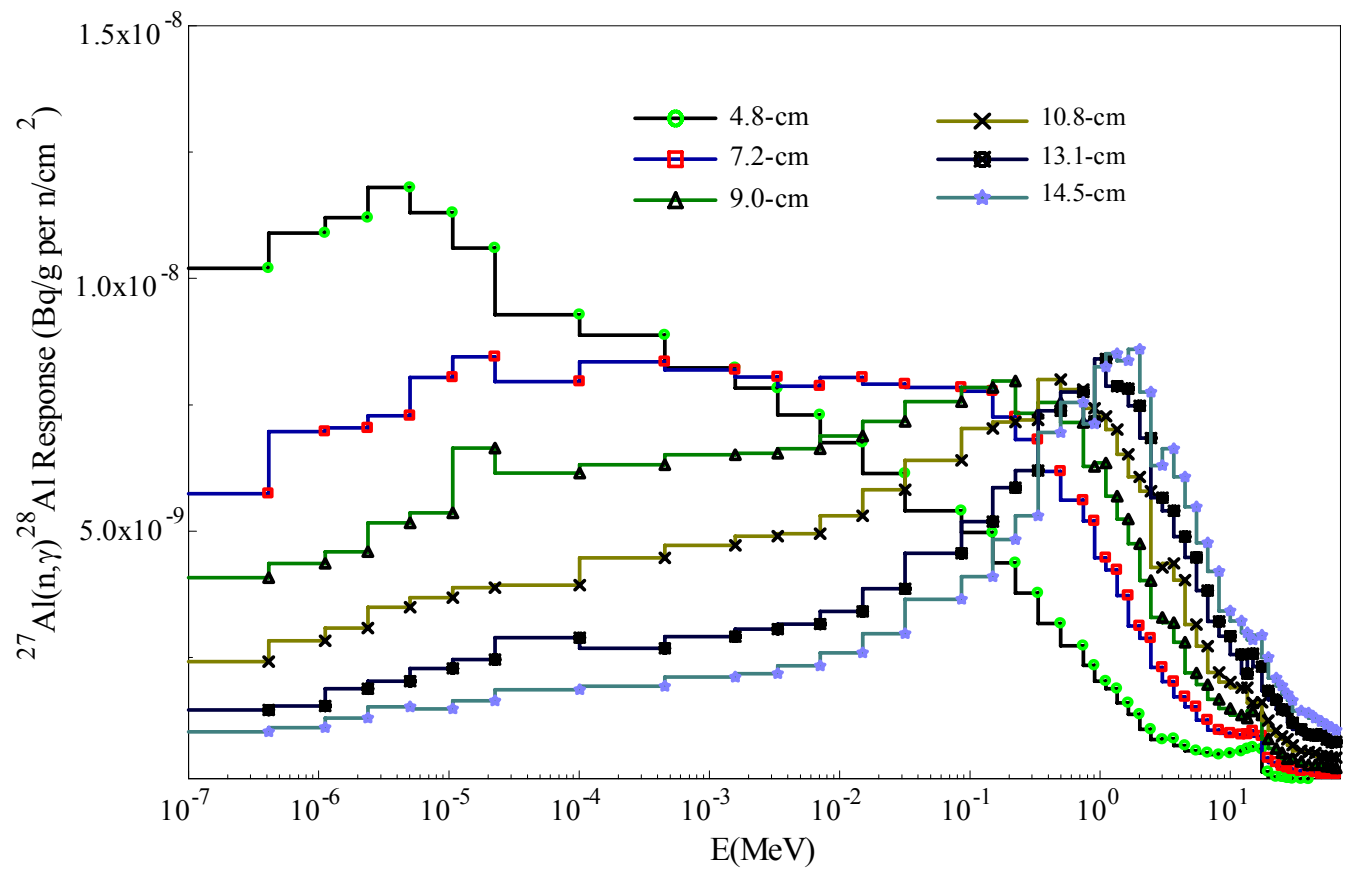

Figure 6: ${ }^{27} \mathrm{Al}(\mathrm{n}, \gamma)^{28} \mathrm{Al}$ Response functions behind various moderator thicknesses

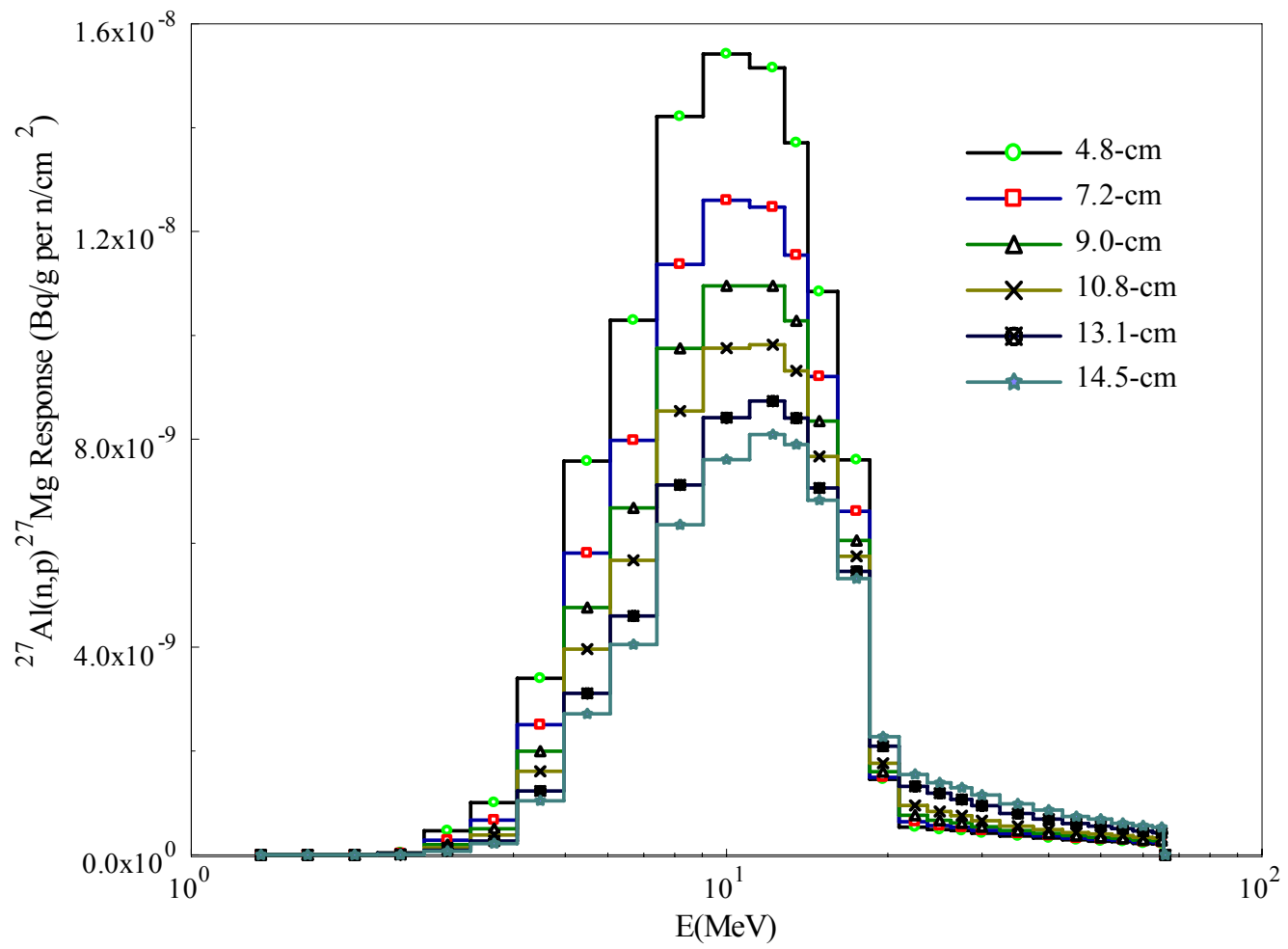

Figure 7: ${ }^{27} \mathrm{Al}(\mathrm{n}, \mathrm{p})^{27} \mathrm{Mg}$ Response functions behind various moderator thicknesses 


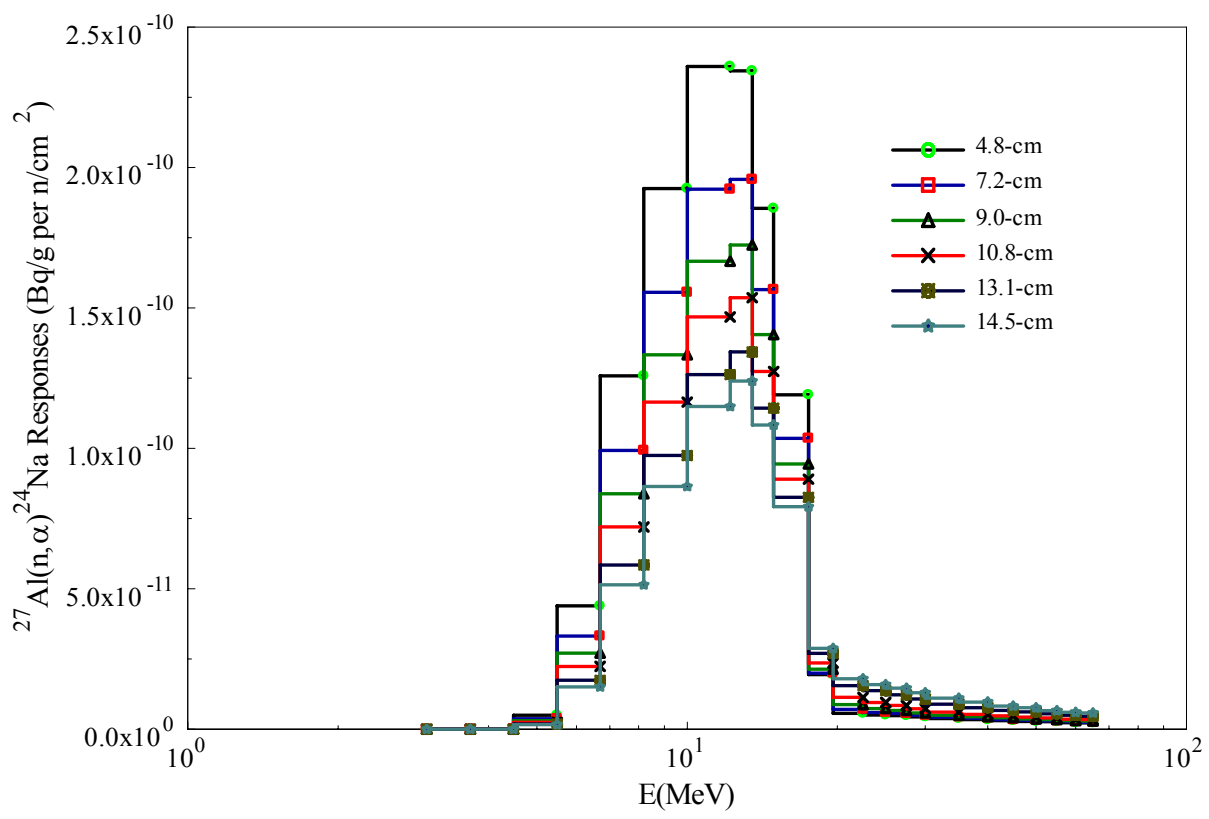

Figure 8: ${ }^{27} \mathrm{Al}(\mathrm{n}, \boldsymbol{\alpha})^{24} \mathrm{Na}$ Response functions behind various moderator thicknesses

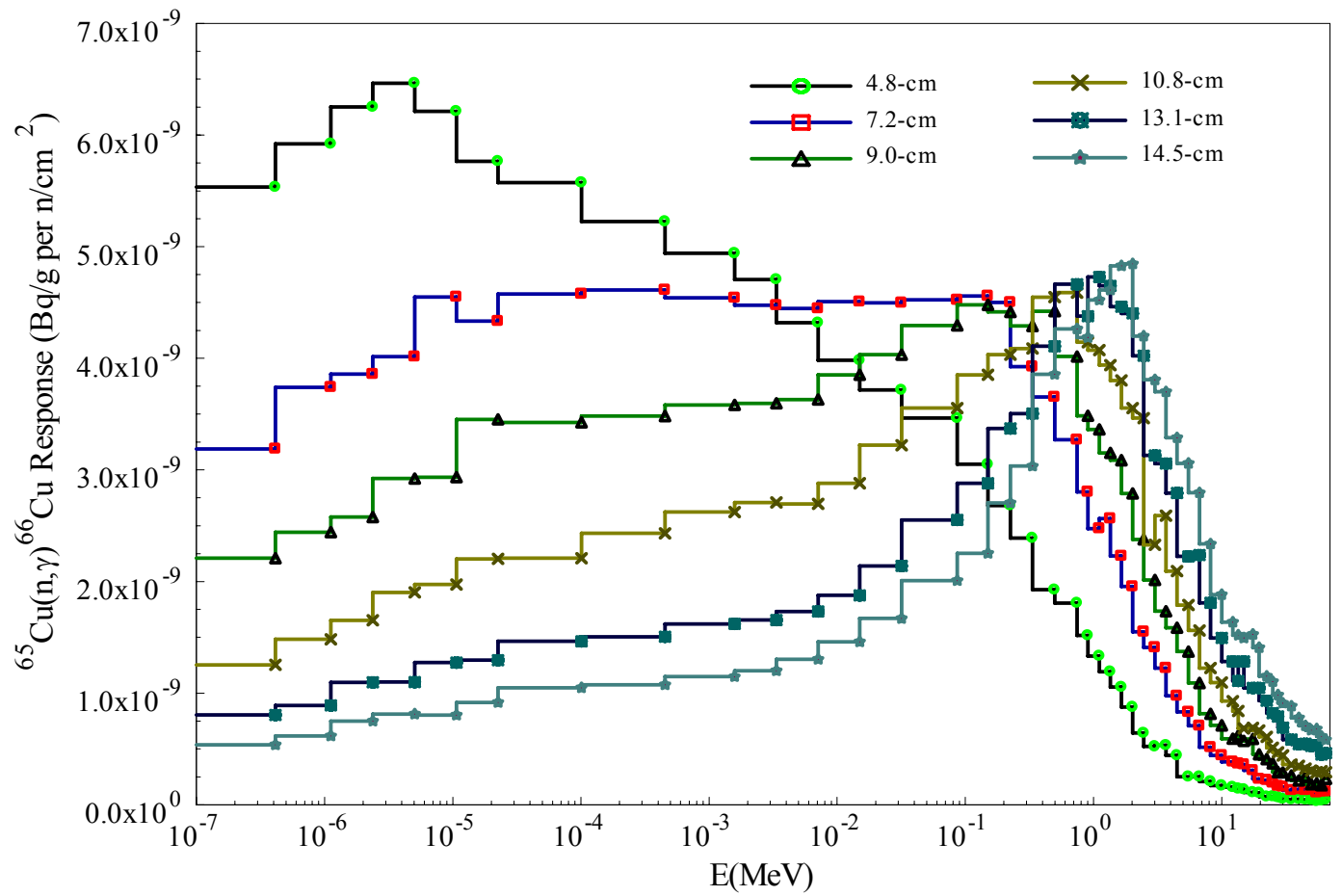

Figure 9: ${ }^{65} \mathrm{Cu}(\mathrm{n}, \gamma){ }^{66} \mathrm{Cu}$ Response functions behind various moderator thicknesses 


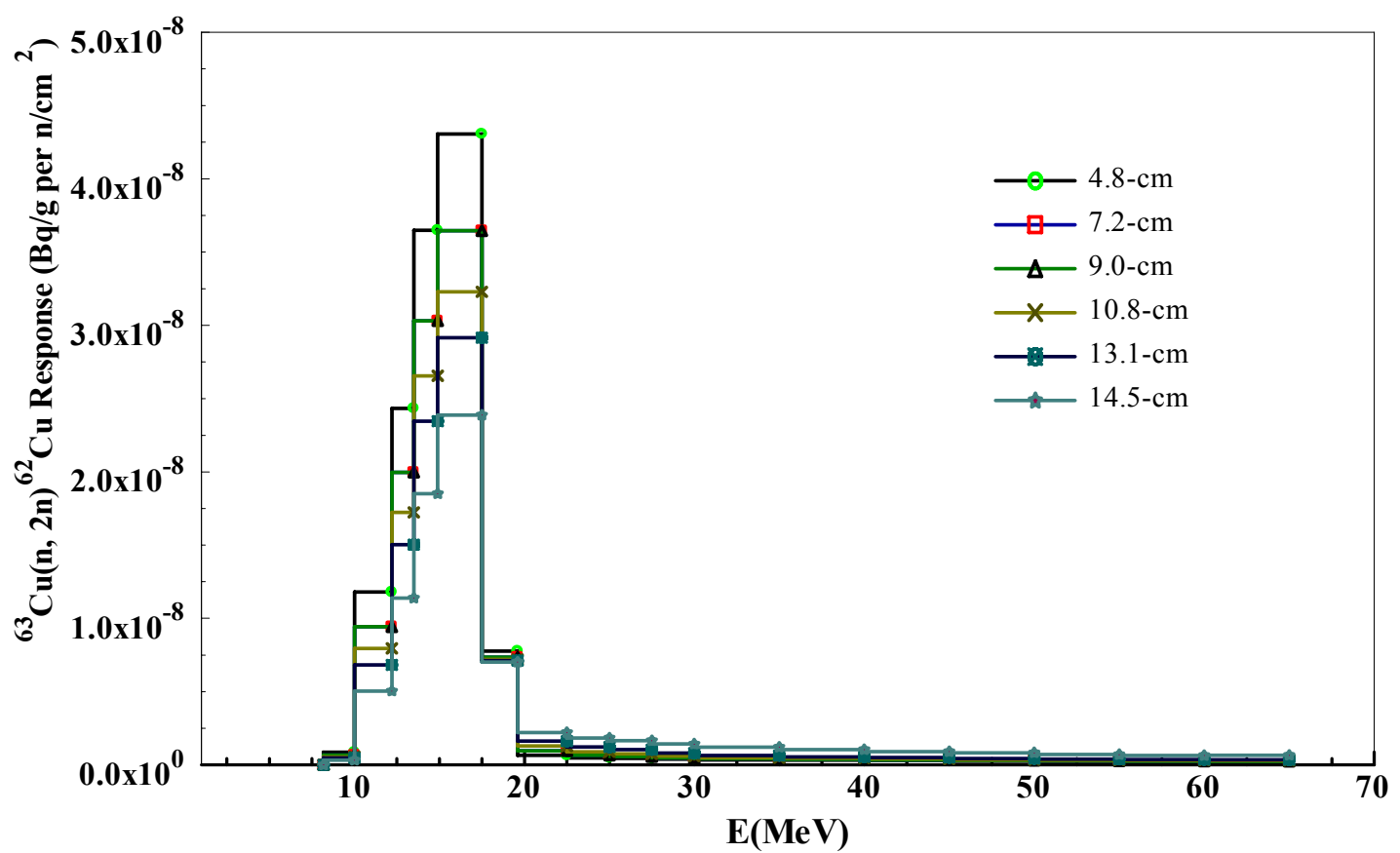

Figure 10: ${ }^{63} \mathrm{Cu}(\mathrm{n}, 2 \mathrm{n}){ }^{62} \mathrm{Cu}$ Response functions behind various moderator thicknesses

\subsection{Foil Activation and Counting}

Pure $(99.99 \%)$ aluminum foils $1.693 \mathrm{~cm}$ in diameter and $0.1-\mathrm{cm}$ thick and pure copper foil of the same diameter and $0.05-\mathrm{cm}$ thick were placed at the center of the outside surface of the backside of the moderator. The copper foil is on the moderator wall. The front face of the moderator is at the isocenter $(190 \mathrm{~cm}$ from the berillium target). The setup is the same as described in the MCNPX simulations. For each irradiation, a dose of $1 \mathrm{MU}$ or $2 \mathrm{MU}$ was preset, resulting in run times of 3.4 or 6.8 minutes. The start and stop time of the irradiation and other proton current information were recorded.

The foils were counted immediately after irradiation using an ORTEC manufactured HPGe detector (GEM20190) gamma spectrometer. The aluminum foil was counted first for less than $5 \mathrm{~min}$ to determine the activity of its short half-life (2.24 $\mathrm{min}$ ) activation product ${ }^{28} \mathrm{Al}$ and then copper foil was counted for about 5 to 10 mins. A 
relatively long count of the aluminum foil was performed for the activity determinations of the longer lived activation products ${ }^{27} \mathrm{Mg}$ and ${ }^{24} \mathrm{Na}$.

\subsection{Results}

The activity production rates for foils behind various moderation thicknesses are given in Table 5. Because of the short irradiation time, saturated activities of the activation products were not attained. So the activity production rates were calculated using equations (4.1) and (4.2). Because the unfolding of the spectrum is actually a spectral adjusting process, the accuracy of the result relies not only on the accuracy of the response matrices and foil activity determinations, but also on supplying a spectral shape of the initial guess spectrum that is similar in shape to the spectrum measured. Two starting spectra, the MCNPX-calculated NTF neutron spectrum and the spectrum measured by Cupps et al. [60] were used as the starting spectra for unfolding. The unfolded spectra and the MCNPX calculated spectrum are shown in Figure 11. For a better view, the spectrum is also plotted in lethargy in Figure 12. A comparison of this work and Cupps et al.[59] is shown in Figure 13.

The unfolded total neutron fluence rate at the isocenter for a $10 \times 10 \mathrm{~cm}^{2}$ field is $1.22 \times 10^{8} \mathrm{n} / \mathrm{cm}^{2}$-s for a beam current of $1.5 \times 10^{14}$ proton/s. The fluence density measured in this work agrees with Cupps et al.[59], which yielded a total flux rate of $1.35 \times 10^{8}$ $\mathrm{n} / \mathrm{cm}^{2}-\mathrm{s}$ for a beam current of $1.7 \times 10^{14}$ proton $/ \mathrm{s}$.

An MCNPX calculation was performed for $10^{9}$ proton particles and a fluence of $6.34 \times 10^{-7}$ neutrons $/ \mathrm{cm}^{2}$ per proton at the $190 \mathrm{~cm}$ isocenter was calculated. This resulted in a total neutron fluence rate of $9.52 \times 10^{7} \mathrm{n} / \mathrm{cm}^{2}$-s for the beam current of $1.5 \times 10^{14}$ proton/s. The ratio of the measured to the calculated flux is 1.29. The previous MCNPX 
input file of Sweezy [53] used an isotropic proton surface source instead of a parallel beam, causing half of the protons to not hit the beryllium target. Therefore, the previously observed factor of 3 was incorrect.

\begin{tabular}{|c|c|c|c|c|c|c|}
\hline $\begin{array}{c}\text { Moderation } \\
\text { thickness }\end{array}$ & $4.8 \mathrm{~cm}$ & $7.2 \mathrm{~cm}$ & $9 \mathrm{~cm}$ & $10.8 \mathrm{~cm}$ & $13.1 \mathrm{~cm}$ & $14.5 \mathrm{~cm}$ \\
\hline${ }^{28} \mathrm{Al}$ & 12.51 & 19.91 & 26.30 & 32.11 & 37.33 & 41.45 \\
\hline${ }^{27} \mathrm{Mg}$ & 30.69 & 25.75 & 24.01 & 22.36 & 22.14 & 21.13 \\
\hline${ }^{24} \mathrm{Na}$ & 0.34 & 0.30 & 0.28 & 0.28 & 0.26 & 0.24 \\
\hline${ }^{62} \mathrm{Cu}$ & -- & 64.41 & 45.00 & 38.56 & 46.73 & 39.83 \\
\hline${ }^{66} \mathrm{Cu}$ & 7.83 & 10.53 & 13.48 & 19.12 & 23.20 & 26.54 \\
\hline
\end{tabular}

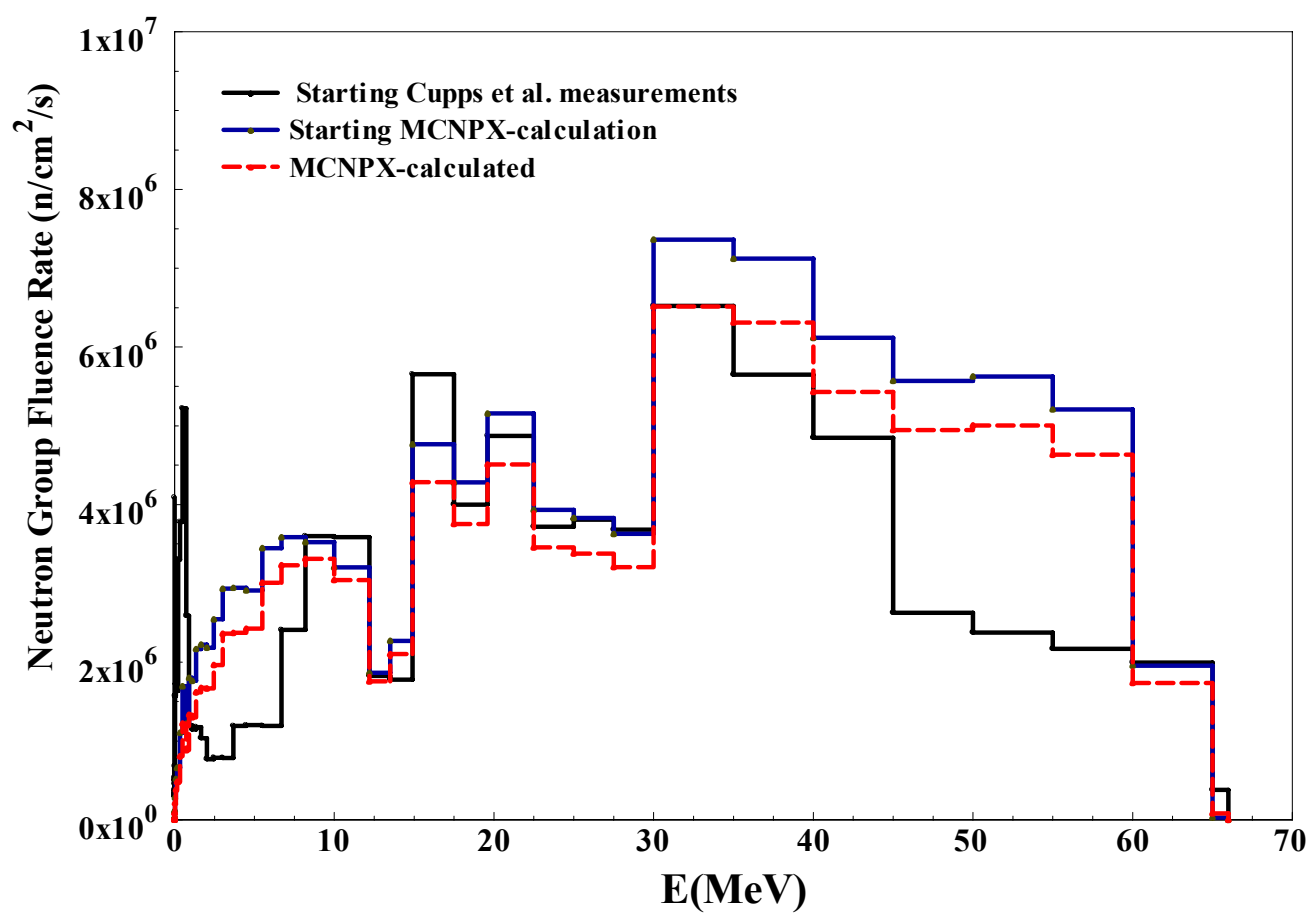

Figure 11: Fermilab NTF neutron spectrum at isocenter for a $10 \times 10 \mathrm{~cm}^{2}$ standard treatment beam. The fluence rate is corresponding to a proton current of $1.5 \times 10^{14} \mathrm{p} / \mathrm{s}$ 


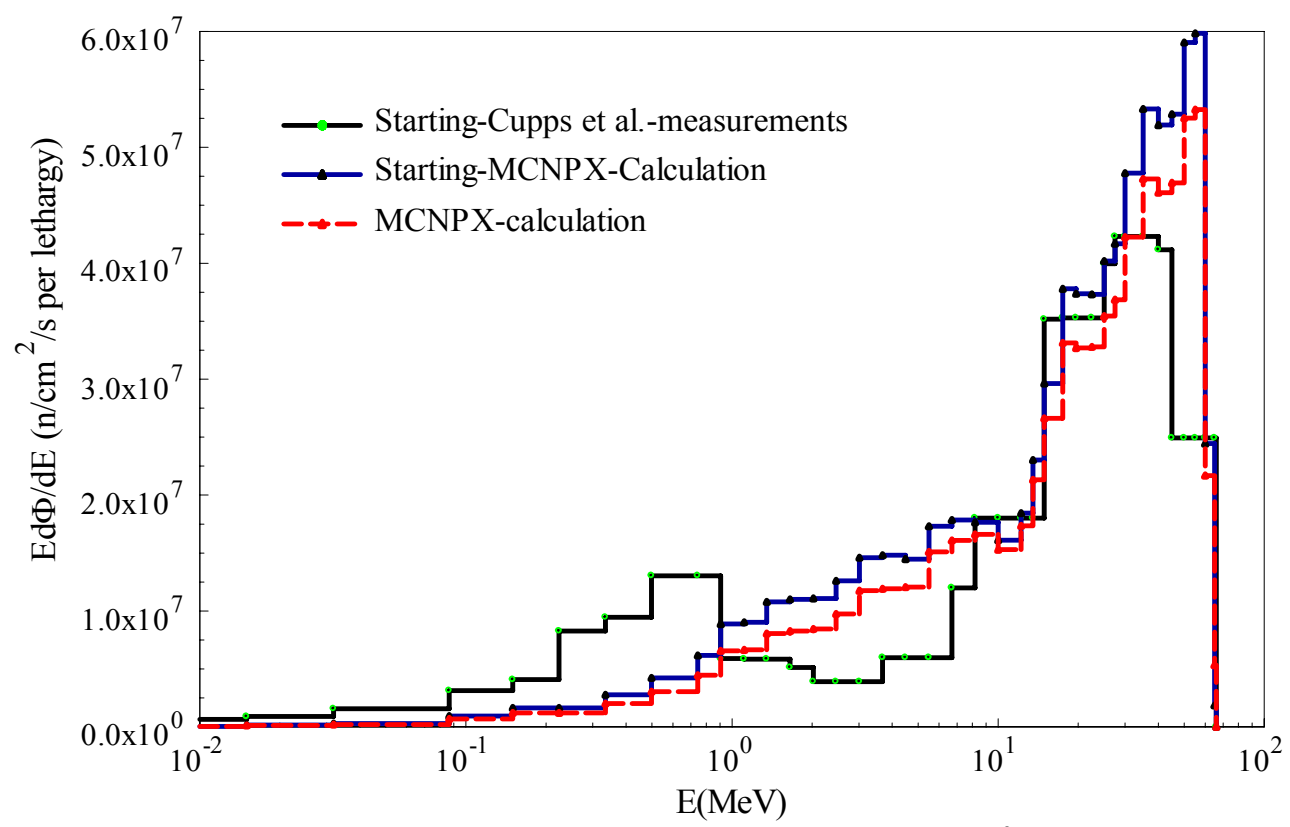

Figure 12: Fermilab NTF neutron spectrum at isocenter for a $10 \times 10 \mathrm{~cm}^{2}$ standard treatment beam displayed in lethargy. The fluence rate is corresponding to a proton current of $1.5 \times 10^{14} \mathrm{p} / \mathrm{s}$

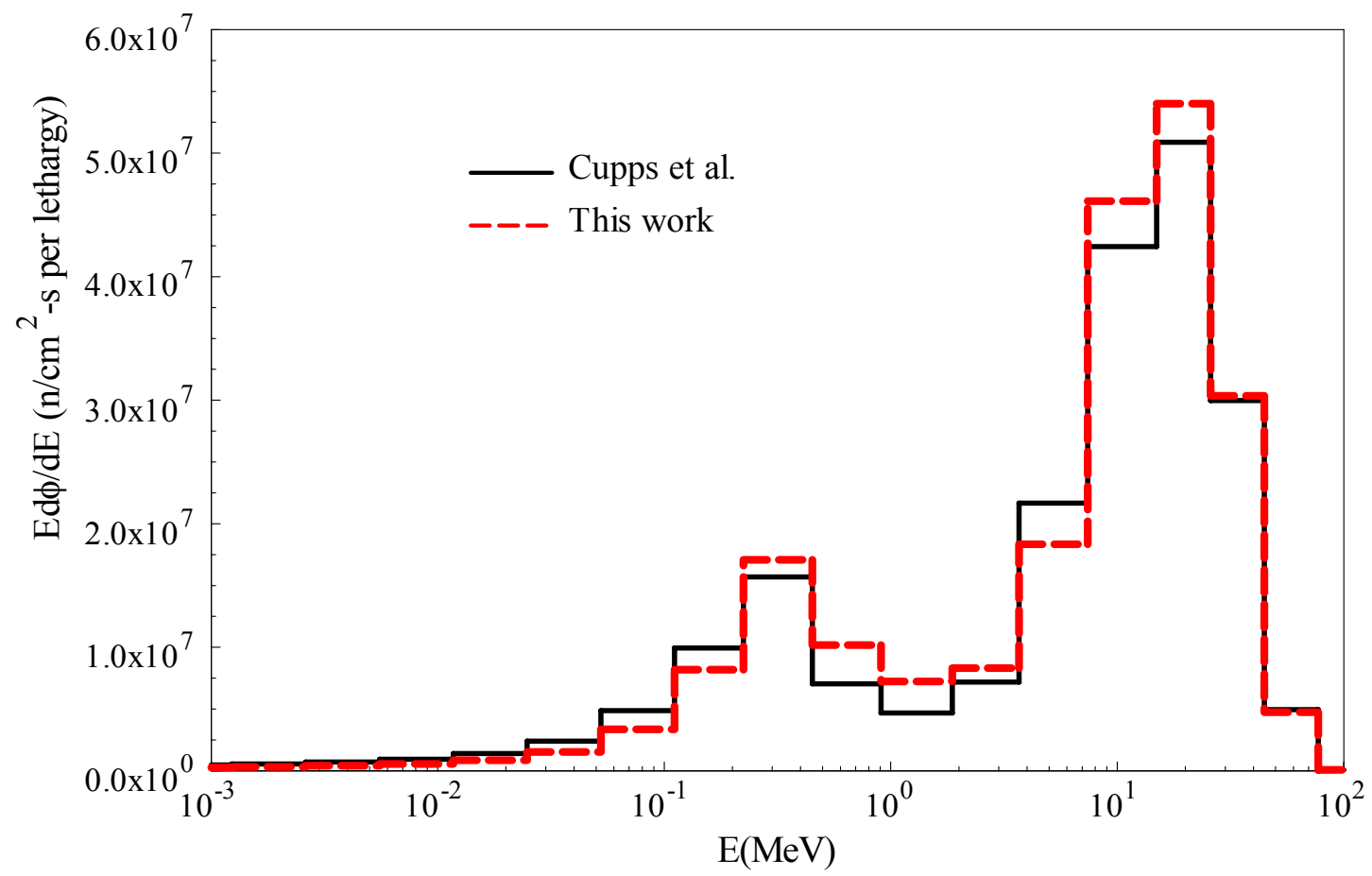

Figure 13: Comparison of the Fermilab NTF neutron spectra determined by Cupps et al. and this work starting with measured spectrum by Cupps et al.

Uncertainties in the measurement of the activities of the activation products ranged from 1 to $20 \%$ for counting statistics and for between $3.5-5.0 \%$ detector 
efficiencies. The production rates also suffer from the fluctuation of the proton current and the uncertainty in the determination of the proton current. The uncertainty in the unfolded neutron fluence density is about $15 \%$.

The advantages in selection of aluminum and copper foils as the activation detectors are that the short half-lives of the activation products require short irradiation time and the gamma-ray energies and high gamma-ray emission probabilities make it easy to determine their activities.

From the response functions shown in Figure 6 to 10, one can see that the moderation thicknesses for the threshold reactions do not differentiate high energy neutrons very well (the peaks of the response functions does not shift significantly for different thickness). If some of the PMMA slabs were replaced by high- $Z$ material, such as lead or tungsten, more energy-dependent features can be added to the responses. 


\section{CHAPTER 5}

\section{DESIGN OF THE BNCEFNT ASSEMBLY}

The RSVP head phantom ${ }^{\mathrm{TM}^{*}}$ [71] was used to simulate the depth-dose and PDE distributions as a function of depth using MCNP5 code. It was also used to verify the design of the BNCEFNT reflective assembly. The shell of the RSVP phantom is formed from $1 / 4$ inch cellulose acetate butyrate $(\mathrm{CAB})$ sheet, a transparent material chosen for its strength and low water absorption. The elemental composition of $\mathrm{CAB}$ is, by weight percentage, Hydrogen: $6.7125 \%$, Carbon: $54.5403 \%$, and Oxygen: $38.7472 \%$. The shell is mounted on a polycarbonate end plate by water-tight seal. The details of the RSVP phantom, such as the nose, eyes, ears and etc., were not modeled. The phantom is filled with deionized water for the modeling.

Moderation and reflection of neutrons using graphite, water, or heavy water around the head phantom was studied by Pignol [48] for Boron Neutron Capture Enhanced Fast Neutron Therapy. He concluded that a graphite moderator produced the largest dose enhancement. Monte Carlo simulations performed for graphite, water, heavy water, and polyethylene at Fermilab Neutron Therapy facility supported Pignol's conclusion.

\subsection{Selection of Material for the Filter and Collimator}

The use of filtration, collimation and reflection near the head phantom was investigated using the Monte Carlo method for this study. A MCNP5 model of the moderator/reflector, heavy metal filter and collimator, and the simplified RSVP head

\footnotetext{
* Phantom Laboratory, Inc., 2727 State Route 29, Greenwich, NY 12834
} 
phantom is shown in Figure 14. While Graphite was used as the moderator/reflector, the filter and collimator materials were studied for iron, tungsten, and lead in various combinations.
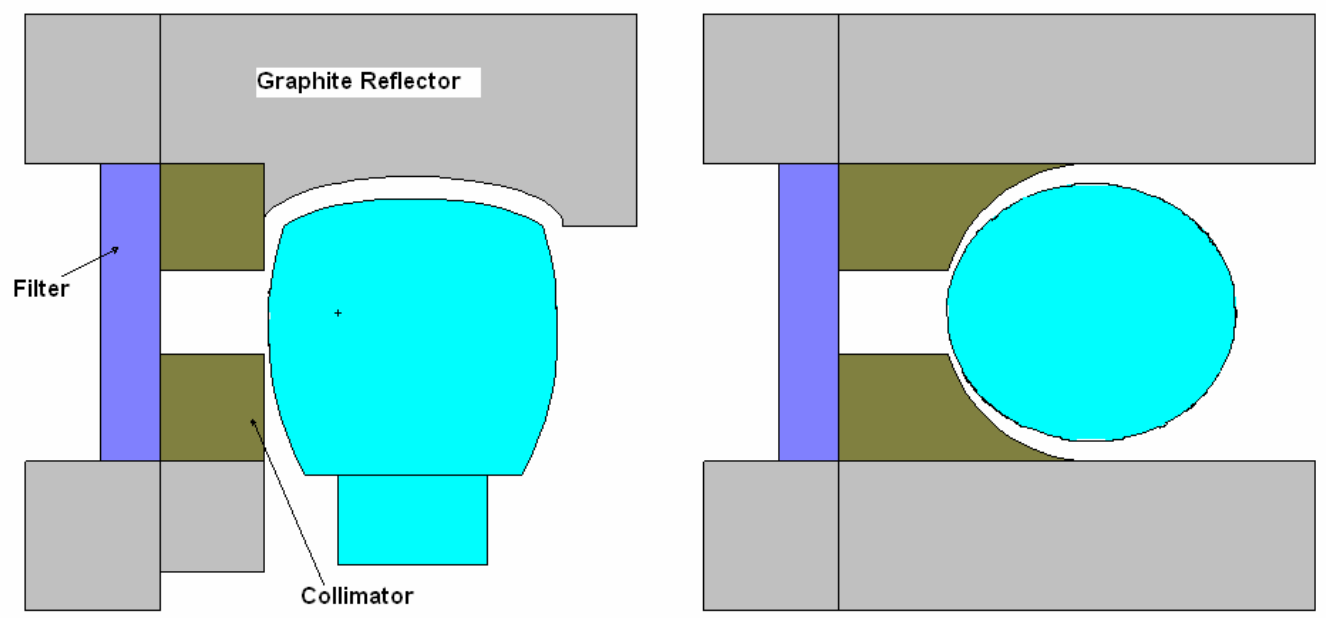

Figure 14: Diagram of the MCNP5 model of graphite moderator/reflector, iron, lead and tungsten filter and collimator combinations, and the simplified RSVP head phantom.

A parallel beam of $20 \times 20 \mathrm{~cm}^{2}$ size is directed perpendicularly to the $20 \times 20 \mathrm{~cm}^{2}$ filter surface and the centerline of the beam coincides with the axis of the collimator. The neutron spectrum determined in Chapter 4 was used as the source energy distribution in the SDEF card of MCNP input files. A relationship between the neutron fluence and proton, $8.13 \times 10^{-7} \mathrm{n} / \mathrm{cm}^{2}$ per proton determined in Chapter 4, was used for the normalization. A proton current of $1.7 \times 10^{14}$ protons $/ \mathrm{sec}$ (most common for the treatment) was used to normalize the MCNP5 calculated absorbed dose rates to the unit of Gy/min.

Figure 15 displays the Percent Dose Enhancement (PDE) per $100-p p m{ }^{10} \mathrm{~B}$ at 5 $\mathrm{cm}$ depth in the water-filled head phantom for various filter and collimator combinations. Figure 16 is the total dose rate at $5-\mathrm{cm}$ depth in the water filled phantom for various combinations of iron, lead and tungsten as filter and collimator.

The relationship between PDE and the total dose rate in 5.0-cm depth of the water filled head phantom for various filter and collimator combinations studied is shown in Figure 17. In this study, the collimator, no matter what material it is made of, is the same 
size and shape, while the filter thickness varies. It is obvious from Figure 17 that tungsten is superior as both collimator and filter to other materials for the same total dose rate.

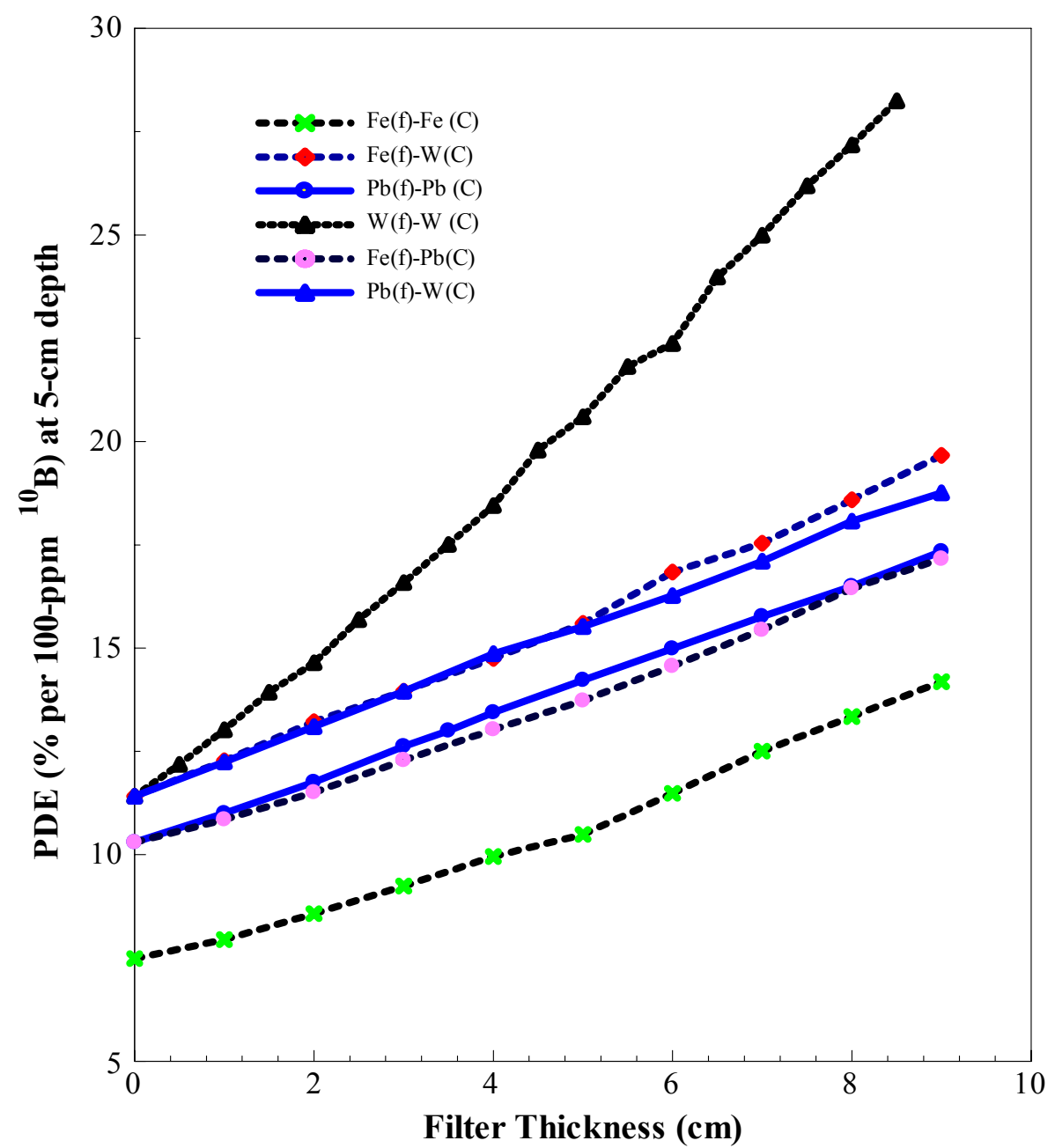

Figure 15: PDE at 5-cm depth in the head phantom for various filter and collimator combinations. In the legend, (f) stands for filter and (C) stands for collimator. A $20 \times 10 \mathrm{~cm}^{2}$ standard treatment beam field is used and the opening of the collimator is equivalent to $5 \times 5 \mathrm{~cm}^{2}$ size. The thickness of the collimator is $7 \mathrm{~cm}$ for all materials. 


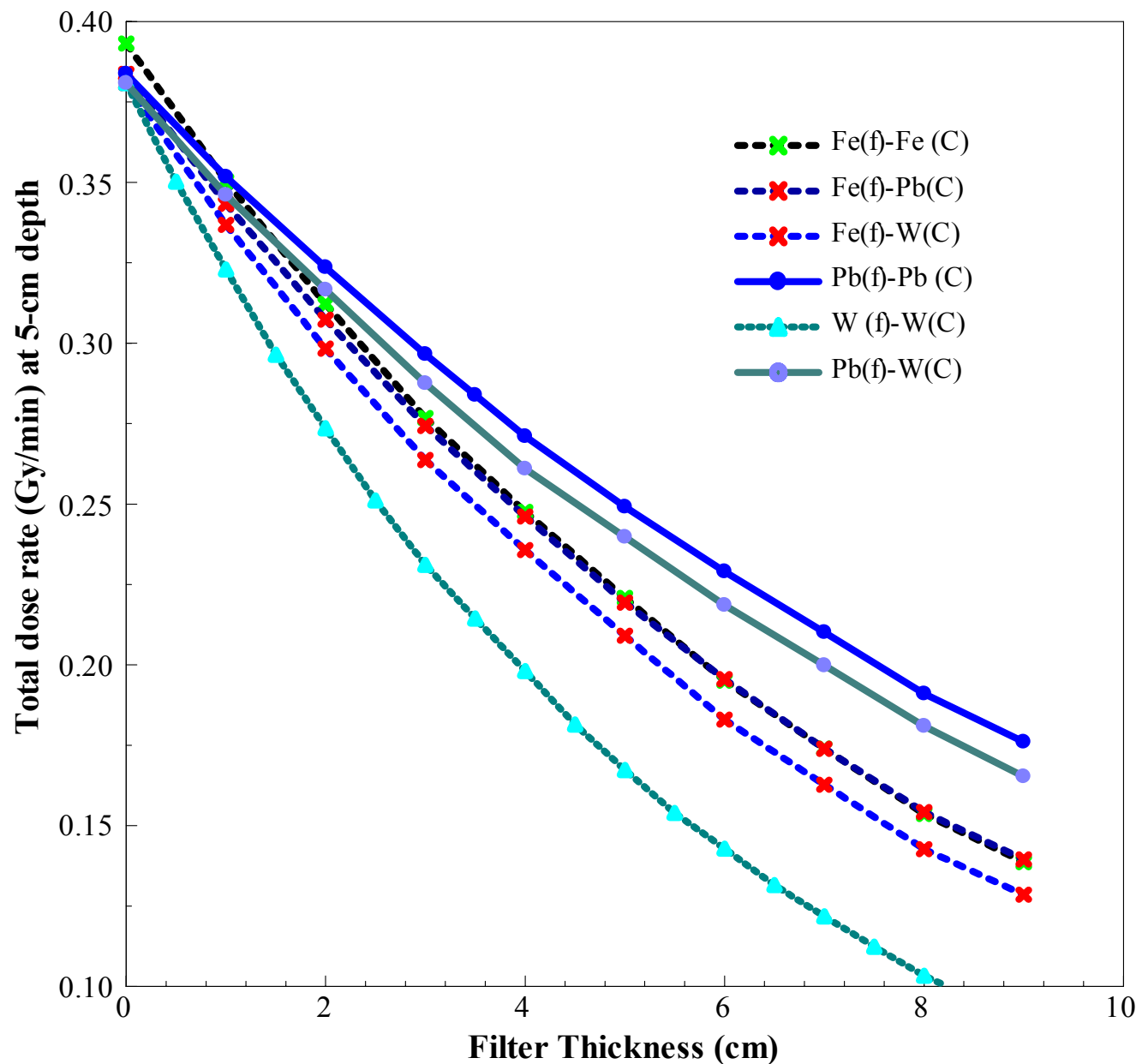

Figure 16: Total dose rate at 5-cm depth in the head phantom for various filter and collimator combinations. In the legend, (f) stands for filter and (C) stands for collimator. A $20 \times 10 \mathrm{~cm}^{2}$ standard treatment beam field is used and the opening of the collimator is equivalent to $5 \times 5 \mathrm{~cm}^{2}$ size. The thickness of the collimator is $7 \mathrm{~cm}$ for all materials. A proton current of $1.7 \times 10^{14}$ protons $/ \mathrm{sec}$ is assumed. 


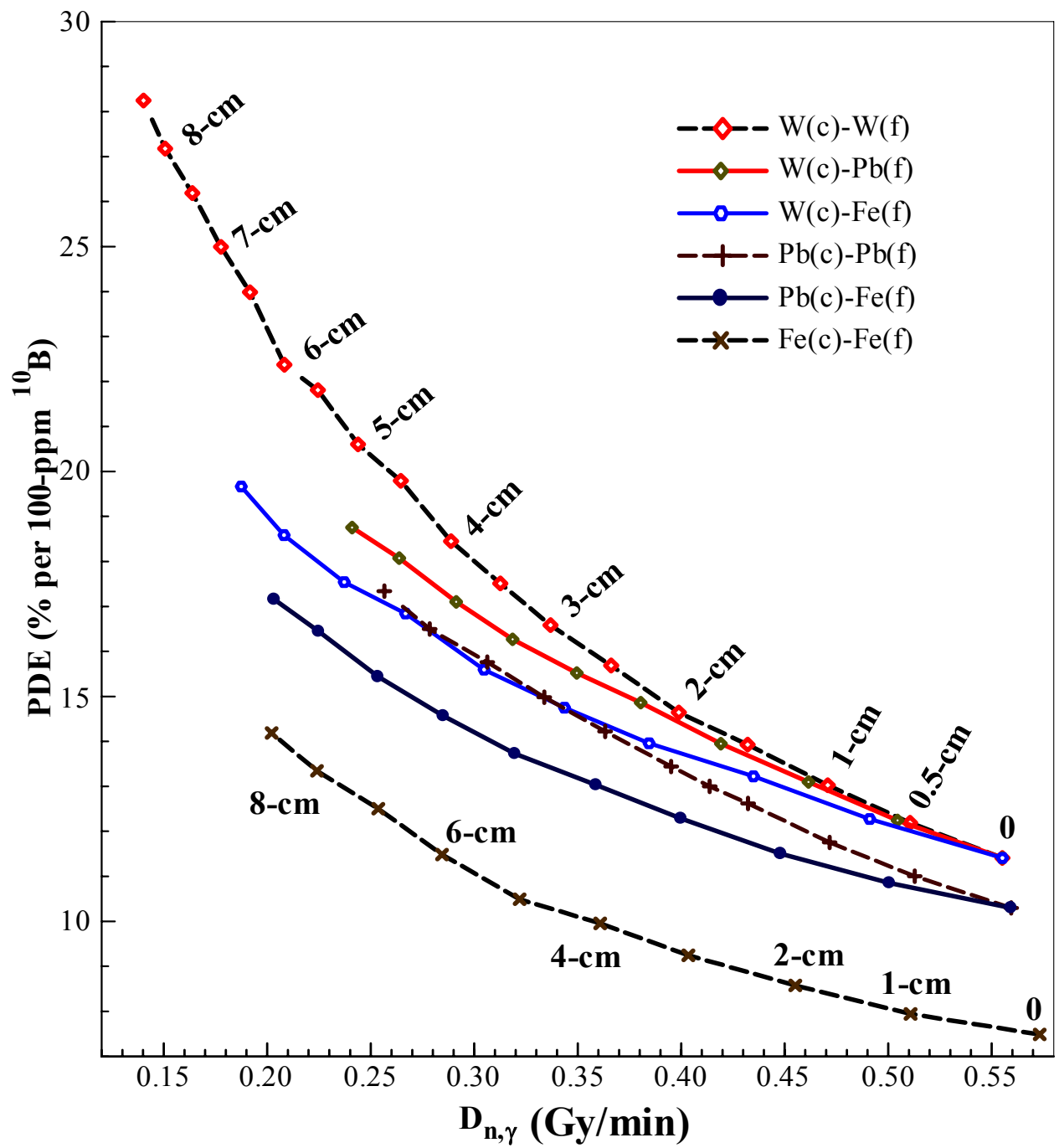

Figure 17: Relationship between PDE and total dose rate at 5-cm depth in the head phantom for various filter and collimator combinations. In the legend, (f) stands for filter and (C) stands for collimator. Values in the graph $(1 \mathrm{~cm}, 2 \mathrm{~cm}$, etc.) indicate the filter thickness of the corresponding material. A $20 \times 20 \mathrm{~cm}^{2}$ standard treatment beam field is used and the opening of the collimator is equivalent to $5 \times 5 \mathrm{~cm}^{2}$ size. The thickness of the collimator is $10 \mathrm{~cm}$ for all materials. A proton current of $1.7 \times 10^{14}$ protons/sec is assumed for the normalization of the MCNP results.

\subsection{Characterizations of the Designed Assembly Using MCNP Simulations}

The sizes of the graphite moderator/reflector, the tungsten collimator and filter were optimized by MCNP simulations for the purpose of obtaining the maximum PDE while retaining an acceptable total dose rate for treatment. It was found that $10-\mathrm{cm}$ thick graphite reflector is sufficient and that further increasing of the reflector thickness will not result in a larger PDE. 
Two collimator sizes were studied, one with a inner diameter of $5.64 \mathrm{~cm}$ (an area equivalent to $5 \times 5 \mathrm{~cm}^{2}$ ) and one with diameter of $11.29-\mathrm{cm}$ (an area equivalent to 10 $\mathrm{x} 10 \mathrm{~cm}^{2}$ ). The MCNP5 model of the graphite reflector, 5.64-cm diameter and 7.0-cm tungsten collimator, and tungsten filter is shown in Figure 18.

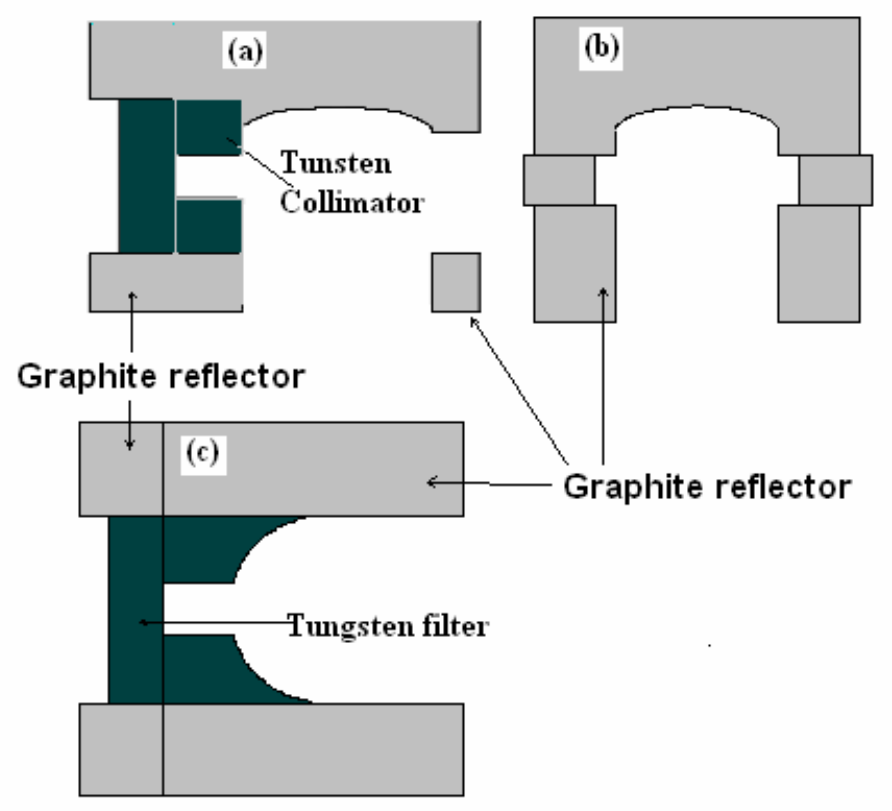

Figure 18: Diagram of the MCNP model of a tungsten filter, tungsten collimator and graphite reflector. These are cross-sectional views at the centerline of the collimator: (a) side view, (b) front view, and (c) top view. The thickness of the tungsten collimator and the graphite reflector are $10 \mathrm{~cm}$

The isodose curve for neutrons and gamma rays in the head for the $4.0-\mathrm{cm}$ tungsten filter, tungsten collimator and graphite reflector is given in Figure 19. This plot, produced using the mesh tally feature of MCNP5, shows that this design produces good collimation. The collimator projects a $5.64-\mathrm{cm}$ diameter field at the isocenter, which is located at $5-\mathrm{cm}$ depth from the back head and $7.5-\mathrm{cm}$ from the top of the head phantom. The MCNP F6 tally, which yields kerma values, was used in the computation of neutron and photon doses. This resulted in higher dose values at shallow depths in the head than the true absorbed dose. Doses at depths shallower than $1.7 \mathrm{~cm}$ calculated by F6 tally are 
not correct due to the lack of charged particle equilibrium condition, i.e., the condition for kerma to be equal to absorbed dose.

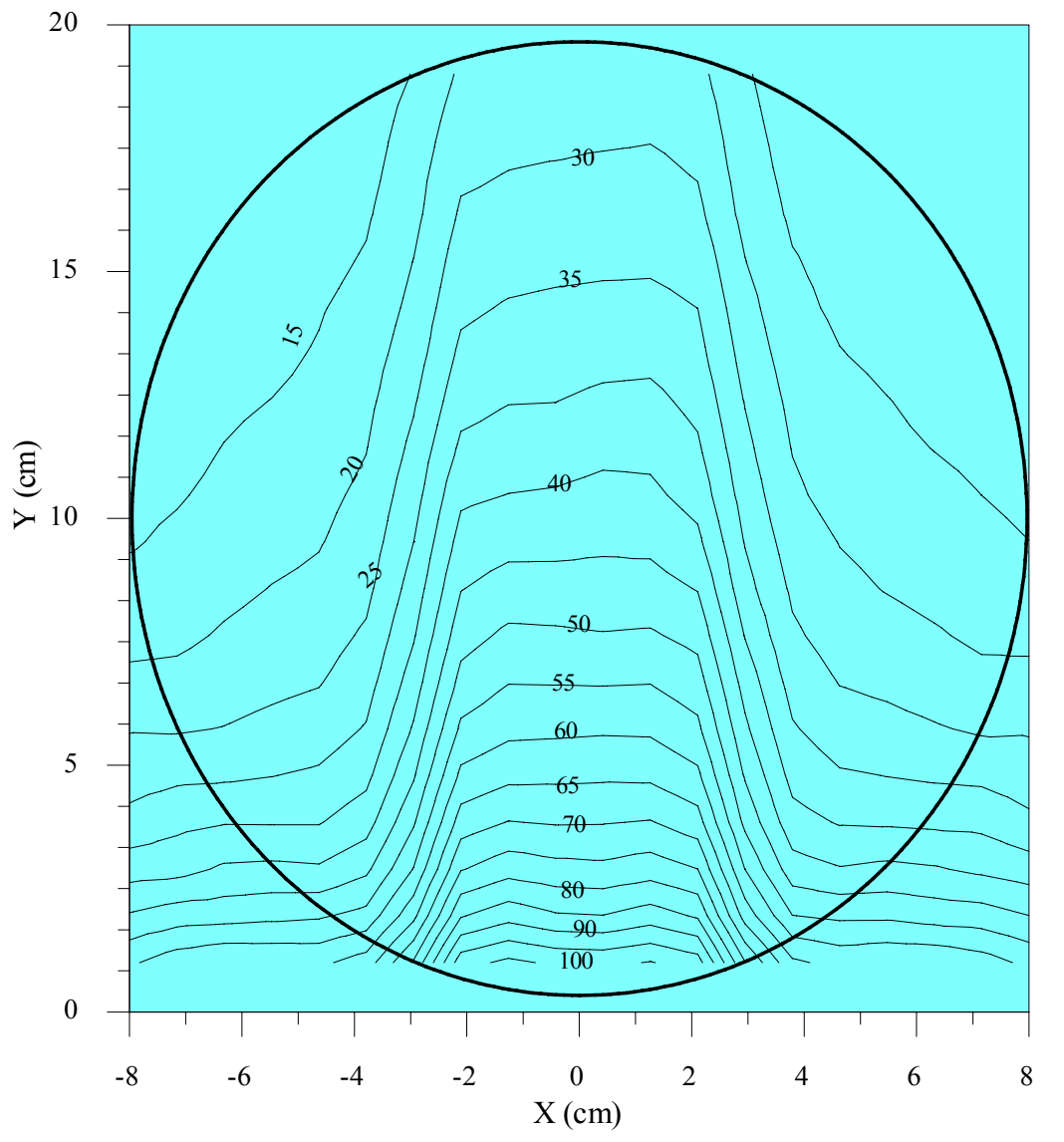

Figure 19: Calculated isokerma curve of the neutron and gamma dose for 5.64-cm diameter and 7.0$\mathrm{cm}$ thick tungsten collimator, $4.0-\mathrm{cm}$ tungsten filter and $10-\mathrm{cm}$ thick graphite reflector as shown in Figure 18. The thick elliptical line is the outline of the head phantom. (Curves outside the head should be ignored)

The isodose curve for the boron capture dose alone is plotted in Figure 20. The ${ }^{10} \mathrm{~B}$ concentration $(100 \mu \mathrm{g} / \mathrm{g})$ is assumed to be uniformly distributed in the head for the boron dose calculation. The peak of the boron capture dose is at $5-\mathrm{cm}$ depth, around the beam centerline. 


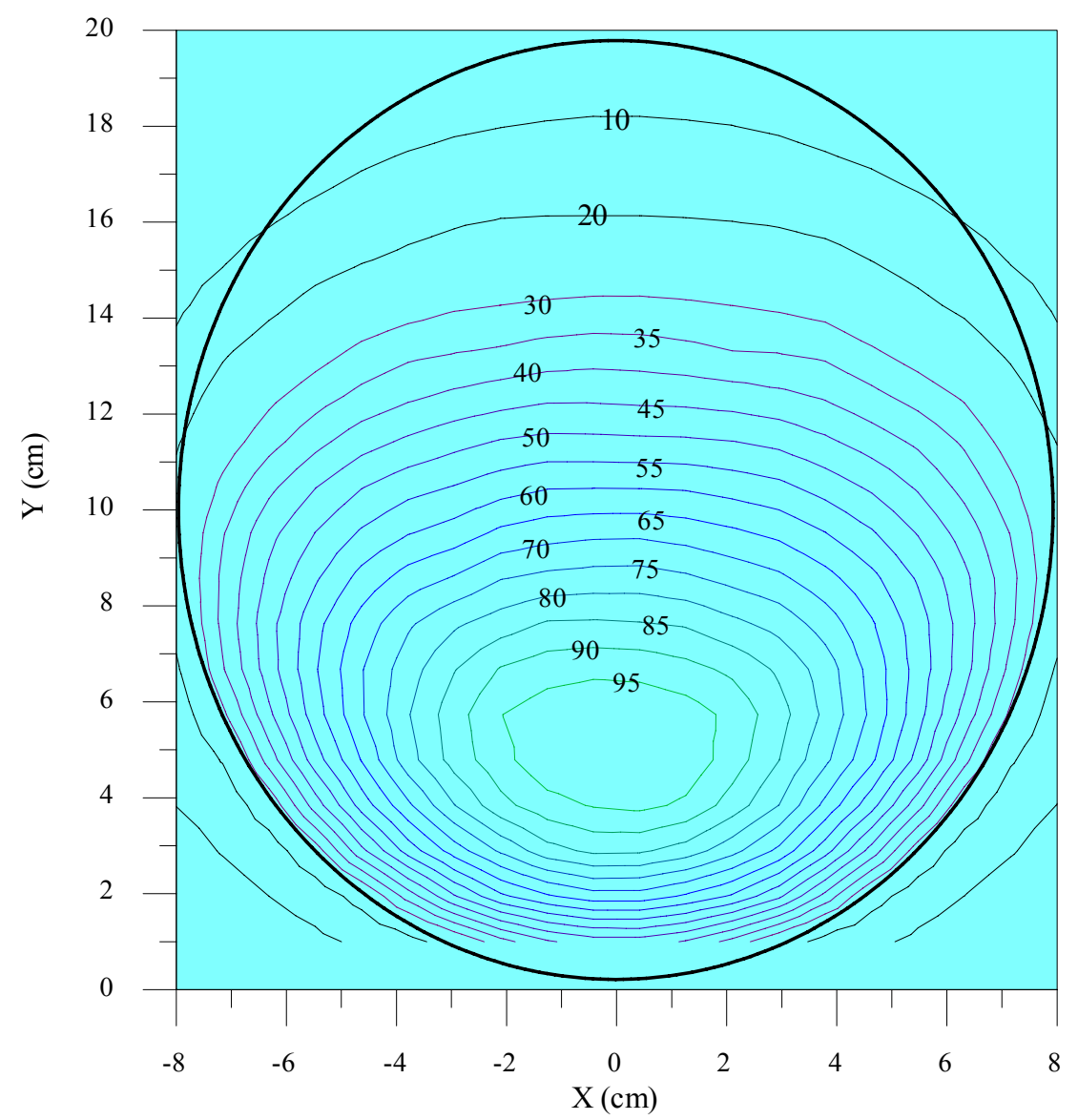

Figure 20: Calculated isodose curve of the boron capture dose $\left({ }^{10} \mathrm{~B}\right.$ concentration is uniformly distributed through the head) for $5.64-\mathrm{cm}$ diameter and $7.0-\mathrm{cm}$ thick tungsten collimator, $4.0-\mathrm{cm}$ tungsten filter and 10-cm thick graphite reflector as shown in Figure 18. The thick elliptical line is the outline of the head phantom. (Curves outside the head should be ignored)

The total kerma rates due to neutrons and gammas and the PDEs for the 5.64-cm and $11.29-\mathrm{cm}$ diameter collimators were calculated in various phantom depths for different filter thicknesses and the results are shown in Figure 21 and Figure 23. The boron capture dose rate in units of $\mathrm{Gy} / \mathrm{min}$ as a function of depth for the $5.64-\mathrm{cm}$ diameter collimator is shown in Figure 22. It is found that increase of filter thickness results in a decrease of the absolute boron capture dose. The reason that thicker filters have higher PDE values is that the neutron dose decreases much faster than does boron capture dose as the filter thickness increases. 

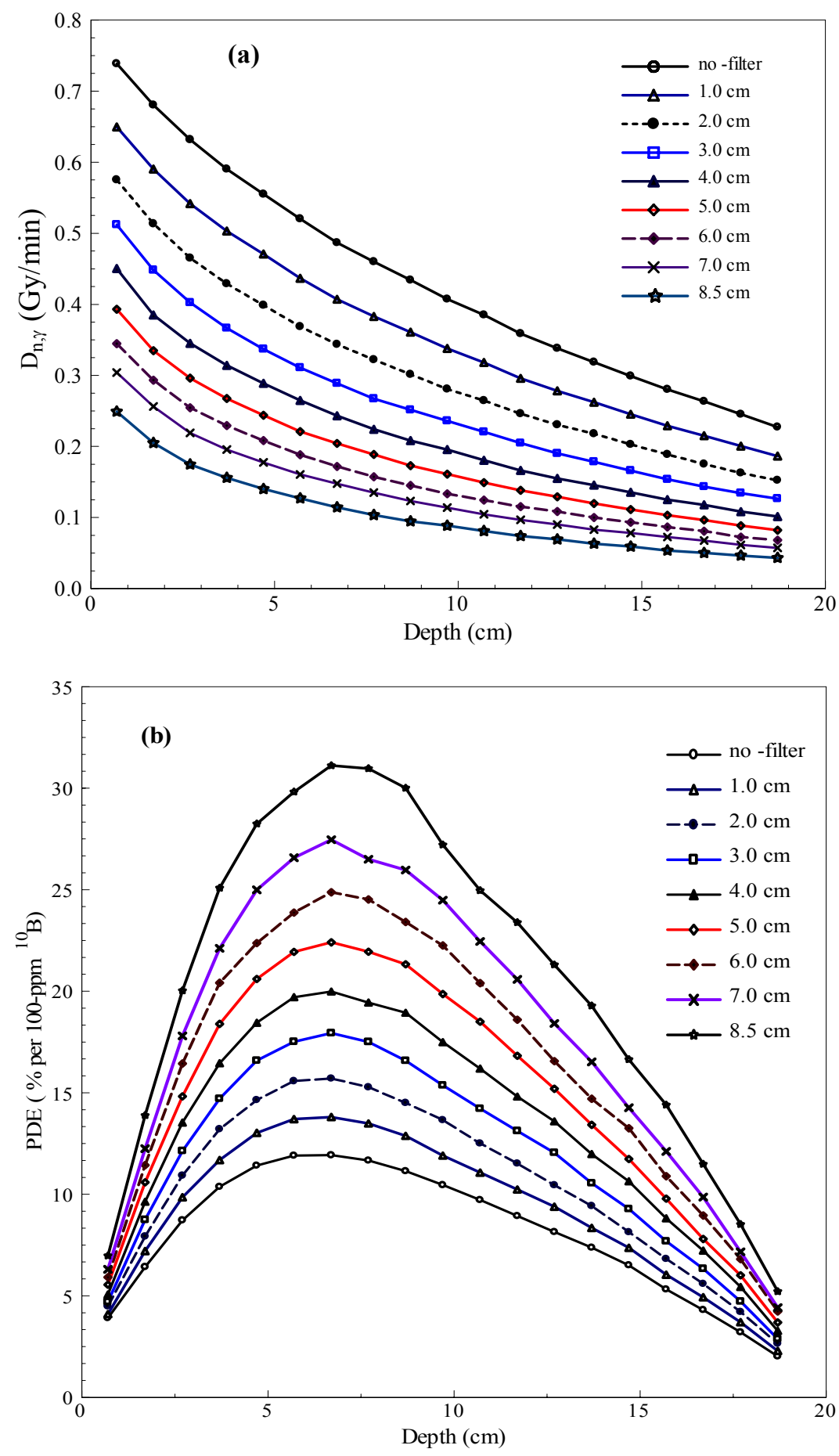

Figure 21: The MCNP calculated (a) depth-kerma distribution $\left(1.7 \times 10^{14}\right.$ protons/sec) and (b) depthPDE distribution of the 5.64-cm collimator along the centerline for various thick filters. 


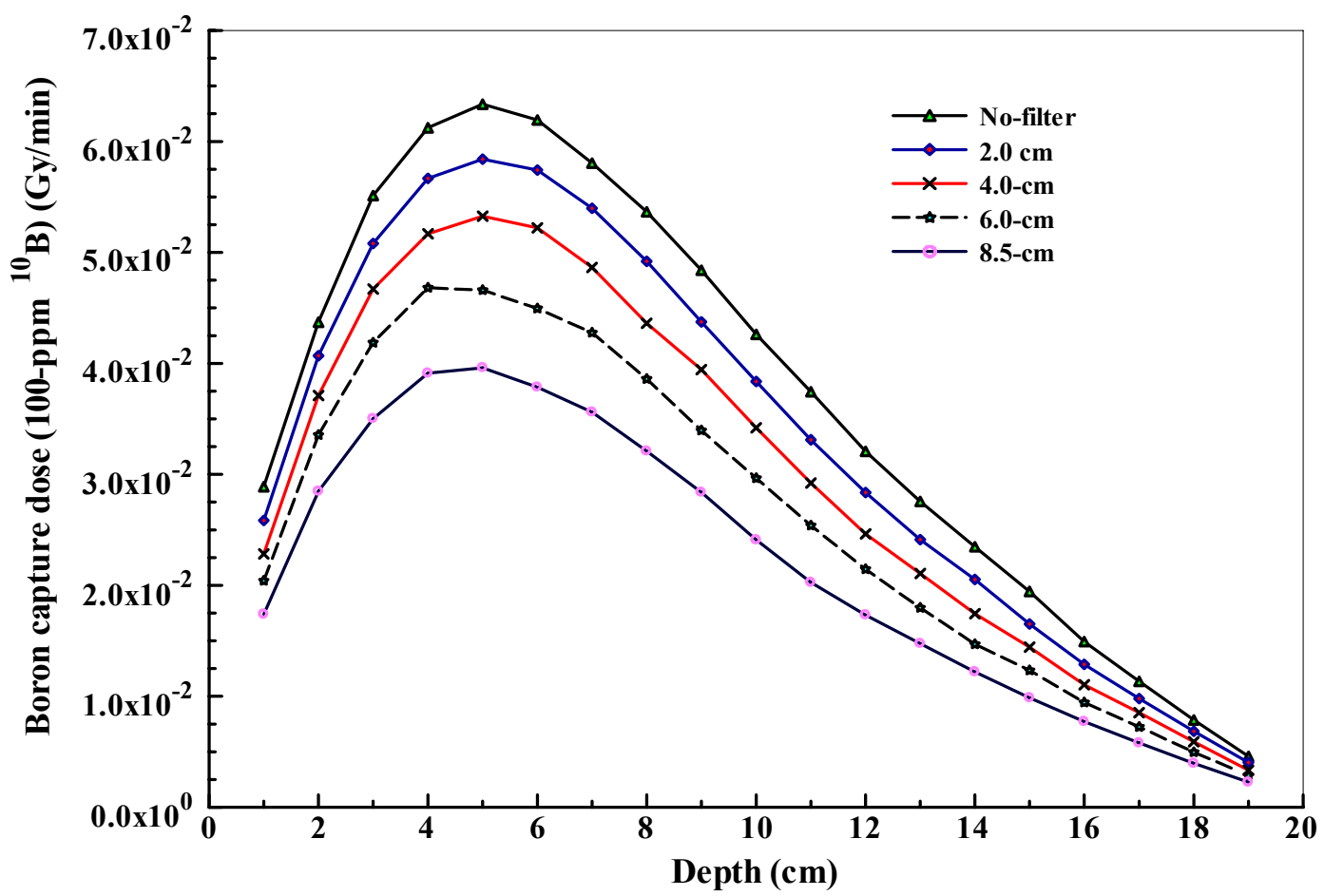

Figure 22: MCNP5 calculated depth-boron capture dose distribution of the 5.64-cm collimator along the centerline for various thick filters. $100-\mathrm{ppm}{ }^{10} \mathrm{~B}$ uniformly distributed in the water-filled head phantom and $1.7 \times 10^{14}$ protons/sec are assumed in the calculation. The error due to statistics is smaller than the symbol and the systematic error due to normalization is not considered here.

From the MCNP calculations shown in Figure 21 and Figure 23, the maximum values of PDE for any filter was found to be at depths in the phantom ranging from 5 to 9 $\mathrm{cm}$. Increasing the filter thickness results in an increase in the PDE but a decrease in the total kerma rate. The relationship between PDE and total kerma rate as a function of the filter thickness is shown in Figure 24 for the 5.64-cm diameter collimator at 5.7-cm depth in the water-filled head phantom. The maximum PDE for the 5.64-cm diameter collimator with an 8.5 -cm thick tungsten filter was found to be $31 \%$ while the total kerma rate at the corresponding location in the phantom was $0.11 \mathrm{~Gy} / \mathrm{min}$. The maximum PDE for the $11.29-\mathrm{cm}$ diameter collimator with an $8.5-\mathrm{cm}$ thick tungsten filter was found to be $29 \%$ while the total kerma rate at the corresponding location in the phantom was 0.14 Gy/min.

The gamma kerma depth distributions for various tungsten filters were also computed using MCNP simulation. The percentage of gamma dose in the total dose for 
several tungsten filters are shown in Figure 25. At 5.7-cm depth, the gamma percentage varies from $4.1 \%$ for no-filter to $8.5 \%$ for 8.5 -cm tungsten filter.
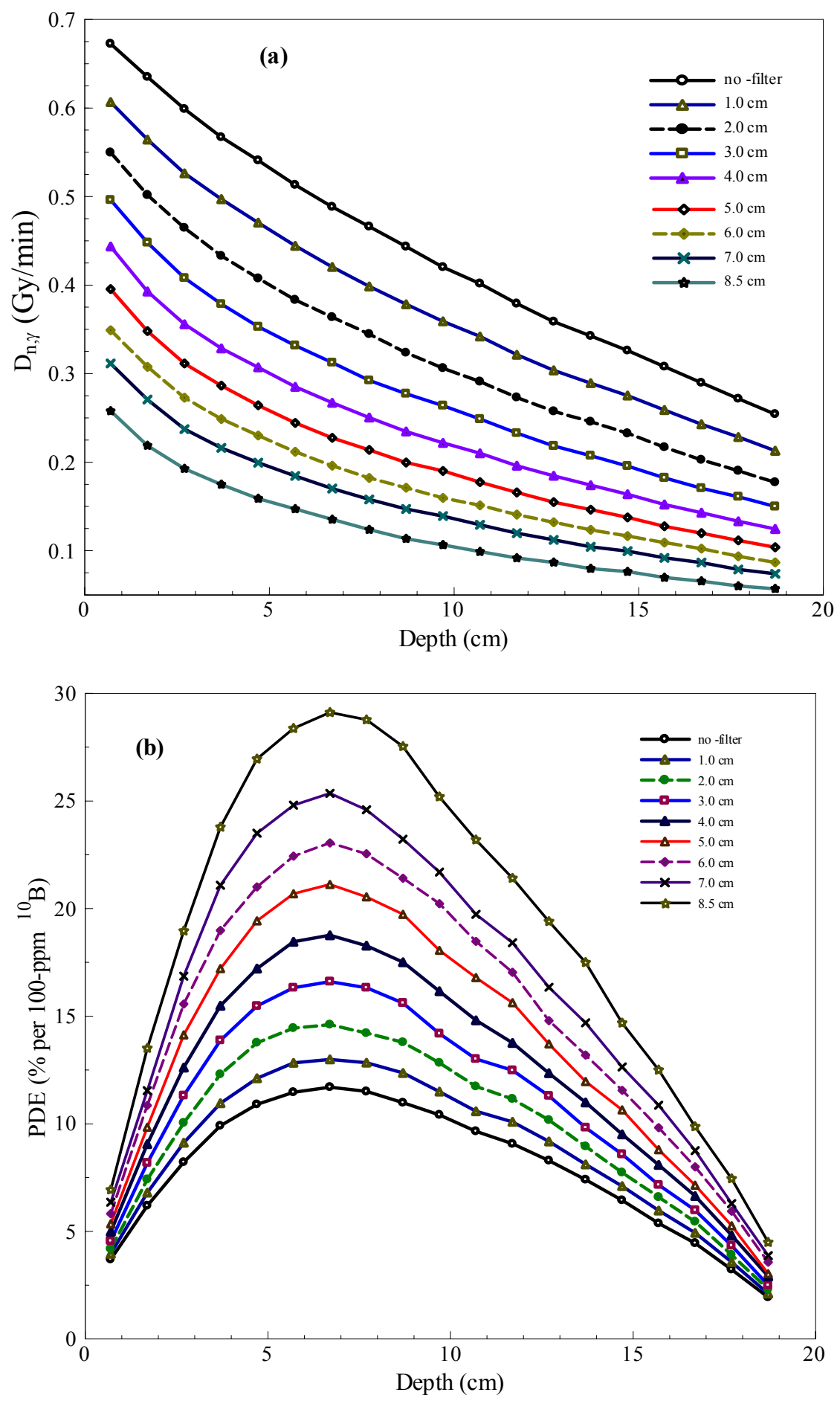

Figure 23: The MCNP5 calculated (a) depth-kerma distribution $\left(1.7 \times 10^{14}\right.$ protons/sec) and (b) depth-PDE distribution of the $11.29-\mathrm{cm}$ collimator along the centerline for various thick filters. 


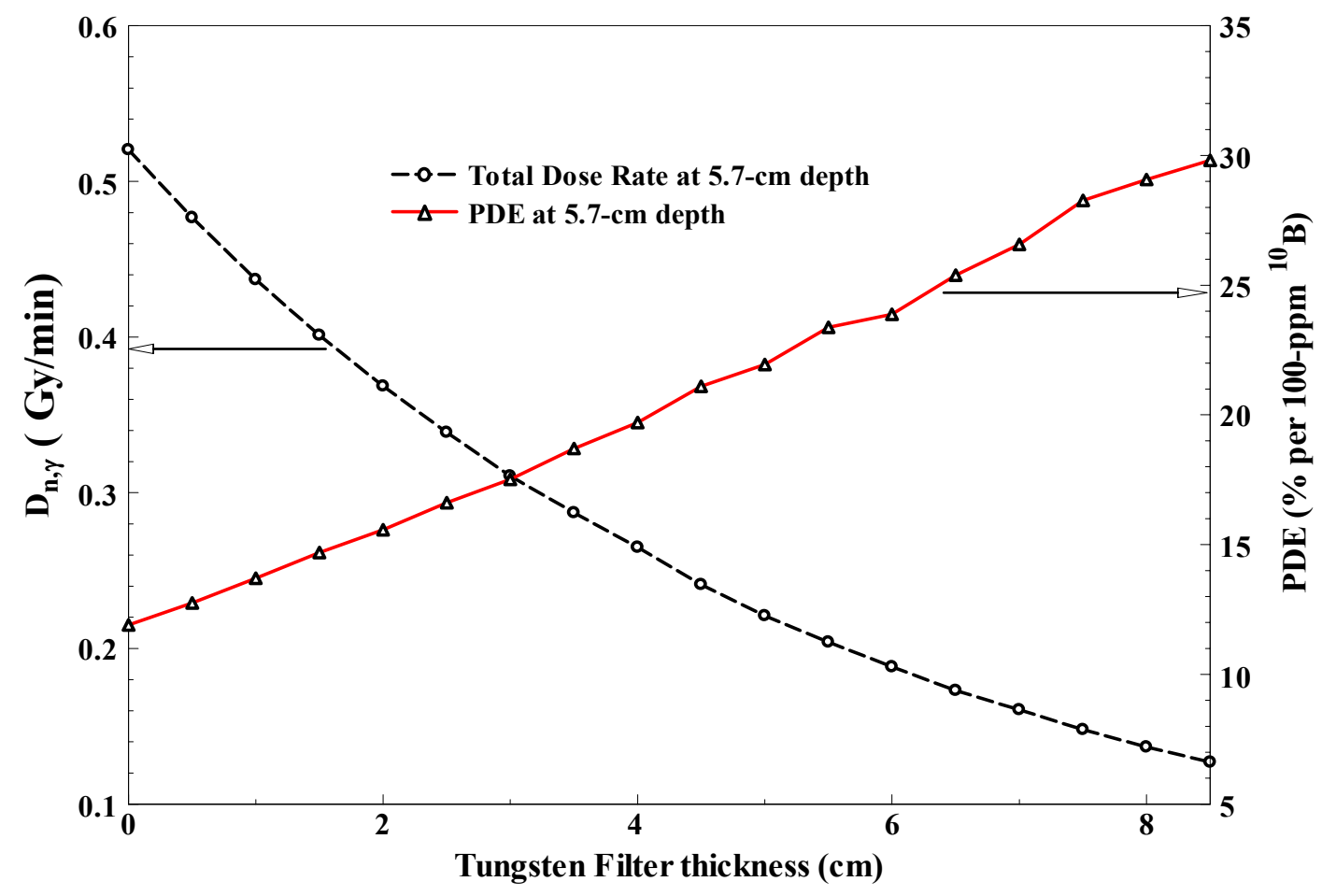

Figure 24: Relationship between PDE and total kerma rate as a function of filter thickness for the 5.64-cm collimator at $5.7-\mathrm{cm}$ depth in the water filled head phantom.

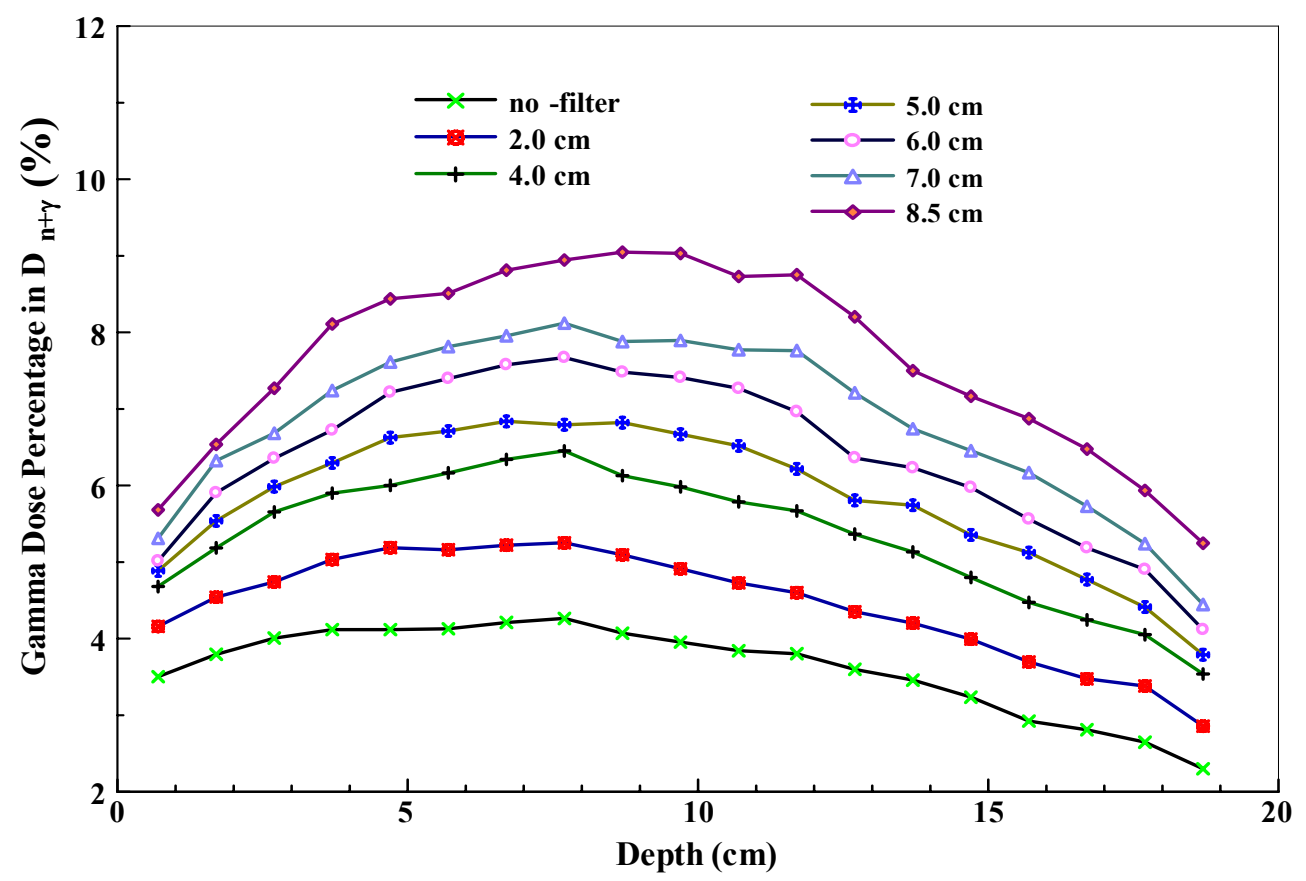

Figure 25: The percentage of gamma kerma in the total dose as a function of depth in the water-filled head phantom for various tungsten filter thickness. Statistic uncertainties range from $2 \%$ to $4 \%$, not plot in the graph. 


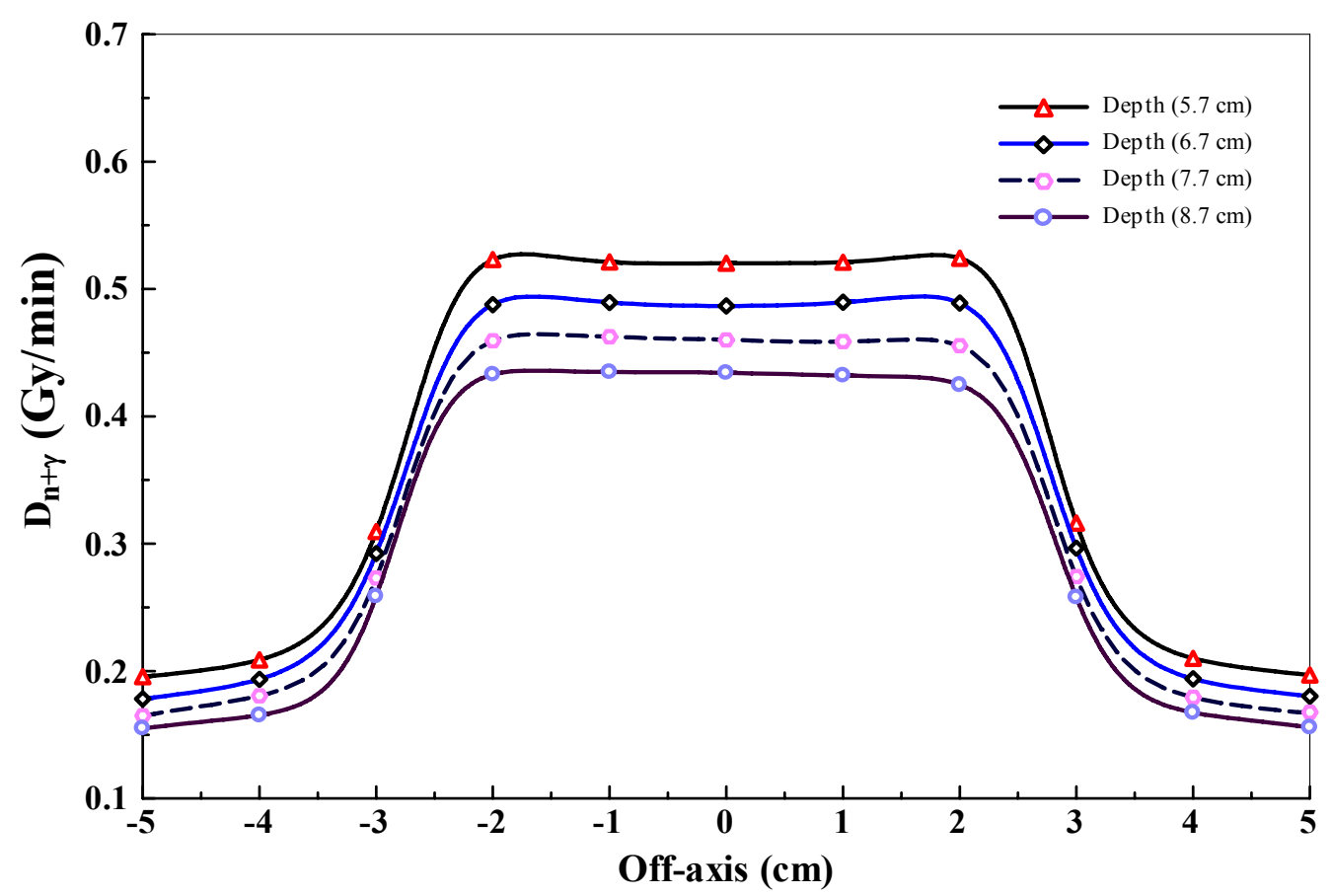

Figure 26: Total kerma rate off-axis profile at various depths in the water-filled head phantom in the designed BNCEFNT assembly with $5 \times 5 \mathrm{~cm}^{2}$ equivalent collimator and no-filter.

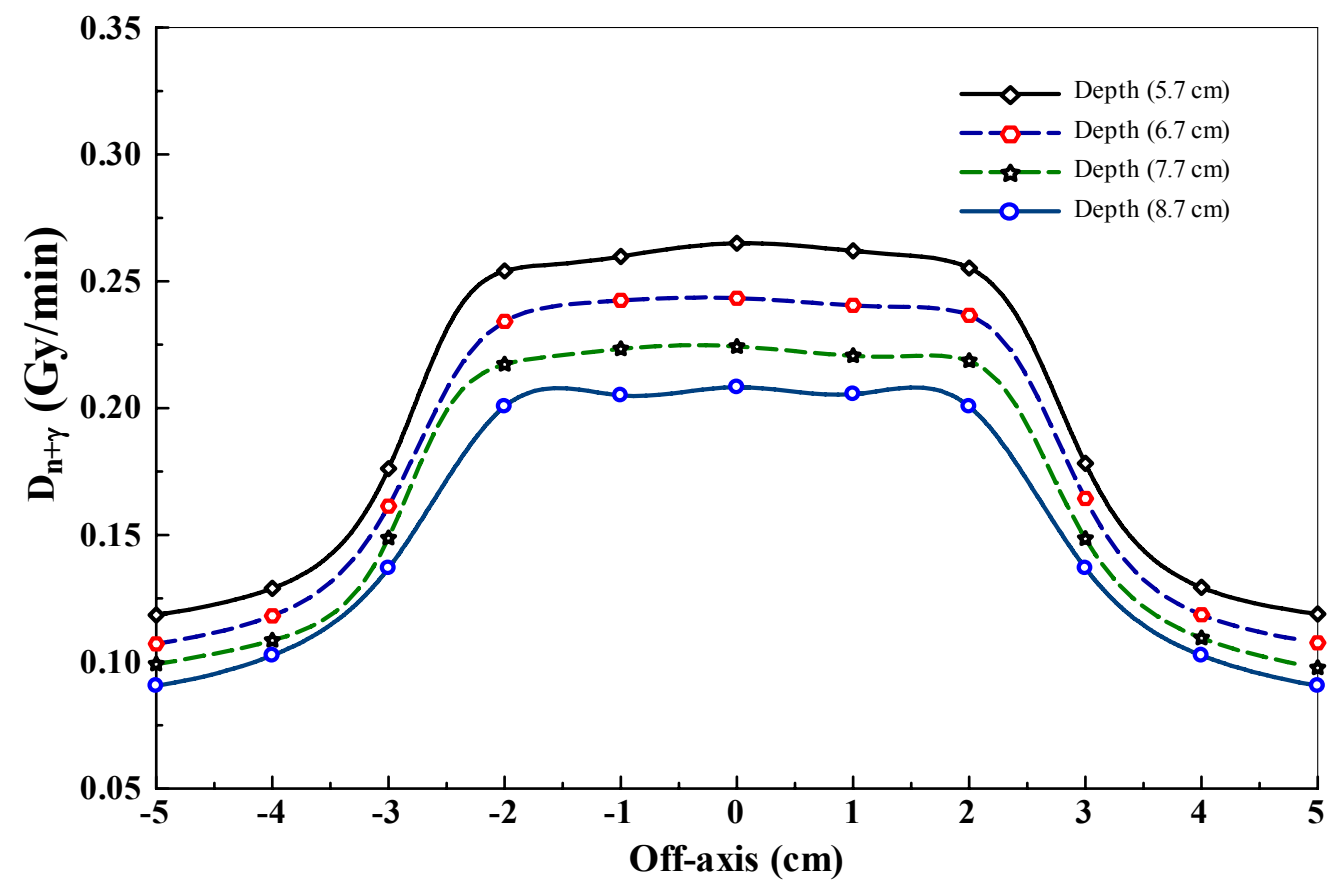

Figure 27: Total kerma rate off-axis profile at various depths in the water-filled head phantom in the designed BNCEFNT assembly with $5 \times 5 \mathrm{~cm}^{2}$ equivalent collimator and $4.0-\mathrm{cm}$ thick tungsten filter. 
The total kerma rate off-axis profiles at depth from 5.7 to $8.7 \mathrm{~cm}$ in the waterfilled head phantom in the BNCEFNT assembly with 5.64-cm diameter collimator plus no-filter and 4.0-cm tungsten filter are shown in Figure 26 and Figure 27, respectively. They demonstrate the effect of the collimator. The kerma rates across the opening of the collimator are relatively flat; the ratios of the dose rate at the center to the dose rate at 2.0 $\mathrm{cm}$ off axis range from 0.992 to 1.01 for no-filter and from 1.03 to 1.04 for $4.0-\mathrm{cm}$ tungsten filter. The statistical uncertainties in these ratios range from $1.2 \%$ to $1.6 \%$. It is also noted that the collimator performs better when there is no filter.

The boron capture dose rate off-axis profiles at depths from 5.7 to $8.7 \mathrm{~cm}$ in the water-filled head phantom in the BNCEFNT assembly $(5.64-\mathrm{cm}$ diameter collimator plus no-filter and 4.0-cm tungsten filter) are shown in Figure 28 and Figure 29, respectively. The curves are more like a cosine function because they depend almost exclusively on the thermal neutron fluence rates, which can be explained using diffusion theory.

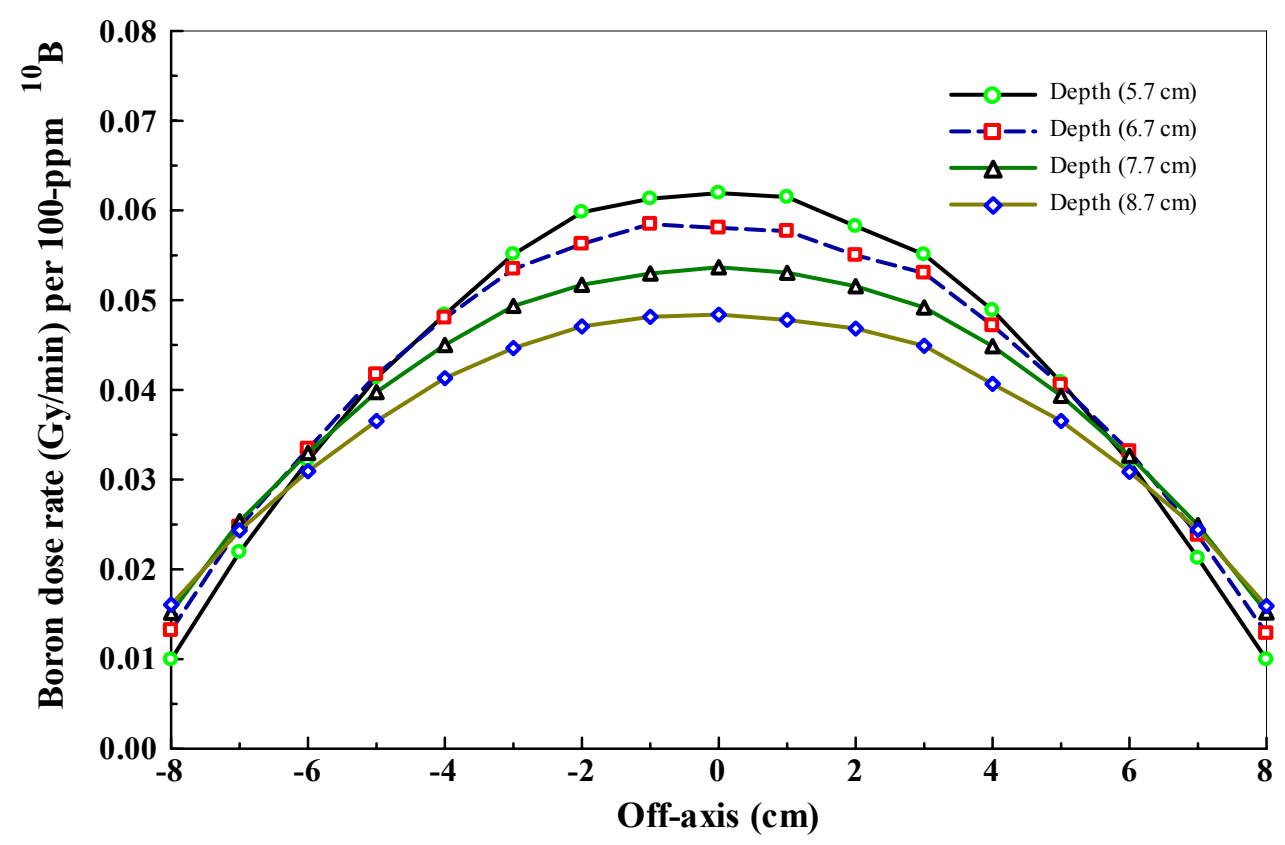

Figure 28: Boron dose rate off-axis profile per $100-\mathrm{ppm}{ }^{10} \mathrm{~B}$ uniformly distributed in a water-filled head phantom in the designed BNCEFNT assembly with no-filter 


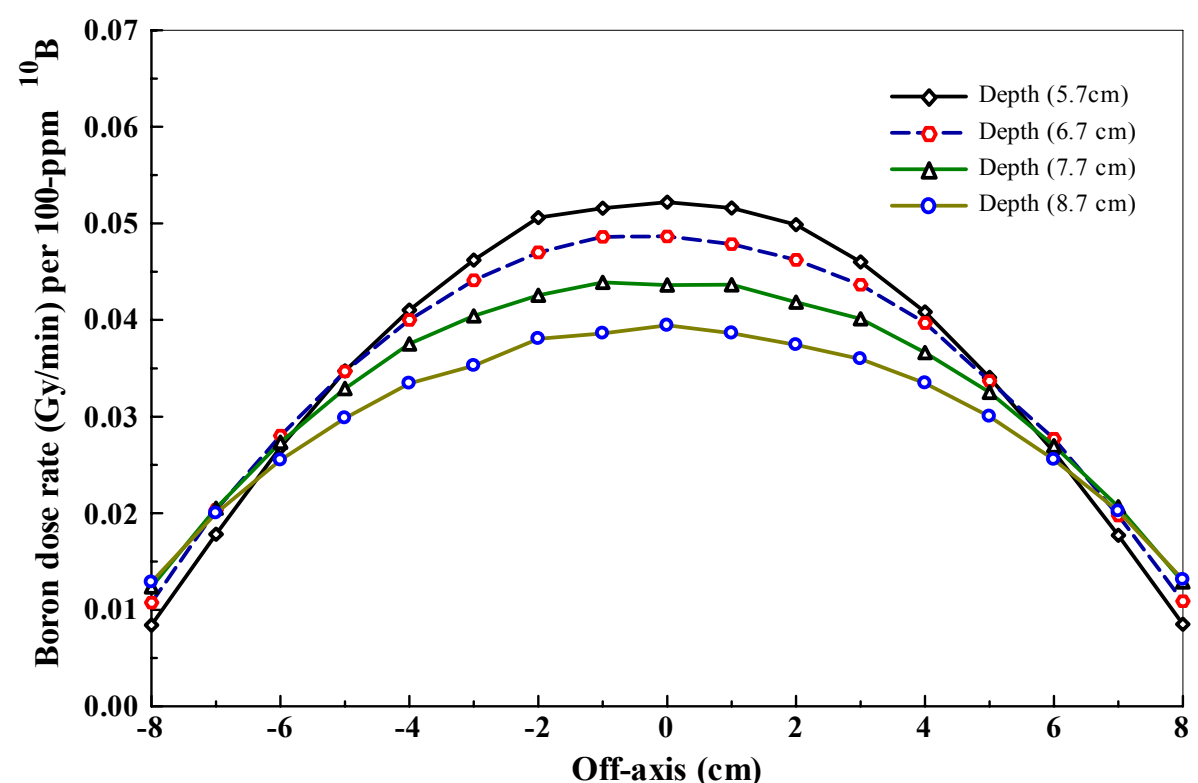

Figure 29: Boron dose rate off-axis profile per $100-p p m ~{ }^{10} \mathrm{~B}$ uniformly distributed in a water-filled head phantom in the designed BNCEFNT assembly with 4.0-cm tungsten filter

\subsection{Validation of the Design}

The MCNP-calculated PDE and total dose rate of the BNCEFNT assembly must be validated by experiments. According to the simulation, the system shown in Figure 18 will work. The exploded view of the assembly of the system is shown in Figure 30 . The reflector (Figure 30(a)) is made of graphite. The largest cylinder in the center of the moderator is $22 \mathrm{~cm}$ in diameter with a curvature at the top to accommodate the head phantom. The cylindrical hole on the back of the moderator is $20-\mathrm{cm}$ in diameter and for the insertion of the tungsten collimator. The two $10-\mathrm{cm}$ diameter cylindrical holes on both sides of the moderator are for viewing and adjusting the position of the head and will be filled with two $10-\mathrm{cm}$ diameter and 10-cm long graphite cylindrical plugs (Figure 30 (f)) after the head is positioned. The frame (Figure 30 (e)) is made of steel and serves as filter holder, collimator and reflector. Based on the MCNP calculations a frame made of tungsten results in higher PDE, but it is too heavy and expensive, so steel is used to substitute for tungsten. This leads to a PDE close to the PDE obtained by a tungsten frame. The collimator (Figure 30 (b) and (c)) is made of tungsten and consists two pieces 
for two different collimator diameters. The large piece should be always inserted in the moderator, and provides a $10-\mathrm{cm} \times 10-\mathrm{cm}$ equivalent collimation if the small piece is not inserted. A $5-\mathrm{cm} \times 5-\mathrm{cm}$ equivalent collimation can be obtained if the small piece is inserted into the larger one. The filter (Figure 30 (e)) is made of tungsten and is 20-cm in diameter and $1-\mathrm{cm}$ thick ( 8 pieces) and 0.5 thick (1 piece) disks. The combination of these tungsten disks can make 16 filter thicknesses range from 0.5 to $8.5 \mathrm{~cm}$.

For each collimator $(5-\mathrm{cm} \times 5-\mathrm{cm}$ and $10-\mathrm{cm} \times 10-\mathrm{cm})$, depth-dose distribution and depth-PDE distribution in the head phantom for a representative filter thickness should be measured using the borated and non-borated TE ion chamber as described in Chapter 3. This serves to validate the MCNP results shown in Figure 21, Figure 23, and Figure 24 .

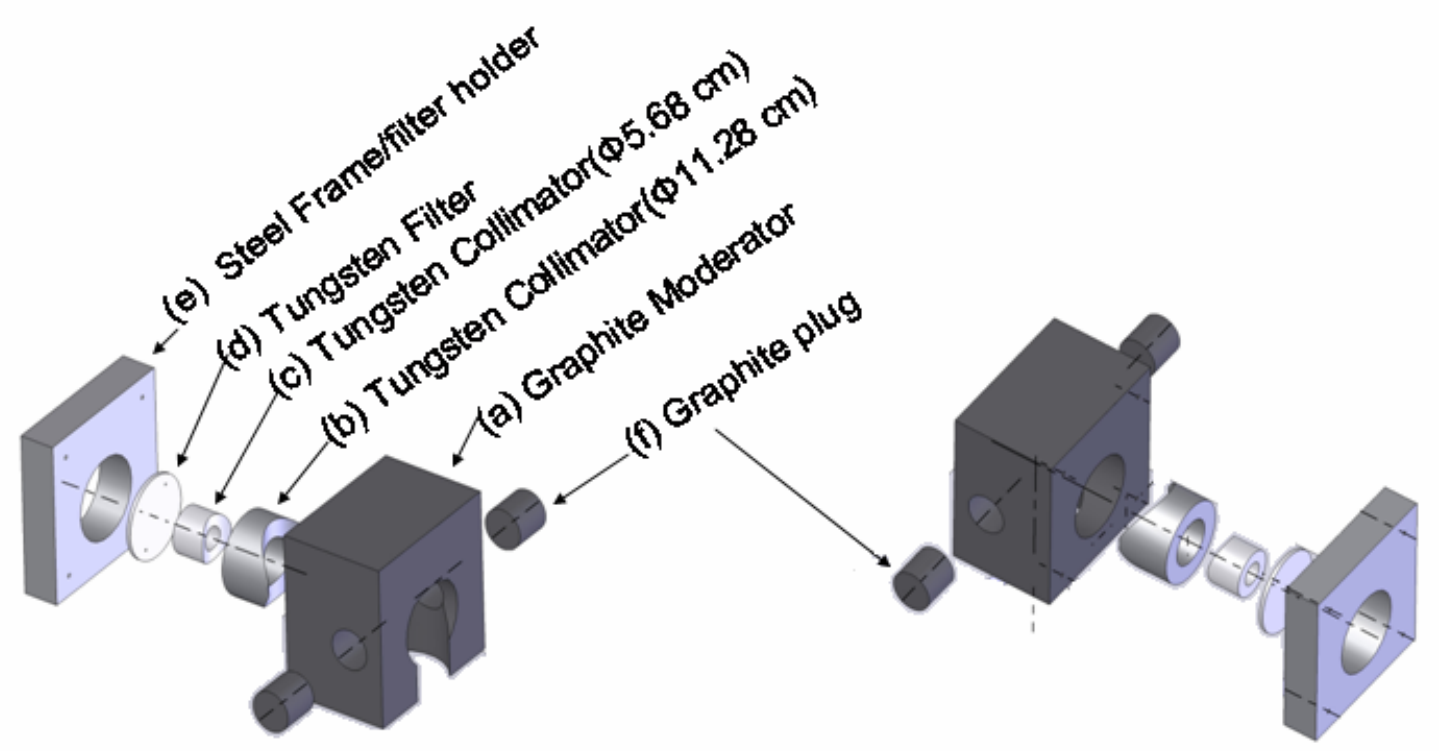

Figure 30: Drawings of the moderator, frame, collimator, and filter of the designed system

However, the cost of purchasing and machining tungsten is too prohibitive for a testing phase. So to validate the MCNP simulations, a simplified BNCEFNT assembly was built using tungsten plates (filter), lead bricks (collimator) and graphite blocks (reflector). The $5 \mathrm{~cm}$ x $5 \mathrm{~cm}$ collimator was made of four lead bricks is shown in Figure 
31. The thickness of the collimator is $10 \mathrm{~cm}$. The finished test assembly is shown in Figure 32. In order to reduce surface contamination, all the graphite bricks/blocks were wrapped with plastic foils. The center of the $5 \mathrm{~cm} \times 5 \mathrm{~cm}$ collimator was aligned along the centerline of the $20 \mathrm{~cm} \times 20 \mathrm{~cm}$ neutron beam (shown in Figure 32).

A picture of the RSVP head phantom used in the experiment is given in Figure 34. It was filled with deionized water and placed in the center of the built assembly in an upside down position.

An $\mathrm{X}-\mathrm{Y}$ positioner is used to move the ion chamber remotely during the experiment. The small dimension of the neck of the head phantom makes it difficult to move the ion chamber inside the head phantom over a large range. Two ion chamber holders, one at an angle of $22^{\circ}$ and one perpendicular to the X-Y table, were used in the experiment to move the ion chamber from $1 \mathrm{~cm}$ to $12.8 \mathrm{~cm}$ along the beam centerline (in the $\mathrm{X}$ axis), and to move the ion chamber laterally along the $\mathrm{Y}$ axis in a range of $\pm 3.0 \mathrm{~cm}$. $\mathrm{X}-\mathrm{Y}$ positioner with the $22^{\circ}$ angle ion chamber holder, the head phantom and the graphite reflective assembly is shown in Figure 35. 


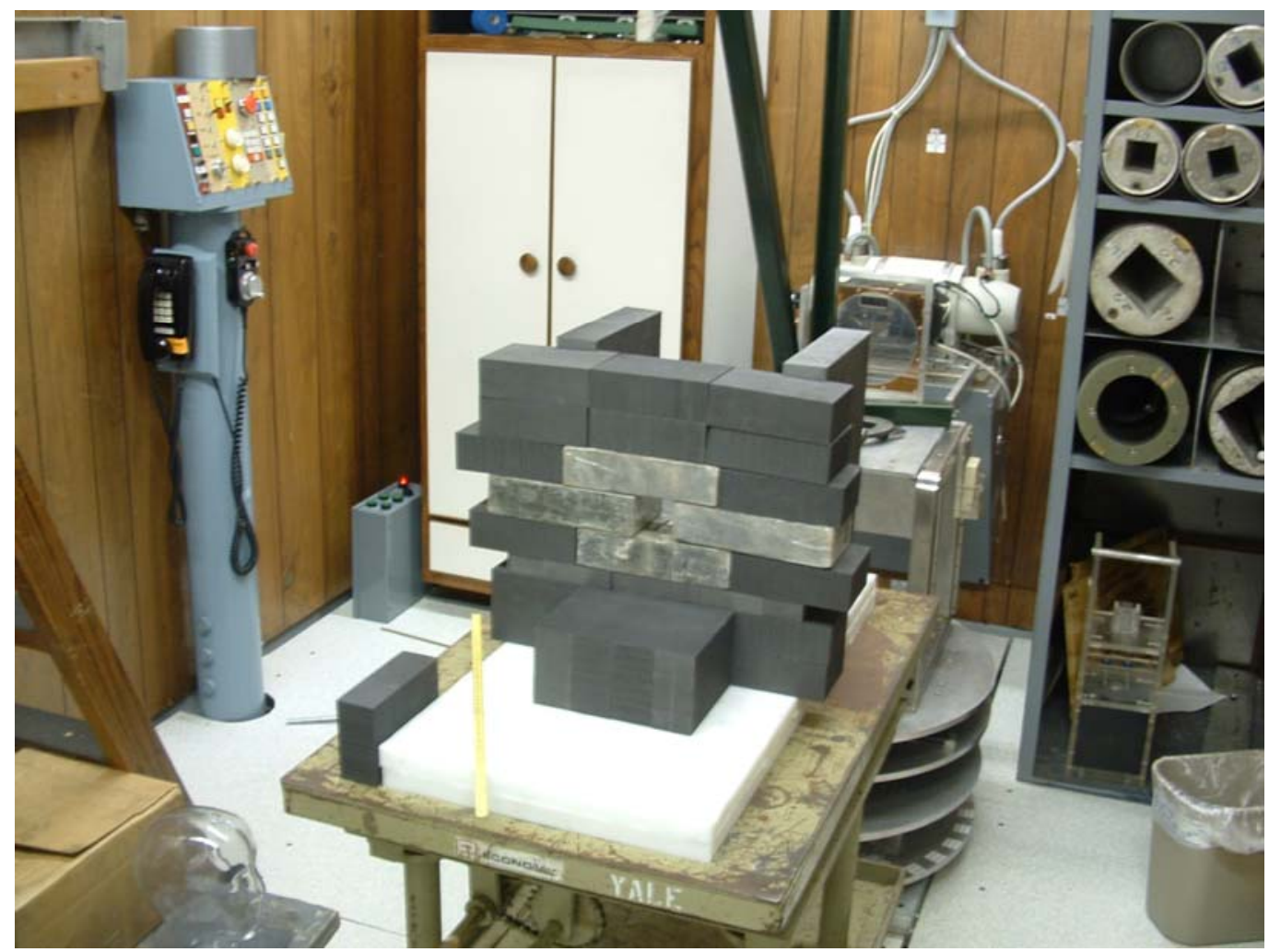

Figure 31: The $5 \mathrm{~cm} \times 5 \mathrm{~cm}$ collimator made of four lead bricks (the brown colored in the center). The thickness of the collimator is $10 \mathrm{~cm}$. The lead brick has a dimension of $20 \mathrm{~cm} \times 10 \mathrm{~cm} \times 5 \mathrm{~cm}$. The black bricks are graphite. The assembly is placed on a cart and between the assembly and cart is 10cm thick polyethylene plate. 


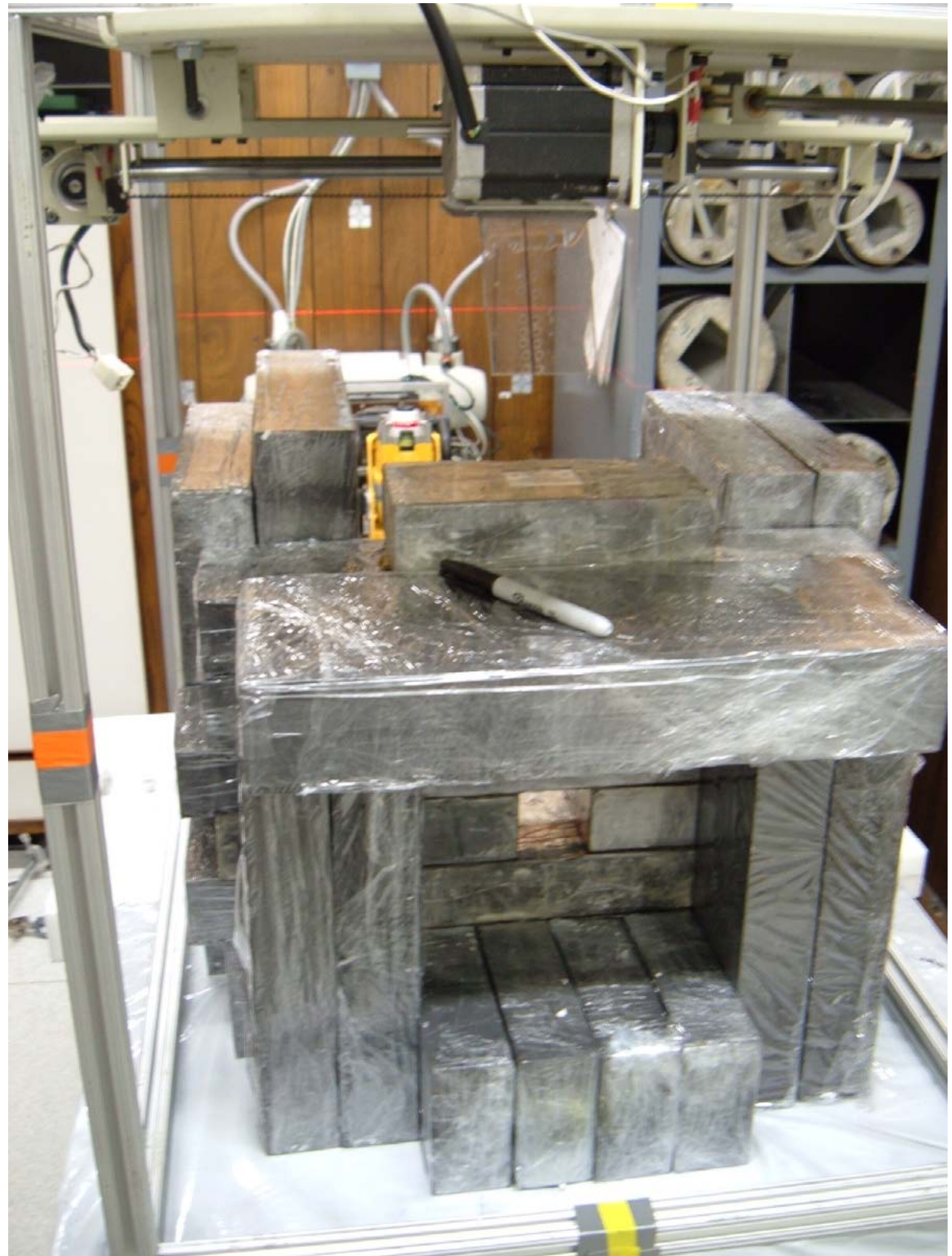

Figure 32: Picture of the simplified moderator/collimator assembly. The tungsten filter will be placed in the center. All graphite bricks are wrapped with plastic foil to avoid contamination. 


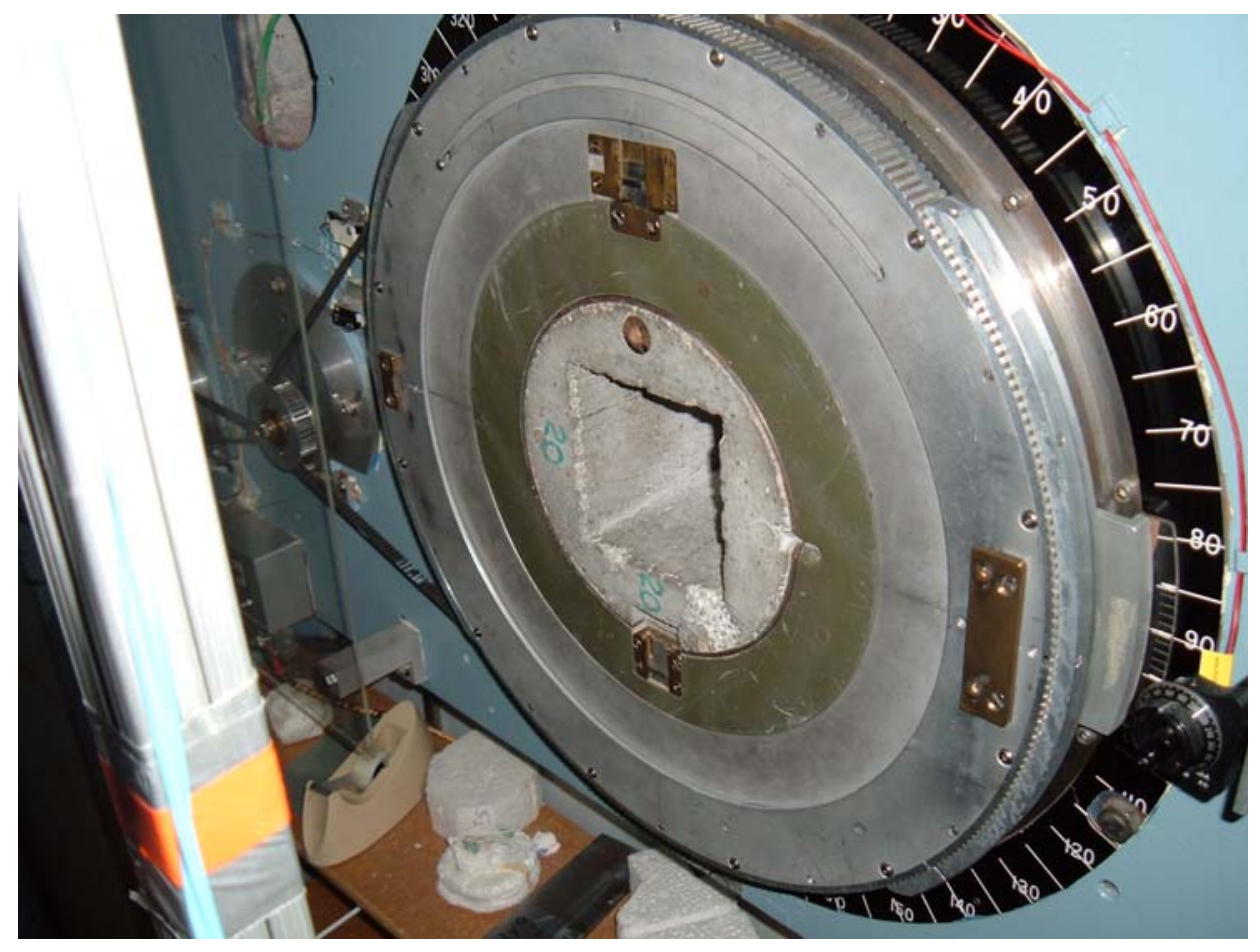

Figure 33: The standard $20 \mathrm{~cm} \times 20 \mathrm{~cm}$ beam collimator used in the experiment.

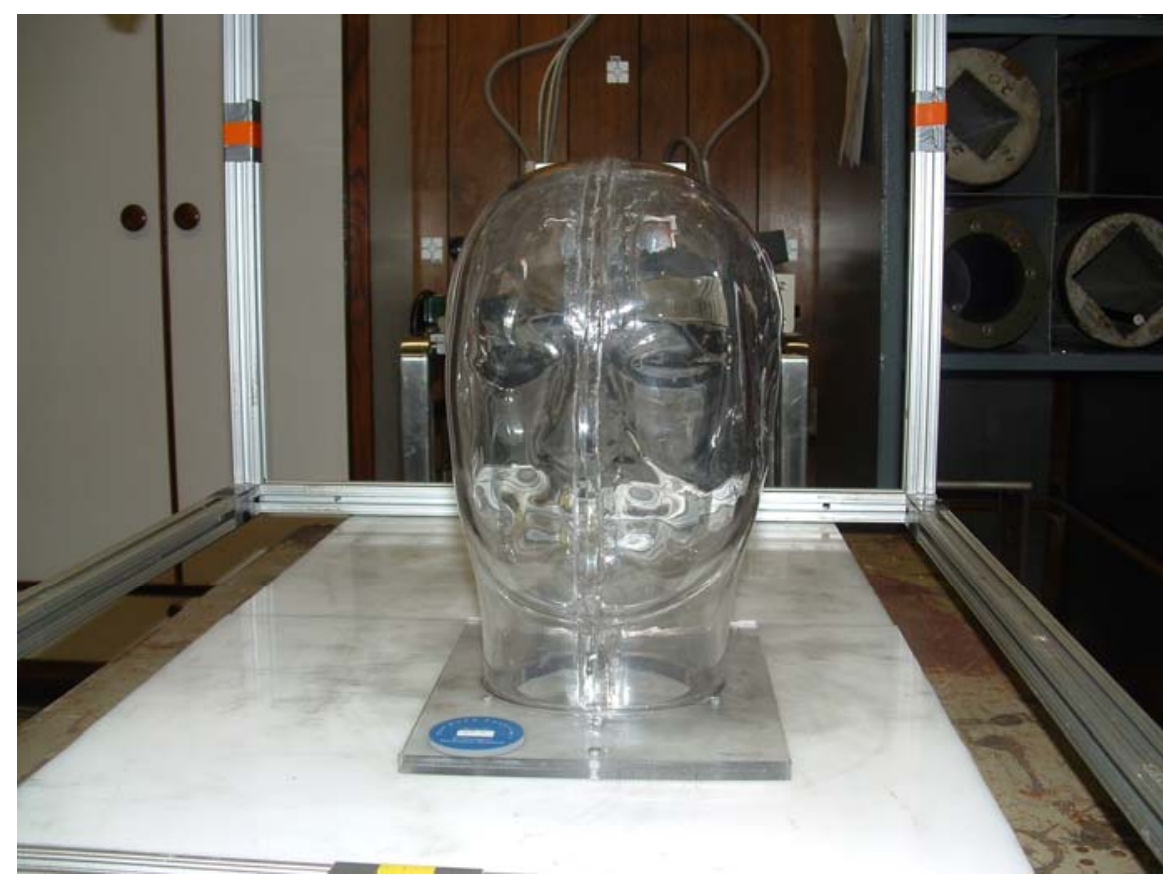

Figure 34: Head phantom used in the experiment. It will be filled with deionized water and placed upside down during the experiment. 


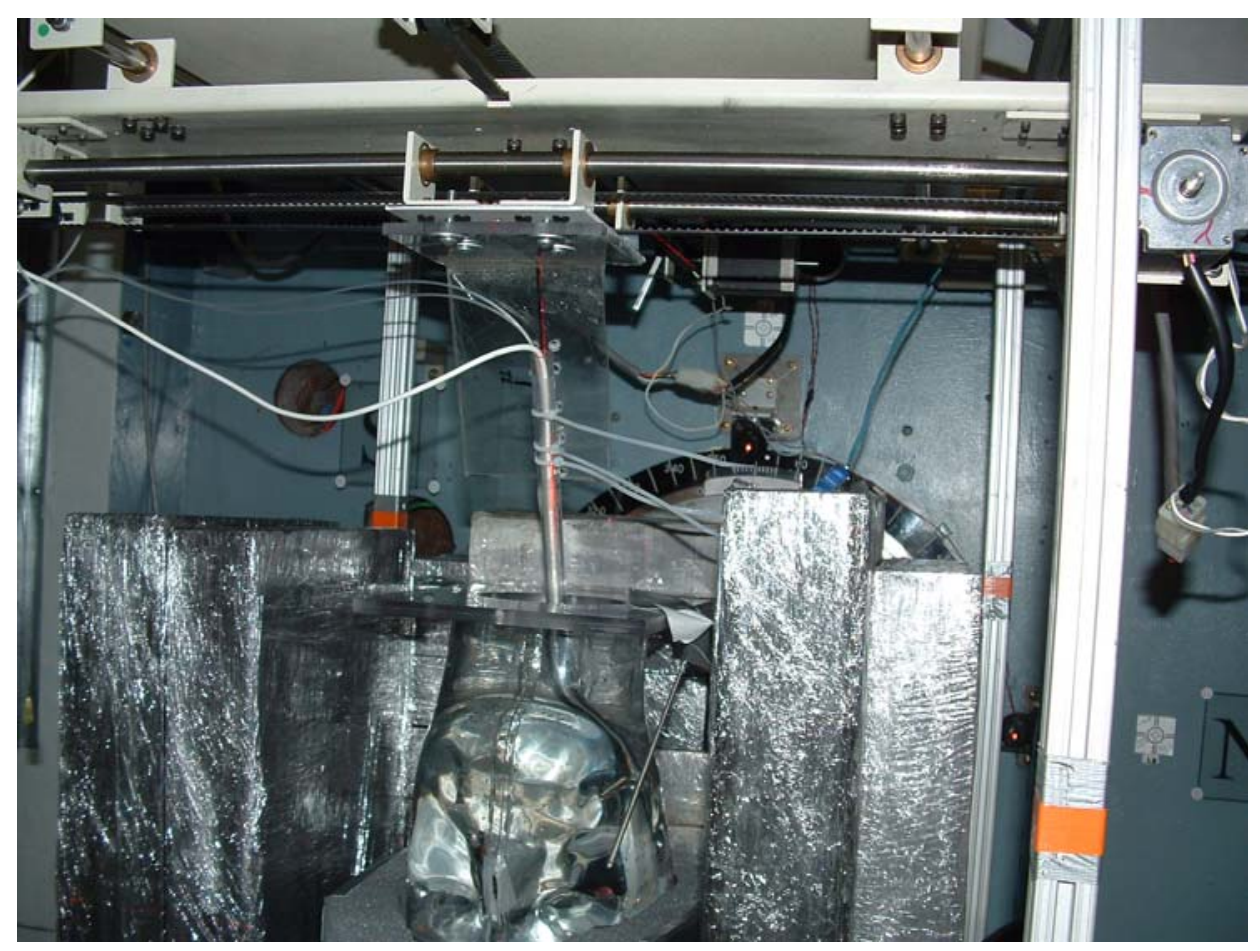

Figure 35: The head phantom filled with deionized water inside the assembly. The ion chamber is mounted on an $\mathrm{X}-\mathrm{Y}$ positioner which can be remotely controlled to the designed position. The ion chamber holder has a $22^{\circ}$ angle so that it can reach the wall of the head phantom.

The isocenter is at 5.8-cm depth (from back of the head) and $7.5 \mathrm{~cm}$ above the top of the head phantom (upside down), so the distance from the beryllium target to the rear surface of the head phantom is $184.2 \mathrm{~cm}$. Six sets of dose data, no-filter and 1 to $5 \mathrm{~cm}$ thick tungsten filters, were taken using the borated and non-borated TE ion chambers. The irradiation ranged from 0.3 to $0.9 \mathrm{MU}$ depending on the filter thickness and the ion chamber locations to ensure that the integrated charge measured by the Keithley 617 electrometer was more than $5.0 \mathrm{nC}$ (with a few exceptions). This ensured good statistical data.

The neutron and gamma depth-dose distributions in the water-filled head phantom for the six different filter thickness were measured using the non-borated ion chamber and Equation (3.24). The boron capture dose was measured using the borated and nonborated ion chambers and Equation (3.22). The percent dose enhancement (PDE) was 
obtained using Equation (3.23). The boron capture dose was normalized to $100-\mathrm{ppm}{ }^{10} \mathrm{~B}$. The measurements of the depth-dose for no-filter, $1.0-\mathrm{cm}$ to $5.0-\mathrm{cm}$ filter are shown through Figure 36 to Figure 41, respectively. The measured total dose for each filter thickness, including the neutron, photon and boron capture doses, are also shown in Figure 36 to Figure 41. The MCNP5-calculated neutron and photon kermas for these filters are also shown in these figures for comparison. The relationship between the number of protons and the MU during the experiment was found to be $3.3 \times 10^{16}$ protons/MU, which was used to normalize the MCNP5 results to Gy/MU.

From Figure 36 to Figure 41, the measured neutron and photon doses agree with the MCNP-calculated neutron and photon doses within uncertainties. The 9\% error in the Bragg-Gray equation was not accounted in the error bar of the measured curves. The $15 \%$ error in the normalization factor for the MCNP5-calculated neutron and gamma dose was not included. The errors in the boron capture dose consist the 5.5\% error from the thermal calibration factor and 3.5\% error in the charge measured by the ion chambers. This charge error is mainly due to uncertainty in the ion chamber positioning.

It is also observed from Figure 36 to Figure 41 that the first data points of the MCNP calculated dose in all figures are consistently higher than the measured values. This is because the F6 MCNP tally is a kerma tally, not absorbed dose tally. Charged particle equilibrium does not exist at shallow depths in the head phantom, at these locations the kerma value is higher than the absorbed dose. For the Fermilab neutron beam, the maximum absorbed dose $\left(\mathrm{D}_{\max }\right)$ is at $1.7 \mathrm{~cm}$ depth. So the MCNP-calculated kerma at positions deeper than $1.7 \mathrm{~cm}$ should be smaller than the absorbed dose. These phenomena were clearly seen in Figures 36 to 41. 


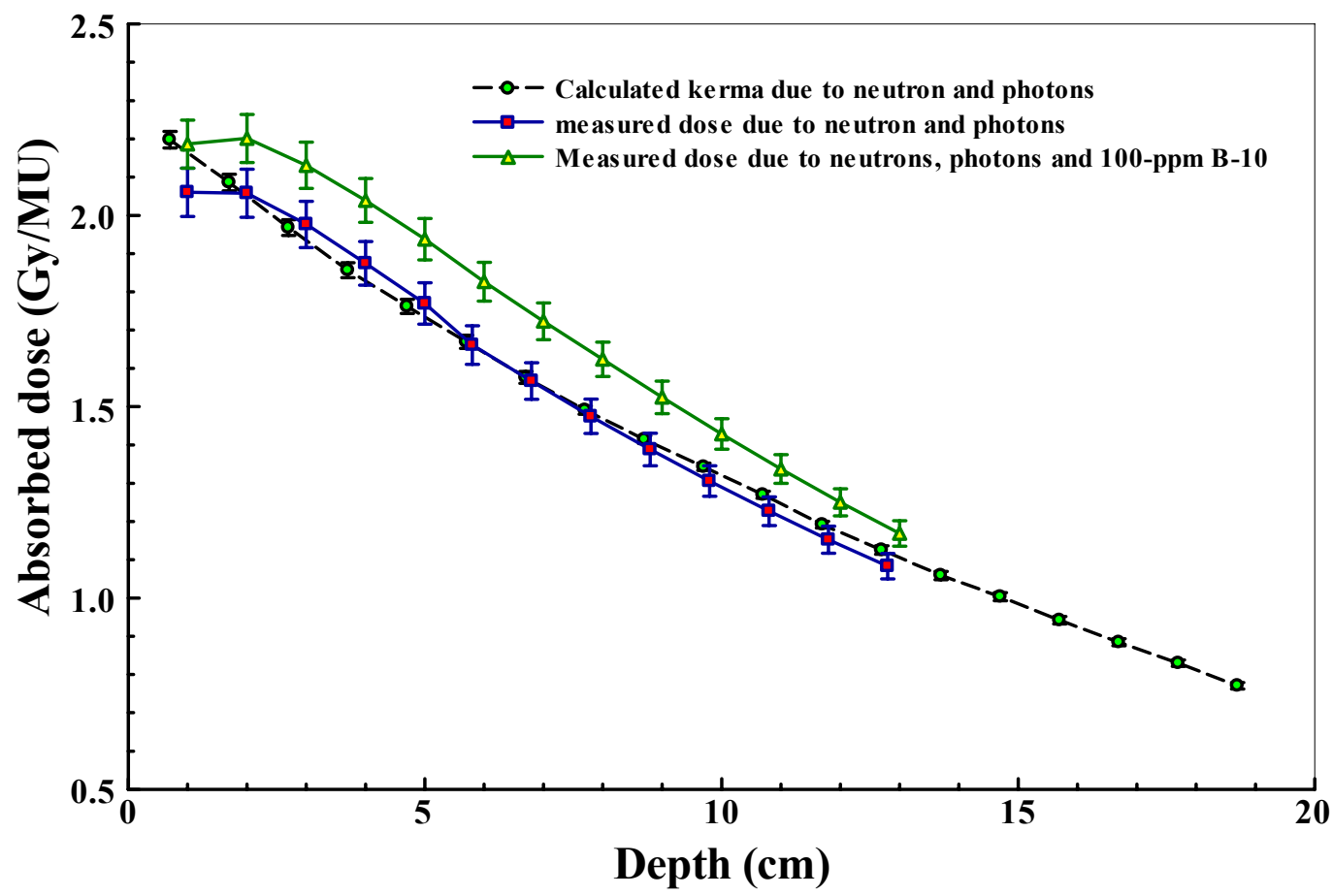

Figure 36: MCNP5 calculated and measured depth-dose distribution in the water filled head phantom for $0-\mathrm{cm}$ filter. The measured $(n+\gamma)$ dose is obtained using the non-borated ion chamber and equation (3.24); the (n+ $\gamma+$ boron) dose is measured using the borated and non borated ion chamber using equations (3.24) and (3.22).

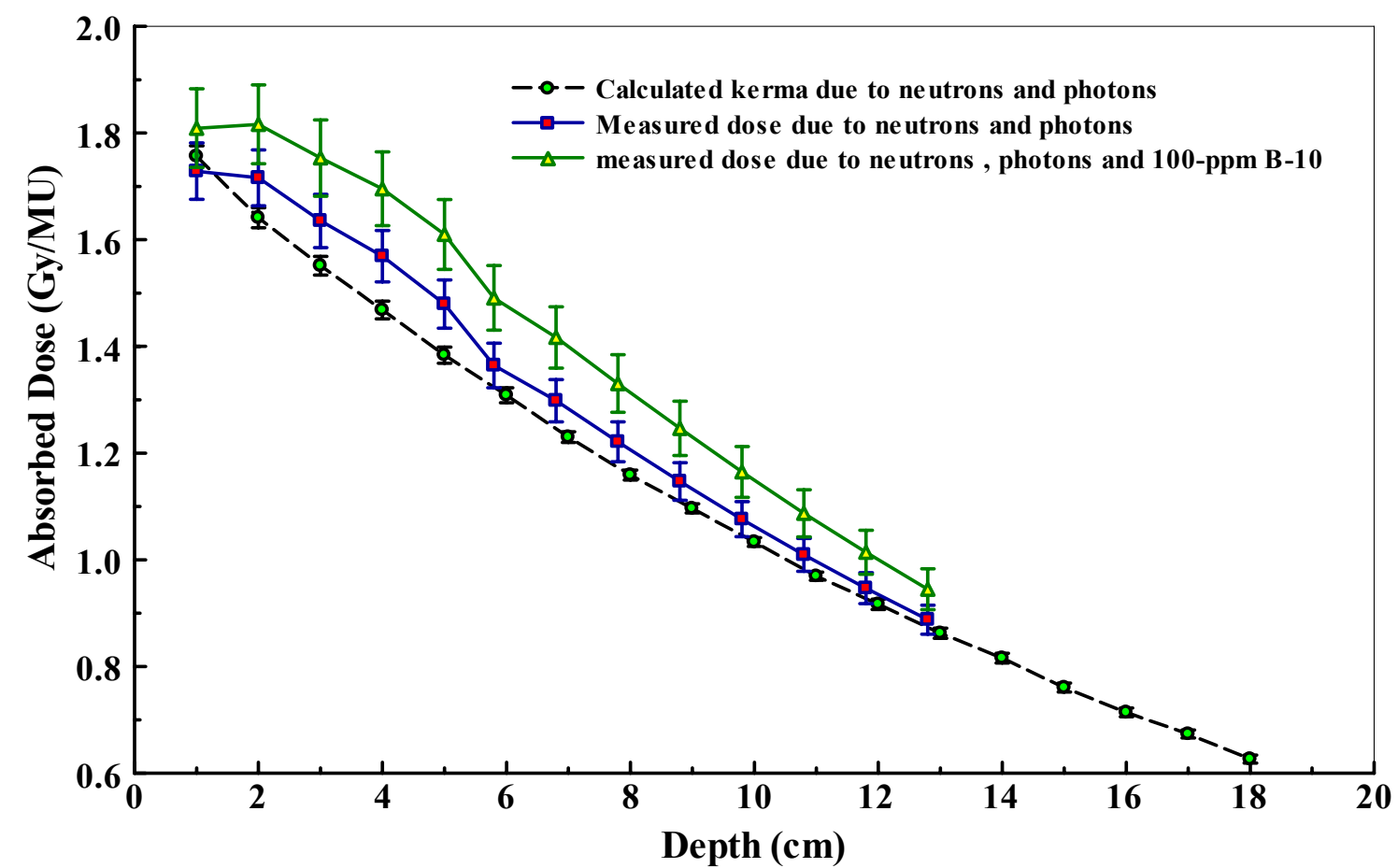

Figure 37: MCNP5 calculated and measured depth-dose distribution in the water filled head phantom for $1.0-\mathrm{cm}$ filter. The measured $(\mathrm{n}+\gamma)$ dose is obtained using the non-borated ion chamber; the $(n+\gamma+$ boron) dose is measured using the borated and non borated ion chamber. 


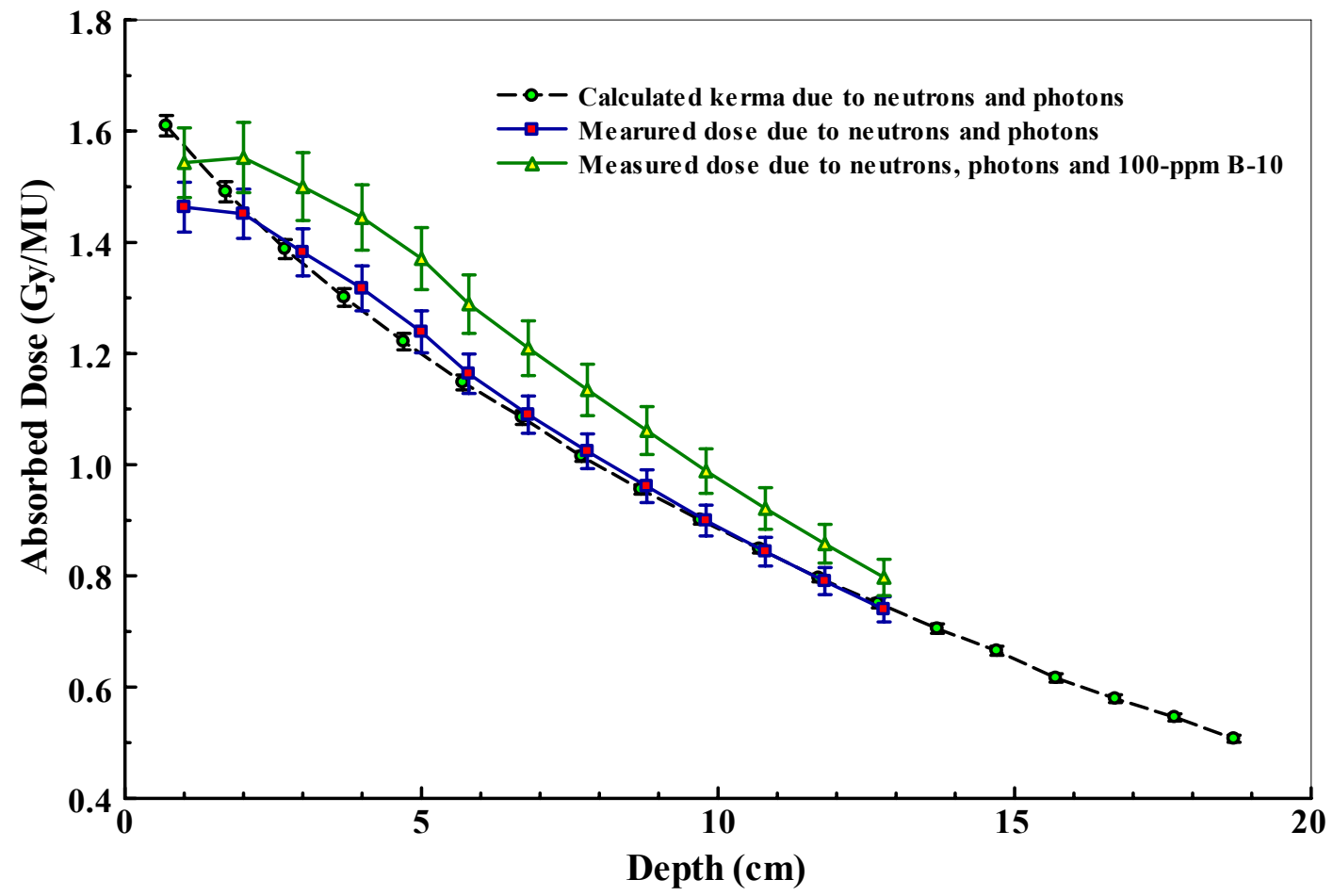

Figure 38: MCNP5 calculated and measured depth-dose distribution in the water filled head phantom for $2.0-\mathrm{cm}$ filter. The measured $(\mathrm{n}+\gamma)$ dose is obtained using the non-borated ion chamber; the $(n+\gamma+$ boron) dose is measured using the borated and non borated ion chamber.

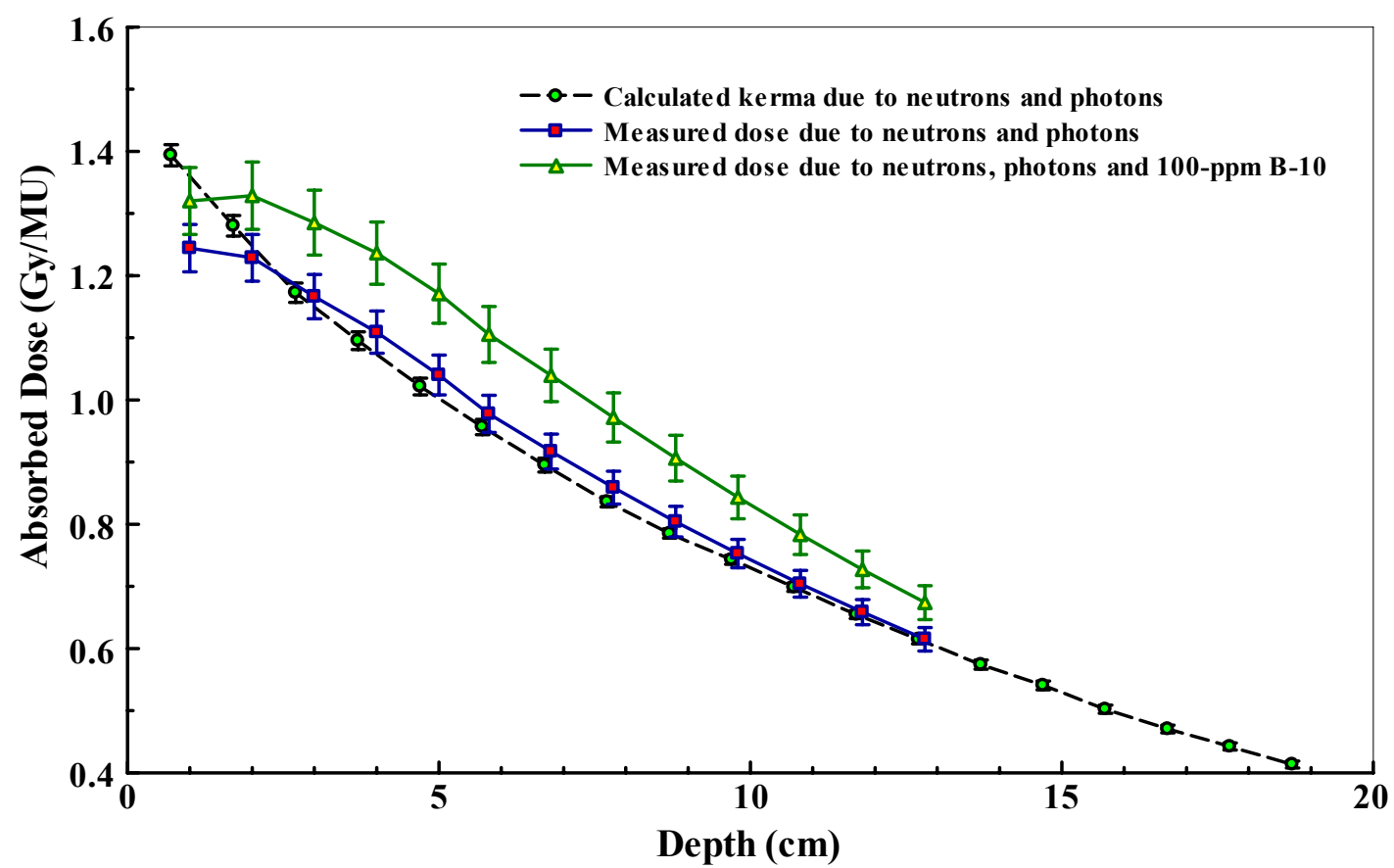

Figure 39: MCNP5 calculated and measured depth-dose distribution in the water filled head phantom for $3.0-\mathrm{cm}$ filter. The measured $(\mathrm{n}+\gamma)$ dose is obtained using the non-borated ion chamber; the $(n+\gamma+$ boron $)$ dose is measured using the borated and non borated ion chamber. 


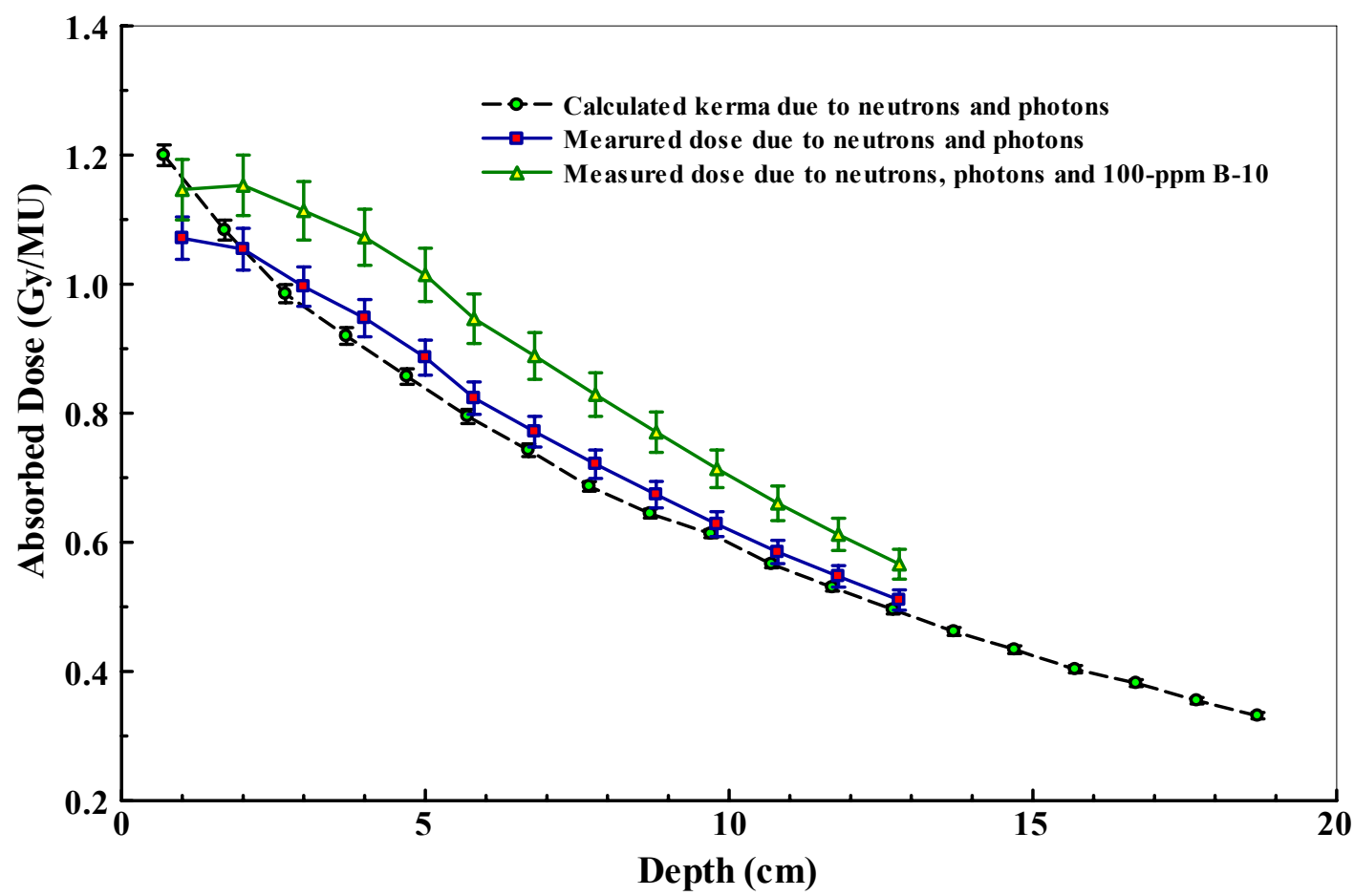

Figure 40: MCNP5 calculated and measured depth-dose distribution in the water filled head phantom for $4.0-\mathrm{cm}$ filter. The measured $(n+\gamma)$ dose is obtained using the non-borated ion chamber; the $(n+\gamma+$ boron $)$ dose is measured using the borated and non borated ion chamber.

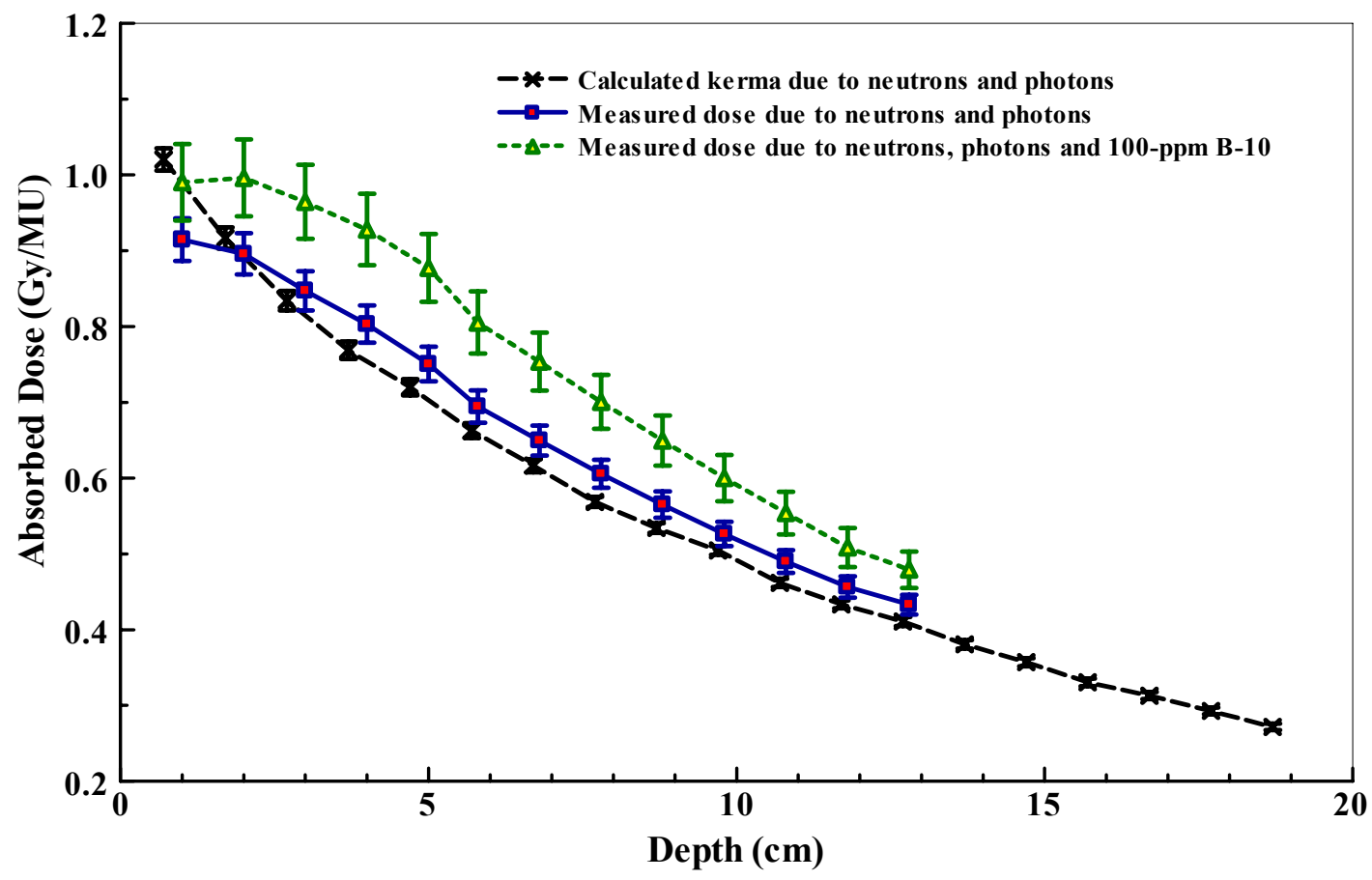

Figure 41: MCNP5 calculated and measured depth-dose distribution in the water filled head phantom for $5.0-\mathrm{cm}$ filter. The measured $(\mathrm{n}+\gamma)$ dose is obtained using the non-borated ion chamber; the $(n+\gamma+$ boron $)$ dose is measured using the borated and non borated ion chamber. 
The comparisons of measurements and calculations of the PDE values for the six conditions are shown in Figure 42 to Figure 47. The measurements and calculations agree within uncertainty. The error bars of the measurements do not include the $9 \%$ error from the Brag-Gray equation. The error consists of the 5.5\% error from borated ion chamber thermal neutron calibration coefficient and about $4.0 \%$ error due to the positioning of the borated and non-borated ion chambers. The error in the calculated PDE is a combination of statistical uncertainties in boron, neutron and gamma dose calculations. The simplification of the head phantom and the neglecting of foams surrounding the head phantom in the simulation may also lead to uncertainty in the calculated PDE values, but this error is not included in the error bars.

The importance of the graphite reflector on both sides of the head phantom can be seen clearly from Figure 47 . The PDE with the graphite reflector is $25 \%$ higher than the PDE with graphite reflector on both sides removed.

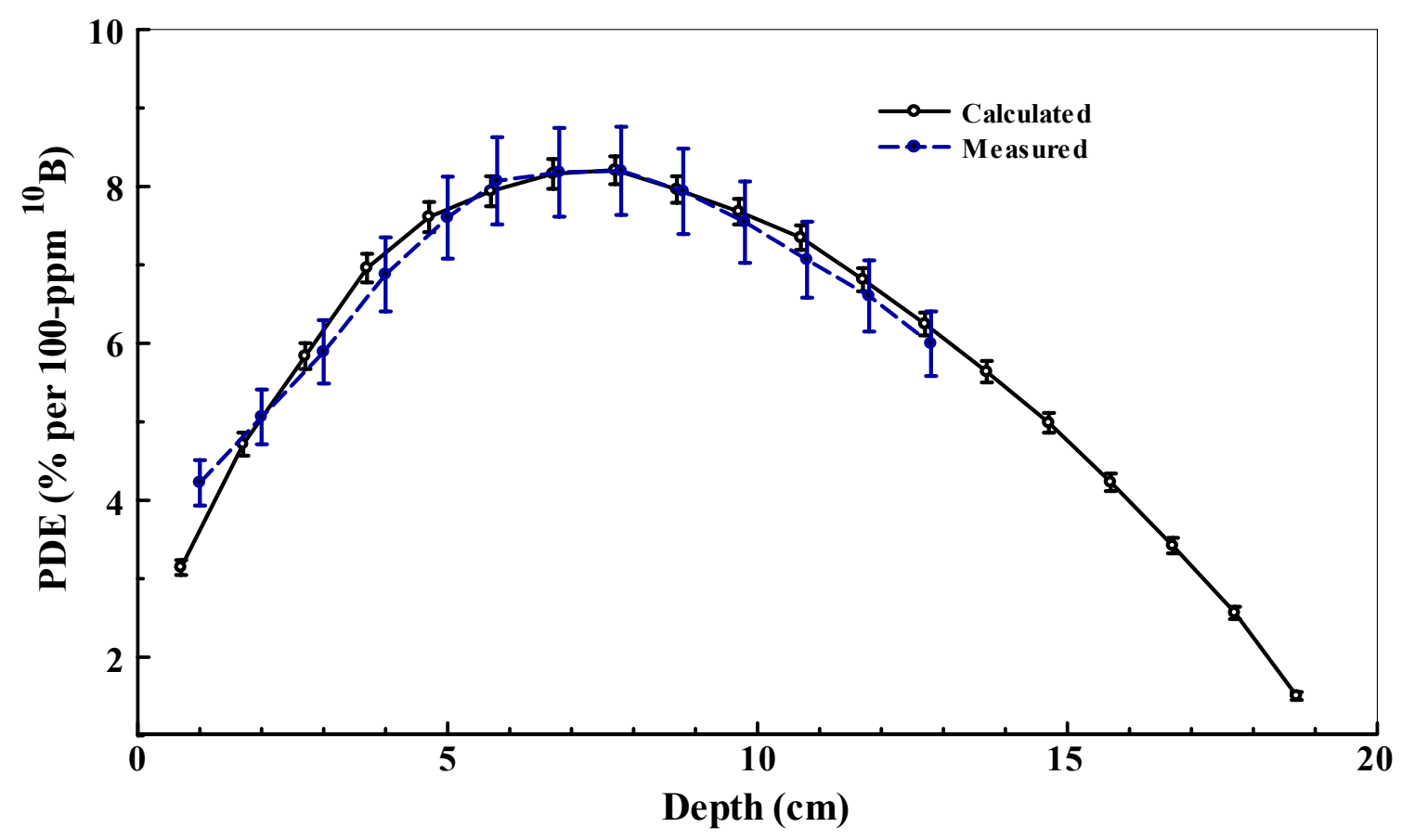

Figure 42: PDE for 100-ppm ${ }^{10} \mathrm{~B}$ in the water filled head phantom for $0.0-\mathrm{cm}$ filter. The measured PDE is obtained using Equation (3.23) and the borated and non-borated ion chamber readings. 


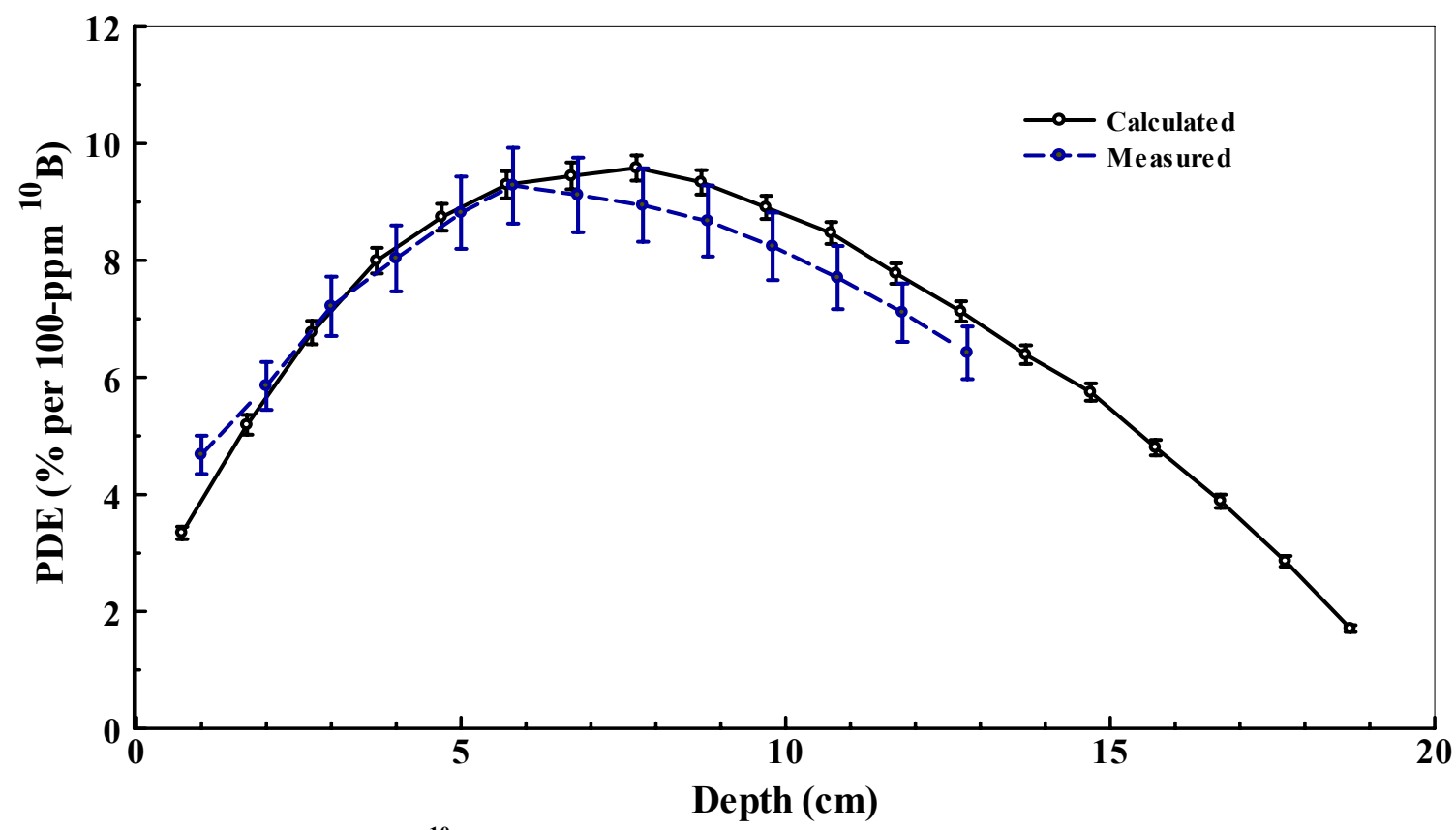

Figure 43: PDE for 100-ppm ${ }^{10} \mathrm{~B}$ in the water filled head phantom for 1.0-cm filter. The measured PDE is obtained using Equation (3.23) and the borated and non-borated ion chamber readings.

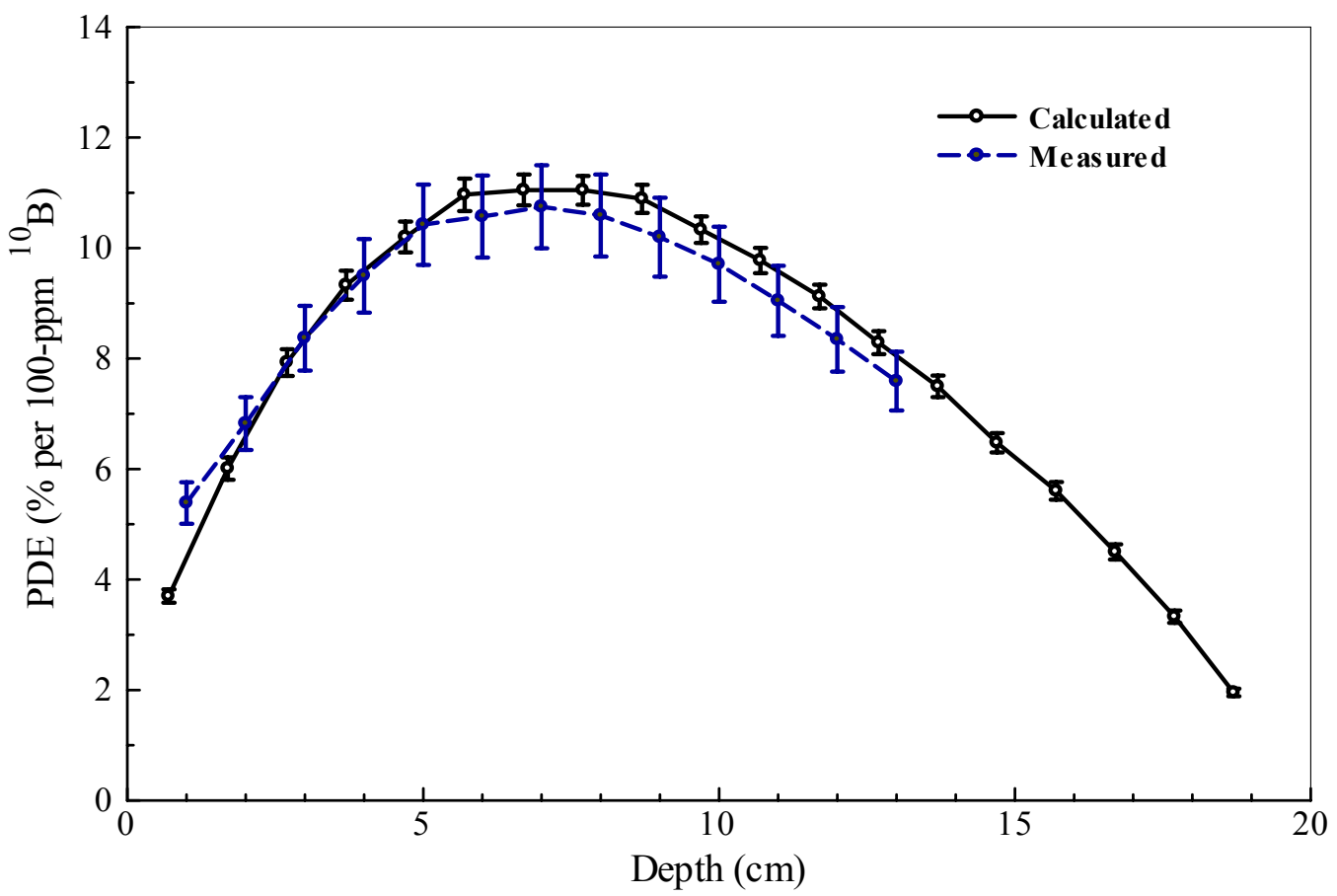

Figure 44: PDE for 100-ppm ${ }^{10} \mathrm{~B}$ in the water filled head phantom for $2.0-\mathrm{cm}$ filter. The measured PDE is obtained using Equation (3.23) and the borated and non-borated ion chamber readings. 


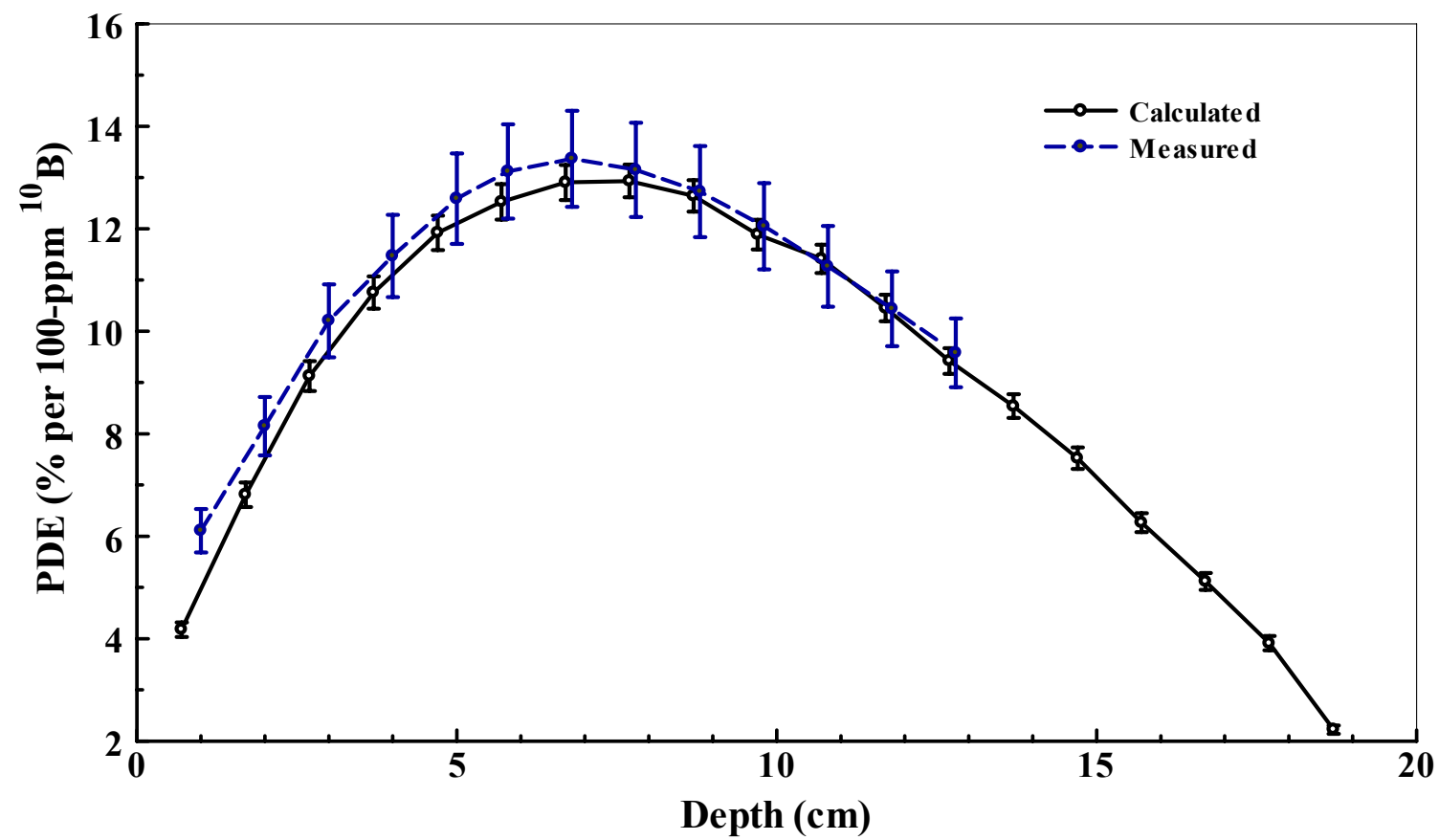

Figure 45: PDE for 100-ppm ${ }^{10} \mathrm{~B}$ in the water filled head phantom for 3.0-cm filter. The measured PDE is obtained using Equation (3.23) and the borated and non-borated ion chamber readings.

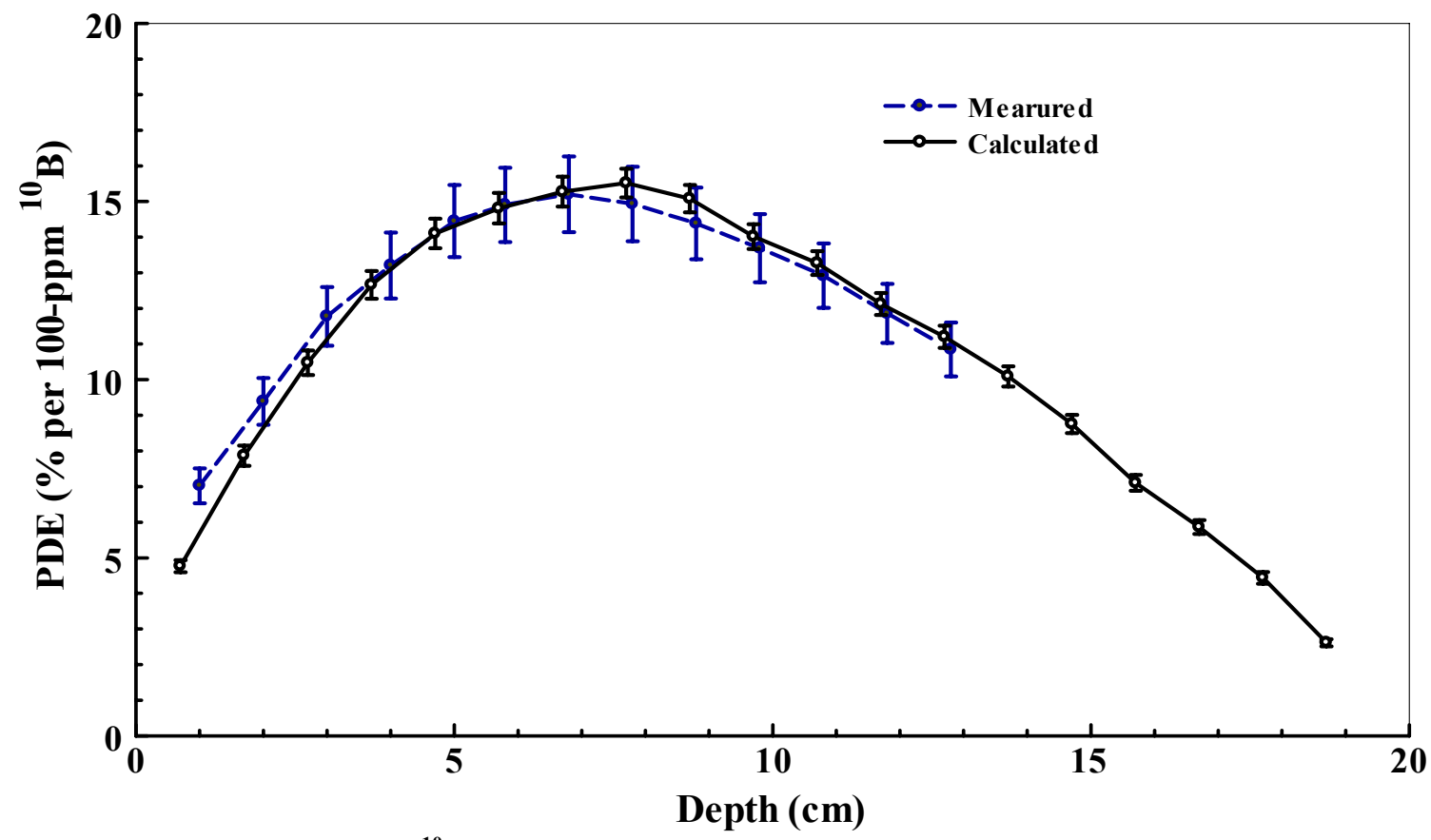

Figure 46: PDE for 100-ppm ${ }^{10} \mathrm{~B}$ in the water filled head phantom for 4.0-cm filter. The measured PDE is obtained using Equation (3.23) and the borated and non-borated ion chamber readings. 


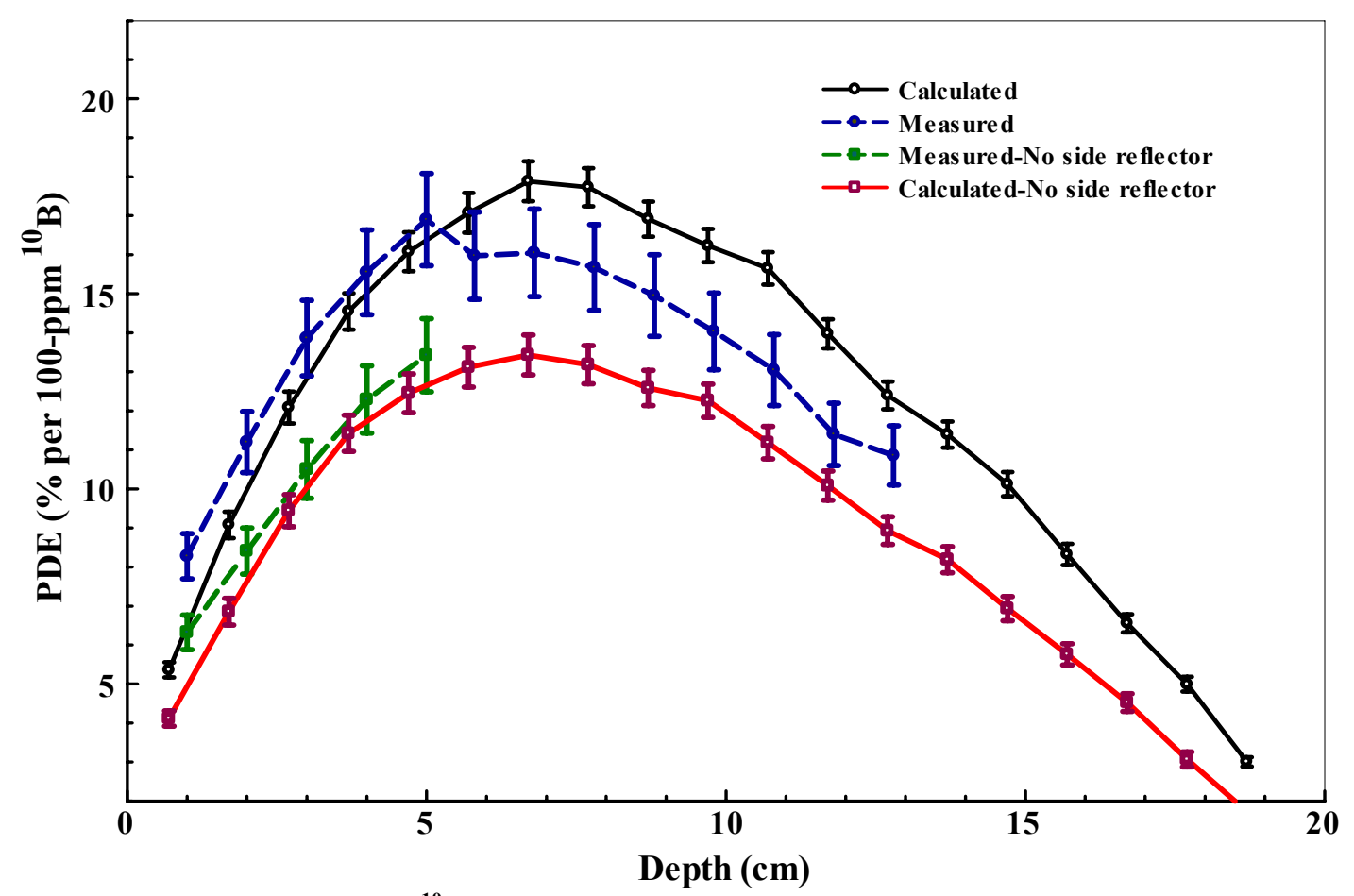

Figure 47: PDE for 100-ppm ${ }^{10} \mathrm{~B}$ in the water filled head phantom for 5.0-cm filter. The measured PDE is obtained using Equation (3.23) and the borated and non-borated ion chamber readings. Graphite reflector on both sides were removed and the PDEs were measured at 1-cm to 5-cm depth to see their effects on PDEs. The present of the side graphite reflectors can increase PDE at 5.0-cm depth by more than $25 \%$.

In Figure 47, the measured PDE curve behaves abnormally starting at position of 5.8-cm depth. Because the ion chamber holder was changed at this point, the author believes that this abnormality is due to the position recording of the borated ion chambers. Comparisons of the measured boron capture dose (from Equation (3.22)) and the MCNP-calculated boron capture dose for the 5.0-cm and 4.0-cm tungsten filter are shown in Figure 48 and Figure 49, respectively. The two figures imply that the measured boron doses for the $5.0-\mathrm{cm}$ tungsten filter at depth of $5.8-\mathrm{cm}$ and deeper in the head phantom are lower than they should be. Further analysis of the data suggests that the data might be misrecorded: the borated ion chamber readings of the $5.8-\mathrm{cm}$ to $12.8-\mathrm{cm}$ depth may be the readings for $6.8-\mathrm{cm}$ to $12.8-\mathrm{cm}$ depth, and the data point for $5.8-\mathrm{cm}$ may have been missed. Figure 47 is re-plotted in Figure 51 according to the above argument. In this case the measurements and calculations agree much better after the data adjustment. 
However, the measurements and calculations agree within uncertainty even before the data adjustment.

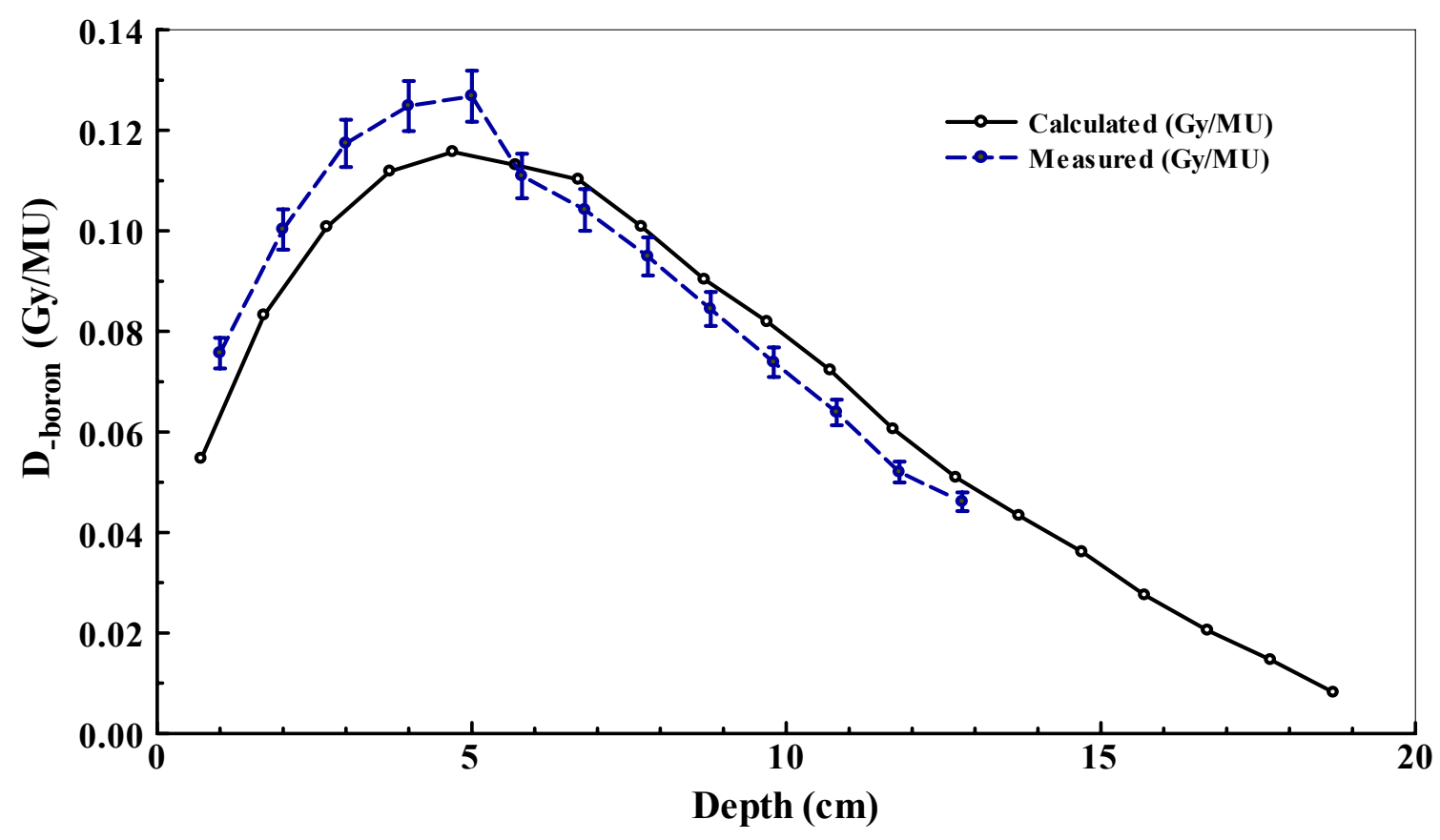

Figure 48: Comparison of the calculation and measurements of the boron dose distribution for 5.0$\mathrm{cm}$ thick tungsten filter. Abnormality of the trend of the measured data occurs at the position where ion chamber holder was changed.

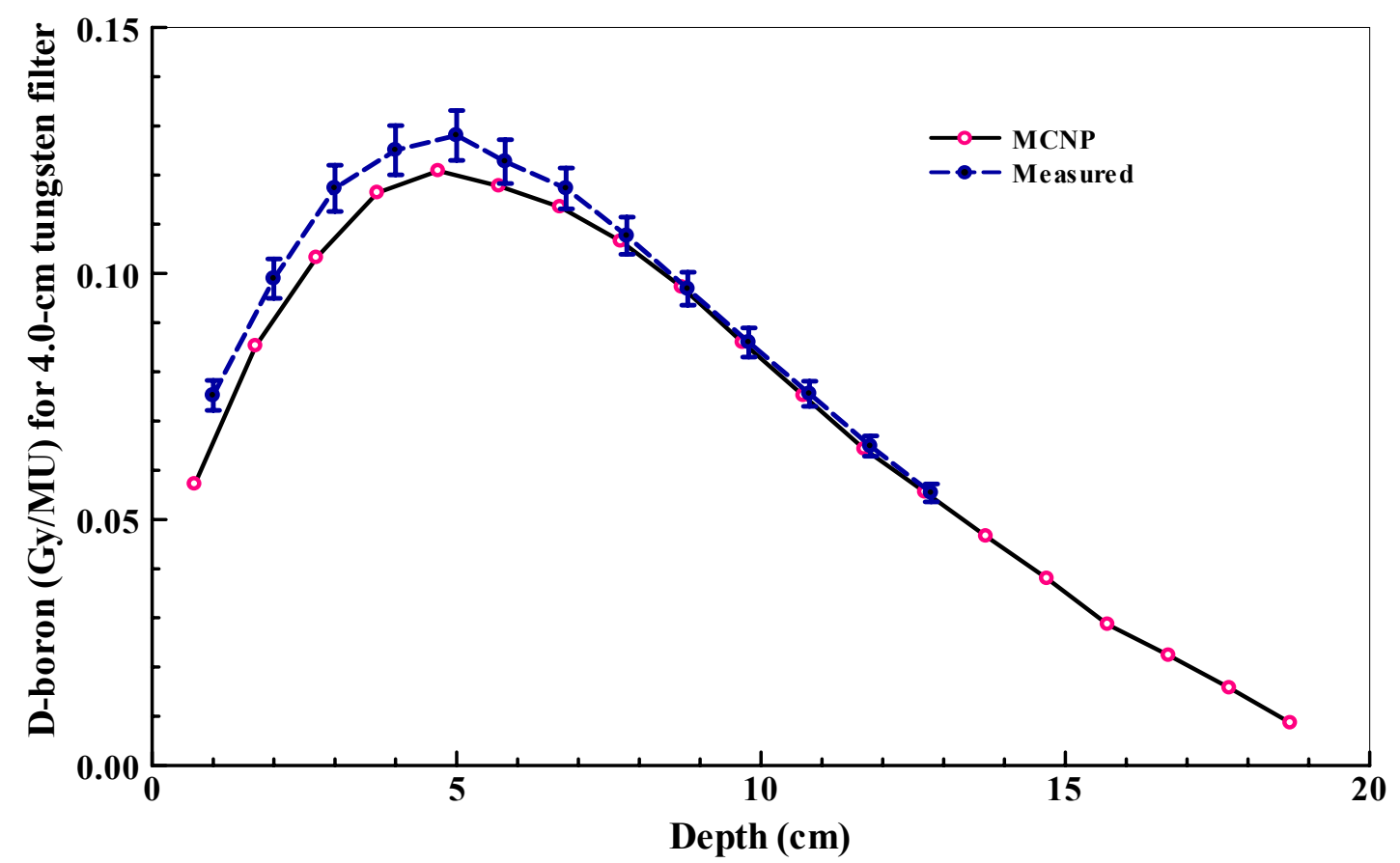

Figure 49: Comparison of the calculation and measurements of the boron dose distribution for 4.0cm thick tungsten filter. Both measured and calculated curves vary smoothly with depth. 


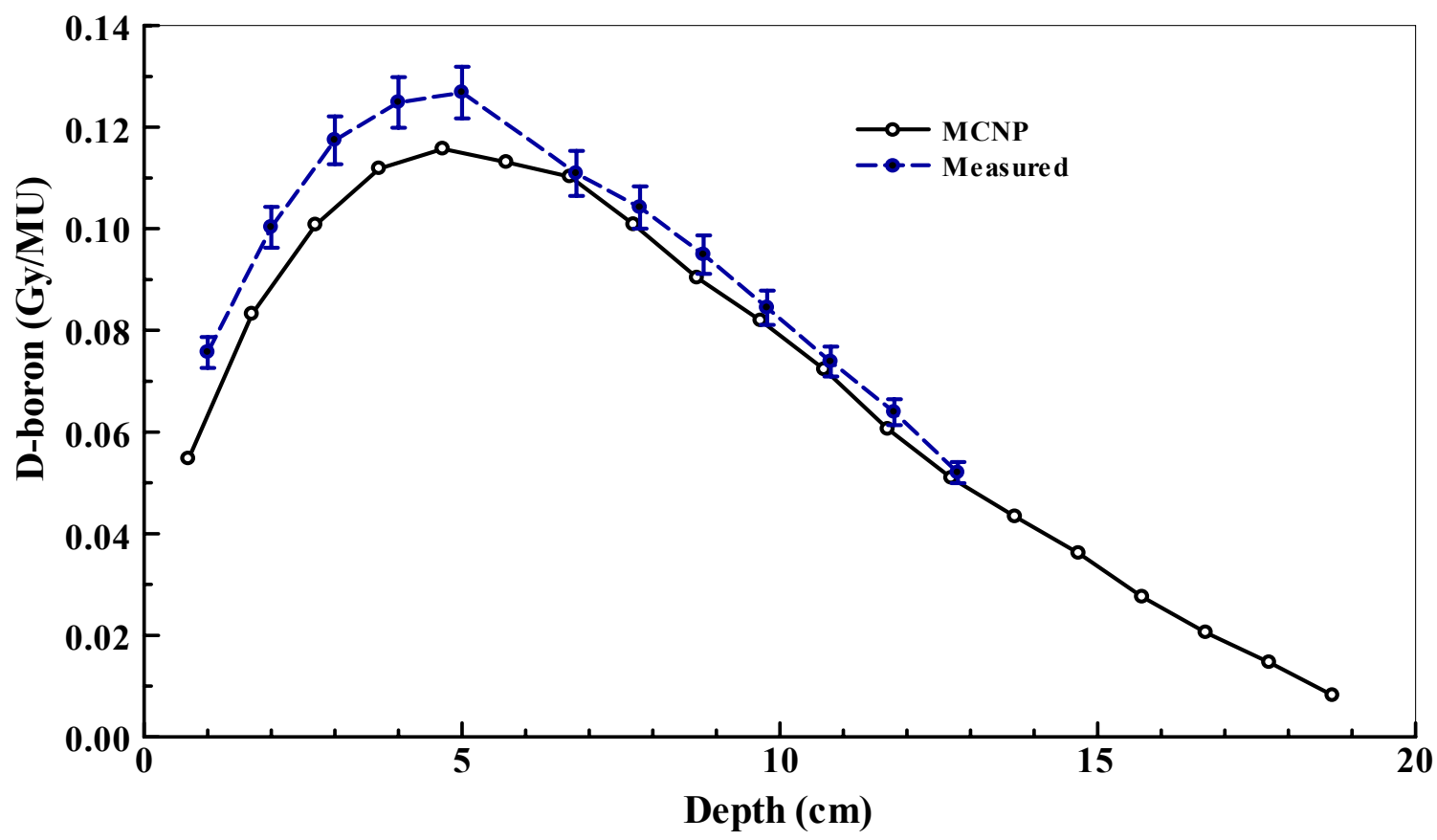

Figure 50: Comparison of the calculation and measurements of the boron dose distribution for 5.0cm thick tungsten filter with adjusted data.

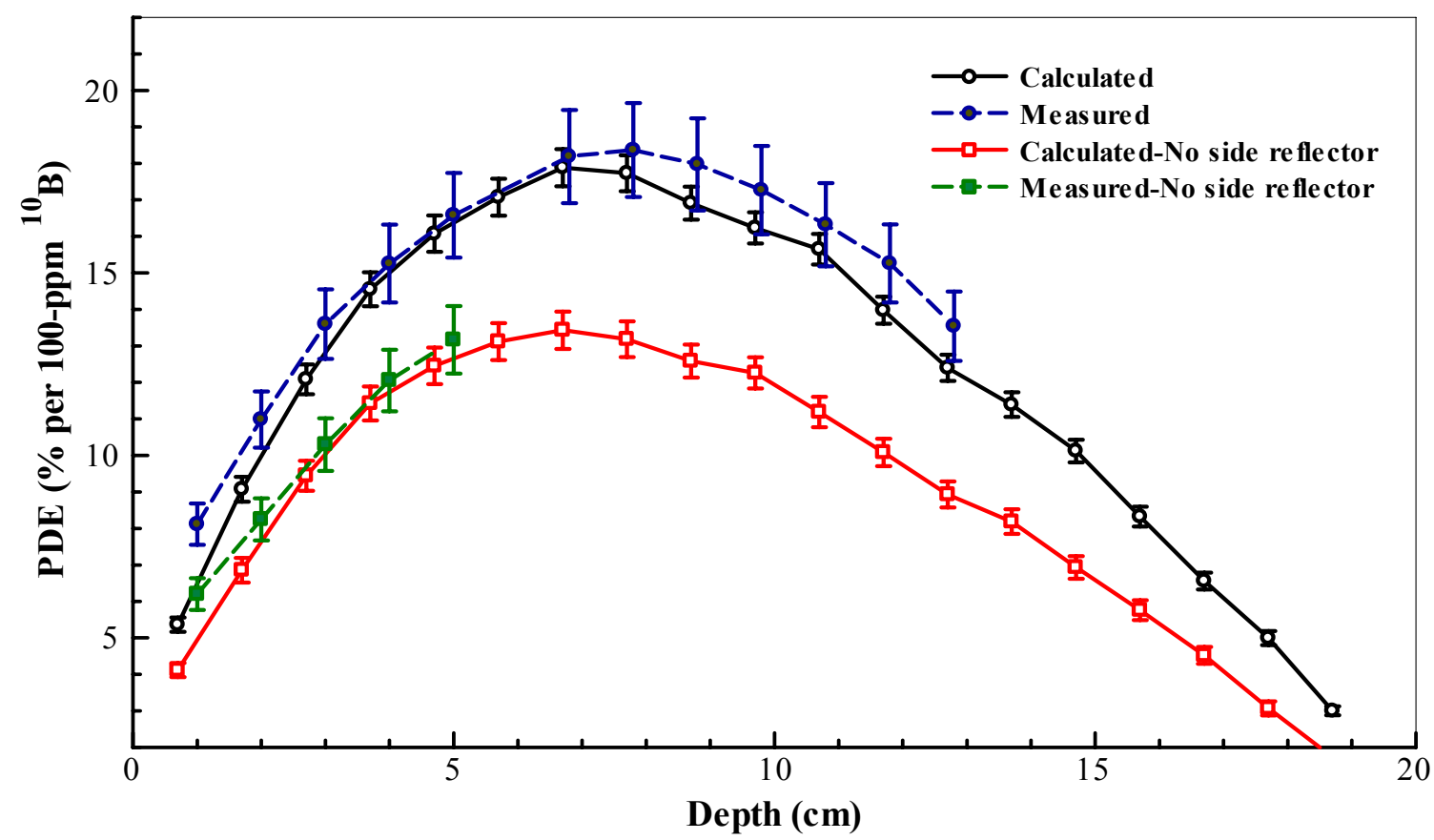

Figure 51: PDE for 100-ppm ${ }^{10} \mathrm{~B}$ in the water filled head phantom for 5.0-cm filter after adjustment (a re-plot of Figure 47). 
The off-axis total absorbed dose rate profiles of the MCNP calculations and the measurements at $8.8-\mathrm{cm}$ depth in the water-filled head phantom in the simplified BNCEFNT assembly with no-filter and 5.0-cm tungsten filter are shown in Figure 52 and Figure 53, respectively. The $15 \%$ normalization error (from the neutron fluence rate) is not plotted for the MCNP data. The error bars of the measured data points are from the uncertainties in the positioning of ion chamber during the measurement and do not include the $9 \%$ error from the Bragg-Gray equation. The discrepancy at $\pm 3.0 \mathrm{~cm}$ off axis position between the calculation and measurement are mainly due to the positioning of the ion chamber in the experiment.

The MCNP calculated results, the total absorbed dose, the boron dose and the PDE as a function of depth in the water filled head phantom, agree well with the measurements. The measurements have demonstrated that the MCNP5 simulations are valid.

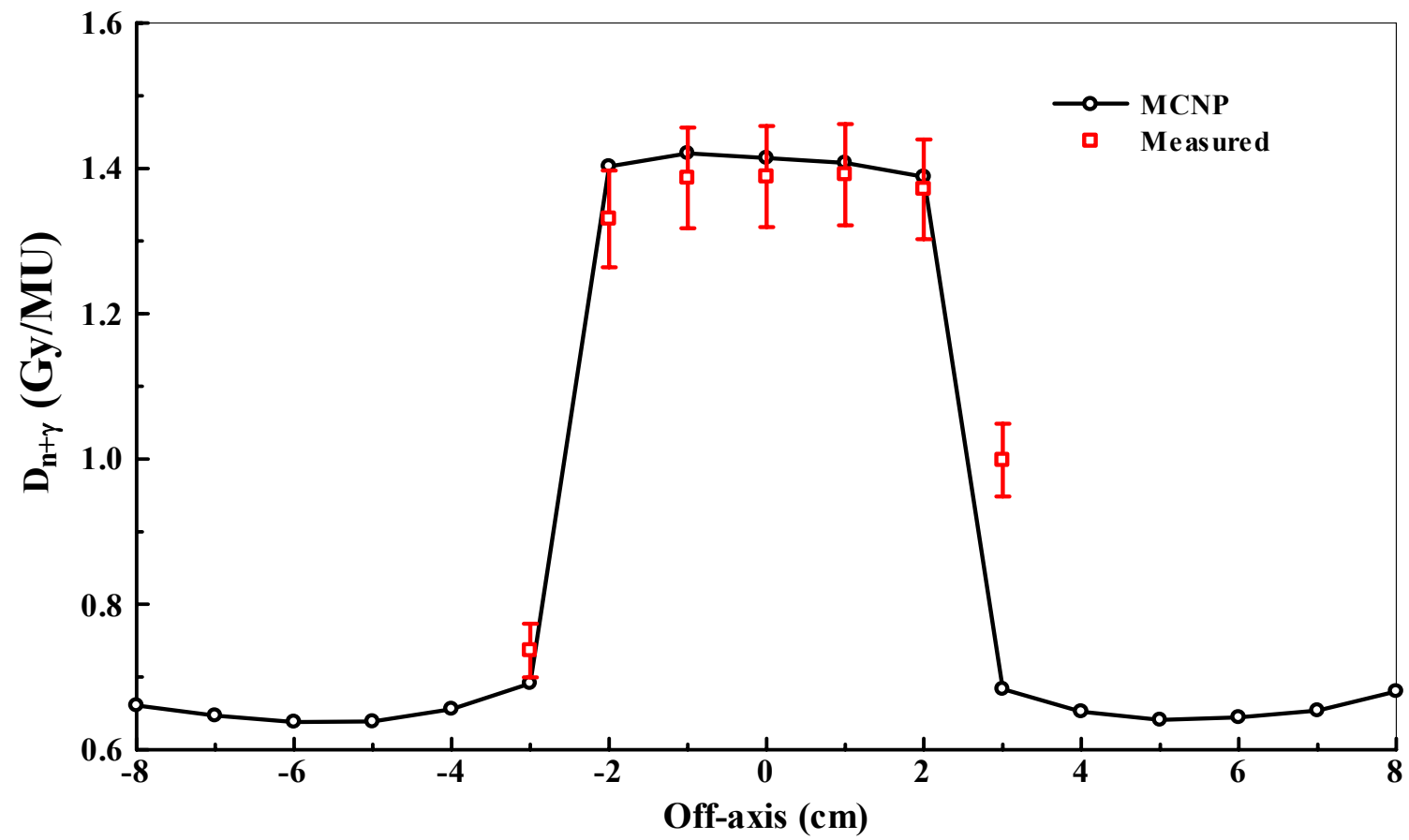

Figure 52: Comparison of the off-axis total dose rate profiles between MCNP calculations and the experiment at 8.8-cm depth in a water-filled head phantom in the simplified BNCEFNT assembly with no-filter. The error bars of the measured data do not include the $9 \%$ error from the BraggGray equation. The $15 \%$ normalization error in the MCNP results is not plotted. 


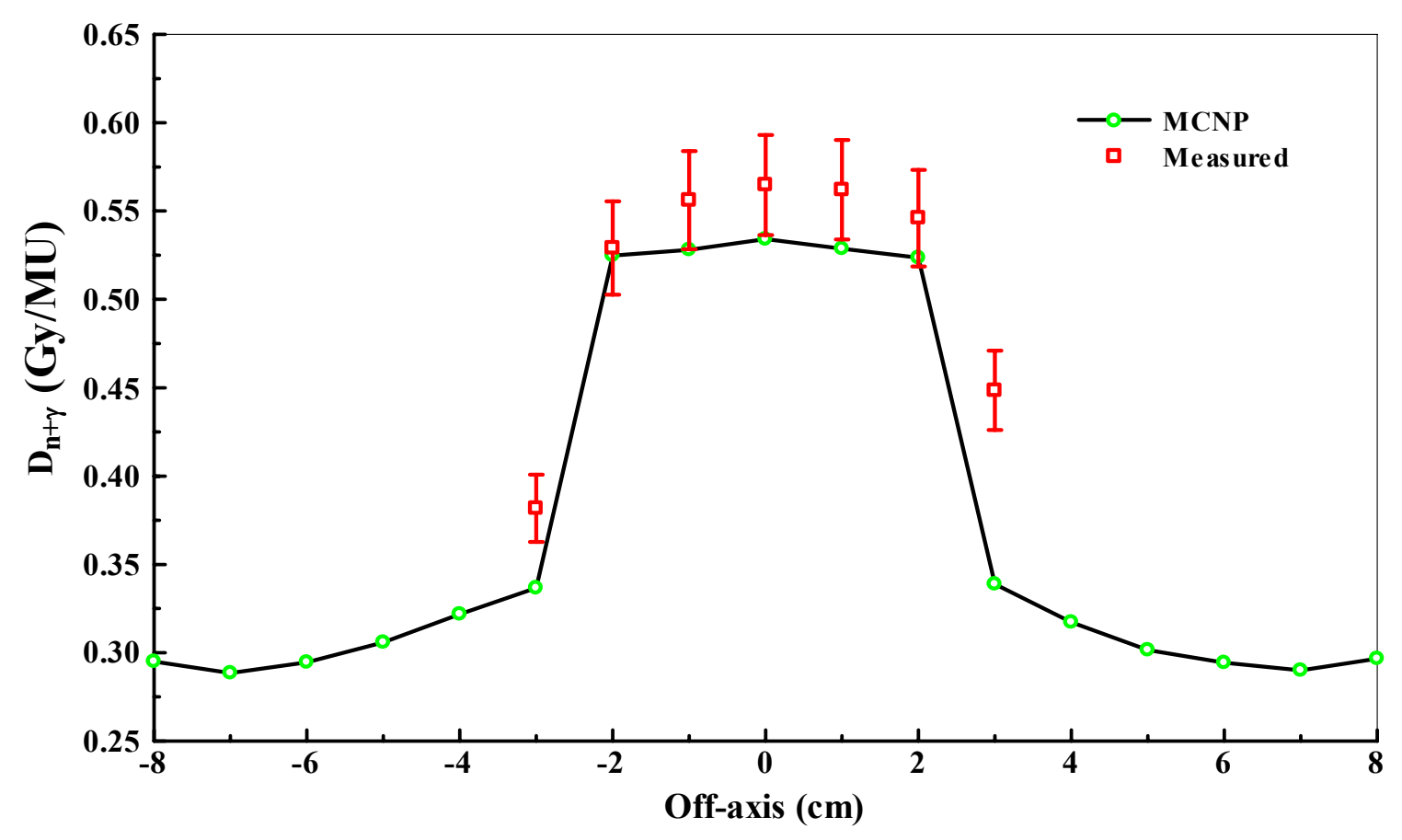

Figure 53: Comparison of the off-axis total dose rate profiles between MCNP calculations and the experiment at 8.8-cm depth in a water-filled head phantom in the simplified BNCEFNT assembly with $5.0-\mathrm{cm}$ tungsten filter. The error bars of the measured data do not include the $9 \%$ error from the Bragg-Gray equation. The $15 \%$ normalization error in the MCNP results is not plotted.

\subsection{Dose Enhancement Calculation in a Hypothetic Tumor}

In the previous sections, all the boron percent dose enhancement (PDE) depth distribution were computed based on the assumption that the $100-\mathrm{ppm}{ }^{10} \mathrm{~B}$ concentration were uniformly distributed in the water-filled head phantom. This assumption is useful in the characterization of the designed BNCEFNT assembly, but not suitable for determining the PDE at a tumor site.

A hypothetic tumor with a size of $4 \times 4 \times 2 \mathrm{~cm}^{3}$ is placed in the water-filled head phantom model at $4.0-\mathrm{cm}$ depth from the back. A BNCEFNT assembly with a $5 \times 5 \mathrm{~cm}^{2}$ tungsten collimator was used and the axis of the collimator coincides with the center of the tumor. 100-ppm of ${ }^{10} \mathrm{~B}$ was uniformly distributed in the tumor and a $30 \mathrm{ppm}{ }^{10} \mathrm{~B}$ concentration in the rest of the head. The isodose curve in the head was calculated for nofilter and 5.0-cm tungsten filter. Figure 54 shows the relative dose due to boron neutron 
capture reactions in the water filled head phantom inserted in the designed BNCEFNT assembly with a 5.64-cm diameter tungsten collimator and no filter. The relative boron dose curve for a 5.0-cm tungsten filter looks the same and is not shown here.
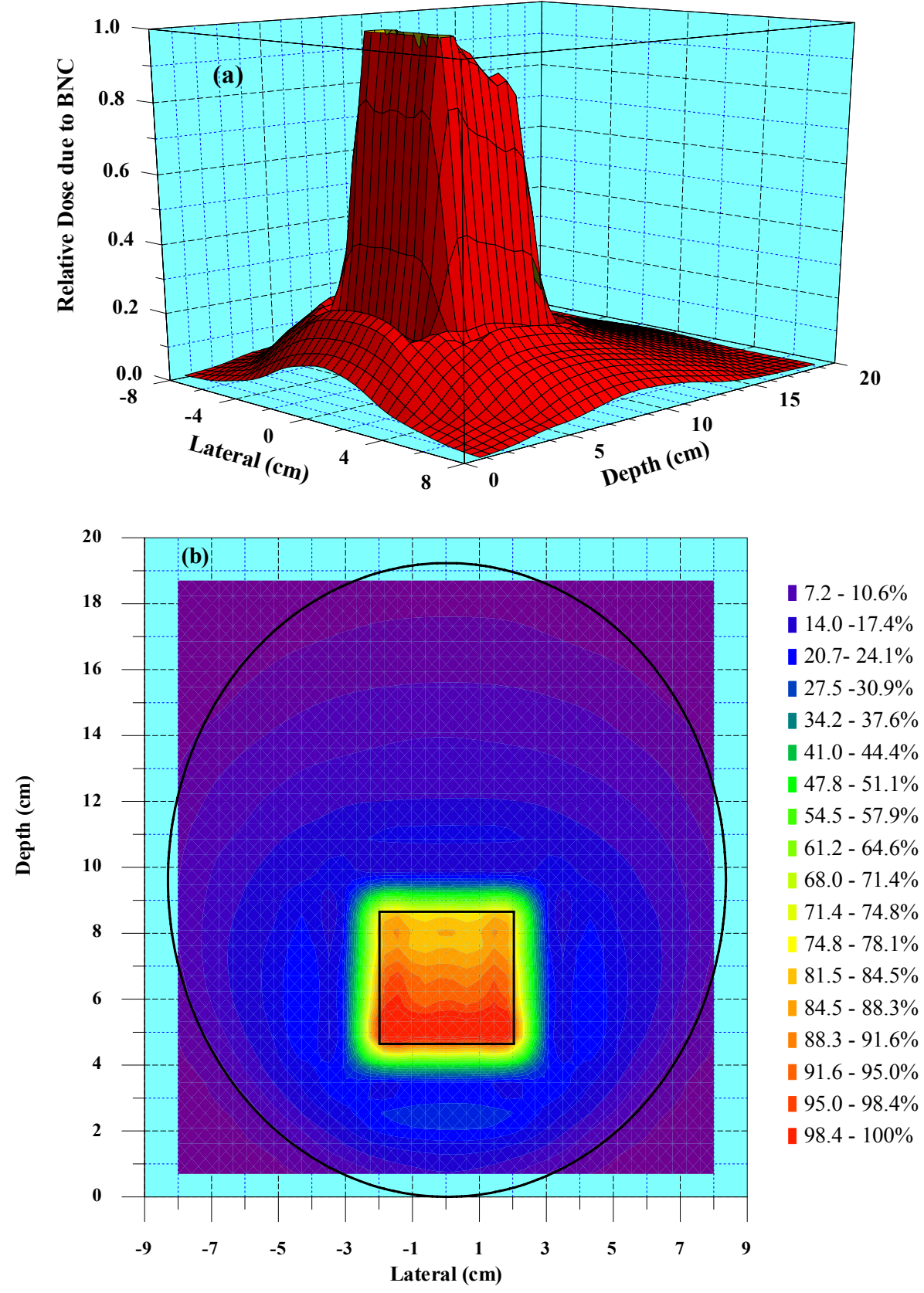

Figure 54: Relative dose due to boron neutron capture reaction in a water-filled head phantom inserted in the BNCEFNT assembly with $5 \times 5 \mathrm{~cm}^{2}$ tungsten collimator and no filter. The tumor size is $4 \times 4 \times 2 \mathrm{~cm}^{3}$ (the black square in (b)) and has ${ }^{10} \mathrm{~B}$ concentration of $100 \mathrm{ppm}$, the rest of the head has 30ppm ${ }^{10}$ B. (a) 3-D plot, (b) isodose plot. 
The calculated isodose curves due to $(n+\gamma)$, and due to $(n+\gamma+$ BNC) in a water-filled head phantom for the BNCEFNT assembly of 5.64-cm diameter tungsten collimator and no filter are shown in Figure 55 (a) and (b), respectively. The calculated isodose curves due to $(n+\gamma)$ and due to $(n+\gamma+B N C)$ in a water-filled head phantom for the BNCEFNT assembly of 5.64-cm diameter tungsten collimator and 5.0-cm tungsten filter are shown in Figure 56 (a) and (b), respectively. From Figure 55 and Figure 56 it is very obvious that boron neutron capture enhanced the tumor total dose significantly. However, comparisons of Figure 55 (a) and Figure 56 (a), and of Figure 55 (b) and Figure 56 (b) indicate that the increase of tungsten filter thickness deteriorates the collimation effects, reduces the penetrating ability of the beam, and also decreases the tumor dose. In these calculations relative biological effectiveness $(\mathrm{RBE})$ of boron neutron capture, fast neutrons and photons are not considered.
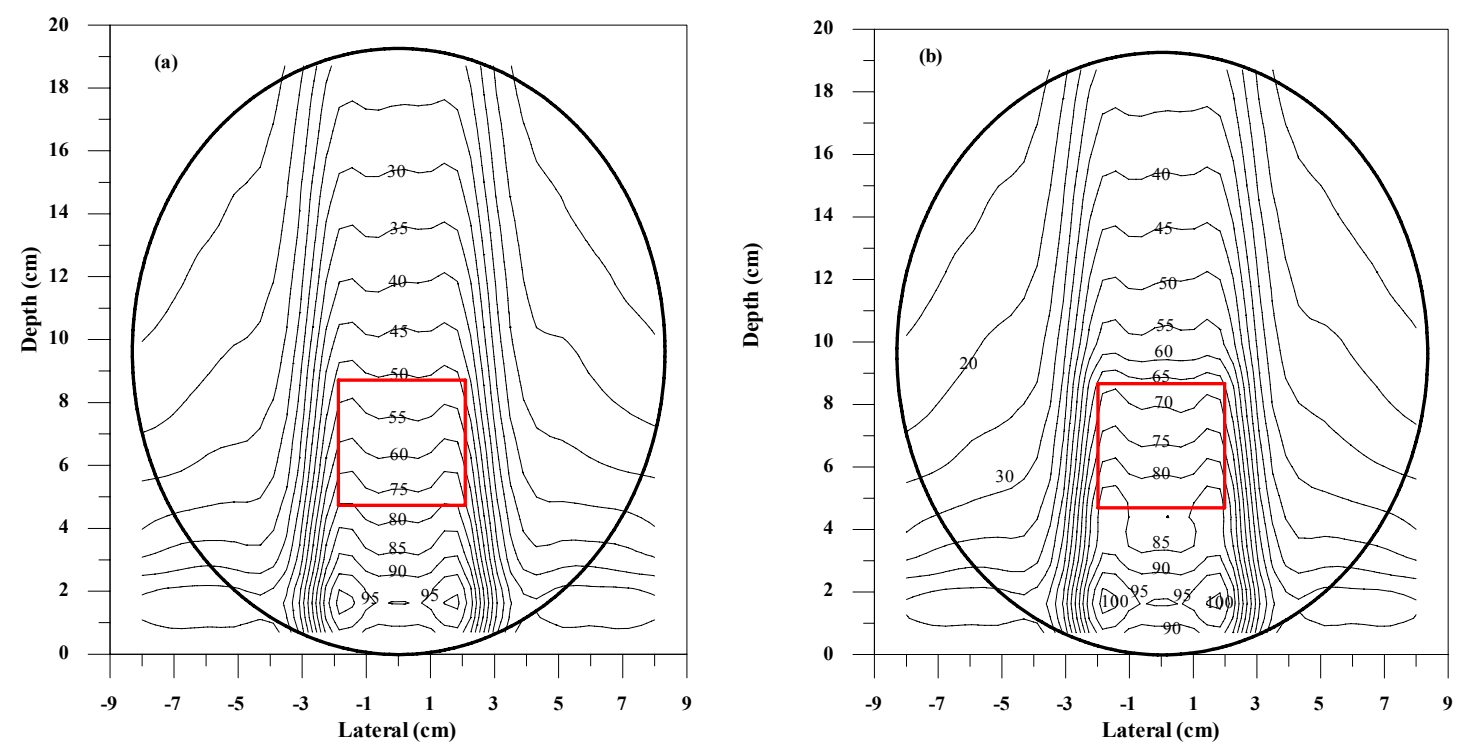

Figure 55: Calculated isodose curves for $(a)(n+\gamma)$ and $(b)(n+\gamma+$ BNC) in a water-filled head phantom for a BNCEFNT assembly with $5.64-\mathrm{cm}$ diameter tungsten collimator and no filter. The red square is the tumor $\left(4 \times 4 \times 2 \mathrm{~cm}^{3}\right)$ with $100-\mathrm{ppm}{ }^{10} \mathrm{~B}$, the rest is with $30-\mathrm{ppm}{ }^{10} \mathrm{~B}$. (Curves outside the head should be ignored) 

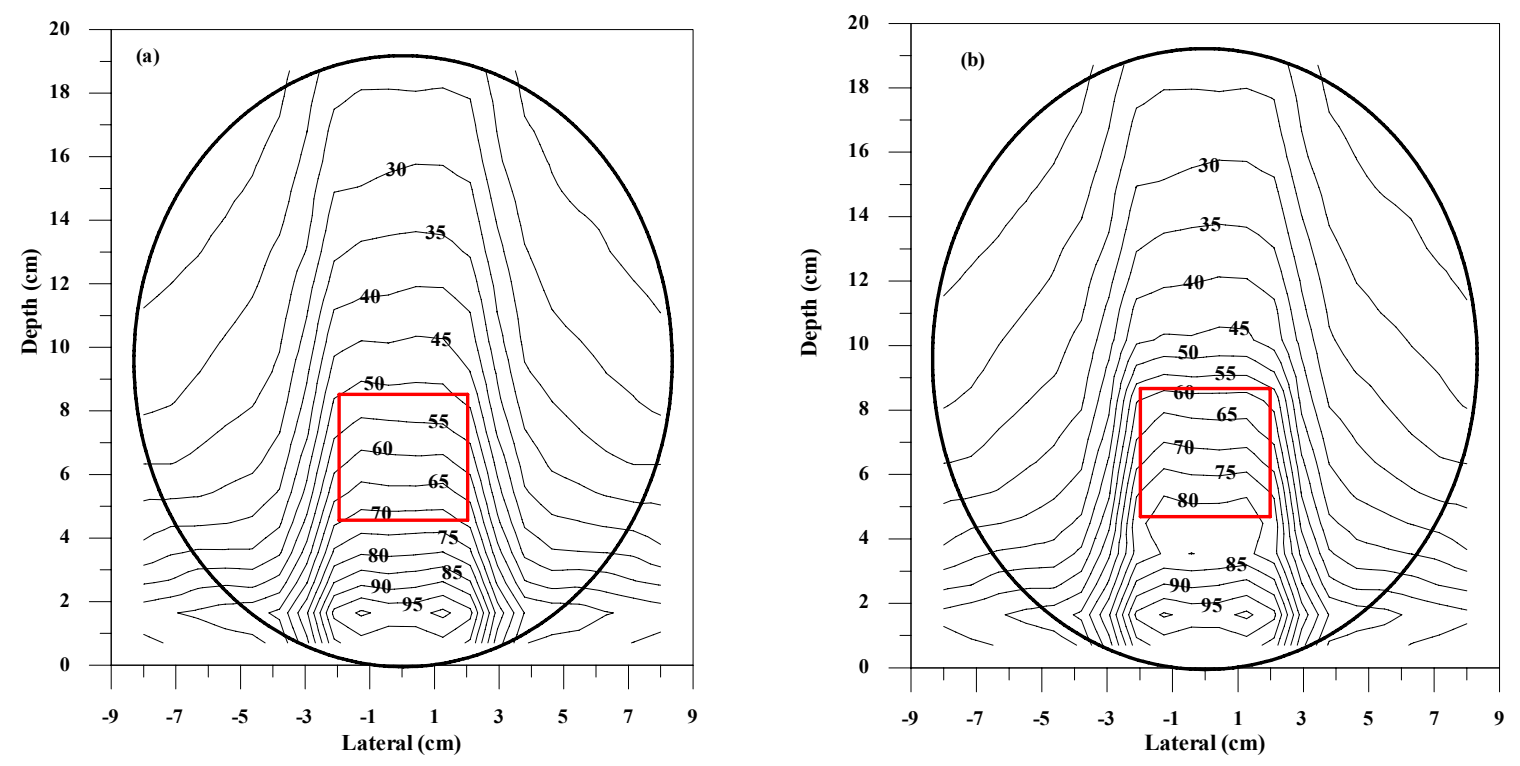

Figure 56: Calculated isodose curves for $(a)(n+\gamma)$ and $(b)(n+\gamma+B N C)$ in a water-filled head phantom for a BNCEFNT assembly with 5.64-cm diameter tungsten collimator and 5.0-cm tungsten filter. The red square is the tumor $\left(4 \times 4 \times 2 \mathrm{~cm}^{3}\right)$ with $100-\mathrm{ppm}^{10} \mathrm{~B}$, the rest is with $30-\mathrm{ppm}{ }^{10} \mathrm{~B}$. (Curves outside the head should be ignored)

Percent dose enhancements (PDE) calculated for the no-filter and 5.0-cm tungsten filter BNCEFNT assembly with 5.64-cm diameter tungsten collimator are shown in Figure 57 and Figure 58, respectively. As calculated in the previous sections, the tumor PDE with the 5.0-cm tungsten filter is much higher than the tumor PDE with no-filter. The PDE and absolute dose due to boron neutron capture reaction trend differently with tungsten filter thickness. An increase in the filter thickness will result in an increase of PDE but a decrease of the absolute boron capture dose. So the thickness of tungsten filter should be optimized based on the requirement of PDE and absolute boron capture dose enhancement.

The 100 -ppm ${ }^{10} \mathrm{~B}$ concentration in tumor is not attainable using the currently available boron delivery agent. However, if we use boronophenylalanine fructose (BPAf) as the boron delivery agent, a ${ }^{10} \mathrm{~B}$ concentration in blood of approximately $15 \mathrm{ppm}$ within 0.5 to $1.5 \mathrm{~h}$ after infusion can be realized using the infusion schedule currently 
employed for BNCT treatments at the Massachusetts Institute of Technology, Cambridge, MA [28]. The boron concentration in the bloodstream is generally used as a surrogate for the concentration in normal healthy tissue since this quantity is difficult to measure. According to the observations by Coderre et al. [26-27], a tumor-to-blood uptake ratio of approximately $3.5-4$ to 1 has been attained $0.5-1.5 \mathrm{~h}$ after infusion. So it is practical to assume ${ }^{10} \mathrm{~B}$ concentration of 15 and $55 \mathrm{ppm}$ for blood (normal brain tissue) and tumor, respectively. Based on this assumption and the tumor size and location described previously, the absorbed dose rate and PDE-depth distributions were calculated for the head phantom in a BNCEFNT assembly with a 5.64-cm diameter collimator and $7.5-\mathrm{cm}$ tungsten filter and are shown in Figure 59. The minimum tungsten filter thickness required to attain a PDE of $15 \%$ was calculated to be $7.5 \mathrm{~cm}$.

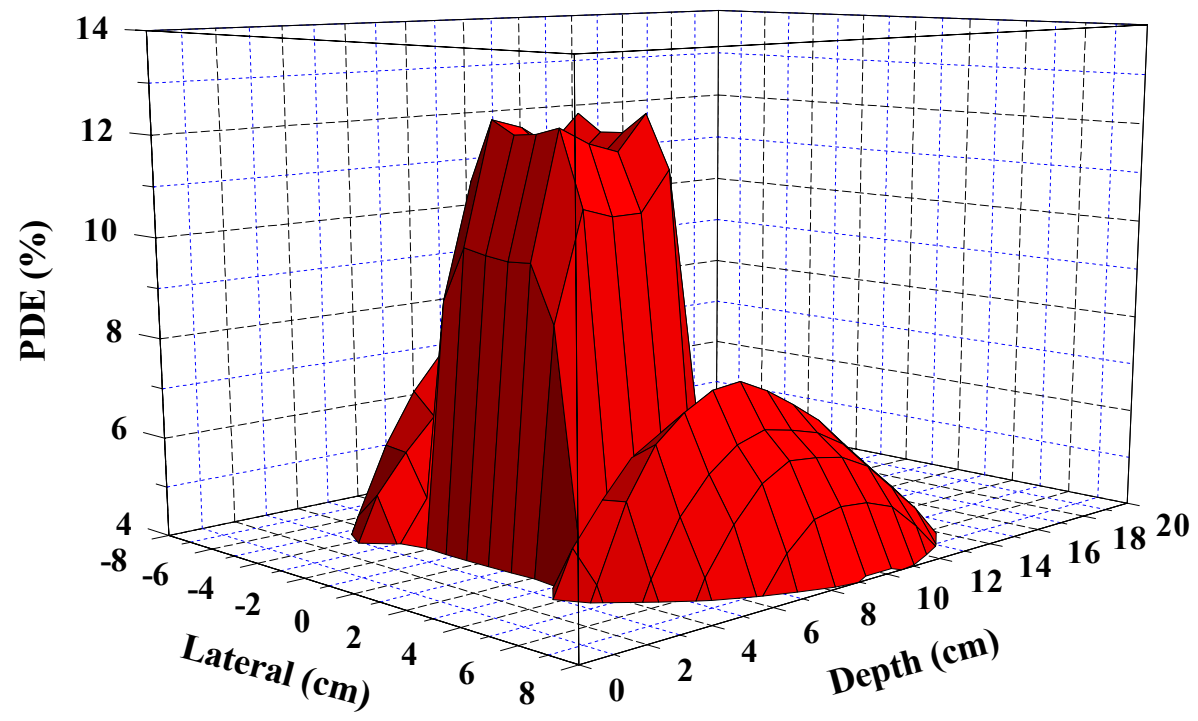

Figure 57: PDE for the water-filled head phantom inserted in the BNCEFNT assembly with 5.65-cm diameter tungsten collimator and no-filter. Tumor $\left(4 \times 4 \times 2 \mathrm{~cm}^{3}\right)$ is located between depth 4.7 and 8.7 $\mathrm{cm}$ and centered in the collimator. Tumor has $100-\mathrm{ppm}{ }^{10} \mathrm{~B}$ the rest of the head has $30-\mathrm{ppm}{ }^{10} \mathrm{~B}$. 


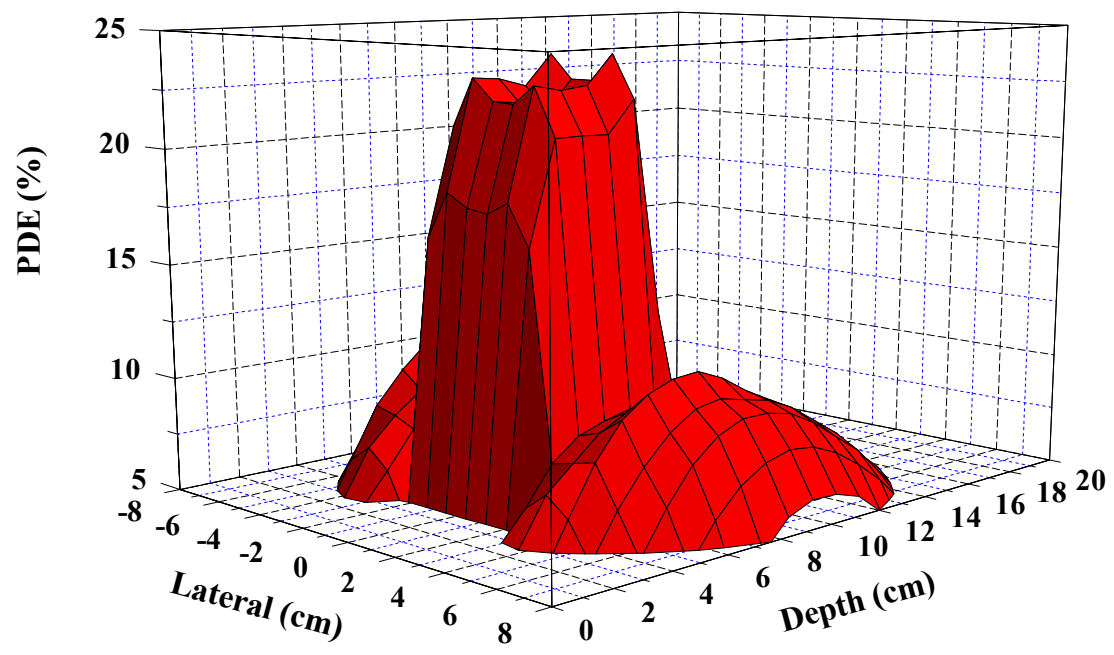

Figure 58: PDE for the water-filled head phantom inserted in the BNCEFNT assembly with 5.65-cm diameter tungsten collimator and 5.0-cm tungsten filter. Tumor $\left(4 \times 4 \times 2 \mathrm{~cm}^{3}\right)$ is located between depth 4.7 and $8.7 \mathrm{~cm}$ and centered in the collimator. Tumor has $100-\mathrm{ppm}{ }^{10} \mathrm{~B}$ the rest of the head has 30 ppm ${ }^{10} \mathrm{~B}$.

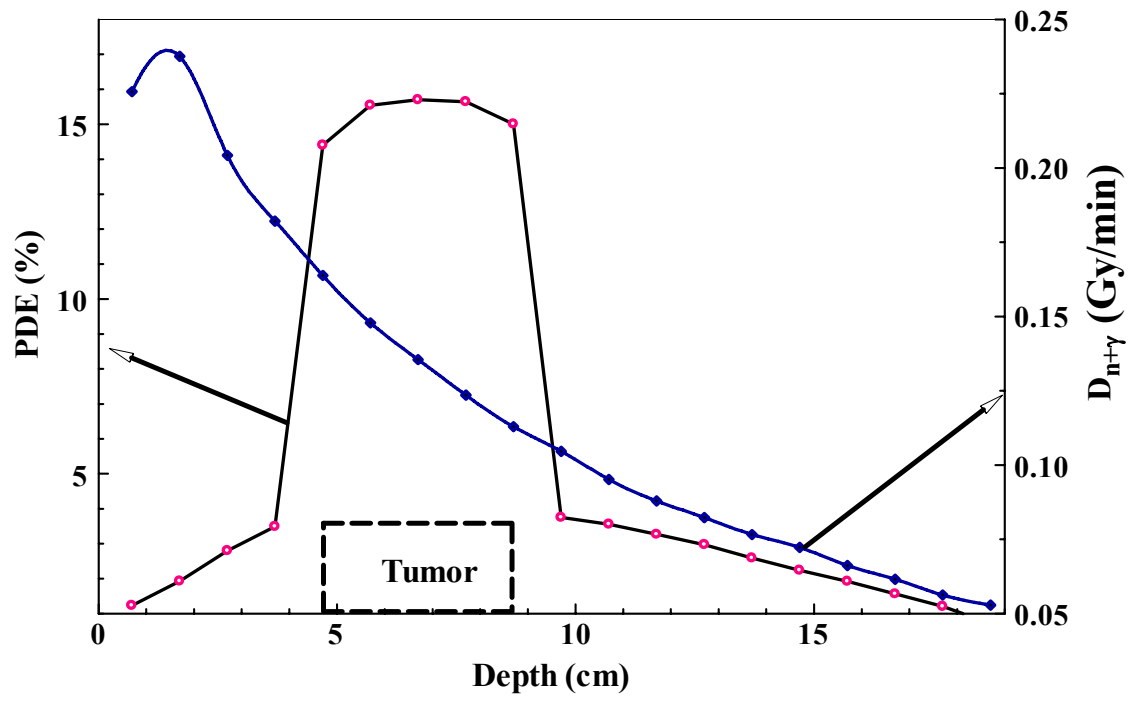

Figure 59: Absorbed dose rate and PDE-depth distribution in the head phantom in a BNCEFNT assembly with a $5.64-\mathrm{cm}$ diameter collimator and a $7.5-\mathrm{cm}$ tungsten filter. The tumor location is shown as the dashed box. 


\subsection{Discussion}

The kerma-depth distribution in a water-filled head phantom in the BNCEFNT assembly calculated using MCNP5 code can result in misinterpretation of the dose enhancement effect of the assembly. Figure 60 is a re-plot of no-filter and 5.0-cm curves from Figures 21(a), which are normalized at 4.7-cm depth. The decrease of the kerma with the increase of depth is much faster for 5-cm tungsten filter than for no-filter. If a tumor is located at $4.7-\mathrm{cm}$ depth, the tumor will receive much less kerma using $5.0-\mathrm{cm}$ tungsten filter than kerma using no-filter.

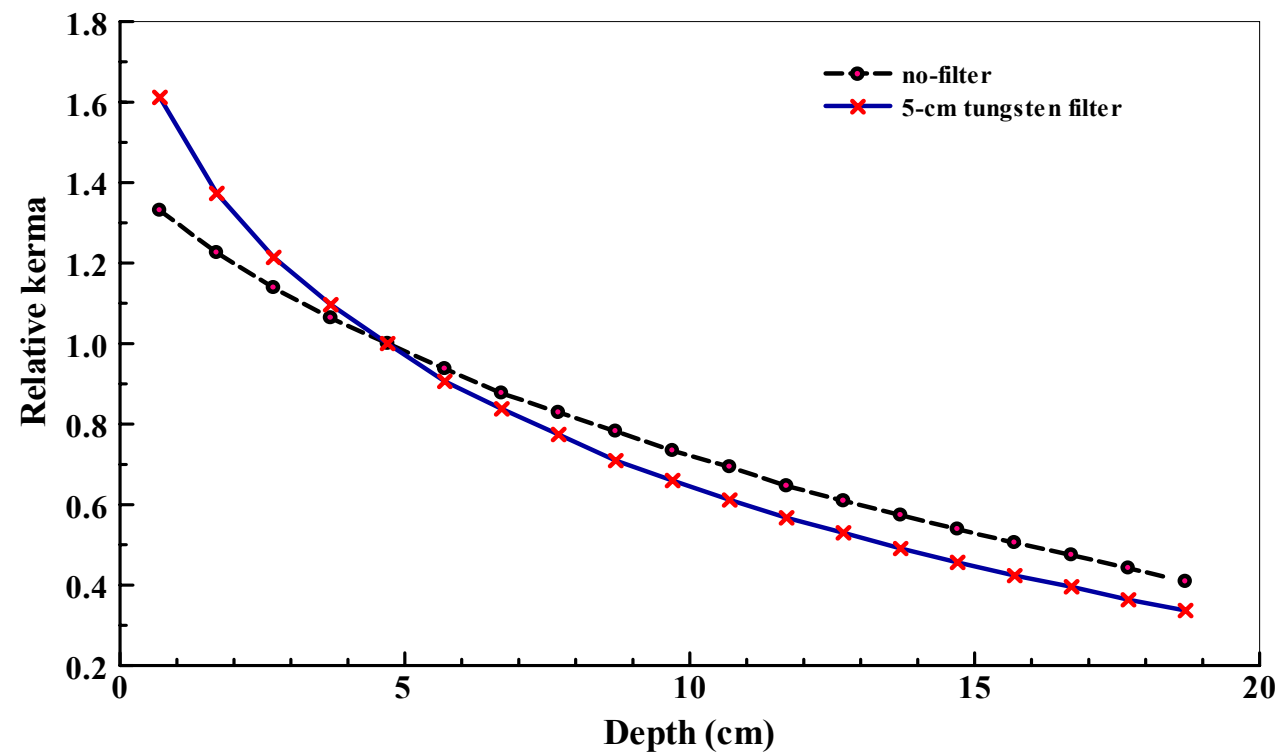

Figure 60: Relative kerma $(n+\gamma)$ distributions in a water-filled head phantom in the BNCEFNT assembly with 5.64-cm diameter collimator for no-filter and 5.0-cm tungsten filter.

Fortunately, the decrease of the absorbed dose with the increase of depth in the head phantom is much slower than that of the kerma. The measured absorbed dose at shallow depth in the water-filled head phantom is much smaller than the kerma calculated using MCNP5 code, as shown in Figures 36 to 41. The relative measured absorbed dose distributions in the water-filled head phantom in the simplified BNCEFNT assembly for no-filter and 5-cm tungsten filter are shown in Figure 61. It is assumed that a tumor is 
located at depth ranging from 3 to $7 \mathrm{~cm}$, and ${ }^{10} \mathrm{~B}$ concentration is $100 \mathrm{ppm}$ in tumor and $30 \mathrm{ppm}$ in normal tissue. The relative ( $\mathrm{n}+\gamma+{ }^{10} \mathrm{~B}$ capture) dose depth distributions for no-filter and 5.0-cm tungsten filter are shown in Figure 62. It is obvious that the dose enhancement effect for the 5.0-cm tungsten filter is better than that of no-filter. From the calculations and measurements, it is concluded that the BNCEFNT assembly works better for shallow $(5 \mathrm{~cm}$ and less) tumors than deep-seated (greater than $7 \mathrm{~cm}$ ) tumors in the tumor dose enhancement.

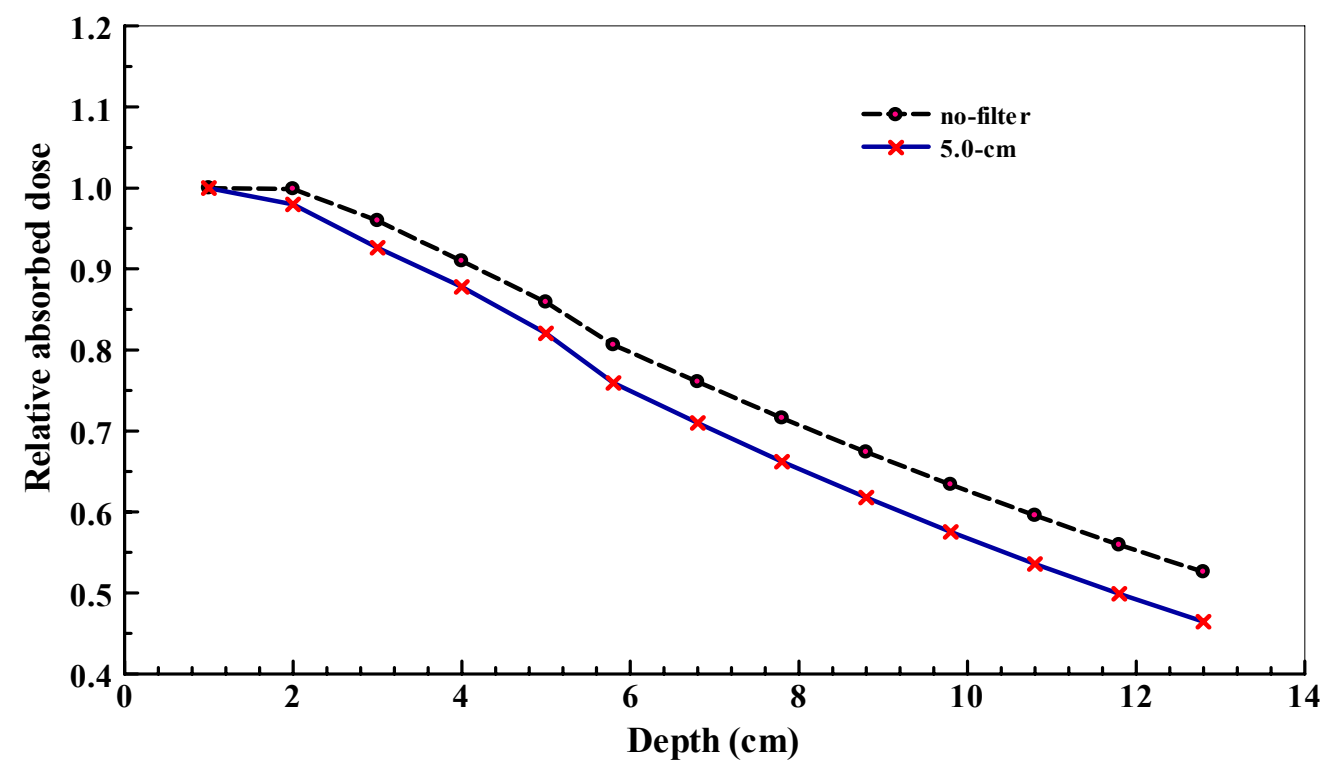

Figure 61: Relative measured absorbed dose $(n+\gamma)$ distributions in the water-filled head phantom using the simplified BNCEFNT assembly for no-filter and $5.0-\mathrm{cm}$ filter. 


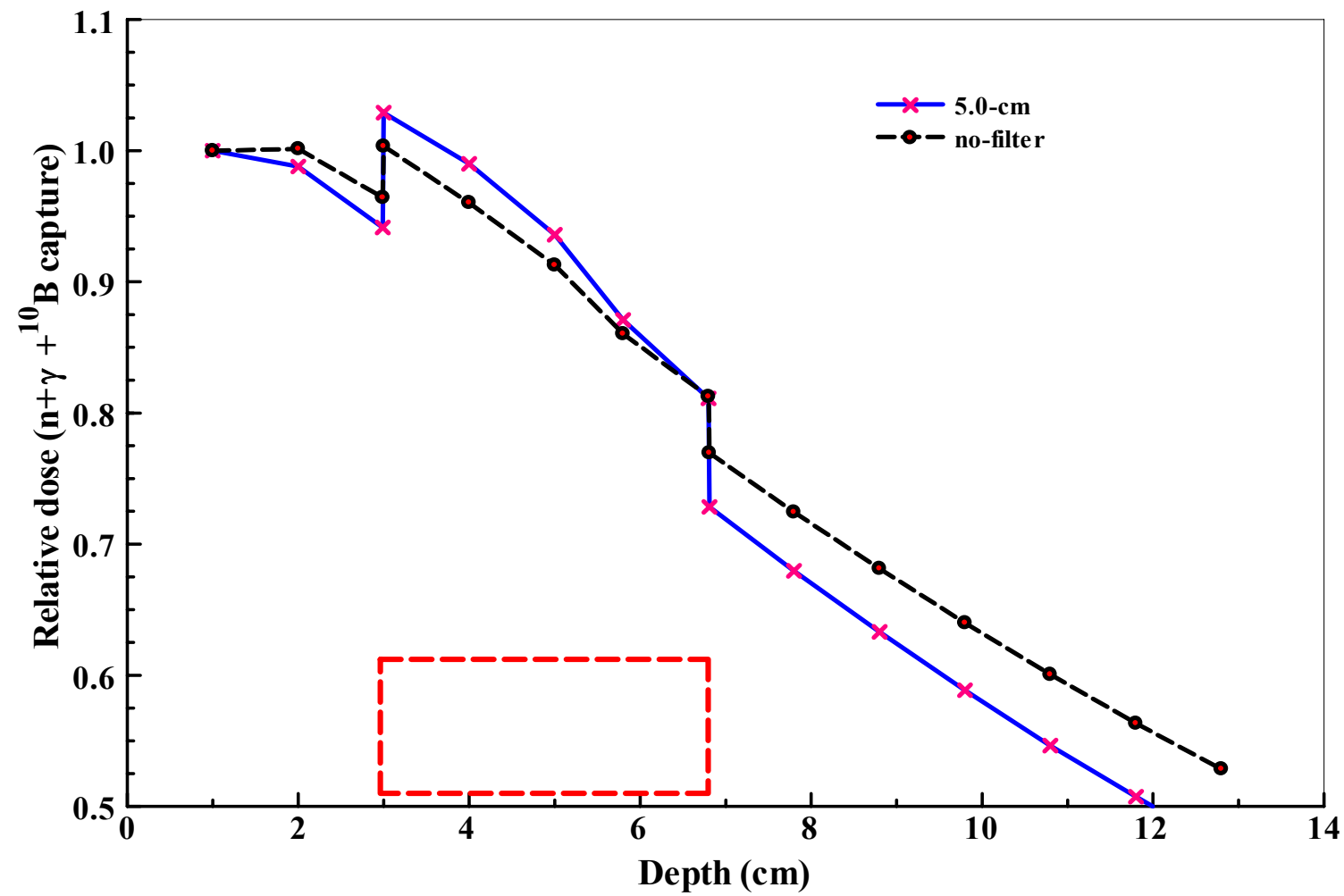

Figure 62: Demonstration of dose enhancement in tumor for the simplified BNCEFNT assembly with no-filter and 5.0-cm tungsten filter. The red box represents the tumor. ${ }^{10} \mathrm{~B}$ concentration is $100 \mathrm{ppm}$ in tumor and $30 \mathrm{ppm}$ in normal tissue. 


\section{CHAPTER 6}

\section{EVALUATION OF THE ABSORBED DOSES IN OTHER ORGANS}

In an effort to evaluate the absorbed dose in other organs for using BNCEFNT to treat brain tumors, two anthropomorphic phantoms of man and woman were created using the software package, BodyBuilder [72]. The models developed in this program are based on the Medical Internal Radiation Dose (MIRD) reports and are generated in an MCNP geometry format [73]. The phantom head is inserted into the designed reflective BNCEFNT assembly (Figure 30) as shown in Figure 63. Chair and tables or other supporting tools were not modeled.
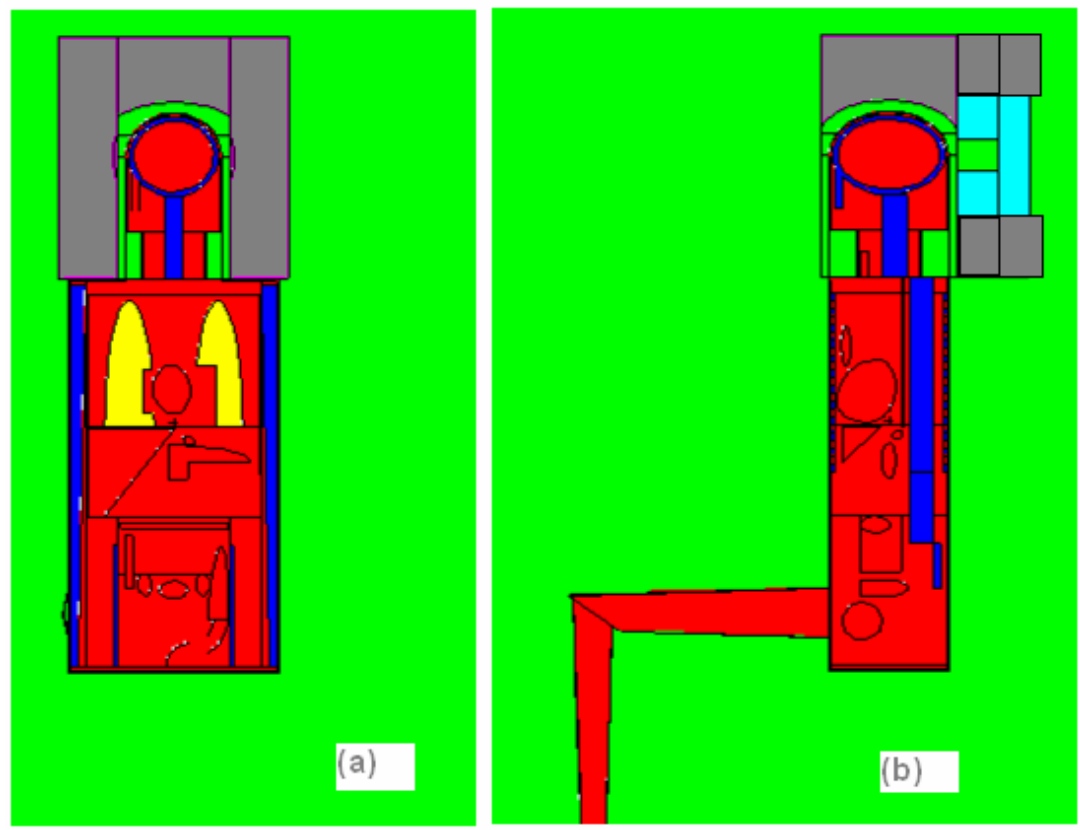

Figure 63: Cross-sectional view (a) from front and (b) from side, of an anthropomorphic phantom in a sitting posture with its head in the BNCEFNT reflective assembly for the computation of organ doses.

The doses in organs were calculated for two situations for male and female phantoms: (a) with the heads in the reflective BNCEFNT assembly of 5.64-cm diameter tungsten collimator and 5.0-cm tungsten filter in a $20 \times 20 \mathrm{~cm}^{2}$ beam field, and (b) with 
the above reflective BNCEFNT assembly removed from the heads in a $10 \times 10 \mathrm{~cm}^{2}$ standard treatment beam. The dose in each organ is shown in Table 6 .

The average doses to the entire brain were normalized to $1000 \mathrm{cGy}$. The doses to all other organs were increased significantly due to the use of the reflective BNCEFNT assembly. The impact of the increased dose in other organs to the patient's health needs to be evaluated.

Table 6: Doses in other organs relative to brain dose.

\begin{tabular}{cccc|ccc}
\hline & \multicolumn{6}{c}{ Total dose (cGy) } \\
\cline { 2 - 7 } organ & \multicolumn{3}{c}{ male phantom } & \multicolumn{3}{c}{ female phantom } \\
\cline { 2 - 7 } M+C+F5.0 & air $^{\text {b }}$ & Ratio & M+C+F5.0 & air & Ratio \\
\hline head skin & 843 & 271 & 3.1 & 860 & 302 & 2.8 \\
neck skin & 189 & 11.8 & 16.1 & 217 & 7.98 & 27.3 \\
lower spine & 1.97 & 0.06 & 32.8 & 2.91 & 0.07 & 41.6 \\
middle spine & 27.1 & 1.39 & 19.5 & 34.3 & 0.70 & 49.0 \\
upper spine & 266 & 80.5 & 3.3 & 280 & 21.3 & 13.2 \\
skull & 613 & 543 & 1.1 & 620 & 438 & 1.4 \\
brain & 1000 & 1000 & 1.0 & 1000 & 1000 & 1.0 \\
bladder & 2.46 & 0.11 & 22.4 & 3.60 & 0.12 & 30.0 \\
stomach & 3.28 & 0.15 & 21.9 & 4.80 & 0.17 & 28.2 \\
small intestine & 1.19 & 0.05 & 23.8 & 1.87 & 0.06 & 31.2 \\
heart & 9.51 & 0.55 & 17.3 & 12.9 & 0.45 & 28.6 \\
kidney & 3.13 & 0.1 & 31.3 & 4.64 & 0.12 & 38.7 \\
liver & 4.23 & 0.2 & 21.2 & 5.97 & 0.22 & 27.1 \\
lung & 19.2 & 1.22 & 15.7 & 23.7 & 0.82 & 28.9 \\
pancreas & 3.88 & 0.19 & 20.4 & 5.78 & 0.19 & 30.4 \\
spleen & 4.49 & 0.2 & 22.5 & 6.22 & 0.23 & 27.0 \\
thyroid & 95.5 & 9.81 & 9.7 & 109 & 6.80 & 16.0 \\
testicles & 1.13 & 0.07 & 16.1 & & & \\
Uterus & & & & 1.13 & 0.04 & 28.3 \\
breast & & & & 15.5 & 0.80 & 19.4 \\
\hline
\end{tabular}

a. $20 \times 20 \mathrm{~cm}^{2}$ beam field + optimized 5.64-cm diameter BNCEFNT assembly with 5.0-cm filter b. $10 \times 10 \mathrm{~cm}^{2}$ standard treatment beam 


\section{CHAPTER 7}

\section{RADIOACTIVITY GENERATED IN THE BNCEFNT ASSEMBLY AND THEIR DOSE CALCULATIONS}

Radioactivity will be produced when material is irradiated in the neutron field. After the BNCEFNT assembly is used to treat a patient or phantom in the Fermilab Fast Neutron Therapy facility, a variety of radioisotopes will be produced. The photons emitted from these activation products will dose the patient and the medical personnel. While the dose to the patient is secondary importance compared to the dose from the neutron beam, this dose to the medical staff may be the major source of their dose. Therefore, it should be evaluated for radiation protection purposes. Procedures should be developed according to these dose rates.

Activities of the major activation products of tungsten and lead were calculated using MCNP5 code. Reactions such as (n, $\gamma),(n, 2 n),(n, 3 n),(n, p),(n, d),(n, t),(n, n ' p)$, $(\mathrm{n}, \alpha)$ and $\left(\mathrm{n}, \mathrm{n}^{\prime} \alpha\right)$ were considered if radioactive products have half-lives greater than 1 minute. The cross sections for the activation were taken from the LA150N library (with extension .24c in the material ID) if available and from ACTL [74] (material card with extension .30y) (an evaluated neutron activation cross section library from the Lawrence Livermore National Laboratory (LLNL)) if not available in the LA150N library.

After the activities of the activation products at the end of the irradiation (dose delivery) are calculated, the dose rate per unit activity of the radioisotope is computed using MCNP5 code. Since the half-lives of these radioisotopes range from minutes to years, the dose rate due to all of the activation products at different times after neutron beam delivery were calculated separately. 


\subsection{Calculation of the Activities of the Activation Products}

\subsubsection{Activities of the Activation Products in Tungsten Filter}

The tungsten filter with the dimensions of $20 \mathrm{~cm} \times 20 \mathrm{~cm} \times 5 \mathrm{~cm}$ was used in the calculations. The $20 \mathrm{~cm} \times 20 \mathrm{~cm}$ neutron beam with the spectrum determined in Chapter 4 was used in the calculations as was the simplified BNCEFNT assembly described in section 5.2. The particle weight in the SDEF card is set to 400 (the area of the neutron field) so that the results will be normalized to unit fluence on the filter (per neutron $/ \mathrm{cm}^{2}$ ). The filter is divided into 5 cells, each with the dimension of $20 \mathrm{~cm} \times 20 \mathrm{~cm} \times 1 \mathrm{~cm}$ and were tallied separately. The constant $\mathrm{C}$ in the FM card is the number of target atoms in 1 gram of tungsten (units of atoms-barn/g) so that the result will be the number of radionuclide generated in 1 gram of tungsten per unit fluence on the filter. $\mathrm{C}$ is calculated as follows,

$$
C=\frac{(1 \mathrm{~g})}{\left(W_{A} \frac{\mathrm{g}}{\mathrm{mol}}\right)} \cdot q \cdot\left(6.022 \times 10^{23} \frac{\text { atoms }}{\mathrm{mol}}\right)\left(10^{-24} \frac{\mathrm{cm}^{2}}{\mathrm{barn}}\right)
$$

where $W_{A}$ is the atomic weight of tungsten, $W_{A}=183.84 \mathrm{~g} / \mathrm{mol}$, and $q$ is the abundance of the target nucleus.

The dose rate due to 16 radioisotopes produced in the tungsten filter were calculated and their resulting concentrations in nuclei per gram of tungsten per unit neutron fluence (neutron $/ \mathrm{cm}^{2}$ ) are displayed in Table 7. Assuming the proton current is $1.5 \times 10^{14}$ protons/s, and the total mass of tungsten filter is $3.86 \times 10^{4}$ grams, the total activities $(\mathrm{Bq})$ of the activation products at the end of 12, 20 and 100-minute irradiations were calculated and are displayed in Table 8. 
Table 7: Number of nuclei of the activation products generated in 1 gram of tungsten per unit neutron fluence

\begin{tabular}{|c|c|c|c|c|c|c|c|c|}
\hline Isotope & $\mathrm{T}_{1 / 2}$ & reactions & Layer 1 & Layer 2 & Layer 3 & Layer 4 & Layer 5 & total \\
\hline${ }^{178} \mathrm{~W}$ & $21.6 \mathrm{~d}$ & ${ }^{180} W(n, 3 n)$ & $2.26^{-6^{*}}$ & $2.01^{-6}$ & $1.76^{-6}$ & $1.54^{-6}$ & $1.33^{-6}$ & $8.89^{-6}$ \\
\hline${ }^{179} \mathrm{~W}$ & $37.05 \mathrm{~m}$ & ${ }^{180} W(n, 2 n)$ & $2.97^{-6}$ & $2.69^{-6}$ & $2.38^{-6}$ & $2.09^{-6}$ & $1.81^{-6}$ & $11.9^{-6}$ \\
\hline${ }^{181} \mathrm{~W}$ & $121.2 \mathrm{~d}$ & $\begin{array}{c}{ }^{180} \mathrm{~W}(\mathrm{n}, \gamma) \\
{ }^{182} \mathrm{~W}(\mathrm{n}, 2 \mathrm{n}) \\
{ }^{183} \mathrm{~W}(\mathrm{n}, 3 \mathrm{n})\end{array}$ & $3.10^{-4}$ & $2.86^{-4}$ & $2.56^{-4}$ & $2.26^{-4}$ & $1.97^{-4}$ & $12.8^{-4}$ \\
\hline${ }^{185} \mathrm{~W}$ & $75.1 \mathrm{~d}$ & $\begin{array}{c}{ }^{184} \mathrm{~W}(\mathrm{n}, \gamma) \\
{ }^{186} \mathrm{~W}(\mathrm{n}, 2 \mathrm{n})\end{array}$ & $4.17^{-4}$ & $4.36^{-4}$ & $4.29^{-4}$ & $4.07^{-4}$ & $3.84^{-4}$ & $20.7^{-4}$ \\
\hline${ }^{187} \mathrm{~W}$ & $23.72 \mathrm{~h}$ & ${ }^{186} \mathrm{~W}(\mathrm{n}, \gamma)$ & $4.43^{-4}$ & $3.33^{-4}$ & $2.97^{-4}$ & $3.08^{-4}$ & $4.58^{-4}$ & $18.4^{-4}$ \\
\hline${ }^{179} \mathrm{Ta}$ & $1.82 \mathrm{y}$ & $\begin{array}{c}{ }^{180} \mathrm{~W}(\mathrm{n}, \mathrm{n} \text { 'p }) \\
{ }^{180} \mathrm{~W}(\mathrm{n}, \mathrm{d})\end{array}$ & $7.92^{-9}$ & $7.05^{-9}$ & $6.18^{-9}$ & $5.38^{-9}$ & $4.65^{-9}$ & $31.2^{-9}$ \\
\hline${ }^{180} \mathrm{Ta}$ & $8.152 \mathrm{~h}$ & ${ }^{180} \mathrm{~W}(\mathrm{n}, \mathrm{p})$ & $8.16^{-9}$ & $7.36^{-9}$ & $6.51^{-9}$ & $5.69^{-9}$ & $4.93^{-9}$ & $32.7^{-9}$ \\
\hline${ }^{182} \mathrm{Ta}$ & $114.43 \mathrm{~d}$ & $\begin{array}{c}{ }^{182} \mathrm{~W}(\mathrm{n}, \mathrm{p}) \\
{ }^{183} \mathrm{~W}(\mathrm{n}, \mathrm{n} \text { 'p }) \\
{ }^{183} \mathrm{~W}(\mathrm{n}, \mathrm{d})\end{array}$ & $1.57^{-6}$ & $1.42^{-6}$ & $1.26^{-6}$ & $1.10^{-6}$ & $0.944^{-6}$ & $6.29^{-6}$ \\
\hline \multirow[t]{2}{*}{${ }^{183} \mathrm{Ta}$} & \multirow[t]{2}{*}{$5.1 \mathrm{~d}$} & $\begin{array}{c}{ }^{183} \mathrm{~W}(\mathrm{n}, \mathrm{p}) \\
{ }^{184} \mathrm{~W}\left(\mathrm{n}, \mathrm{n}{ }^{\prime} \mathrm{p}\right)\end{array}$ & \multirow[t]{2}{*}{$8.35^{-7}$} & \multirow[t]{2}{*}{$7.50^{-7}$} & \multirow[t]{2}{*}{$6.61^{-7}$} & \multirow[t]{2}{*}{$5.75^{-7}$} & \multirow[t]{2}{*}{$4.95^{-7}$} & \multirow[t]{2}{*}{$33.2^{-7}$} \\
\hline & & ${ }^{184} \mathrm{~W}(\mathrm{n}, \mathrm{d})$ & & & & & & \\
\hline${ }^{184} \mathrm{Ta}$ & $8.7 \mathrm{~h}$ & ${ }^{184} \mathrm{~W}(\mathrm{n}, \mathrm{p})$ & $10.0^{-7}$ & $9.09^{-7}$ & $8.05^{-7}$ & $7.02^{-7}$ & $6.06^{-7}$ & $40.3^{-7}$ \\
\hline${ }^{185} \mathrm{Ta}$ & $49.4 \mathrm{~m}$ & $\begin{array}{l}{ }^{186} \mathrm{~W}(\mathrm{n}, \mathrm{d}) \\
{ }^{186} \mathrm{~W}(\mathrm{n}, \mathrm{n} \text { 'p })\end{array}$ & $5.55^{-7}$ & $4.99^{-7}$ & $4.39^{-7}$ & $3.82^{-7}$ & $3.29^{-7}$ & $22.0^{-7}$ \\
\hline${ }^{186} \mathrm{Ta}$ & $10.5 \mathrm{~m}$ & ${ }^{186} \mathrm{~W}(\mathrm{n}, \mathrm{p})$ & & & & & & \\
\hline${ }^{179 m} \mathrm{Hf}$ & $25.05 \mathrm{~d}$ & ${ }^{183} \mathrm{~W}\left(\mathrm{n}, \mathrm{n}{ }^{\prime} \alpha\right)$ & $2.75^{-8}$ & $2.46^{-8}$ & $2.16^{-8}$ & $1.89^{-8}$ & $1.63^{-8}$ & $10.9^{-8}$ \\
\hline${ }^{181} \mathrm{Hf}$ & $42.39 \mathrm{~d}$ & ${ }^{184} \mathrm{~W}(\mathrm{n}, \alpha)$ & $5.00^{-7}$ & $4.52^{-7}$ & $3.99^{-7}$ & $3.48^{-7}$ & $3.00^{-7}$ & $20.0^{-7}$ \\
\hline${ }^{182 \mathrm{~m}} \mathrm{Hf}$ & $61.5 \mathrm{~m}$ & ${ }^{186} \mathrm{~W}\left(\mathrm{n}, \mathrm{n}^{\prime} \alpha\right)$ & $4.95^{-8}$ & $4.41^{-8}$ & $3.88^{-8}$ & $3.37^{-8}$ & $2.92^{-8}$ & $19.5^{-8}$ \\
\hline${ }^{183} \mathrm{Hf}$ & $1.067 \mathrm{~h}$ & ${ }^{186} \mathrm{~W}(\mathrm{n}, \alpha)$ & $2.66^{-7}$ & $2.41^{-7}$ & $2.13^{-7}$ & $1.85^{-7}$ & $1.60^{-7}$ & $10.6^{-7}$ \\
\hline
\end{tabular}

$* 2.26^{-6}$ stands for $2.26 \times 10^{-6}$

The total number of absorptions, $(n, 2 n)$ and $(n, 3 n)$ reactions in each $1-\mathrm{cm}$ thickness $20 \times 20 \mathrm{~cm}^{2}$ tungsten filter per unit fluence of the $20 \times 20 \mathrm{~cm}^{2}$ neutron beam were also calculated and are shown in Figure 64. It is understandable that the $(n, 2 n)$ and (n, 3n) interactions decrease as neutrons penetrate deeper into the tungsten filter since they lose energy. For the absorption reactions, the interactions decrease slightly in the first 3 $\mathrm{cm}$ and then start to increase as neutrons go through more tungsten. This is because the low-energy neutrons accumulate deeper into the tungsten filter and the neutron capture reactions start to dominate in the absorption. The total number of absorptions, (n, 2n) and $(\mathrm{n}, 3 \mathrm{n})$ reactions in the 5-cm thick tungsten filter per unit fluence are computed as 46.4 , 
31.6 and 8.32 reactions per $\mathrm{n} / \mathrm{cm}^{2}$, respectively. So on average, there are more neutrons produced than lost in the tungsten filter of 5-cm thickness. A neutron multiplication of 1.39 was obtained for $5-\mathrm{cm}$ tungsten filter in the simplified BNCEFNT assembly.

Table 8: Total activities $(\mathrm{Bq})$ produced in 5-cm tungsten filter for 12, 20 and 100 minutes

\begin{tabular}{|c|c|c|c|}
\hline \multirow{2}{*}{ Isotope } & \multicolumn{3}{|c|}{ Total Activity $(\mathrm{Bq})$ for the irradiation time of } \\
\cline { 2 - 4 } & $12 \mathrm{~min}$ & $20 \mathrm{~min}$ & $100 \mathrm{~min}$ \\
\hline${ }^{178} \mathrm{~W}$ & $2.24 \mathrm{E}+03$ & $3.73 \mathrm{E}+03$ & $1.86 \mathrm{E}+04$ \\
\hline${ }^{179} \mathrm{~W}$ & $2.26 \mathrm{E}+06$ & $3.51 \mathrm{E}+06$ & $9.51 \mathrm{E}+06$ \\
\hline${ }^{181} \mathrm{~W}$ & $5.98 \mathrm{E}+04$ & $9.97 \mathrm{E}+04$ & $4.99 \mathrm{E}+05$ \\
\hline${ }^{185} \mathrm{~W}$ & $1.50 \mathrm{E}+05$ & $2.50 \mathrm{E}+05$ & $1.25 \mathrm{E}+06$ \\
\hline${ }^{187} \mathrm{~W}$ & $1.01 \mathrm{E}+07$ & $1.68 \mathrm{E}+07$ & $8.22 \mathrm{E}+07$ \\
\hline${ }^{179} \mathrm{Ta}$ & $2.55 \mathrm{E}-01$ & $4.25 \mathrm{E}-01$ & $2.13 \mathrm{E}+00$ \\
\hline${ }^{180} \mathrm{Ta}$ & $5.19 \mathrm{E}+02$ & $8.59 \mathrm{E}+02$ & $4.06 \mathrm{E}+03$ \\
\hline${ }^{182} \mathrm{Ta}$ & $2.99 \mathrm{E}+02$ & $4.98 \mathrm{E}+02$ & $2.49 \mathrm{E}+03$ \\
\hline${ }^{183} \mathrm{Ta}$ & $5.78 \mathrm{E}+03$ & $9.62 \mathrm{E}+03$ & $4.79 \mathrm{E}+04$ \\
\hline${ }^{184} \mathrm{Ta}$ & $5.99 \mathrm{E}+04$ & $9.94 \mathrm{E}+04$ & $4.71 \mathrm{E}+05$ \\
\hline${ }^{185} \mathrm{Ta}$ & $3.22 \mathrm{E}+05$ & $5.08 \mathrm{E}+05$ & $1.57 \mathrm{E}+06$ \\
\hline${ }^{186} \mathrm{Ta}$ & $2.07 \mathrm{E}+06$ & $2.78 \mathrm{E}+06$ & $3.79 \mathrm{E}+06$ \\
\hline${ }^{179 m} \mathrm{Hf}$ & $2.36 \mathrm{E}+01$ & $3.94 \mathrm{E}+01$ & $1.97 \mathrm{E}+02$ \\
\hline${ }^{181} \mathrm{Hf}$ & $2.57 \mathrm{E}+02$ & $4.28 \mathrm{E}+02$ & $2.14 \mathrm{E}+03$ \\
\hline${ }^{182 \mathrm{~m}} \mathrm{Hf}$ & $2.33 \mathrm{E}+04$ & $3.71 \mathrm{E}+04$ & $1.24 \mathrm{E}+05$ \\
\hline${ }^{183} \mathrm{Hf}$ & $1.22 \mathrm{E}+05$ & $1.95 \mathrm{E}+05$ & $6.63 \mathrm{E}+05$ \\
\hline
\end{tabular}

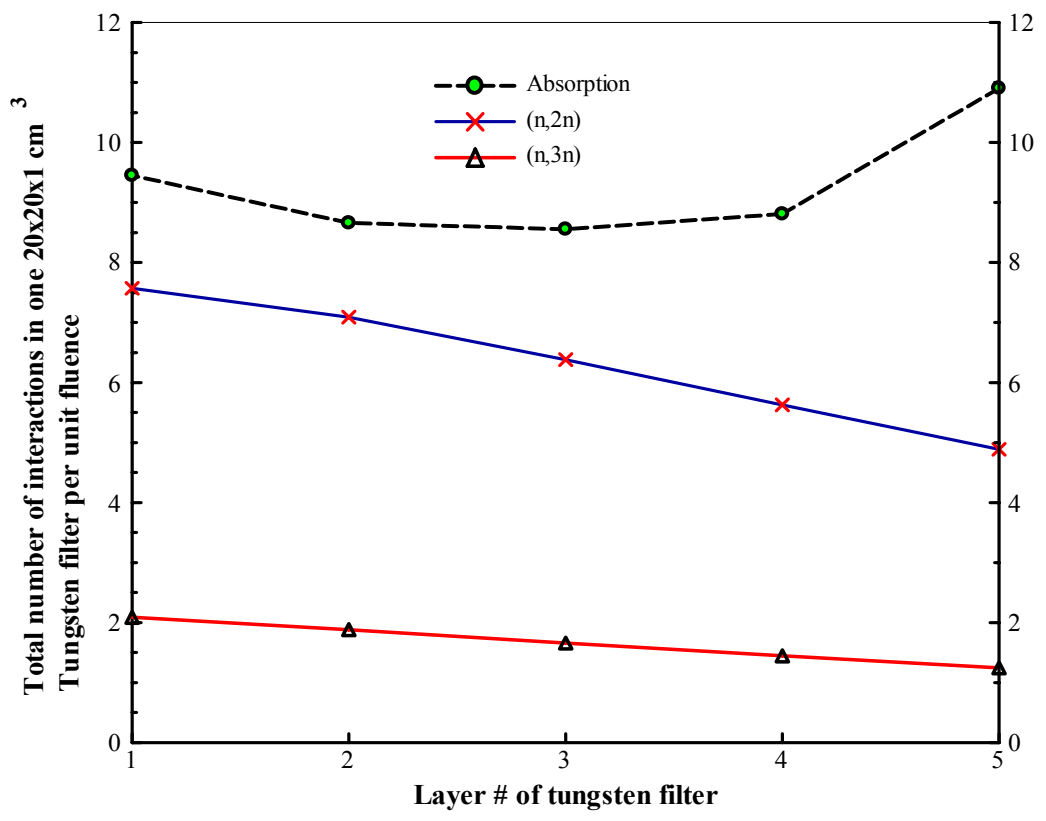

Figure 64: Number of absorption, (n, 2n) and (n, 3n) interactions in each $20 \times 20 \times 1 \mathrm{~cm}^{3}$ tungsten filter per unit fluence in a $20 \times 20 \mathrm{~cm}^{2}$ standard neutron therapy beam. Layer \#1 is at the upstream end of the beam. 


\subsubsection{Activities of the Activation Products in Lead Collimator}

The lead collimator has an outer dimension of $20 \times 20 \times 10 \mathrm{~cm}^{3}$ and an inner dimension of $5 \times 5 \times 10 \mathrm{~cm}^{3}$. It was divided into 5 layers along the neutron beam direction. The activities of the activation products in lead were calculated following the same method as for tungsten. A total of 11 radioisotopes from activation products in the lead were calculated, and are listed in Table 9.

Table 9: Total activities $(\mathrm{Bq})$ produced in the lead collimator for 21,20 and 100 minute irradiation

\begin{tabular}{ccccc} 
radioisotope & \multirow{2}{*}{ T1/2 } & \multicolumn{2}{c}{ Total activities $(\mathrm{Bq})$ produce in lead collimator } \\
& & 12-min & 20-min & 100-min \\
\hline $\mathrm{Pb}-202$ & $52.5 \mathrm{e} 3 \mathrm{y}$ & $1.50 \mathrm{E}-02$ & $2.50 \mathrm{E}-02$ & $1.25 \mathrm{E}-01$ \\
$\mathrm{~Pb}-203$ & $51.873 \mathrm{~h}$ & $1.36 \mathrm{E}+05$ & $2.26 \mathrm{E}+05$ & $1.12 \mathrm{E}+06$ \\
$\mathrm{~Pb}-204 \mathrm{~m}$ & $67.2 \mathrm{~m}$ & $6.71 \mathrm{E}+05$ & $1.07 \mathrm{E}+06$ & $3.71 \mathrm{E}+06$ \\
$\mathrm{~Pb}-209$ & $3.253 \mathrm{~h}$ & $5.76 \mathrm{E}+05$ & $9.46 \mathrm{E}+05$ & $4.12 \mathrm{E}+06$ \\
$\mathrm{Tl}-202$ & $12.23 \mathrm{~d}$ & $7.67 \mathrm{E}-01$ & $1.28 \mathrm{E}+00$ & $6.38 \mathrm{E}+00$ \\
$\mathrm{Tl} 204$ & $3.78 \mathrm{y}$ & $1.82 \mathrm{E}+00$ & $3.03 \mathrm{E}+00$ & $1.51 \mathrm{E}+01$ \\
$\mathrm{Tl}-206$ & $4.2 \mathrm{~m}$ & $1.98 \mathrm{E}+06$ & $2.21 \mathrm{E}+06$ & $2.29 \mathrm{E}+06$ \\
$\mathrm{Tl}-207$ & $4.77 \mathrm{~m}$ & $9.78 \mathrm{E}+06$ & $1.12 \mathrm{E}+07$ & $1.19 \mathrm{E}+07$ \\
$\mathrm{Tl}-208$ & $3.053 \mathrm{~m}$ & $6.35 \mathrm{E}+06$ & $6.72 \mathrm{E}+06$ & $6.79 \mathrm{E}+06$ \\
$\mathrm{Hg}-203$ & $46.612 \mathrm{~d}$ & $4.38 \mathrm{E}+02$ & $7.30 \mathrm{E}+02$ & $3.65 \mathrm{E}+03$ \\
$\mathrm{Hg}-205$ & $5.2 \mathrm{~m}$ & $9.85 \mathrm{E}+05$ & $1.15 \mathrm{E}+06$ & $1.23 \mathrm{E}+06$ \\
\hline
\end{tabular}

\subsection{Calculation of the dose rate for unit activity of the Activation Products}

The dose rate at $50 \mathrm{~cm}$ from the BNCEFNT assembly on the side, back and front was calculated using the MCNP5 code. Dose rates due to beta particles was not considered because dose due to beta particle is not significant to the medical personnel compared with the gamma dose. The gamma energies and emission probabilities were taken from decay data of Rad Toolbox [75], which is based on ICRP-38 decay data [76]. For radionuclides produced in tungsten filter, the photon source was distributed in the five 1-cm layer tungsten plate as per section 7.1.1. A uniform distribution in each plate was assumed. For radioisotopes produced in the lead collimator, the same method is 
applied for each 2-cm thick lead layer. The Photon fluence rates at each location of interest per disintegration of each radionuclide were calculated and dose rates were computed using different photon flux-to-dose rate conversion factors. Photon flux-todose conversion factors as given in the ANSI/ANS-6.1.1 [77] and ICRP-21 reports [78] have been widely used in the past. These coefficients yield results in biological dose equivalent in rem, or they can be converted to physical dose in rad easily because the quality factor for photon is considered to be 1 . These factors are used to convert MCNP calculated photon flux to rad-in-tissue. To determine the rad-in-air dose value from photon flux, the kerma factors for air are to be used. This is normally done using F6 tally or ICRP 74 [79] kerma factors for air. The differences in calculated dose rate resulted from using different conversion factors has been studied [80].

In the MCNP calculation for this work, photon flux-to-dose rate conversion factors of ANSI/ANS-C6.1.1(1977), ICRP-21(1971) and ANSI/ANS-C6.1.1(1991) were used to calculate dose rate-in-tissue per decay and ICRP-74(1996) conversion factors and the F6 tally were used to calculate dose rate-in-air per decay of the interested radionuclide. To convert the result of MCNP F6 tally (MeV/g per disintegration) to $\mathrm{rad} / \mathrm{h}$ per $\mathrm{Bq}$, one needs to multiply it by a constant, $\mathrm{C}$. The constant can be calculated by

$$
\boldsymbol{C}=1\left(\frac{\mathbf{M e V} / \mathbf{g}}{\operatorname{decay}}\right) \cdot\left(\frac{1.602 \times 10^{-8}(\mathbf{R a d})}{1(\mathbf{M e V} / \mathbf{g})}\right)\left(\frac{\operatorname{decay} / \mathbf{s}}{\mathbf{B q}}\right)\left(\frac{3600 \mathrm{~s}}{1 \boldsymbol{h}}\right)=5.767 \times 10^{-5}\left(\frac{\boldsymbol{R a d} / \mathbf{h}}{\mathbf{B q}}\right)
$$

The MCNP5-calculated dose rate at a distance of $50 \mathrm{~cm}$ from the back (upstream of neutron beam), the front (downstream of the neutron beam) and the side of the simplified BNCEFNT assembly due to $1 \mathrm{~Bq}$ of activation products in the 5-cm tungsten filter and in the 10-cm thick lead collimator are listed in Table 10 and Table 11, respectively. 
Table 10: Calculated Dose rate by different conversion factors at $50 \mathrm{~cm}$ from back, front and side of the BNCEFNT assembly due to unit activity of the activation products in tungsten filter.

\begin{tabular}{|c|c|c|c|c|c|c|}
\hline & & \multicolumn{3}{|c|}{ rem/hr per Bq (tissue) } & \multicolumn{2}{|c|}{$\mathrm{rad} / \mathrm{hr}$ per Bq (air) } \\
\hline & $\begin{array}{c}\text { Dose } \\
\text { position }\end{array}$ & $\begin{array}{c}\text { ANS6.1.1 } \\
(1977)\end{array}$ & $\begin{array}{c}\text { ANS6.1.1 } \\
(1991)\end{array}$ & $\begin{array}{l}\text { ICRP-21 } \\
\text { (1971) }\end{array}$ & $\begin{array}{c}\text { ICRP-74 } \\
(1996)\end{array}$ & F6 tally \\
\hline${ }^{178} \mathrm{~W}$ & $\begin{array}{l}\text { back } \\
\text { front } \\
\text { side }\end{array}$ & $\begin{array}{l}7.50 \mathrm{E}-15 \\
4.54 \mathrm{E}-18 \\
2.20 \mathrm{E}-16\end{array}$ & $\begin{array}{l}3.69 \mathrm{E}-15 \\
2.06 \mathrm{E}-18 \\
8.57 \mathrm{E}-17\end{array}$ & $\begin{array}{l}3.15 \mathrm{E}-15 \\
1.88 \mathrm{E}-18 \\
9.14 \mathrm{E}-17\end{array}$ & $\begin{array}{l}2.99 \mathrm{E}-15 \\
1.81 \mathrm{E}-18 \\
8.92 \mathrm{E}-17\end{array}$ & $\begin{array}{l}3.00 \mathrm{E}-15 \\
1.82 \mathrm{E}-18 \\
9.00 \mathrm{E}-17\end{array}$ \\
\hline${ }^{179} \mathrm{~W}$ & $\begin{array}{l}\text { back } \\
\text { front } \\
\text { side }\end{array}$ & $\begin{array}{l}2.60 \mathrm{E}-18 \\
2.24 \mathrm{E}-19 \\
9.36 \mathrm{E}-19\end{array}$ & $\begin{array}{l}1.22 \mathrm{E}-18 \\
8.74 \mathrm{E}-20 \\
2.12 \mathrm{E}-19\end{array}$ & $\begin{array}{l}1.07 \mathrm{E}-18 \\
9.09 \mathrm{E}-20 \\
4.04 \mathrm{E}-19\end{array}$ & $\begin{array}{l}1.04 \mathrm{E}-18 \\
8.88 \mathrm{E}-20 \\
4.08 \mathrm{E}-19\end{array}$ & $\begin{array}{l}1.06 \mathrm{E}-18 \\
8.94 \mathrm{E}-20 \\
4.15 \mathrm{E}-19\end{array}$ \\
\hline${ }^{181} \mathrm{~W}$ & $\begin{array}{l}\text { back } \\
\text { front } \\
\text { side }\end{array}$ & $\begin{array}{l}\text { 5.31E-18 } \\
7.69 \mathrm{E}-21 \\
3.00 \mathrm{E}-18\end{array}$ & $\begin{array}{l}1.85 \mathrm{E}-18 \\
4.46 \mathrm{E}-21 \\
7.87 \mathrm{E}-19\end{array}$ & $\begin{array}{l}2.12 \mathrm{E}-18 \\
3.52 \mathrm{E}-21 \\
1.26 \mathrm{E}-18\end{array}$ & $\begin{array}{l}2.08 \mathrm{E}-18 \\
3.27 \mathrm{E}-21 \\
1.26 \mathrm{E}-18\end{array}$ & $\begin{array}{l}2.13 \mathrm{E}-18 \\
3.26 \mathrm{E}-21 \\
1.28 \mathrm{E}-18\end{array}$ \\
\hline${ }^{185} \mathrm{~W}$ & $\begin{array}{l}\text { back } \\
\text { front } \\
\text { side }\end{array}$ & $\begin{array}{l}3.14 \mathrm{E}-21 \\
1.43 \mathrm{E}-21 \\
5.98 \mathrm{E}-21\end{array}$ & $\begin{array}{l}1.47 \mathrm{E}-21 \\
6.91 \mathrm{E}-22 \\
2.34 \mathrm{E}-21\end{array}$ & $\begin{array}{l}1.29 \mathrm{E}-21 \\
5.99 \mathrm{E}-22 \\
2.44 \mathrm{E}-21\end{array}$ & $\begin{array}{l}1.29 \mathrm{E}-21 \\
5.99 \mathrm{E}-22 \\
2.44 \mathrm{E}-21\end{array}$ & $\begin{array}{l}1.26 \mathrm{E}-21 \\
5.79 \mathrm{E}-22 \\
2.41 \mathrm{E}-21\end{array}$ \\
\hline${ }^{179} \mathrm{Ta}$ & $\begin{array}{l}\text { back } \\
\text { front } \\
\text { side }\end{array}$ & $\begin{array}{l}1.76 \mathrm{E}-14 \\
3.56 \mathrm{E}-17 \\
4.92 \mathrm{E}-16\end{array}$ & $\begin{array}{l}8.43 \mathrm{E}-15 \\
1.44 \mathrm{E}-17 \\
1.88 \mathrm{E}-16\end{array}$ & $\begin{array}{l}7.44 \mathrm{E}-15 \\
1.47 \mathrm{E}-17 \\
2.03 \mathrm{E}-16\end{array}$ & $\begin{array}{l}7.09 \mathrm{E}-15 \\
1.43 \mathrm{E}-17 \\
1.99 \mathrm{E}-16\end{array}$ & $\begin{array}{l}7.16 \mathrm{E}-15 \\
1.44 \mathrm{E}-17 \\
2.01 \mathrm{E}-16\end{array}$ \\
\hline${ }^{180} \mathrm{Ta}$ & $\begin{array}{l}\text { back } \\
\text { front } \\
\text { side }\end{array}$ & $\begin{array}{l}5.60 \mathrm{E}-19 \\
9.01 \mathrm{E}-20 \\
3.64 \mathrm{E}-19\end{array}$ & $\begin{array}{l}6.61 \mathrm{E}-19 \\
7.18 \mathrm{E}-20 \\
3.37 \mathrm{E}-19\end{array}$ & $\begin{array}{l}1.54 \mathrm{E}-18 \\
1.75 \mathrm{E}-19 \\
8.26 \mathrm{E}-19\end{array}$ & $\begin{array}{l}5.60 \mathrm{E}-19 \\
9.01 \mathrm{E}-20 \\
3.64 \mathrm{E}-19\end{array}$ & $\begin{array}{l}6.59 \mathrm{E}-19 \\
6.80 \mathrm{E}-20 \\
3.27 \mathrm{E}-19\end{array}$ \\
\hline${ }^{182} \mathrm{Ta}$ & $\begin{array}{l}\text { back } \\
\text { front } \\
\text { side }\end{array}$ & $\begin{array}{l}1.20 \mathrm{E}-11 \\
9.12 \mathrm{E}-14 \\
7.22 \mathrm{E}-13\end{array}$ & $\begin{array}{l}9.51 \mathrm{E}-12 \\
7.27 \mathrm{E}-14 \\
5.76 \mathrm{E}-13\end{array}$ & $\begin{array}{l}\text { 1.07E-11 } \\
8.12 \mathrm{E}-14 \\
6.39 \mathrm{E}-13\end{array}$ & $\begin{array}{l}9.68 \mathrm{E}-12 \\
7.33 \mathrm{E}-14 \\
5.77 \mathrm{E}-13\end{array}$ & $\begin{array}{l}9.66 \mathrm{E}-12 \\
7.34 \mathrm{E}-14 \\
5.76 \mathrm{E}-13\end{array}$ \\
\hline${ }^{183} \mathrm{Ta}$ & $\begin{array}{l}\text { back } \\
\text { front } \\
\text { side }\end{array}$ & $\begin{array}{l}4.23 \mathrm{E}-14 \\
1.59 \mathrm{E}-16 \\
7.95 \mathrm{E}-16\end{array}$ & $\begin{array}{l}3.14 \mathrm{E}-14 \\
1.12 \mathrm{E}-16 \\
5.79 \mathrm{E}-16\end{array}$ & $\begin{array}{l}3.15 \mathrm{E}-14 \\
1.12 \mathrm{E}-16 \\
5.85 \mathrm{E}-16\end{array}$ & $\begin{array}{l}2.80 \mathrm{E}-14 \\
1.00 \mathrm{E}-16 \\
5.22 \mathrm{E}-16\end{array}$ & $\begin{array}{l}2.81 \mathrm{E}-14 \\
1.01 \mathrm{E}-16 \\
5.15 \mathrm{E}-16\end{array}$ \\
\hline${ }^{184} \mathrm{Ta}$ & $\begin{array}{l}\text { back } \\
\text { front } \\
\text { side }\end{array}$ & $\begin{array}{l}\text { 7.49E-12 } \\
3.89 \mathrm{E}-14 \\
3.67 \mathrm{E}-13\end{array}$ & $\begin{array}{l}\text { 7.49E-12 } \\
3.89 \mathrm{E}-14 \\
3.67 \mathrm{E}-13\end{array}$ & $\begin{array}{l}6.46 \mathrm{E}-12 \\
3.36 \mathrm{E}-14 \\
3.15 \mathrm{E}-13\end{array}$ & $\begin{array}{l}5.83 \mathrm{E}-12 \\
3.03 \mathrm{E}-14 \\
2.85 \mathrm{E}-13\end{array}$ & $\begin{array}{l}5.82 \mathrm{E}-12 \\
3.03 \mathrm{E}-14 \\
2.84 \mathrm{E}-13\end{array}$ \\
\hline${ }^{185} \mathrm{Ta}$ & $\begin{array}{l}\text { back } \\
\text { front } \\
\text { side }\end{array}$ & $\begin{array}{l}2.48 \mathrm{E}-13 \\
1.26 \mathrm{E}-15 \\
1.17 \mathrm{E}-14\end{array}$ & $\begin{array}{l}1.99 \mathrm{E}-13 \\
1.01 \mathrm{E}-15 \\
9.39 \mathrm{E}-15\end{array}$ & $\begin{array}{l}2.11 \mathrm{E}-13 \\
1.07 \mathrm{E}-15 \\
9.91 \mathrm{E}-15\end{array}$ & $\begin{array}{l}1.91 \mathrm{E}-13 \\
9.69 \mathrm{E}-16 \\
8.96 \mathrm{E}-15\end{array}$ & $\begin{array}{l}1.90 \mathrm{E}-13 \\
9.68 \mathrm{E}-16 \\
8.95 \mathrm{E}-15\end{array}$ \\
\hline${ }^{186} \mathrm{Ta}$ & $\begin{array}{l}\text { back } \\
\text { front } \\
\text { side }\end{array}$ & $\begin{array}{l}6.19 \mathrm{E}-12 \\
2.81 \mathrm{E}-14 \\
2.75 \mathrm{E}-13\end{array}$ & $\begin{array}{l}4.92 \mathrm{E}-12 \\
2.23 \mathrm{E}-14 \\
2.17 \mathrm{E}-13\end{array}$ & $\begin{array}{l}5.22 \mathrm{E}-12 \\
2.40 \mathrm{E}-14 \\
2.30 \mathrm{E}-13\end{array}$ & $\begin{array}{l}4.73 \mathrm{E}-12 \\
2.17 \mathrm{E}-14 \\
2.09 \mathrm{E}-13\end{array}$ & $\begin{array}{l}4.72 \mathrm{E}-12 \\
2.17 \mathrm{E}-14 \\
2.08 \mathrm{E}-13\end{array}$ \\
\hline${ }^{179 m} \mathrm{Hf}$ & $\begin{array}{l}\text { back } \\
\text { front } \\
\text { side }\end{array}$ & $\begin{array}{l}8.33 \mathrm{E}-13 \\
2.62 \mathrm{E}-15 \\
2.53 \mathrm{E}-14\end{array}$ & $\begin{array}{l}6.31 \mathrm{E}-13 \\
1.98 \mathrm{E}-15 \\
1.91 \mathrm{E}-14\end{array}$ & $\begin{array}{l}6.31 \mathrm{E}-13 \\
1.98 \mathrm{E}-15 \\
1.91 \mathrm{E}-14\end{array}$ & $\begin{array}{l}5.80 \mathrm{E}-13 \\
1.82 \mathrm{E}-15 \\
1.74 \mathrm{E}-14\end{array}$ & $\begin{array}{l}5.79 \mathrm{E}-13 \\
1.82 \mathrm{E}-15 \\
1.74 \mathrm{E}-14\end{array}$ \\
\hline${ }^{181} \mathrm{Hf}$ & $\begin{array}{l}\text { back } \\
\text { front } \\
\text { side }\end{array}$ & $\begin{array}{l}1.05 \mathrm{E}-12 \\
3.15 \mathrm{E}-15 \\
3.34 \mathrm{E}-14\end{array}$ & $\begin{array}{l}\text { 8.04E-13 } \\
2.42 \mathrm{E}-15 \\
2.55 \mathrm{E}-14\end{array}$ & $\begin{array}{l}\text { 8.04E-13 } \\
2.42 \mathrm{E}-15 \\
2.55 \mathrm{E}-14\end{array}$ & $\begin{array}{l}7.47 \mathrm{E}-13 \\
2.23 \mathrm{E}-15 \\
2.35 \mathrm{E}-14\end{array}$ & $\begin{array}{l}7.45 \mathrm{E}-13 \\
2.23 \mathrm{E}-15 \\
2.35 \mathrm{E}-14\end{array}$ \\
\hline${ }^{183} \mathrm{Hf}$ & $\begin{array}{l}\text { back } \\
\text { front } \\
\text { side }\end{array}$ & $\begin{array}{l}4.42 \mathrm{E}-12 \\
2.15 \mathrm{E}-14 \\
2.14 \mathrm{E}-13\end{array}$ & $\begin{array}{l}3.54 \mathrm{E}-12 \\
1.71 \mathrm{E}-14 \\
1.70 \mathrm{E}-13\end{array}$ & $\begin{array}{l}3.79 \mathrm{E}-12 \\
1.85 \mathrm{E}-14 \\
1.82 \mathrm{E}-13\end{array}$ & $\begin{array}{l}3.43 \mathrm{E}-12 \\
1.67 \mathrm{E}-14 \\
1.65 \mathrm{E}-13\end{array}$ & $\begin{array}{l}3.42 \mathrm{E}-12 \\
1.67 \mathrm{E}-14 \\
1.64 \mathrm{E}-13\end{array}$ \\
\hline
\end{tabular}

To calculate the dose rate at the end of 12,20 , and 100-minute irradiation for the 5 -cm thick tungsten filter and 10-cm thick lead collimator in the BNCEFNT assembly, one multiplies the activities of the activation products in Table 8 and Table 9 with the 
corresponding activity-to-dose rate coefficients in Table 10 and Table 11. For example, multiplying the activities with the coefficients in column 6 of Table 10 and Table 11, one can obtain the air kerma rates $(\mathrm{rad} / \mathrm{h})$ at the end of irradiation from all the activation products listed in the above tables, which are listed in Table 12.

Table 11: Calculated Dose rate by different conversion factors at $50 \mathrm{~cm}$ from back, front and side of the BNCEFNT assembly due to unit activity of the activation products in lead collimator.

\begin{tabular}{ccccccc}
\hline & & \multicolumn{3}{c}{ rem/hr per Bq (tissue) } & \multicolumn{2}{c}{ rad/hr per Bq (air) } \\
\hline & Dose & ANS6.1.1 & ANS6.1.1 & ICRP-21 & ICRP-74 & \\
& position & $(1977)$ & $(1991)$ & $(1971)$ & $(1996)$ & F6 tally \\
\hline${ }^{203} \mathrm{~Pb}$ & back & $4.94 \mathrm{E}-15$ & $8.87 \mathrm{E}-15$ & $5.57 \mathrm{E}-14$ & $5.02 \mathrm{E}-14$ & $5.03 \mathrm{E}-14$ \\
& front & $7.11 \mathrm{E}-15$ & $6.73 \mathrm{E}-15$ & $6.42 \mathrm{E}-14$ & $5.76 \mathrm{E}-14$ & $5.76 \mathrm{E}-14$ \\
& side & $6.17 \mathrm{E}-15$ & $7.76 \mathrm{E}-15$ & $7.31 \mathrm{E}-14$ & $6.62 \mathrm{E}-14$ & $6.61 \mathrm{E}-14$ \\
& back & $3.42 \mathrm{E}-12$ & $2.70 \mathrm{E}-12$ & $2.81 \mathrm{E}-12$ & $2.54 \mathrm{E}-12$ & $2.53 \mathrm{E}-12$ \\
${ }^{204 m} \mathrm{~Pb}$ & front & $4.12 \mathrm{E}-12$ & $3.31 \mathrm{E}-12$ & $3.47 \mathrm{E}-12$ & $3.13 \mathrm{E}-12$ & $3.13 \mathrm{E}-12$ \\
& side & $4.42 \mathrm{E}-12$ & $3.50 \mathrm{E}-12$ & $3.64 \mathrm{E}-12$ & $3.29 \mathrm{E}-12$ & $3.28 \mathrm{E}-12$ \\
& back & $7.84 \mathrm{E}-17$ & $6.05 \mathrm{E}-17$ & $1.39 \mathrm{E}-12$ & $5.62 \mathrm{E}-17$ & $5.61 \mathrm{E}-17$ \\
${ }^{206} \mathrm{TI}$ & front & $9.18 \mathrm{E}-17$ & $7.22 \mathrm{E}-17$ & $1.85 \mathrm{E}-12$ & $6.76 \mathrm{E}-17$ & $6.75 \mathrm{E}-17$ \\
& side & $1.00 \mathrm{E}-16$ & $7.73 \mathrm{E}-17$ & $1.84 \mathrm{E}-12$ & $7.21 \mathrm{E}-17$ & $7.19 \mathrm{E}-17$ \\
& back & $4.04 \mathrm{E}-15$ & $3.21 \mathrm{E}-15$ & $3.34 \mathrm{E}-15$ & $3.02 \mathrm{E}-15$ & $3.01 \mathrm{E}-15$ \\
${ }^{207} \mathrm{TI}$ & front & $4.76 \mathrm{E}-15$ & $3.84 \mathrm{E}-15$ & $4.03 \mathrm{E}-15$ & $3.64 \mathrm{E}-15$ & $3.64 \mathrm{E}-15$ \\
& side & $5.17 \mathrm{E}-15$ & $4.11 \mathrm{E}-15$ & $4.28 \mathrm{E}-15$ & $3.87 \mathrm{E}-15$ & $3.86 \mathrm{E}-15$ \\
& back & $7.92 \mathrm{E}-12$ & $6.53 \mathrm{E}-12$ & $7.10 \mathrm{E}-12$ & $6.40 \mathrm{E}-12$ & $6.28 \mathrm{E}-12$ \\
${ }^{208} \mathrm{TI}$ & front & $9.89 \mathrm{E}-12$ & $8.23 \mathrm{E}-12$ & $8.99 \mathrm{E}-12$ & $8.09 \mathrm{E}-12$ & $7.95 \mathrm{E}-12$ \\
& side & $1.01 \mathrm{E}-11$ & $8.35 \mathrm{E}-12$ & $9.07 \mathrm{E}-12$ & $8.17 \mathrm{E}-12$ & $8.03 \mathrm{E}-12$ \\
& back & $7.04 \mathrm{E}-14$ & $4.86 \mathrm{E}-14$ & $4.53 \mathrm{E}-14$ & $4.09 \mathrm{E}-14$ & $4.10 \mathrm{E}-14$ \\
${ }^{203} \mathrm{Hg}$ & front & $7.47 \mathrm{E}-14$ & $5.33 \mathrm{E}-14$ & $5.05 \mathrm{E}-14$ & $4.54 \mathrm{E}-14$ & $4.54 \mathrm{E}-14$ \\
& side & $8.74 \mathrm{E}-14$ & $6.01 \mathrm{E}-14$ & $5.59 \mathrm{E}-14$ & $5.05 \mathrm{E}-14$ & $5.05 \mathrm{E}-14$ \\
& back & $1.30 \mathrm{E}-15$ & $9.19 \mathrm{E}-16$ & $9.17 \mathrm{E}-16$ & $8.31 \mathrm{E}-16$ & $8.29 \mathrm{E}-16$ \\
${ }^{205} \mathrm{Hg}$ & front & $1.56 \mathrm{E}-15$ & $1.15 \mathrm{E}-15$ & $1.16 \mathrm{E}-15$ & $1.05 \mathrm{E}-15$ & $1.05 \mathrm{E}-15$ \\
& side & $1.80 \mathrm{E}-15$ & $1.24 \mathrm{E}-15$ & $1.24 \mathrm{E}-15$ & $1.12 \mathrm{E}-15$ & $1.12 \mathrm{E}-15$ \\
\hline
\end{tabular}

The major contributors to the air kerma rate in Table 12 are ${ }^{187} \mathrm{~W},{ }^{186} \mathrm{Ta}$, and ${ }^{208} \mathrm{Tl}$, which account for more than $95 \%$ of the calculated air kerma. From Table 12, one can see that the air kerma rate due to these known activation products is not significantly high. However, the dose rate due to activation of unknown impurities in graphite, lead and tungsten may predominate. One should measure the actual dose rate in the treatment room using a dosimeter for radiation protection purpose. 
Table 12: Total photon air kerma $\mathrm{rate}(\operatorname{Rad} / \mathrm{h})$ due to activation products in the tungsten filter and lead collimator at the end of 12, 20, and 100-minute irradiation

\begin{tabular}{cccc}
\hline Dose & \multicolumn{3}{c}{ Air Kerma $(\mathrm{rad} / \mathrm{h})$ at the end of irradiation } \\
\cline { 2 - 4 } position & $12-\mathrm{min}$ & $20-\mathrm{min}$ & $100-\mathrm{min}$ \\
\hline back & $9.56 \mathrm{E}-05$ & $1.28 \mathrm{E}-04$ & $3.55 \mathrm{E}-04$ \\
front & $5.38 \mathrm{E}-05$ & $5.83 \mathrm{E}-05$ & $6.87 \mathrm{E}-05$ \\
side & $5.70 \mathrm{E}-05$ & $6.30 \mathrm{E}-05$ & $8.44 \mathrm{E}-05$ \\
\hline
\end{tabular}




\section{CHAPTER 8}

\section{CONCLUSIONS AND FUTURE WORK}

\subsection{Conclusions}

A reflective boron neutron capture enhanced fast neutron therapy (BNCEFNT) assembly has been designed for the Fermilab Neutron Therapy Facility. This assembly consists of a tungsten collimator of $20-\mathrm{cm}$ outer diameter, $5.64-\mathrm{cm}$ inner diameter and $10-\mathrm{cm}$ thickness, a tungsten filter of $20 \times 20 \mathrm{~cm}^{2}$ area and various thicknesses, and a $10-\mathrm{cm}$ thick graphite reflector around the patient's head. It is designed for a $20 \times 20 \mathrm{~cm}^{2}$ standard treatment beam. The MCNP5 calculated boron dose enhancement of the assembly at 5.7$\mathrm{cm}$ depth in a water-filled head phantom was $21.9 \%$ and $29.8 \%$ per $100-\mathrm{ppm}{ }^{10} \mathrm{~B}$ for 5.0 $\mathrm{cm}$ and $8.5-\mathrm{cm}$ thick tungsten filter, respectively. The corresponding dose rate for the 5.0$\mathrm{cm}$ and $8.5-\mathrm{cm}$ thick filters were 0.22 and $0.13 \mathrm{~Gy} / \mathrm{min}$, respectively..

The design was validated with a simplified BNCEFNT assembly that was built using four lead bricks to form a $5 \times 5 \mathrm{~cm}^{2}$ collimator, five $1.0-\mathrm{cm}$ thick $20 \times 20 \mathrm{~cm}^{2}$ tungsten plates as filter and graphite bricks and blocks as reflector. Measurements of the dose enhancement of the simplified assembly in a water-filled head phantom were performed using a pair of tissue equivalent ion chambers. One of the ion chambers is

loaded with 1000-ppm natural boron $\left(184-\mathrm{ppm}{ }^{10} \mathrm{~B}\right)$ to measure dose due to boron neutron capture. The measured dose enhancement at $5.0-\mathrm{cm}$ depth in the head phantom for the 5.0-cm thick tungsten filter is $(16.6 \pm 1.8) \%$, which agrees with the MCNP simulation of the simplified BNCEFNT assembly, 16.4\%. The dose rate measured using the non-borated ion chamber is $(0.765 \pm 0.075) \mathrm{Gy} / \mathrm{MU}$, about $61 \%$ of the total dose rate 
for the standard $10 \times 10 \mathrm{~cm}^{2}$ treatment beam (1.255 Gy/MU at 5.0-cm depth), which also agrees with the MCNP5 simulation, $0.701 \mathrm{~Gy} / \mathrm{MU}$, within uncertainty.

The measurements of the boron dose enhancement and total dose rate using the pair of TE ion chamber have shown that the MCNP5 code is a viable tool to design the BNCEFNT assembly. The excellent agreement between the measurements and the simulation indicates that the Fermilab NTF neutron spectral fluence rate determined by foil activation is reasonably accurate. The results also demonstrated that the calibration factors for the TE ion chambers are accurate.

The increased doses to other organs due to the use of the BNCEFNT assembly were calculated using MCNP5 and a MIRD phantom. There is a significant increase of dose to other organs using the BNCEFNT assembly compared to the standard beam treatment. The impact of these dose increases in other organs need to be evaluated.

\subsection{Future Work}

A BNCEFNT assembly more closely resembling the optimized design should be built and experiments to measure the boron dose enhancement and total dose-depth distribution in a head phantom should be performed. Skin dose measurements should also be evaluated. The photon dose contribution to the total dose in the head phantom with the BNCEFNT assembly should be measured.

The relative biological effectiveness (RBE) of the neutron beam with the use of the BNCEFNT assembly should be evaluated. The use of the BNCEFNT assembly changes the energy spectrum of the standard therapy beam and also changes the dose profile in the head. An evaluation of the effects of the altered neutron beam to brain tissue should be performed. 
The neutron capture cross section of gadolinium- 157 is $2.25 \times 10^{5}$ barns, about 60 times larger than that of ${ }^{10} \mathrm{~B}$. Investigation of the gadolinium capture dose enhancement using the designed assembly is of interest in finding a therapeutic window of fast neutron therapy for GBM patients. 


\section{APPENDIX A}

TABLES OF NTF NEUTRON SPECTRUM AND RESPONSE MATRICES 
Table 13: Measured and MCNPX calculated NTF neutron spectrum at isocenter

\begin{tabular}{|c|c|c|c|}
\hline \multirow[b]{2}{*}{$\mathrm{E}(\mathrm{MeV})$} & \multicolumn{2}{|c|}{ Unfolded starting with } & \multirow{2}{*}{$\begin{array}{c}\text { MCNPX } \\
\text { Calculated }\end{array}$} \\
\hline & Cupps et al & MCNPX-Calculated & \\
\hline \multicolumn{4}{|l|}{$1.00 \mathrm{E}-10$} \\
\hline 4.14E-07 & $4.50 \mathrm{E}+06$ & $1.11 \mathrm{E}+05$ & $8.58 \mathrm{E}+04$ \\
\hline 1.12E-06 & $3.86 \mathrm{E}+05$ & $9.64 \mathrm{E}+03$ & $7.22 \mathrm{E}+03$ \\
\hline $2.38 \mathrm{E}-06$ & $3.32 E+05$ & $5.74 \mathrm{E}+03$ & $4.26 \mathrm{E}+03$ \\
\hline 5.04E-06 & $3.45 E+05$ & $5.21 \mathrm{E}+03$ & $3.84 \mathrm{E}+03$ \\
\hline 1.07E-05 & $3.41 \mathrm{E}+05$ & $4.32 \mathrm{E}+03$ & $3.14 \mathrm{E}+03$ \\
\hline $2.26 \mathrm{E}-05$ & $3.22 \mathrm{E}+05$ & $3.53 \mathrm{E}+03$ & $2.56 \mathrm{E}+03$ \\
\hline 1.01E-04 & $5.91 E+05$ & $1.09 \mathrm{E}+04$ & $7.76 \mathrm{E}+03$ \\
\hline 4.54E-04 & $5.58 \mathrm{E}+05$ & $9.21 \mathrm{E}+03$ & $6.55 E+03$ \\
\hline $1.58 \mathrm{E}-03$ & $4.99 \mathrm{E}+05$ & $1.59 \mathrm{E}+04$ & $1.12 \mathrm{E}+04$ \\
\hline 3.35E-03 & $3.51 E+05$ & $1.00 \mathrm{E}+04$ & $7.04 \mathrm{E}+03$ \\
\hline 7.10E-03 & $4.21 \mathrm{E}+05$ & $2.92 \mathrm{E}+04$ & $2.04 \mathrm{E}+04$ \\
\hline $1.50 \mathrm{E}-02$ & $5.36 \mathrm{E}+05$ & $4.27 \mathrm{E}+04$ & $2.99 \mathrm{E}+04$ \\
\hline 3.18E-02 & $7.48 E+05$ & $1.30 \mathrm{E}+05$ & $8.98 \mathrm{E}+04$ \\
\hline 8.65E-02 & $1.73 \mathrm{E}+06$ & $3.12 \mathrm{E}+05$ & $2.13 \mathrm{E}+05$ \\
\hline 1.50E-01 & $1.89 \mathrm{E}+06$ & $5.69 \mathrm{E}+05$ & $3.83 \mathrm{E}+05$ \\
\hline 2.24E-01 & $1.80 \mathrm{E}+06$ & $7.25 \mathrm{E}+05$ & $4.82 \mathrm{E}+05$ \\
\hline 3.34E-01 & $3.63 E+06$ & $7.26 \mathrm{E}+05$ & $4.81 \mathrm{E}+05$ \\
\hline 4.98E-01 & $4.16 \mathrm{E}+06$ & $1.22 \mathrm{E}+06$ & $8.08 \mathrm{E}+05$ \\
\hline 7.43E-01 & $5.74 \mathrm{E}+06$ & $1.86 \mathrm{E}+06$ & $1.22 \mathrm{E}+06$ \\
\hline 9.06E-01 & $2.85 E+06$ & $1.34 \mathrm{E}+06$ & $8.83 E+05$ \\
\hline $1.11 \mathrm{E}+00$ & $1.32 E+06$ & $1.98 \mathrm{E}+06$ & $1.33 \mathrm{E}+06$ \\
\hline $1.35 \mathrm{E}+00$ & $1.26 \mathrm{E}+06$ & $1.94 \mathrm{E}+06$ & $1.30 \mathrm{E}+06$ \\
\hline $1.65 \mathrm{E}+00$ & $1.29 \mathrm{E}+06$ & $2.38 \mathrm{E}+06$ & $1.62 \mathrm{E}+06$ \\
\hline $2.02 \mathrm{E}+00$ & $1.14 \mathrm{E}+06$ & $2.45 E+06$ & $1.67 \mathrm{E}+06$ \\
\hline $2.46 \mathrm{E}+00$ & $8.45 E+05$ & $2.40 \mathrm{E}+06$ & $1.67 \mathrm{E}+06$ \\
\hline $3.01 E+00$ & $8.66 \mathrm{E}+05$ & $2.80 E+06$ & $1.97 \mathrm{E}+06$ \\
\hline $3.68 \mathrm{E}+00$ & $8.63 E+05$ & $3.23 E+06$ & $2.36 \mathrm{E}+06$ \\
\hline $4.49 \mathrm{E}+00$ & $1.31 \mathrm{E}+06$ & $3.24 \mathrm{E}+06$ & $2.37 \mathrm{E}+06$ \\
\hline $5.49 \mathrm{E}+00$ & $1.32 \mathrm{E}+06$ & $3.20 \mathrm{E}+06$ & $2.43 E+06$ \\
\hline $6.70 \mathrm{E}+00$ & $1.31 \mathrm{E}+06$ & $3.79 \mathrm{E}+06$ & $3.01 \mathrm{E}+06$ \\
\hline $8.19 \mathrm{E}+00$ & $2.65 E+06$ & $3.95 E+06$ & $3.23 E+06$ \\
\hline $1.00 \mathrm{E}+01$ & $3.96 \mathrm{E}+06$ & $3.88 \mathrm{E}+06$ & $3.31 E+06$ \\
\hline $1.22 \mathrm{E}+01$ & $3.94 \mathrm{E}+06$ & $3.52 \mathrm{E}+06$ & $3.04 \mathrm{E}+06$ \\
\hline $1.35 \mathrm{E}+01$ & $2.01 \mathrm{E}+06$ & $2.05 E+06$ & $1.76 \mathrm{E}+06$ \\
\hline $1.49 \mathrm{E}+01$ & $1.96 \mathrm{E}+06$ & $2.50 \mathrm{E}+06$ & $2.10 \mathrm{E}+06$ \\
\hline $1.75 \mathrm{E}+01$ & $6.22 \mathrm{E}+06$ & $5.24 \mathrm{E}+06$ & $4.28 \mathrm{E}+06$ \\
\hline $1.96 \mathrm{E}+01$ & $4.40 \mathrm{E}+06$ & $4.71 E+06$ & $3.75 E+06$ \\
\hline $2.25 \mathrm{E}+01$ & $5.36 \mathrm{E}+06$ & $5.67 \mathrm{E}+06$ & $4.51 \mathrm{E}+06$ \\
\hline $2.50 \mathrm{E}+01$ & $4.09 \mathrm{E}+06$ & $4.32 \mathrm{E}+06$ & $3.46 \mathrm{E}+06$ \\
\hline $2.75 \mathrm{E}+01$ & $4.19 \mathrm{E}+06$ & $4.21 \mathrm{E}+06$ & $3.38 \mathrm{E}+06$ \\
\hline $3.00 \mathrm{E}+01$ & $4.05 E+06$ & $3.99 \mathrm{E}+06$ & $3.21 \mathrm{E}+06$ \\
\hline $3.50 \mathrm{E}+01$ & 7.17E+06 & $8.10 \mathrm{E}+06$ & $6.51 \mathrm{E}+06$ \\
\hline $4.00 \mathrm{E}+01$ & $6.21 \mathrm{E}+06$ & $7.83 \mathrm{E}+06$ & $6.31 E+06$ \\
\hline $4.50 \mathrm{E}+01$ & $5.33 E+06$ & $6.73 E+06$ & $5.43 E+06$ \\
\hline $5.00 \mathrm{E}+01$ & $2.89 \mathrm{E}+06$ & $6.13 \mathrm{E}+06$ & $4.94 \mathrm{E}+06$ \\
\hline $5.50 \mathrm{E}+01$ & $2.61 \mathrm{E}+06$ & $6.19 \mathrm{E}+06$ & $5.00 \mathrm{E}+06$ \\
\hline $6.00 \mathrm{E}+01$ & $2.39 E+06$ & $5.73 \mathrm{E}+06$ & $4.63 \mathrm{E}+06$ \\
\hline $6.50 \mathrm{E}+01$ & $2.20 \mathrm{E}+06$ & $2.15 E+06$ & $1.74 \mathrm{E}+06$ \\
\hline $6.60 \mathrm{E}+01$ & $4.19 \mathrm{E}+05$ & $3.12 \mathrm{E}+04$ & $8.16 \mathrm{E}+04$ \\
\hline Total & $1.15 \mathrm{E}+08$ & $1.22 \mathrm{E}+08$ & $9.52 \mathrm{E}+07$ \\
\hline
\end{tabular}


Table 14: Al-28 response matrix ( $\mathrm{Bq} / \mathrm{g}$ per $\left.\mathrm{n} / \mathrm{cm}^{2}\right)$

\begin{tabular}{|c|c|c|c|c|c|c|}
\hline \multicolumn{7}{|c|}{ Moderator thickness } \\
\hline $\mathrm{E}(\mathrm{MeV})$ & $4.8 \mathrm{~cm}$ & $7.2 \mathrm{~cm}$ & $9.0 \mathrm{~cm}$ & $10.8 \mathrm{~cm}$ & $13.1 \mathrm{~cm}$ & $14.5 \mathrm{~cm}$ \\
\hline $1.00 \mathrm{E}-10$ & & & & & & \\
\hline 4.14E-07 & 7.03E-07 & $4.20 \mathrm{E}-07$ & $2.53 \mathrm{E}-07$ & 1.58E-07 & 1.09E-07 & $6.14 \mathrm{E}-08$ \\
\hline $1.12 \mathrm{E}-06$ & 1.02E-06 & $5.74 \mathrm{E}-07$ & 4.08E-07 & 2.42E-07 & $1.46 \mathrm{E}-07$ & 1.03E-07 \\
\hline $2.38 \mathrm{E}-06$ & $1.09 \mathrm{E}-06$ & 6.97E-07 & 4.36E-07 & 2.83E-07 & $1.54 \mathrm{E}-07$ & 1.11E-07 \\
\hline $5.04 \mathrm{E}-06$ & $1.12 \mathrm{E}-06$ & 7.04E-07 & 4.59E-07 & 3.08E-07 & 1.88E-07 & $1.30 \mathrm{E}-07$ \\
\hline $1.07 \mathrm{E}-05$ & $1.18 \mathrm{E}-06$ & 7.28E-07 & 5.16E-07 & 3.49E-07 & 2.03E-07 & $1.52 \mathrm{E}-07$ \\
\hline $2.26 \mathrm{E}-05$ & 1.13E-06 & 8.04E-07 & 5.36E-07 & 3.68E-07 & 2.28E-07 & 1.48E-07 \\
\hline $1.01 \mathrm{E}-04$ & 1.06E-06 & 8.45E-07 & 6.64E-07 & 3.88E-07 & 2.46E-07 & 1.64E-07 \\
\hline 4.54E-04 & $9.28 \mathrm{E}-07$ & 7.96E-07 & $6.15 \mathrm{E}-07$ & 3.93E-07 & 2.89E-07 & $1.86 \mathrm{E}-07$ \\
\hline $1.58 \mathrm{E}-03$ & 8.88E-07 & 8.35E-07 & 6.31E-07 & 4.47E-07 & 2.68E-07 & 1.93E-07 \\
\hline $3.35 \mathrm{E}-03$ & 8.23E-07 & 8.19E-07 & $6.51 \mathrm{E}-07$ & 4.72E-07 & 2.91E-07 & $2.11 \mathrm{E}-07$ \\
\hline 7.10E-03 & 7.83E-07 & 8.05E-07 & $6.54 \mathrm{E}-07$ & 4.90E-07 & 3.06E-07 & 2.18E-07 \\
\hline $1.50 \mathrm{E}-02$ & 7.30E-07 & 7.87E-07 & $6.63 \mathrm{E}-07$ & 4.95E-07 & 3.16E-07 & 2.33E-07 \\
\hline $3.18 \mathrm{E}-02$ & $6.75 E-07$ & 8.04E-07 & 6.88E-07 & 5.30E-07 & 3.41E-07 & $2.59 \mathrm{E}-07$ \\
\hline $8.65 \mathrm{E}-02$ & 6.14E-07 & 7.91E-07 & 7.17E-07 & 5.82E-07 & 3.86E-07 & 2.97E-07 \\
\hline $1.50 \mathrm{E}-01$ & 5.40E-07 & 7.84E-07 & 7.56E-07 & $6.40 \mathrm{E}-07$ & 4.56E-07 & $3.65 \mathrm{E}-07$ \\
\hline $2.24 \mathrm{E}-01$ & 4.97E-07 & 7.77E-07 & 7.84E-07 & 7.03E-07 & 5.19E-07 & 4.10E-07 \\
\hline $3.34 \mathrm{E}-01$ & 4.37E-07 & $7.26 \mathrm{E}-07$ & 7.97E-07 & 7.16E-07 & 5.86E-07 & 4.83E-07 \\
\hline $4.98 \mathrm{E}-01$ & 3.77E-07 & 6.81E-07 & 7.33E-07 & $7.20 \mathrm{E}-07$ & $6.20 \mathrm{E}-07$ & 5.30E-07 \\
\hline $7.43 \mathrm{E}-01$ & 3.17E-07 & 6.18E-07 & $7.55 \mathrm{E}-07$ & 8.00E-07 & 7.38E-07 & $6.95 \mathrm{E}-07$ \\
\hline $9.06 \mathrm{E}-01$ & 2.73E-07 & 5.61E-07 & 7.15E-07 & 7.80E-07 & 7.75E-07 & $7.55 \mathrm{E}-07$ \\
\hline $1.11 \mathrm{E}+00$ & 2.34E-07 & 5.20E-07 & $6.28 \mathrm{E}-07$ & 7.43E-07 & 7.17E-07 & $7.12 \mathrm{E}-07$ \\
\hline $1.35 \mathrm{E}+00$ & 2.03E-07 & 4.47E-07 & 6.35E-07 & 7.27E-07 & 8.41E-07 & $8.25 \mathrm{E}-07$ \\
\hline $1.65 \mathrm{E}+00$ & $1.88 \mathrm{E}-07$ & 4.23E-07 & 5.69E-07 & 7.01E-07 & 7.87E-07 & 8.51E-07 \\
\hline $2.02 \mathrm{E}+00$ & $1.60 \mathrm{E}-07$ & $3.72 \mathrm{E}-07$ & $5.24 \mathrm{E}-07$ & $6.52 \mathrm{E}-07$ & 7.82E-07 & 8.37E-07 \\
\hline $2.46 \mathrm{E}+00$ & $1.37 \mathrm{E}-07$ & 3.12E-07 & 4.75E-07 & 6.07E-07 & $7.48 \mathrm{E}-07$ & 8.60E-07 \\
\hline $3.01 \mathrm{E}+00$ & $1.08 \mathrm{E}-07$ & 2.88E-07 & 4.02E-07 & 5.79E-07 & 6.84E-07 & $7.75 \mathrm{E}-07$ \\
\hline $3.68 \mathrm{E}+00$ & 8.76E-08 & 2.30E-07 & 3.29E-07 & $4.28 \mathrm{E}-07$ & $5.66 \mathrm{E}-07$ & $6.30 \mathrm{E}-07$ \\
\hline $4.49 \mathrm{E}+00$ & 8.92E-08 & 2.02E-07 & 3.19E-07 & 4.36E-07 & $5.40 \mathrm{E}-07$ & $6.63 E-07$ \\
\hline $5.49 \mathrm{E}+00$ & 7.58E-08 & $1.72 \mathrm{E}-07$ & 2.80E-07 & 4.03E-07 & 4.89E-07 & 6.07E-07 \\
\hline $6.70 \mathrm{E}+00$ & 6.51E-08 & 1.52E-07 & 2.19E-07 & 3.15E-07 & 4.48E-07 & $5.48 \mathrm{E}-07$ \\
\hline $8.19 \mathrm{E}+00$ & $6.12 \mathrm{E}-08$ & $1.26 \mathrm{E}-07$ & 1.96E-07 & 2.72E-07 & 3.82E-07 & 4.77E-07 \\
\hline $1.00 \mathrm{E}+01$ & 5.77E-08 & 1.06E-07 & $1.67 \mathrm{E}-07$ & $2.20 \mathrm{E}-07$ & $3.21 \mathrm{E}-07$ & 4.20E-07 \\
\hline $1.22 \mathrm{E}+01$ & 5.97E-08 & 9.95E-08 & $1.49 \mathrm{E}-07$ & 2.01E-07 & 2.92E-07 & $3.42 \mathrm{E}-07$ \\
\hline $1.35 \mathrm{E}+01$ & 6.39E-08 & 9.69E-08 & 1.36E-07 & $1.90 \mathrm{E}-07$ & $2.56 \mathrm{E}-07$ & $3.22 \mathrm{E}-07$ \\
\hline $1.49 \mathrm{E}+01$ & 6.90E-08 & 9.74E-08 & 1.30E-07 & $1.90 \mathrm{E}-07$ & $2.18 \mathrm{E}-07$ & $2.99 \mathrm{E}-07$ \\
\hline $1.75 \mathrm{E}+01$ & 7.19E-08 & 1.04E-07 & $1.44 \mathrm{E}-07$ & 1.60E-07 & $2.57 \mathrm{E}-07$ & $2.85 \mathrm{E}-07$ \\
\hline $1.96 \mathrm{E}+01$ & $6.85 E-08$ & 9.43E-08 & 1.36E-07 & 1.61E-07 & 2.32E-07 & $2.94 \mathrm{E}-07$ \\
\hline $2.25 \mathrm{E}+01$ & 2.36E-08 & 5.06E-08 & 8.87E-08 & 1.25E-07 & $1.84 \mathrm{E}-07$ & $2.50 \mathrm{E}-07$ \\
\hline $2.50 \mathrm{E}+01$ & 1.32E-08 & 4.23E-08 & 6.99E-08 & 1.05E-07 & 1.66E-07 & $2.09 \mathrm{E}-07$ \\
\hline $2.75 \mathrm{E}+01$ & 1.26E-08 & 3.47E-08 & 6.17E-08 & 9.39E-08 & 1.47E-07 & $1.94 \mathrm{E}-07$ \\
\hline $3.00 \mathrm{E}+01$ & 1.10E-08 & 3.17E-08 & 4.95E-08 & 8.79E-08 & 1.45E-07 & 1.78E-07 \\
\hline $3.50 \mathrm{E}+01$ & 1.01E-08 & 2.88E-08 & 5.10E-08 & 7.61E-08 & $1.21 \mathrm{E}-07$ & $1.65 \mathrm{E}-07$ \\
\hline $4.00 \mathrm{E}+01$ & 9.27E-09 & 2.49E-08 & 4.39E-08 & $6.52 \mathrm{E}-08$ & $1.08 \mathrm{E}-07$ & $1.44 \mathrm{E}-07$ \\
\hline $4.50 \mathrm{E}+01$ & 8.75E-09 & 2.61E-08 & 3.78E-08 & 6.26E-08 & $9.75 E-08$ & $1.40 \mathrm{E}-07$ \\
\hline $5.00 \mathrm{E}+01$ & 7.83E-09 & 2.22E-08 & 3.76E-08 & 6.07E-08 & 9.50E-08 & $1.30 \mathrm{E}-07$ \\
\hline $5.50 \mathrm{E}+01$ & 7.47E-09 & 1.94E-08 & 3.79E-08 & 5.47E-08 & $9.85 E-08$ & $1.23 \mathrm{E}-07$ \\
\hline $6.00 \mathrm{E}+01$ & 6.82E-09 & $1.94 \mathrm{E}-08$ & 3.43E-08 & 5.49E-08 & 8.74E-08 & 1.17E-07 \\
\hline $6.50 \mathrm{E}+01$ & 6.65E-09 & 2.00E-08 & $3.42 \mathrm{E}-08$ & 5.23E-08 & 8.18E-08 & $1.11 \mathrm{E}-07$ \\
\hline $6.60 \mathrm{E}+01$ & 7.01E-09 & $1.90 \mathrm{E}-08$ & 3.13E-08 & 5.16E-08 & 8.30E-08 & $1.06 \mathrm{E}-07$ \\
\hline
\end{tabular}


Table 15: Mg-27 response matrix (Bq/g per $\left.\mathbf{n} / \mathrm{cm}^{2}\right)$

\begin{tabular}{|c|c|c|c|c|c|c|}
\hline \multicolumn{7}{|c|}{ Moderator thickness } \\
\hline $\mathrm{E}(\mathrm{MeV})$ & $4.8 \mathrm{~cm}$ & $7.2 \mathrm{~cm}$ & $9.0 \mathrm{~cm}$ & $10.8 \mathrm{~cm}$ & $13.1 \mathrm{~cm}$ & $14.5 \mathrm{~cm}$ \\
\hline $1.00 \mathrm{E}-10$ & - & - & - & - & - & - \\
\hline $4.14 \mathrm{E}-07$ & - & - & - & - & - & - \\
\hline $1.12 \mathrm{E}-06$ & - & - & - & - & - & - \\
\hline $2.38 \mathrm{E}-06$ & - & - & - & - & - & - \\
\hline $5.04 \mathrm{E}-06$ & - & - & - & - & - & - \\
\hline $1.07 \mathrm{E}-05$ & - & - & - & - & - & - \\
\hline $2.26 \mathrm{E}-05$ & - & - & - & - & - & - \\
\hline $1.01 \mathrm{E}-04$ & - & - & - & - & - & - \\
\hline 4.54E-04 & - & - & - & - & - & - \\
\hline $1.58 \mathrm{E}-03$ & - & - & - & - & - & - \\
\hline $3.35 \mathrm{E}-03$ & - & - & - & - & - & - \\
\hline $7.10 \mathrm{E}-03$ & - & - & - & - & - & - \\
\hline $1.50 \mathrm{E}-02$ & - & - & - & - & - & - \\
\hline $3.18 \mathrm{E}-02$ & - & - & - & - & - & - \\
\hline $8.65 \mathrm{E}-02$ & - & - & - & - & - & - \\
\hline $1.50 \mathrm{E}-01$ & - & - & - & - & - & - \\
\hline $2.24 \mathrm{E}-01$ & - & - & - & - & - & - \\
\hline $3.34 \mathrm{E}-01$ & - & - & - & - & - & - \\
\hline 4.98E-01 & - & - & - & - & - & - \\
\hline 7.43E-01 & - & - & - & - & - & - \\
\hline $9.06 \mathrm{E}-01$ & - & - & - & - & - & - \\
\hline $1.11 \mathrm{E}+00$ & - & - & - & - & - & - \\
\hline $1.35 \mathrm{E}+00$ & - & - & - & - & - & - \\
\hline $1.65 \mathrm{E}+00$ & - & - & - & - & - & - \\
\hline $2.02 \mathrm{E}+00$ & $1.43 \mathrm{E}-13$ & 7.95E-14 & 5.13E-14 & 3.37E-14 & 1.92E-14 & $1.35 \mathrm{E}-14$ \\
\hline $2.46 \mathrm{E}+00$ & 3.95E-11 & $2.40 \mathrm{E}-11$ & 1.66E-11 & 1.16E-11 & 7.24E-12 & 5.49E-12 \\
\hline $3.01 \mathrm{E}+00$ & 3.77E-09 & 2.29E-09 & 1.57E-09 & 1.10E-09 & 6.92E-10 & $5.20 \mathrm{E}-10$ \\
\hline $3.68 \mathrm{E}+00$ & 4.67E-08 & 2.80E-08 & 1.95E-08 & 1.39E-08 & 8.93E-09 & 6.75E-09 \\
\hline $4.49 \mathrm{E}+00$ & 1.01E-07 & $6.72 \mathrm{E}-08$ & 5.05E-08 & 3.84E-08 & 2.70E-08 & 2.19E-08 \\
\hline $5.49 \mathrm{E}+00$ & $3.40 \mathrm{E}-07$ & 2.50E-07 & $2.00 \mathrm{E}-07$ & $1.61 \mathrm{E}-07$ & 1.23E-07 & $1.04 \mathrm{E}-07$ \\
\hline $6.70 \mathrm{E}+00$ & 7.58E-07 & 5.81E-07 & 4.76E-07 & 3.96E-07 & 3.11E-07 & 2.71E-07 \\
\hline $8.19 \mathrm{E}+00$ & 1.03E-06 & 7.98E-07 & 6.68E-07 & 5.67E-07 & 4.60E-07 & 4.05E-07 \\
\hline $1.00 \mathrm{E}+01$ & 1.42E-06 & 1.14E-06 & $9.75 \mathrm{E}-07$ & 8.54E-07 & 7.12E-07 & 6.35E-07 \\
\hline $1.22 \mathrm{E}+01$ & $1.54 \mathrm{E}-06$ & $1.26 \mathrm{E}-06$ & 1.10E-06 & $9.76 \mathrm{E}-07$ & 8.42E-07 & 7.61E-07 \\
\hline $1.35 \mathrm{E}+01$ & 1.52E-06 & $1.25 \mathrm{E}-06$ & 1.10E-06 & 9.82E-07 & 8.74E-07 & 8.09E-07 \\
\hline $1.49 \mathrm{E}+01$ & 1.37E-06 & 1.15E-06 & 1.03E-06 & 9.32E-07 & 8.41E-07 & 7.90E-07 \\
\hline $1.75 \mathrm{E}+01$ & $1.08 \mathrm{E}-06$ & $9.21 \mathrm{E}-07$ & 8.35E-07 & 7.67E-07 & 7.06E-07 & 6.83E-07 \\
\hline $1.96 \mathrm{E}+01$ & 7.60E-07 & $6.62 \mathrm{E}-07$ & 6.05E-07 & 5.75E-07 & 5.46E-07 & 5.32E-07 \\
\hline $2.25 \mathrm{E}+01$ & 1.46E-07 & 1.49E-07 & $1.60 \mathrm{E}-07$ & 1.76E-07 & 2.09E-07 & 2.27E-07 \\
\hline $2.50 \mathrm{E}+01$ & 5.31E-08 & $6.39 E-08$ & 7.64E-08 & 9.53E-08 & 1.32E-07 & $1.55 \mathrm{E}-07$ \\
\hline $2.75 \mathrm{E}+01$ & 4.88E-08 & 5.64E-08 & 6.68E-08 & 8.36E-08 & 1.19E-07 & $1.39 \mathrm{E}-07$ \\
\hline $3.00 \mathrm{E}+01$ & 4.72E-08 & 5.29E-08 & $6.15 \mathrm{E}-08$ & 7.55E-08 & 1.07E-07 & $1.29 \mathrm{E}-07$ \\
\hline $3.50 \mathrm{E}+01$ & 4.16E-08 & 4.73E-08 & 5.41E-08 & $6.59 \mathrm{E}-08$ & $9.48 \mathrm{E}-08$ & 1.15E-07 \\
\hline $4.00 \mathrm{E}+01$ & 3.61E-08 & 4.08E-08 & 4.67E-08 & 5.56E-08 & 8.00E-08 & 9.83E-08 \\
\hline $4.50 \mathrm{E}+01$ & 3.23E-08 & 3.67E-08 & 4.16E-08 & 4.86E-08 & 6.85E-08 & 8.63E-08 \\
\hline $5.00 \mathrm{E}+01$ & $2.89 \mathrm{E}-08$ & 3.20E-08 & 3.72E-08 & 4.32E-08 & $6.00 \mathrm{E}-08$ & 7.37E-08 \\
\hline $5.50 \mathrm{E}+01$ & 2.64E-08 & 3.00E-08 & 3.38E-08 & 4.02E-08 & 5.55E-08 & $6.87 \mathrm{E}-08$ \\
\hline $6.00 \mathrm{E}+01$ & 2.57E-08 & 2.85E-08 & 3.17E-08 & 3.73E-08 & 5.08E-08 & $6.05 E-08$ \\
\hline $6.50 \mathrm{E}+01$ & $2.24 \mathrm{E}-08$ & 2.54E-08 & 2.87E-08 & 3.36E-08 & 4.61E-08 & 5.59E-08 \\
\hline $6.60 \mathrm{E}+01$ & 2.15E-08 & 2.39E-08 & 2.73E-08 & $3.24 \mathrm{E}-08$ & 4.29E-08 & 5.31E-08 \\
\hline
\end{tabular}


Table 16: Na-24 response matrix $\left(\mathrm{Bq} / \mathrm{g}\right.$ per $\left.\mathrm{n} / \mathrm{cm}^{2}\right)$

\begin{tabular}{|c|c|c|c|c|c|c|}
\hline \multicolumn{7}{|c|}{ Moderator thickness } \\
\hline $\mathrm{E}(\mathrm{MeV})$ & $4.8 \mathrm{~cm}$ & $7.2 \mathrm{~cm}$ & $9.0 \mathrm{~cm}$ & $10.8 \mathrm{~cm}$ & $13.1 \mathrm{~cm}$ & $14.5 \mathrm{~cm}$ \\
\hline $1.00 \mathrm{E}-10$ & - & - & - & - & - & - \\
\hline 4.14E-07 & - & - & - & - & - & - \\
\hline $1.12 \mathrm{E}-06$ & - & - & - & - & - & - \\
\hline $2.38 \mathrm{E}-06$ & - & - & - & - & - & - \\
\hline $5.04 \mathrm{E}-06$ & - & - & - & - & - & - \\
\hline $1.07 \mathrm{E}-05$ & - & - & - & - & - & - \\
\hline $2.26 \mathrm{E}-05$ & - & - & - & - & - & - \\
\hline $1.01 \mathrm{E}-04$ & - & - & - & - & - & - \\
\hline 4.54E-04 & - & - & - & - & - & - \\
\hline $1.58 \mathrm{E}-03$ & - & - & - & - & - & - \\
\hline $3.35 \mathrm{E}-03$ & - & - & - & - & - & - \\
\hline $7.10 \mathrm{E}-03$ & - & - & - & - & - & - \\
\hline $1.50 \mathrm{E}-02$ & - & - & - & - & - & - \\
\hline $3.18 \mathrm{E}-02$ & - & - & - & - & - & - \\
\hline $8.65 \mathrm{E}-02$ & - & - & - & - & - & - \\
\hline $1.50 \mathrm{E}-01$ & - & - & - & - & - & - \\
\hline $2.24 \mathrm{E}-01$ & - & - & - & - & - & - \\
\hline $3.34 \mathrm{E}-01$ & - & - & - & - & - & - \\
\hline $4.98 \mathrm{E}-01$ & - & - & - & - & - & - \\
\hline 7.43E-01 & - & - & - & - & - & - \\
\hline $9.06 \mathrm{E}-01$ & - & - & - & - & - & - \\
\hline $1.11 \mathrm{E}+00$ & - & - & - & - & - & - \\
\hline $1.35 \mathrm{E}+00$ & - & - & - & - & - & - \\
\hline $1.65 \mathrm{E}+00$ & - & - & - & - & - & - \\
\hline $2.02 \mathrm{E}+00$ & - & - & - & - & - & - \\
\hline $2.46 \mathrm{E}+00$ & - & - & - & - & - & - \\
\hline $3.01 \mathrm{E}+00$ & - & - & - & - & - & - \\
\hline $3.68 \mathrm{E}+00$ & $2.82 \mathrm{E}-28$ & $1.64 \mathrm{E}-28$ & 1.12E-28 & 7.66E-29 & 4.68E-29 & $3.45 E-29$ \\
\hline $4.49 \mathrm{E}+00$ & 4.67E-16 & 3.07E-16 & $2.27 \mathrm{E}-16$ & $1.68 \mathrm{E}-16$ & $1.07 \mathrm{E}-16$ & $8.44 \mathrm{E}-17$ \\
\hline $5.49 \mathrm{E}+00$ & 6.10E-12 & 4.43E-12 & 3.47E-12 & $2.74 \mathrm{E}-12$ & 2.02E-12 & 1.69E-12 \\
\hline $6.70 \mathrm{E}+00$ & 4.97E-10 & 3.75E-10 & 3.04E-10 & $2.49 \mathrm{E}-10$ & $1.90 \mathrm{E}-10$ & $1.63 \mathrm{E}-10$ \\
\hline $8.19 \mathrm{E}+00$ & 4.40E-09 & 3.32E-09 & 2.71E-09 & 2.24E-09 & 1.75E-09 & 1.50E-09 \\
\hline $1.00 \mathrm{E}+01$ & 1.26E-08 & 9.92E-09 & 8.39E-09 & 7.20E-09 & 5.85E-09 & 5.14E-09 \\
\hline $1.22 \mathrm{E}+01$ & 1.93E-08 & $1.56 \mathrm{E}-08$ & 1.33E-08 & 1.16E-08 & 9.74E-09 & 8.64E-09 \\
\hline $1.35 \mathrm{E}+01$ & 2.36E-08 & $1.92 \mathrm{E}-08$ & 1.67E-08 & $1.47 \mathrm{E}-08$ & 1.26E-08 & 1.15E-08 \\
\hline $1.49 \mathrm{E}+01$ & 2.34E-08 & 1.96E-08 & 1.72E-08 & $1.54 \mathrm{E}-08$ & $1.34 \mathrm{E}-08$ & $1.24 \mathrm{E}-08$ \\
\hline $1.75 \mathrm{E}+01$ & 1.85E-08 & 1.57E-08 & 1.41E-08 & 1.27E-08 & 1.14E-08 & $1.08 \mathrm{E}-08$ \\
\hline $1.96 \mathrm{E}+01$ & 1.19E-08 & $1.04 \mathrm{E}-08$ & 9.45E-09 & 8.90E-09 & 8.26E-09 & 7.93E-09 \\
\hline $2.25 \mathrm{E}+01$ & 1.95E-09 & 2.00E-09 & 2.14E-09 & 2.36E-09 & 2.70E-09 & 2.88E-09 \\
\hline $2.50 \mathrm{E}+01$ & $5.66 \mathrm{E}-10$ & 7.07E-10 & 8.78E-10 & 1.13E-09 & 1.56E-09 & 1.80E-09 \\
\hline $2.75 \mathrm{E}+01$ & 5.05E-10 & $6.00 \mathrm{E}-10$ & 7.36E-10 & $9.57 \mathrm{E}-10$ & 1.37E-09 & 1.59E-09 \\
\hline $3.00 \mathrm{E}+01$ & 4.83E-10 & $5.58 \mathrm{E}-10$ & 6.69E-10 & 8.49E-10 & 1.22E-09 & 1.46E-09 \\
\hline $3.50 \mathrm{E}+01$ & 4.37E-10 & 5.03E-10 & 5.84E-10 & $7.28 \mathrm{E}-10$ & 1.08E-09 & 1.30E-09 \\
\hline $4.00 \mathrm{E}+01$ & 3.79E-10 & 4.35E-10 & 5.03E-10 & 6.09E-10 & 8.98E-10 & 1.10E-09 \\
\hline $4.50 \mathrm{E}+01$ & $3.44 \mathrm{E}-10$ & 3.94E-10 & $4.51 \mathrm{E}-10$ & $5.34 \mathrm{E}-10$ & 7.70E-10 & $9.68 \mathrm{E}-10$ \\
\hline $5.00 \mathrm{E}+01$ & 3.08E-10 & $3.45 E-10$ & 4.07E-10 & 4.76E-10 & $6.72 \mathrm{E}-10$ & 8.26E-10 \\
\hline $5.50 \mathrm{E}+01$ & $2.78 \mathrm{E}-10$ & 3.19E-10 & 3.64E-10 & 4.35E-10 & $6.16 \mathrm{E}-10$ & 7.66E-10 \\
\hline $6.00 \mathrm{E}+01$ & $2.72 \mathrm{E}-10$ & 3.01E-10 & 3.40E-10 & 4.01E-10 & 5.51E-10 & $6.66 \mathrm{E}-10$ \\
\hline $6.50 \mathrm{E}+01$ & 2.31E-10 & $2.66 \mathrm{E}-10$ & 3.04E-10 & 3.57E-10 & 4.99E-10 & $6.03 E-10$ \\
\hline $6.60 \mathrm{E}+01$ & 2.23E-10 & 2.49E-10 & $2.88 \mathrm{E}-10$ & $3.45 \mathrm{E}-10$ & 4.63E-10 & $5.85 \mathrm{E}-10$ \\
\hline
\end{tabular}


Table 17: $\mathrm{Cu}-66$ response matrix $\left(\mathrm{Bq} / \mathrm{g}\right.$ per $\left.\mathrm{n} / \mathrm{cm}^{2}\right)$

\begin{tabular}{|c|c|c|c|c|c|c|}
\hline \multicolumn{7}{|c|}{ Moderator thickness } \\
\hline $\mathrm{E}(\mathrm{MeV})$ & $4.8 \mathrm{~cm}$ & $7.2 \mathrm{~cm}$ & $9.0 \mathrm{~cm}$ & $10.8 \mathrm{~cm}$ & $13.1 \mathrm{~cm}$ & $14.5 \mathrm{~cm}$ \\
\hline $1.00 \mathrm{E}-10$ & & & & & & \\
\hline & 3.97E-07 & 2.23E-07 & $1.38 \mathrm{E}-0 /$ & $8.83 \mathrm{E}-08$ & $6.10 \mathrm{E}-08$ & 3.29E-08 \\
\hline $1.12 \mathrm{E}-06$ & 5.53E-07 & 3.19E-07 & 2.21E-07 & $1.25 \mathrm{E}-07$ & 8.05E-08 & 5.37E-08 \\
\hline $2.38 \mathrm{E}-06$ & 5.92E-07 & 3.74E-07 & 2.44E-07 & $1.48 \mathrm{E}-07$ & 8.90E-08 & 6.17E-08 \\
\hline $5.04 \mathrm{E}-06$ & $6.25 \mathrm{E}-07$ & 3.86E-07 & $2.58 \mathrm{E}-07$ & 1.65E-07 & 1.10E-07 & 7.51E-08 \\
\hline $1.07 \mathrm{E}-05$ & $6.46 \mathrm{E}-07$ & 4.01E-07 & 2.92E-07 & $1.90 \mathrm{E}-07$ & 1.10E-07 & $8.12 \mathrm{E}-08$ \\
\hline $2.26 \mathrm{E}-05$ & $6.21 \mathrm{E}-07$ & $4.55 \mathrm{E}-07$ & 2.93E-07 & 1.97E-07 & 1.27E-07 & 8.02E-08 \\
\hline $1.01 \mathrm{E}-04$ & $5.76 \mathrm{E}-07$ & 4.33E-07 & 3.45E-07 & $2.20 \mathrm{E}-07$ & 1.30E-07 & $9.16 \mathrm{E}-08$ \\
\hline 4.54E-04 & 5.57E-07 & $4.58 \mathrm{E}-07$ & 3.43E-07 & 2.21E-07 & $1.46 \mathrm{E}-07$ & 1.05E-07 \\
\hline $1.58 \mathrm{E}-03$ & 5.23E-07 & 4.61E-07 & 3.48E-07 & 2.43E-07 & $1.50 \mathrm{E}-07$ & 1.08E-07 \\
\hline $3.35 \mathrm{E}-03$ & 4.94E-07 & 4.54E-07 & 3.58E-07 & $2.62 \mathrm{E}-07$ & $1.62 \mathrm{E}-07$ & 1.15E-07 \\
\hline 7.10E-03 & 4.71E-07 & 4.47E-07 & 3.60E-07 & 2.71E-07 & $1.66 \mathrm{E}-07$ & 1.20E-07 \\
\hline $1.50 \mathrm{E}-02$ & 4.32E-07 & 4.45E-07 & 3.63E-07 & 2.70E-07 & 1.73E-07 & 1.30E-07 \\
\hline $3.18 \mathrm{E}-02$ & $3.98 \mathrm{E}-07$ & 4.51E-07 & 3.85E-07 & $2.88 \mathrm{E}-07$ & $1.88 \mathrm{E}-07$ & 1.46E-07 \\
\hline $8.65 \mathrm{E}-02$ & 3.72E-07 & 4.50E-07 & 4.03E-07 & $3.22 \mathrm{E}-07$ & $2.14 \mathrm{E}-07$ & 1.67E-07 \\
\hline $1.50 \mathrm{E}-01$ & 3.46E-07 & $4.52 E-07$ & 4.29E-07 & 3.55E-07 & 2.55E-07 & 2.01E-07 \\
\hline $2.24 \mathrm{E}-01$ & 3.05E-07 & 4.56E-07 & 4.48E-07 & 3.85E-07 & 2.88E-07 & $2.25 \mathrm{E}-07$ \\
\hline 3.34E-01 & $2.68 \mathrm{E}-07$ & 4.50E-07 & 4.42E-07 & 4.03E-07 & 3.37E-07 & 2.70E-07 \\
\hline 4.98E-01 & 2.39E-07 & 3.93E-07 & 4.29E-07 & 4.09E-07 & 3.50E-07 & 3.04E-07 \\
\hline $7.43 \mathrm{E}-01$ & 1.93E-07 & 3.65E-07 & 4.42E-07 & 4.55E-07 & 4.11E-07 & 3.86E-07 \\
\hline $9.06 \mathrm{E}-01$ & 1.81E-07 & $3.27 \mathrm{E}-07$ & 4.02E-07 & 4.59E-07 & 4.66E-07 & 4.26E-07 \\
\hline $1.11 \mathrm{E}+00$ & $1.52 \mathrm{E}-07$ & 2.80E-07 & 3.48E-07 & 4.14E-07 & 4.38E-07 & 4.19E-07 \\
\hline $1.35 \mathrm{E}+00$ & 1.33E-07 & 2.48E-07 & 3.36E-07 & 4.07E-07 & 4.73E-07 & 4.52E-07 \\
\hline $1.65 \mathrm{E}+00$ & 1.19E-07 & $2.56 \mathrm{E}-07$ & 3.15E-07 & 3.94E-07 & 4.65E-07 & 4.61E-07 \\
\hline $2.02 \mathrm{E}+00$ & $1.05 \mathrm{E}-07$ & 2.23E-07 & 3.09E-07 & 3.80E-07 & 4.46E-07 & 4.83E-07 \\
\hline $2.46 \mathrm{E}+00$ & 8.76E-08 & $1.95 \mathrm{E}-07$ & 2.79E-07 & 3.55E-07 & 4.40E-07 & 4.85E-07 \\
\hline $3.01 \mathrm{E}+00$ & 6.43E-08 & $1.55 \mathrm{E}-07$ & 2.38E-07 & 3.46E-07 & 4.02E-07 & 4.20E-07 \\
\hline $3.68 \mathrm{E}+00$ & 5.24E-08 & $1.41 \mathrm{E}-07$ & 2.01E-07 & 2.33E-07 & 3.13E-07 & 3.81E-07 \\
\hline $4.49 \mathrm{E}+00$ & 5.33E-08 & $1.23 \mathrm{E}-07$ & 1.73E-07 & 2.59E-07 & 3.06E-07 & 3.70E-07 \\
\hline $5.49 \mathrm{E}+00$ & 4.42E-08 & $9.76 \mathrm{E}-08$ & $1.59 \mathrm{E}-07$ & 2.09E-07 & $2.79 \mathrm{E}-07$ & 3.29E-07 \\
\hline $6.70 \mathrm{E}+00$ & 2.51E-08 & 8.32E-08 & 1.37E-07 & 1.79E-07 & 2.22E-07 & 3.06E-07 \\
\hline $8.19 \mathrm{E}+00$ & 2.51E-08 & 7.07E-08 & $1.09 E-07$ & 1.56E-07 & 2.24E-07 & 2.80E-07 \\
\hline $1.00 \mathrm{E}+01$ & 2.08E-08 & 5.15E-08 & 8.15E-08 & 1.22E-07 & 1.81E-07 & 2.34E-07 \\
\hline $1.22 \mathrm{E}+01$ & 1.73E-08 & 4.43E-08 & 7.13E-08 & 1.10E-07 & 1.50E-07 & 1.88E-07 \\
\hline $1.35 \mathrm{E}+01$ & 1.58E-08 & 3.85E-08 & 5.92E-08 & $9.28 \mathrm{E}-08$ & $1.28 \mathrm{E}-07$ & $1.64 \mathrm{E}-07$ \\
\hline $1.49 \mathrm{E}+01$ & 1.44E-08 & 3.69E-08 & $6.21 \mathrm{E}-08$ & 8.39E-08 & 1.11E-07 & $1.52 \mathrm{E}-07$ \\
\hline $1.75 \mathrm{E}+01$ & 1.38E-08 & 3.60E-08 & $5.72 \mathrm{E}-08$ & 6.84E-08 & $1.28 \mathrm{E}-07$ & $1.49 \mathrm{E}-07$ \\
\hline $1.96 \mathrm{E}+01$ & 1.11E-08 & 3.08E-08 & 5.89E-08 & 6.89E-08 & $1.05 \mathrm{E}-07$ & $1.53 \mathrm{E}-07$ \\
\hline $2.25 \mathrm{E}+01$ & 1.07E-08 & 2.30E-08 & 4.52E-08 & 6.65E-08 & $1.05 \mathrm{E}-07$ & $1.41 \mathrm{E}-07$ \\
\hline $2.50 \mathrm{E}+01$ & 7.28E-09 & $2.21 \mathrm{E}-08$ & 4.10E-08 & 6.09E-08 & 9.33E-08 & $1.15 \mathrm{E}-07$ \\
\hline $2.75 \mathrm{E}+01$ & 7.58E-09 & 1.97E-08 & 3.70E-08 & 5.11E-08 & 8.22E-08 & 1.10E-07 \\
\hline $3.00 \mathrm{E}+01$ & 6.50E-09 & $1.68 \mathrm{E}-08$ & 2.93E-08 & 4.71E-08 & 7.92E-08 & 9.84E-08 \\
\hline $3.50 \mathrm{E}+01$ & 5.36E-09 & $1.61 \mathrm{E}-08$ & 2.89E-08 & 4.42E-08 & 6.92E-08 & $9.11 \mathrm{E}-08$ \\
\hline $4.00 \mathrm{E}+01$ & 4.78E-09 & 1.30E-08 & 2.63E-08 & 3.61E-08 & $5.84 \mathrm{E}-08$ & 8.84E-08 \\
\hline $4.50 \mathrm{E}+01$ & 5.04E-09 & $1.38 \mathrm{E}-08$ & 2.19E-08 & 3.49E-08 & 5.44E-08 & 7.79E-08 \\
\hline $5.00 \mathrm{E}+01$ & 4.67E-09 & 1.30E-08 & 2.51E-08 & 3.25E-08 & 5.48E-08 & 7.09E-08 \\
\hline $5.50 \mathrm{E}+01$ & 4.19E-09 & 1.46E-08 & 1.84E-08 & 3.07E-08 & $5.27 \mathrm{E}-08$ & $6.70 \mathrm{E}-08$ \\
\hline $6.00 \mathrm{E}+01$ & 3.20E-09 & $1.10 \mathrm{E}-08$ & 1.93E-08 & 2.89E-08 & 5.35E-08 & 6.81E-08 \\
\hline $6.50 \mathrm{E}+01$ & 3.56E-09 & $1.22 \mathrm{E}-08$ & 1.75E-08 & 2.99E-08 & 4.51E-08 & 6.13E-08 \\
\hline $6.60 \mathrm{E}+01$ & 4.52E-09 & 1.17E-08 & 2.34E-08 & 2.93E-08 & 4.63E-08 & 5.82E-08 \\
\hline
\end{tabular}


Table 18: $\mathrm{Cu}-62$ response matrix $\left(\mathrm{Bq} / \mathrm{g}\right.$ per $\left.\mathrm{n} / \mathrm{cm}^{2}\right)$

\begin{tabular}{|c|c|c|c|c|c|c|}
\hline \multicolumn{7}{|c|}{ Moderator thickness } \\
\hline $\mathrm{E}(\mathrm{MeV})$ & $4.8 \mathrm{~cm}$ & $7.2 \mathrm{~cm}$ & $9.0 \mathrm{~cm}$ & $10.8 \mathrm{~cm}$ & $13.1 \mathrm{~cm}$ & $14.5 \mathrm{~cm}$ \\
\hline $\begin{array}{l}1.00 \mathrm{E}-10 \\
4.14 \mathrm{E}-07\end{array}$ & - & $\begin{array}{l}- \\
-\end{array}$ & $\begin{array}{l}- \\
-\end{array}$ & $\begin{array}{l}- \\
-\end{array}$ & $\begin{array}{l}- \\
-\end{array}$ & $\begin{array}{l}- \\
-\end{array}$ \\
\hline $1.12 \mathrm{E}-06$ & - & - & - & - & - & - \\
\hline $2.38 \mathrm{E}-06$ & - & - & - & - & - & - \\
\hline $5.04 \mathrm{E}-06$ & - & - & - & - & - & - \\
\hline $1.07 \mathrm{E}-05$ & - & - & - & - & - & - \\
\hline $2.26 \mathrm{E}-05$ & - & - & - & - & - & - \\
\hline $1.01 \mathrm{E}-04$ & - & - & - & - & - & - \\
\hline $4.54 \mathrm{E}-04$ & - & - & - & - & - & - \\
\hline $1.58 \mathrm{E}-03$ & - & - & - & - & - & - \\
\hline $3.35 \mathrm{E}-03$ & - & - & - & - & - & - \\
\hline $7.10 \mathrm{E}-03$ & - & - & - & - & - & - \\
\hline $1.50 \mathrm{E}-02$ & - & - & - & - & - & - \\
\hline $3.18 \mathrm{E}-02$ & - & - & - & - & - & - \\
\hline $8.65 \mathrm{E}-02$ & - & - & - & - & - & - \\
\hline $1.50 \mathrm{E}-01$ & - & - & - & - & - & - \\
\hline $2.24 \mathrm{E}-01$ & - & - & - & - & - & - \\
\hline $3.34 \mathrm{E}-01$ & - & - & - & - & - & - \\
\hline 4.98E-01 & - & - & - & - & - & - \\
\hline 7.43E-01 & - & - & - & - & - & - \\
\hline $9.06 \mathrm{E}-01$ & - & - & - & - & - & - \\
\hline $1.11 \mathrm{E}+00$ & - & - & - & - & - & - \\
\hline $1.35 \mathrm{E}+00$ & - & - & - & - & - & - \\
\hline $1.65 \mathrm{E}+00$ & - & - & - & - & - & - \\
\hline $2.02 \mathrm{E}+00$ & - & - & - & - & - & - \\
\hline $2.46 \mathrm{E}+00$ & - & - & - & - & - & - \\
\hline $3.01 \mathrm{E}+00$ & - & - & - & - & - & - \\
\hline $3.68 \mathrm{E}+00$ & - & - & - & - & - & - \\
\hline $4.49 \mathrm{E}+00$ & - & - & - & - & - & - \\
\hline $5.49 \mathrm{E}+00$ & - & - & - & - & - & - \\
\hline $6.70 \mathrm{E}+00$ & - & - & - & - & - & - \\
\hline $8.19 \mathrm{E}+00$ & - & - & - & - & - & - \\
\hline $1.00 \mathrm{E}+01$ & - & - & - & - & - & - \\
\hline $1.22 \mathrm{E}+01$ & 8.61E-08 & $6.75 \mathrm{E}-08$ & $5.59 \mathrm{E}-08$ & 4.75E-08 & $3.80 \mathrm{E}-08$ & $3.23 \mathrm{E}-08$ \\
\hline $1.35 \mathrm{E}+01$ & $1.18 \mathrm{E}-06$ & $9.42 \mathrm{E}-07$ & 7.95E-07 & $6.81 \mathrm{E}-07$ & $5.62 \mathrm{E}-07$ & $5.04 \mathrm{E}-07$ \\
\hline $1.49 \mathrm{E}+01$ & $2.43 \mathrm{E}-06$ & 2.00E-06 & $1.72 \mathrm{E}-06$ & 1.50E-06 & $1.26 \mathrm{E}-06$ & $1.14 \mathrm{E}-06$ \\
\hline $1.75 \mathrm{E}+01$ & $3.65 \mathrm{E}-06$ & 3.03E-06 & 2.66E-06 & 2.35E-06 & 2.02E-06 & $1.85 \mathrm{E}-06$ \\
\hline $1.96 \mathrm{E}+01$ & 4.31E-06 & 3.65E-06 & 3.23E-06 & 2.92E-06 & $2.56 \mathrm{E}-06$ & 2.39E-06 \\
\hline $2.25 \mathrm{E}+01$ & 7.77E-07 & $7.35 \mathrm{E}-07$ & 7.21E-07 & $7.12 \mathrm{E}-07$ & 7.07E-07 & 7.02E-07 \\
\hline $2.50 \mathrm{E}+01$ & $6.63 \mathrm{E}-08$ & $9.71 \mathrm{E}-08$ & $1.28 \mathrm{E}-07$ & 1.62E-07 & $2.02 \mathrm{E}-07$ & 2.21E-07 \\
\hline $2.75 \mathrm{E}+01$ & $4.76 \mathrm{E}-08$ & $6.53 \mathrm{E}-08$ & 8.96E-08 & $1.22 \mathrm{E}-07$ & $1.64 \mathrm{E}-07$ & $1.84 \mathrm{E}-07$ \\
\hline $3.00 \mathrm{E}+01$ & $4.48 \mathrm{E}-08$ & $5.66 \mathrm{E}-08$ & 7.53E-08 & $1.04 \mathrm{E}-07$ & $1.43 \mathrm{E}-07$ & $1.66 \mathrm{E}-07$ \\
\hline $3.50 \mathrm{E}+01$ & $3.98 \mathrm{E}-08$ & 4.77E-08 & $5.90 \mathrm{E}-08$ & 8.05E-08 & $1.20 \mathrm{E}-07$ & 1.43E-07 \\
\hline $4.00 \mathrm{E}+01$ & 3.39E-08 & 4.15E-08 & 4.96E-08 & $6.40 \mathrm{E}-08$ & 9.87E-08 & $1.21 \mathrm{E}-07$ \\
\hline $4.50 \mathrm{E}+01$ & $3.24 \mathrm{E}-08$ & $3.81 \mathrm{E}-08$ & 4.53E-08 & 5.57E-08 & 8.52E-08 & $1.05 \mathrm{E}-07$ \\
\hline $5.00 \mathrm{E}+01$ & $2.99 \mathrm{E}-08$ & $3.42 \mathrm{E}-08$ & $4.10 \mathrm{E}-08$ & $5.00 \mathrm{E}-08$ & 7.42E-08 & $8.99 \mathrm{E}-08$ \\
\hline $5.50 \mathrm{E}+01$ & $2.60 \mathrm{E}-08$ & 3.01E-08 & 3.55E-08 & 4.34E-08 & $6.51 \mathrm{E}-08$ & $8.21 \mathrm{E}-08$ \\
\hline $6.00 \mathrm{E}+01$ & $2.40 \mathrm{E}-08$ & $2.74 \mathrm{E}-08$ & $3.26 \mathrm{E}-08$ & $3.94 \mathrm{E}-08$ & $5.73 \mathrm{E}-08$ & 7.06E-08 \\
\hline $6.50 \mathrm{E}+01$ & $2.22 \mathrm{E}-08$ & $2.59 \mathrm{E}-08$ & 3.07E-08 & 3.62E-08 & $5.29 \mathrm{E}-08$ & $6.41 \mathrm{E}-08$ \\
\hline $6.60 \mathrm{E}+01$ & $2.14 \mathrm{E}-08$ & $2.38 \mathrm{E}-08$ & 2.90E-08 & 3.55E-08 & $4.92 \mathrm{E}-08$ & $6.56 \mathrm{E}-08$ \\
\hline
\end{tabular}




\section{APPENDIX B}

\section{MEASUREMENTS AND MCNP5 CALCULATIONS OF THE}

\section{ABSORBED DOSE, BORON DOSE AND PDE}

B.1 MCNP5 calculations for the optimized design of the BNCEFNT assembly: 10cm graphite reflector, $10-\mathrm{cm}$ thick tungsten collimator with $20-\mathrm{cm}$ outer diameter and $5.64-\mathrm{cm}$ inner diameter, $20 \times 20 \mathrm{~cm}^{2}$ standard therapy beam. Normalization of the MCNP results is based on a proton current of $1.7 \times 10^{14}$ protons $/ \mathrm{s}^{\text {and }} 8.13 \times 10^{-7}$ $\mathrm{n} / \mathrm{cm}^{2}$ per proton obtained in chapter 4 .

Table 19: MCNP5 calculated kerma rate (neutrons and gammas) distributions in the simplified water filled head phantom for different thickness of tungsten filter

\begin{tabular}{crllllllll}
\hline Depth & \multicolumn{7}{c}{ Kerma $(\mathrm{Gy} / \mathrm{min})$} \\
$(\mathrm{cm})$ & no -filter & $0.5 \mathrm{~cm}$ & $1.0 \mathrm{~cm}$ & $1.5 \mathrm{~cm}$ & $2.0 \mathrm{~cm}$ & $2.5 \mathrm{~cm}$ & $3.0 \mathrm{~cm}$ & $3.5 \mathrm{~cm}$ & $4.0 \mathrm{~cm}$ \\
\hline 0.7 & 0.739 & 0.694 & 0.650 & 0.612 & 0.575 & 0.543 & 0.512 & 0.481 & 0.450 \\
1.7 & 0.680 & 0.634 & 0.590 & 0.551 & 0.514 & 0.481 & 0.448 & 0.416 & 0.385 \\
2.7 & 0.632 & 0.583 & 0.542 & 0.502 & 0.465 & 0.433 & 0.403 & 0.373 & 0.345 \\
3.7 & 0.590 & 0.544 & 0.503 & 0.466 & 0.429 & 0.398 & 0.367 & 0.339 & 0.314 \\
4.7 & 0.555 & 0.511 & 0.471 & 0.432 & 0.399 & 0.366 & 0.337 & 0.313 & 0.289 \\
5.7 & 0.520 & 0.477 & 0.437 & 0.401 & 0.369 & 0.339 & 0.311 & 0.287 & 0.265 \\
6.7 & 0.487 & 0.445 & 0.407 & 0.373 & 0.344 & 0.315 & 0.289 & 0.264 & 0.243 \\
7.7 & 0.460 & 0.421 & 0.383 & 0.352 & 0.322 & 0.294 & 0.267 & 0.244 & 0.224 \\
8.7 & 0.434 & 0.397 & 0.361 & 0.330 & 0.301 & 0.275 & 0.251 & 0.228 & 0.208 \\
9.7 & 0.407 & 0.372 & 0.338 & 0.308 & 0.281 & 0.258 & 0.236 & 0.215 & 0.196 \\
10.7 & 0.385 & 0.350 & 0.318 & 0.290 & 0.265 & 0.242 & 0.221 & 0.200 & 0.180 \\
11.7 & 0.359 & 0.326 & 0.296 & 0.271 & 0.246 & 0.225 & 0.205 & 0.184 & 0.166 \\
12.7 & 0.338 & 0.307 & 0.278 & 0.254 & 0.231 & 0.210 & 0.190 & 0.171 & 0.155 \\
13.7 & 0.319 & 0.289 & 0.262 & 0.239 & 0.218 & 0.197 & 0.178 & 0.160 & 0.146 \\
14.7 & 0.299 & 0.271 & 0.245 & 0.224 & 0.203 & 0.183 & 0.166 & 0.150 & 0.136 \\
15.7 & 0.280 & 0.253 & 0.229 & 0.208 & 0.189 & 0.171 & 0.154 & 0.139 & 0.125 \\
16.7 & 0.263 & 0.238 & 0.215 & 0.195 & 0.175 & 0.159 & 0.143 & 0.129 & 0.118 \\
17.7 & 0.245 & 0.222 & 0.201 & 0.181 & 0.163 & 0.149 & 0.134 & 0.120 & 0.108 \\
18.7 & 0.227 & 0.206 & 0.187 & 0.168 & 0.152 & 0.140 & 0.127 & 0.113 & 0.101 \\
\hline
\end{tabular}


Table 19: MCNP5 calculated kerma rate (neutrons and gammas) distributions in the simplified water filled head phantom for different thickness of tungsten filter (continue)

\begin{tabular}{cccccccccc}
\hline $\begin{array}{c}\text { Depth } \\
(\mathrm{cm})\end{array}$ & $4.5 \mathrm{~cm}$ & $5.0 \mathrm{~cm}$ & $5.5 \mathrm{~cm}$ & $6.0 \mathrm{~cm}$ & $6.5 \mathrm{~cm}$ & $7.0 \mathrm{~cm}$ & $7.5 \mathrm{~cm}$ & $8.0 \mathrm{~cm}$ & $8.5 \mathrm{~cm}$ \\
\hline 0.7 & 0.419 & 0.393 & 0.369 & 0.345 & 0.322 & 0.304 & 0.284 & 0.267 & 0.249 \\
1.7 & 0.360 & 0.335 & 0.312 & 0.293 & 0.273 & 0.256 & 0.238 & 0.221 & 0.205 \\
2.7 & 0.318 & 0.296 & 0.273 & 0.255 & 0.234 & 0.219 & 0.204 & 0.189 & 0.175 \\
3.7 & 0.289 & 0.267 & 0.246 & 0.229 & 0.211 & 0.196 & 0.182 & 0.168 & 0.156 \\
4.7 & 0.265 & 0.244 & 0.224 & 0.208 & 0.192 & 0.178 & 0.164 & 0.151 & 0.140 \\
5.7 & 0.241 & 0.221 & 0.204 & 0.188 & 0.173 & 0.161 & 0.148 & 0.137 & 0.127 \\
6.7 & 0.223 & 0.204 & 0.188 & 0.172 & 0.159 & 0.148 & 0.135 & 0.125 & 0.114 \\
7.7 & 0.206 & 0.189 & 0.172 & 0.157 & 0.145 & 0.135 & 0.124 & 0.114 & 0.104 \\
8.7 & 0.189 & 0.173 & 0.159 & 0.145 & 0.133 & 0.123 & 0.113 & 0.105 & 0.095 \\
9.7 & 0.176 & 0.161 & 0.146 & 0.133 & 0.124 & 0.114 & 0.105 & 0.097 & 0.088 \\
10.7 & 0.163 & 0.149 & 0.136 & 0.124 & 0.114 & 0.105 & 0.095 & 0.089 & 0.081 \\
11.7 & 0.151 & 0.138 & 0.126 & 0.115 & 0.105 & 0.097 & 0.088 & 0.081 & 0.074 \\
12.7 & 0.141 & 0.129 & 0.119 & 0.109 & 0.098 & 0.090 & 0.082 & 0.076 & 0.069 \\
13.7 & 0.132 & 0.120 & 0.110 & 0.100 & 0.091 & 0.083 & 0.077 & 0.071 & 0.063 \\
14.7 & 0.122 & 0.111 & 0.102 & 0.093 & 0.085 & 0.078 & 0.072 & 0.067 & 0.059 \\
15.7 & 0.114 & 0.103 & 0.094 & 0.087 & 0.079 & 0.073 & 0.066 & 0.061 & 0.054 \\
16.7 & 0.106 & 0.097 & 0.088 & 0.081 & 0.074 & 0.068 & 0.062 & 0.056 & 0.050 \\
17.7 & 0.097 & 0.089 & 0.081 & 0.073 & 0.067 & 0.062 & 0.056 & 0.051 & 0.046 \\
18.7 & 0.091 & 0.082 & 0.076 & 0.068 & 0.062 & 0.057 & 0.053 & 0.048 & 0.043 \\
\hline
\end{tabular}

Table 20: MCNP5 calculated PDE distribution for different thickness of tungsten filter

\begin{tabular}{cccccccccc}
\hline $\begin{array}{c}\text { Depth } \\
\text { (cm) }\end{array}$ & no -filter & $0.5 \mathrm{~cm}$ & $1.0 \mathrm{~cm}$ & $1.5 \mathrm{~cm}$ & $2.0 \mathrm{~cm}$ & $2.5 \mathrm{~cm}$ & $3.0 \mathrm{~cm}$ & $3.5 \mathrm{~cm}$ & $4.0 \mathrm{~cm}$ \\
\hline 0.7 & $3.9 \%$ & $4.0 \%$ & $4.1 \%$ & $4.3 \%$ & $4.5 \%$ & $4.6 \%$ & $4.7 \%$ & $4.9 \%$ & $5.1 \%$ \\
1.7 & $6.4 \%$ & $6.8 \%$ & $7.2 \%$ & $7.5 \%$ & $7.9 \%$ & $8.3 \%$ & $8.7 \%$ & $9.2 \%$ & $9.6 \%$ \\
2.7 & $8.7 \%$ & $9.2 \%$ & $9.9 \%$ & $10.4 \%$ & $10.9 \%$ & $11.5 \%$ & $12.1 \%$ & $12.7 \%$ & $13.5 \%$ \\
3.7 & $10.4 \%$ & $11.1 \%$ & $11.7 \%$ & $12.4 \%$ & $13.2 \%$ & $14.0 \%$ & $14.7 \%$ & $15.5 \%$ & $16.5 \%$ \\
4.7 & $11.4 \%$ & $12.2 \%$ & $13.0 \%$ & $13.9 \%$ & $14.6 \%$ & $15.7 \%$ & $16.6 \%$ & $17.5 \%$ & $18.5 \%$ \\
5.7 & $11.9 \%$ & $12.7 \%$ & $13.7 \%$ & $14.7 \%$ & $15.6 \%$ & $16.6 \%$ & $17.5 \%$ & $18.7 \%$ & $19.7 \%$ \\
6.7 & $11.9 \%$ & $12.8 \%$ & $13.8 \%$ & $14.7 \%$ & $15.7 \%$ & $16.7 \%$ & $17.9 \%$ & $19.1 \%$ & $20.0 \%$ \\
7.7 & $11.7 \%$ & $12.6 \%$ & $13.5 \%$ & $14.3 \%$ & $15.3 \%$ & $16.3 \%$ & $17.5 \%$ & $18.7 \%$ & $19.4 \%$ \\
8.7 & $11.1 \%$ & $12.0 \%$ & $12.9 \%$ & $13.7 \%$ & $14.5 \%$ & $15.6 \%$ & $16.6 \%$ & $17.9 \%$ & $18.9 \%$ \\
9.7 & $10.5 \%$ & $11.1 \%$ & $11.9 \%$ & $12.7 \%$ & $13.7 \%$ & $14.3 \%$ & $15.4 \%$ & $16.5 \%$ & $17.5 \%$ \\
10.7 & $9.7 \%$ & $10.4 \%$ & $11.1 \%$ & $11.9 \%$ & $12.5 \%$ & $13.4 \%$ & $14.2 \%$ & $15.1 \%$ & $16.2 \%$ \\
11.7 & $8.9 \%$ & $9.6 \%$ & $10.2 \%$ & $10.9 \%$ & $11.5 \%$ & $12.3 \%$ & $13.1 \%$ & $14.1 \%$ & $14.8 \%$ \\
12.7 & $8.1 \%$ & $8.8 \%$ & $9.4 \%$ & $9.9 \%$ & $10.5 \%$ & $11.2 \%$ & $12.0 \%$ & $12.9 \%$ & $13.6 \%$ \\
13.7 & $7.4 \%$ & $7.9 \%$ & $8.3 \%$ & $8.8 \%$ & $9.4 \%$ & $10.1 \%$ & $10.5 \%$ & $11.3 \%$ & $12.0 \%$ \\
14.7 & $6.5 \%$ & $6.9 \%$ & $7.4 \%$ & $7.8 \%$ & $8.1 \%$ & $8.7 \%$ & $9.3 \%$ & $9.8 \%$ & $10.6 \%$ \\
15.7 & $5.3 \%$ & $5.7 \%$ & $6.0 \%$ & $6.3 \%$ & $6.8 \%$ & $7.5 \%$ & $7.7 \%$ & $8.3 \%$ & $8.8 \%$ \\
16.7 & $4.3 \%$ & $4.6 \%$ & $4.9 \%$ & $5.1 \%$ & $5.6 \%$ & $6.1 \%$ & $6.3 \%$ & $6.7 \%$ & $7.2 \%$ \\
17.7 & $3.2 \%$ & $3.4 \%$ & $3.7 \%$ & $3.9 \%$ & $4.2 \%$ & $4.5 \%$ & $4.7 \%$ & $5.0 \%$ & $5.4 \%$ \\
18.7 & $2.0 \%$ & $2.1 \%$ & $2.3 \%$ & $2.4 \%$ & $2.6 \%$ & $2.7 \%$ & $2.9 \%$ & $3.1 \%$ & $3.3 \%$ \\
\hline
\end{tabular}


Table 20: MCNP5 calculated PDE distribution for different thickness of tungsten filter (continue)

\begin{tabular}{cccccccccc}
\hline $\begin{array}{c}\text { Depth } \\
(\mathrm{cm})\end{array}$ & $4.5 \mathrm{~cm}$ & $5.0 \mathrm{~cm}$ & $5.5 \mathrm{~cm}$ & $6.0 \mathrm{~cm}$ & $6.5 \mathrm{~cm}$ & $7.0 \mathrm{~cm}$ & $7.5 \mathrm{~cm}$ & $8.0 \mathrm{~cm}$ & $8.5 \mathrm{~cm}$ \\
\hline 0.7 & $5.4 \%$ & $5.6 \%$ & $5.7 \%$ & $5.9 \%$ & $6.3 \%$ & $6.3 \%$ & $6.5 \%$ & $6.7 \%$ & $7.0 \%$ \\
1.7 & $10.1 \%$ & $10.6 \%$ & $10.8 \%$ & $11.4 \%$ & $11.8 \%$ & $12.2 \%$ & $12.8 \%$ & $13.3 \%$ & $13.9 \%$ \\
2.7 & $14.5 \%$ & $14.8 \%$ & $15.7 \%$ & $16.4 \%$ & $17.2 \%$ & $17.8 \%$ & $18.7 \%$ & $19.0 \%$ & $20.0 \%$ \\
3.7 & $17.7 \%$ & $18.4 \%$ & $19.5 \%$ & $20.4 \%$ & $21.5 \%$ & $22.1 \%$ & $23.3 \%$ & $23.9 \%$ & $25.1 \%$ \\
4.7 & $19.8 \%$ & $20.6 \%$ & $21.8 \%$ & $22.4 \%$ & $24.0 \%$ & $25.0 \%$ & $26.2 \%$ & $27.2 \%$ & $28.2 \%$ \\
5.7 & $21.1 \%$ & $21.9 \%$ & $23.4 \%$ & $23.9 \%$ & $25.4 \%$ & $26.6 \%$ & $28.3 \%$ & $29.1 \%$ & $29.8 \%$ \\
6.7 & $21.6 \%$ & $22.4 \%$ & $23.6 \%$ & $24.9 \%$ & $25.9 \%$ & $27.5 \%$ & $28.6 \%$ & $29.4 \%$ & $31.1 \%$ \\
7.7 & $21.1 \%$ & $21.9 \%$ & $23.3 \%$ & $24.5 \%$ & $25.5 \%$ & $26.5 \%$ & $28.4 \%$ & $29.1 \%$ & $31.0 \%$ \\
8.7 & $20.2 \%$ & $21.3 \%$ & $22.7 \%$ & $23.4 \%$ & $24.8 \%$ & $26.0 \%$ & $27.3 \%$ & $28.4 \%$ & $30.0 \%$ \\
9.7 & $18.7 \%$ & $19.9 \%$ & $21.3 \%$ & $22.3 \%$ & $23.1 \%$ & $24.5 \%$ & $25.0 \%$ & $26.0 \%$ & $27.2 \%$ \\
10.7 & $17.2 \%$ & $18.5 \%$ & $19.4 \%$ & $20.4 \%$ & $21.6 \%$ & $22.5 \%$ & $23.7 \%$ & $24.1 \%$ & $25.0 \%$ \\
11.7 & $15.7 \%$ & $16.8 \%$ & $17.5 \%$ & $18.6 \%$ & $19.9 \%$ & $20.6 \%$ & $21.8 \%$ & $22.5 \%$ & $23.4 \%$ \\
12.7 & $14.3 \%$ & $15.2 \%$ & $15.7 \%$ & $16.6 \%$ & $17.8 \%$ & $18.4 \%$ & $19.8 \%$ & $20.3 \%$ & $21.3 \%$ \\
13.7 & $12.7 \%$ & $13.4 \%$ & $13.9 \%$ & $14.7 \%$ & $16.0 \%$ & $16.5 \%$ & $17.3 \%$ & $17.9 \%$ & $19.3 \%$ \\
14.7 & $11.2 \%$ & $11.7 \%$ & $12.6 \%$ & $13.3 \%$ & $13.6 \%$ & $14.3 \%$ & $14.9 \%$ & $15.7 \%$ & $16.6 \%$ \\
15.7 & $9.3 \%$ & $9.8 \%$ & $10.4 \%$ & $10.9 \%$ & $11.3 \%$ & $12.1 \%$ & $12.8 \%$ & $13.5 \%$ & $14.4 \%$ \\
16.7 & $7.6 \%$ & $7.8 \%$ & $8.7 \%$ & $9.0 \%$ & $9.3 \%$ & $9.9 \%$ & $10.4 \%$ & $10.8 \%$ & $11.5 \%$ \\
17.7 & $6.0 \%$ & $6.0 \%$ & $6.5 \%$ & $6.8 \%$ & $7.1 \%$ & $7.2 \%$ & $8.1 \%$ & $8.0 \%$ & $8.5 \%$ \\
18.7 & $3.6 \%$ & $3.7 \%$ & $3.9 \%$ & $4.2 \%$ & $4.3 \%$ & $4.4 \%$ & $4.8 \%$ & $4.8 \%$ & $5.2 \%$ \\
\hline
\end{tabular}

Table 21: MCNP5 calculated gamma kerma percentage in the total kerma for different thickness of tungsten filter

\begin{tabular}{cccccccccc}
\hline $\begin{array}{c}\text { Depth } \\
\text { (cm) }\end{array}$ & no -filter & $0.5 \mathrm{~cm}$ & $1.0 \mathrm{~cm}$ & $1.5 \mathrm{~cm}$ & $2.0 \mathrm{~cm}$ & $2.5 \mathrm{~cm}$ & $3.0 \mathrm{~cm}$ & $3.5 \mathrm{~cm}$ & $4.0 \mathrm{~cm}$ \\
\hline 0.7 & $3.5 \%$ & $3.7 \%$ & $3.8 \%$ & $4.0 \%$ & $4.2 \%$ & $4.3 \%$ & $4.4 \%$ & $4.5 \%$ & $4.7 \%$ \\
1.7 & $3.8 \%$ & $4.0 \%$ & $4.2 \%$ & $4.3 \%$ & $4.5 \%$ & $4.7 \%$ & $4.8 \%$ & $5.0 \%$ & $5.2 \%$ \\
2.7 & $4.0 \%$ & $4.2 \%$ & $4.3 \%$ & $4.5 \%$ & $4.7 \%$ & $5.0 \%$ & $5.2 \%$ & $5.4 \%$ & $5.7 \%$ \\
3.7 & $4.1 \%$ & $4.3 \%$ & $4.6 \%$ & $4.8 \%$ & $5.0 \%$ & $5.2 \%$ & $5.4 \%$ & $5.7 \%$ & $5.9 \%$ \\
4.7 & $4.1 \%$ & $4.4 \%$ & $4.6 \%$ & $4.9 \%$ & $5.2 \%$ & $5.5 \%$ & $5.6 \%$ & $5.8 \%$ & $6.0 \%$ \\
5.7 & $4.1 \%$ & $4.3 \%$ & $4.6 \%$ & $4.9 \%$ & $5.2 \%$ & $5.4 \%$ & $5.6 \%$ & $5.9 \%$ & $6.2 \%$ \\
6.7 & $4.2 \%$ & $4.4 \%$ & $4.7 \%$ & $4.9 \%$ & $5.2 \%$ & $5.5 \%$ & $5.8 \%$ & $6.1 \%$ & $6.3 \%$ \\
7.7 & $4.3 \%$ & $4.5 \%$ & $4.8 \%$ & $5.0 \%$ & $5.2 \%$ & $5.5 \%$ & $5.8 \%$ & $6.1 \%$ & $6.4 \%$ \\
8.7 & $4.1 \%$ & $4.3 \%$ & $4.6 \%$ & $4.9 \%$ & $5.1 \%$ & $5.3 \%$ & $5.5 \%$ & $5.9 \%$ & $6.1 \%$ \\
9.7 & $4.0 \%$ & $4.1 \%$ & $4.5 \%$ & $4.7 \%$ & $4.9 \%$ & $5.0 \%$ & $5.4 \%$ & $5.7 \%$ & $6.0 \%$ \\
10.7 & $3.8 \%$ & $4.1 \%$ & $4.3 \%$ & $4.6 \%$ & $4.7 \%$ & $4.9 \%$ & $5.1 \%$ & $5.5 \%$ & $5.8 \%$ \\
11.7 & $3.8 \%$ & $4.0 \%$ & $4.3 \%$ & $4.5 \%$ & $4.6 \%$ & $4.9 \%$ & $5.1 \%$ & $5.4 \%$ & $5.7 \%$ \\
12.7 & $3.6 \%$ & $3.8 \%$ & $4.0 \%$ & $4.2 \%$ & $4.4 \%$ & $4.6 \%$ & $4.8 \%$ & $5.1 \%$ & $5.4 \%$ \\
13.7 & $3.5 \%$ & $3.7 \%$ & $3.9 \%$ & $4.1 \%$ & $4.2 \%$ & $4.4 \%$ & $4.7 \%$ & $5.0 \%$ & $5.1 \%$ \\
14.7 & $3.2 \%$ & $3.5 \%$ & $3.7 \%$ & $3.9 \%$ & $4.0 \%$ & $4.2 \%$ & $4.5 \%$ & $4.5 \%$ & $4.8 \%$ \\
15.7 & $2.9 \%$ & $3.1 \%$ & $3.3 \%$ & $3.5 \%$ & $3.7 \%$ & $3.8 \%$ & $4.0 \%$ & $4.3 \%$ & $4.5 \%$ \\
16.7 & $2.8 \%$ & $3.1 \%$ & $3.1 \%$ & $3.3 \%$ & $3.5 \%$ & $3.7 \%$ & $3.8 \%$ & $4.1 \%$ & $4.2 \%$ \\
17.7 & $2.6 \%$ & $2.8 \%$ & $2.9 \%$ & $3.1 \%$ & $3.4 \%$ & $3.5 \%$ & $3.5 \%$ & $3.8 \%$ & $4.1 \%$ \\
18.7 & $2.3 \%$ & $2.4 \%$ & $2.5 \%$ & $2.7 \%$ & $2.9 \%$ & $3.0 \%$ & $3.0 \%$ & $3.4 \%$ & $3.5 \%$ \\
\hline
\end{tabular}


Table 21: MCNP5 calculated gamma kerma percentage in the total kerma for different thickness of tungsten filter (continue)

\begin{tabular}{cccccccccc}
\hline $\begin{array}{c}\text { Depth } \\
(\mathrm{cm})\end{array}$ & $4.5 \mathrm{~cm}$ & $5.0 \mathrm{~cm}$ & $5.5 \mathrm{~cm}$ & $6.0 \mathrm{~cm}$ & $6.5 \mathrm{~cm}$ & $7.0 \mathrm{~cm}$ & $7.5 \mathrm{~cm}$ & $8.0 \mathrm{~cm}$ & $8.5 \mathrm{~cm}$ \\
\hline 0.7 & $4.7 \%$ & $4.9 \%$ & $4.9 \%$ & $5.0 \%$ & $5.2 \%$ & $5.3 \%$ & $5.4 \%$ & $5.5 \%$ & $5.7 \%$ \\
1.7 & $5.4 \%$ & $5.5 \%$ & $5.6 \%$ & $5.9 \%$ & $6.1 \%$ & $6.3 \%$ & $6.4 \%$ & $6.5 \%$ & $6.5 \%$ \\
2.7 & $5.8 \%$ & $6.0 \%$ & $6.1 \%$ & $6.4 \%$ & $6.6 \%$ & $6.7 \%$ & $7.1 \%$ & $7.2 \%$ & $7.3 \%$ \\
3.7 & $6.1 \%$ & $6.3 \%$ & $6.5 \%$ & $6.7 \%$ & $7.0 \%$ & $7.2 \%$ & $7.6 \%$ & $7.8 \%$ & $8.1 \%$ \\
4.7 & $6.2 \%$ & $6.6 \%$ & $6.9 \%$ & $7.2 \%$ & $7.4 \%$ & $7.6 \%$ & $8.0 \%$ & $8.2 \%$ & $8.4 \%$ \\
5.7 & $6.5 \%$ & $6.7 \%$ & $7.1 \%$ & $7.4 \%$ & $7.8 \%$ & $7.8 \%$ & $8.2 \%$ & $8.4 \%$ & $8.5 \%$ \\
6.7 & $6.6 \%$ & $6.8 \%$ & $7.2 \%$ & $7.6 \%$ & $7.9 \%$ & $8.0 \%$ & $8.4 \%$ & $8.6 \%$ & $8.8 \%$ \\
7.7 & $6.6 \%$ & $6.8 \%$ & $7.1 \%$ & $7.7 \%$ & $7.7 \%$ & $8.1 \%$ & $8.4 \%$ & $8.8 \%$ & $8.9 \%$ \\
8.7 & $6.4 \%$ & $6.8 \%$ & $7.2 \%$ & $7.5 \%$ & $7.8 \%$ & $7.9 \%$ & $8.3 \%$ & $8.5 \%$ & $9.0 \%$ \\
9.7 & $6.2 \%$ & $6.7 \%$ & $7.1 \%$ & $7.4 \%$ & $7.6 \%$ & $7.9 \%$ & $8.3 \%$ & $8.4 \%$ & $9.0 \%$ \\
10.7 & $6.2 \%$ & $6.5 \%$ & $6.8 \%$ & $7.3 \%$ & $7.4 \%$ & $7.8 \%$ & $7.9 \%$ & $8.3 \%$ & $8.7 \%$ \\
11.7 & $6.1 \%$ & $6.2 \%$ & $6.6 \%$ & $7.0 \%$ & $7.2 \%$ & $7.8 \%$ & $7.8 \%$ & $8.1 \%$ & $8.7 \%$ \\
12.7 & $5.6 \%$ & $5.8 \%$ & $6.2 \%$ & $6.4 \%$ & $6.7 \%$ & $7.2 \%$ & $7.5 \%$ & $7.6 \%$ & $8.2 \%$ \\
13.7 & $5.4 \%$ & $5.7 \%$ & $6.0 \%$ & $6.2 \%$ & $6.5 \%$ & $6.7 \%$ & $6.9 \%$ & $7.0 \%$ & $7.5 \%$ \\
14.7 & $5.0 \%$ & $5.4 \%$ & $5.7 \%$ & $6.0 \%$ & $6.1 \%$ & $6.5 \%$ & $6.7 \%$ & $6.8 \%$ & $7.2 \%$ \\
15.7 & $4.8 \%$ & $5.1 \%$ & $5.2 \%$ & $5.6 \%$ & $5.8 \%$ & $6.2 \%$ & $6.2 \%$ & $6.3 \%$ & $6.9 \%$ \\
16.7 & $4.5 \%$ & $4.8 \%$ & $5.0 \%$ & $5.2 \%$ & $5.3 \%$ & $5.7 \%$ & $5.7 \%$ & $6.1 \%$ & $6.5 \%$ \\
17.7 & $4.2 \%$ & $4.4 \%$ & $4.6 \%$ & $4.9 \%$ & $5.2 \%$ & $5.2 \%$ & $5.4 \%$ & $5.8 \%$ & $5.9 \%$ \\
18.7 & $3.5 \%$ & $3.8 \%$ & $4.0 \%$ & $4.1 \%$ & $4.5 \%$ & $4.4 \%$ & $4.8 \%$ & $5.0 \%$ & $5.2 \%$ \\
\hline
\end{tabular}


B.2 MCNP5 calculations of kerma and PDE distributions in a water-filled head phantom using the simplified BNCEFNT assembly as the measurements. $12.5-\mathrm{cm}$ graphite reflector, $5 \times 5 \mathrm{~cm}^{2}$ size with $10-\mathrm{cm}$ thick lead collimator made of four $20 \times 10 \times 5 \mathrm{~cm}^{3}$ lead bricks, $20 \times 20 \mathrm{~cm}^{2}$ standard therapy beam. Normalization of the MCNP results is based on a proton current of $3.3 \times 10^{16}$ protons/MU and $8.13 \times 10^{-7}$ $\mathrm{n} / \mathrm{cm}^{2}$ per proton obtained in chapter 4 .

Table 22: Calculated absorbed dose distribution (Gy/MU) for different thick tungsten filter as in the measurements

\begin{tabular}{cccccccc}
\hline $\begin{array}{c}\text { Depth } \\
(\mathrm{cm})\end{array}$ & $0-\mathrm{cm}$ & $1.0-\mathrm{cm}$ & $2.0-\mathrm{cm}$ & $3.0-\mathrm{cm}$ & $4.0-\mathrm{cm}$ & $5.0-\mathrm{cm}$ & $5.0-\mathrm{cm} / \mathrm{NSGR}$ \\
\hline 0.7 & 2.198 & 1.875 & 1.610 & 1.394 & 1.199 & 1.020 & 0.953 \\
1.7 & 2.086 & 1.756 & 1.491 & 1.280 & 1.084 & 0.917 & 0.870 \\
2.7 & 1.968 & 1.641 & 1.388 & 1.172 & 0.985 & 0.834 & 0.796 \\
3.7 & 1.857 & 1.551 & 1.301 & 1.095 & 0.920 & 0.769 & 0.737 \\
4.7 & 1.762 & 1.469 & 1.222 & 1.022 & 0.857 & 0.720 & 0.689 \\
5.7 & 1.670 & 1.384 & 1.148 & 0.956 & 0.795 & 0.663 & 0.639 \\
6.7 & 1.576 & 1.309 & 1.085 & 0.895 & 0.743 & 0.616 & 0.593 \\
7.7 & 1.491 & 1.230 & 1.015 & 0.836 & 0.687 & 0.569 & 0.555 \\
8.7 & 1.414 & 1.159 & 0.956 & 0.785 & 0.644 & 0.534 & 0.518 \\
9.7 & 1.343 & 1.096 & 0.901 & 0.743 & 0.613 & 0.504 & 0.481 \\
10.7 & 1.270 & 1.034 & 0.849 & 0.699 & 0.566 & 0.462 & 0.448 \\
11.7 & 1.192 & 0.970 & 0.796 & 0.655 & 0.530 & 0.433 & 0.422 \\
12.7 & 1.126 & 0.917 & 0.751 & 0.615 & 0.496 & 0.411 & 0.396 \\
13.7 & 1.059 & 0.863 & 0.705 & 0.574 & 0.462 & 0.381 & 0.369 \\
14.7 & 1.003 & 0.816 & 0.665 & 0.541 & 0.434 & 0.357 & 0.345 \\
15.7 & 0.942 & 0.761 & 0.616 & 0.502 & 0.403 & 0.331 & 0.321 \\
16.7 & 0.884 & 0.714 & 0.579 & 0.470 & 0.382 & 0.313 & 0.305 \\
17.7 & 0.830 & 0.674 & 0.546 & 0.442 & 0.355 & 0.293 & 0.284 \\
18.7 & 0.771 & 0.627 & 0.507 & 0.413 & 0.331 & 0.272 & 0.266 \\
\hline
\end{tabular}

* Side Graphite Reflectors Removed 
Table 23: Calculated boron dose per 100-ppm ${ }^{10} \mathrm{~B}$

\begin{tabular}{cccccccc}
\hline $\begin{array}{c}\text { Depth } \\
(\mathrm{cm})\end{array}$ & $0-\mathrm{cm}$ & $1.0-\mathrm{cm}$ & $2.0-\mathrm{cm}$ & $3.0-\mathrm{cm}$ & $4.0-\mathrm{cm}$ & $5.0-\mathrm{cm}$ & $5.0-\mathrm{cm} / \mathrm{NSGR}^{*}$ \\
\hline 0.7 & 0.069 & 0.063 & 0.060 & 0.058 & 0.057 & 0.055 & 0.039 \\
1.7 & 0.098 & 0.091 & 0.090 & 0.087 & 0.085 & 0.083 & 0.060 \\
2.7 & 0.115 & 0.111 & 0.110 & 0.107 & 0.103 & 0.101 & 0.075 \\
3.7 & 0.129 & 0.124 & 0.121 & 0.118 & 0.116 & 0.112 & 0.084 \\
4.7 & 0.134 & 0.128 & 0.125 & 0.122 & 0.121 & 0.116 & 0.086 \\
5.7 & 0.133 & 0.129 & 0.126 & 0.120 & 0.118 & 0.113 & 0.084 \\
6.7 & 0.129 & 0.124 & 0.120 & 0.116 & 0.113 & 0.110 & 0.080 \\
7.7 & 0.122 & 0.118 & 0.112 & 0.108 & 0.107 & 0.101 & 0.073 \\
8.7 & 0.113 & 0.108 & 0.104 & 0.099 & 0.097 & 0.090 & 0.065 \\
9.7 & 0.103 & 0.098 & 0.093 & 0.088 & 0.086 & 0.082 & 0.059 \\
10.7 & 0.093 & 0.088 & 0.083 & 0.080 & 0.075 & 0.072 & 0.050 \\
11.7 & 0.081 & 0.075 & 0.073 & 0.068 & 0.064 & 0.061 & 0.043 \\
12.7 & 0.070 & 0.065 & 0.062 & 0.058 & 0.056 & 0.051 & 0.035 \\
13.7 & 0.060 & 0.055 & 0.053 & 0.049 & 0.047 & 0.043 & 0.030 \\
14.7 & 0.050 & 0.047 & 0.043 & 0.041 & 0.038 & 0.036 & 0.024 \\
15.7 & 0.040 & 0.037 & 0.035 & 0.031 & 0.029 & 0.028 & 0.018 \\
16.7 & 0.030 & 0.028 & 0.026 & 0.024 & 0.022 & 0.021 & 0.014 \\
17.7 & 0.021 & 0.019 & 0.018 & 0.017 & 0.016 & 0.015 & 0.009 \\
18.7 & 0.012 & 0.011 & 0.010 & 0.009 & 0.009 & 0.008 & 0.005 \\
\hline
\end{tabular}

* Side Graphite Reflectors Removed

Table 24: Calculated PDE distribution for different thick tungsten filter as in the measurements

\begin{tabular}{cccccccc}
\hline $\begin{array}{c}\text { Depth } \\
(\mathrm{cm})\end{array}$ & $0-\mathrm{cm}$ & $1.0-\mathrm{cm}$ & $2.0-\mathrm{cm}$ & $3.0-\mathrm{cm}$ & $4.0-\mathrm{cm}$ & $5.0-\mathrm{cm}$ & $5.0-\mathrm{cm} /$ NSGR$^{\star}$ \\
\hline 0.7 & $3.1 \%$ & $3.3 \%$ & $3.7 \%$ & $4.2 \%$ & $4.8 \%$ & $5.4 \%$ & $4.1 \%$ \\
1.7 & $4.7 \%$ & $5.2 \%$ & $6.0 \%$ & $6.8 \%$ & $7.9 \%$ & $9.1 \%$ & $6.9 \%$ \\
2.7 & $5.8 \%$ & $6.8 \%$ & $7.9 \%$ & $9.1 \%$ & $10.5 \%$ & $12.1 \%$ & $9.4 \%$ \\
3.7 & $7.0 \%$ & $8.0 \%$ & $9.3 \%$ & $10.8 \%$ & $12.7 \%$ & $14.5 \%$ & $11.4 \%$ \\
4.7 & $7.6 \%$ & $8.7 \%$ & $10.2 \%$ & $11.9 \%$ & $14.1 \%$ & $16.1 \%$ & $12.5 \%$ \\
5.7 & $7.9 \%$ & $9.3 \%$ & $11.0 \%$ & $12.5 \%$ & $14.8 \%$ & $17.1 \%$ & $13.1 \%$ \\
6.7 & $8.2 \%$ & $9.4 \%$ & $11.1 \%$ & $12.9 \%$ & $15.3 \%$ & $17.9 \%$ & $13.4 \%$ \\
7.7 & $8.2 \%$ & $9.6 \%$ & $11.0 \%$ & $12.9 \%$ & $15.5 \%$ & $17.7 \%$ & $13.2 \%$ \\
8.7 & $8.0 \%$ & $9.3 \%$ & $10.9 \%$ & $12.6 \%$ & $15.1 \%$ & $16.9 \%$ & $12.6 \%$ \\
9.7 & $7.7 \%$ & $8.9 \%$ & $10.3 \%$ & $11.9 \%$ & $14.0 \%$ & $16.2 \%$ & $12.3 \%$ \\
10.7 & $7.3 \%$ & $8.5 \%$ & $9.8 \%$ & $11.4 \%$ & $13.3 \%$ & $15.7 \%$ & $11.2 \%$ \\
11.7 & $6.8 \%$ & $7.8 \%$ & $9.1 \%$ & $10.5 \%$ & $12.1 \%$ & $14.0 \%$ & $10.1 \%$ \\
12.7 & $6.2 \%$ & $7.1 \%$ & $8.3 \%$ & $9.4 \%$ & $11.2 \%$ & $12.4 \%$ & $8.9 \%$ \\
13.7 & $5.6 \%$ & $6.4 \%$ & $7.5 \%$ & $8.5 \%$ & $10.1 \%$ & $11.4 \%$ & $8.2 \%$ \\
14.7 & $5.0 \%$ & $5.7 \%$ & $6.5 \%$ & $7.5 \%$ & $8.8 \%$ & $10.1 \%$ & $6.9 \%$ \\
15.7 & $4.2 \%$ & $4.8 \%$ & $5.6 \%$ & $6.3 \%$ & $7.1 \%$ & $8.3 \%$ & $5.8 \%$ \\
16.7 & $3.4 \%$ & $3.9 \%$ & $4.5 \%$ & $5.1 \%$ & $5.9 \%$ & $6.6 \%$ & $4.5 \%$ \\
17.7 & $2.6 \%$ & $2.9 \%$ & $3.3 \%$ & $3.9 \%$ & $4.4 \%$ & $5.0 \%$ & $3.1 \%$ \\
18.7 & $1.5 \%$ & $1.7 \%$ & $2.0 \%$ & $2.2 \%$ & $2.6 \%$ & $3.0 \%$ & $1.7 \%$ \\
\hline
\end{tabular}

* Side Graphite Reflectors Removed 
B.2 Measurements of absorbed dose and PDE distributions in a water-filled RSVP head phantom using the simplified BNCEFNT assembly as described in Chapter 5. 12.5-cm graphite reflector, $5 \times 5 \mathrm{~cm}^{2}$ size with $10-\mathrm{cm}$ thick lead collimator made of four $20 \times 10 \times 5 \mathrm{~cm}^{3}$ lead bricks, $20 \times 20 \mathrm{~cm}^{2}$ standard therapy beam.

Table 25: Measurements of the absorbed dose in the water-filled head phantom using non-borated ion chamber (SN:445) and Equation (3.24)

\begin{tabular}{cccccccc}
\hline $\begin{array}{c}\text { Depth } \\
(\mathrm{cm})\end{array}$ & $0-\mathrm{cm}$ & $1.0-\mathrm{cm}$ & $2.0-\mathrm{cm}$ & $3.0-\mathrm{cm}$ & $4.0-\mathrm{cm}$ & $5.0-\mathrm{cm}$ & $5.0-\mathrm{cm}^{\prime} \mathrm{NSGR}^{\star}$ \\
\hline 1.0 & 2.060 & 1.728 & 1.463 & 1.244 & 1.071 & 0.915 & 0.902 \\
2.0 & 2.058 & 1.716 & 1.452 & 1.229 & 1.054 & 0.896 & 0.890 \\
3.0 & 1.977 & 1.635 & 1.382 & 1.166 & 0.996 & 0.847 & 0.843 \\
4.0 & 1.874 & 1.569 & 1.317 & 1.109 & 0.947 & 0.803 & 0.787 \\
5.0 & 1.770 & 1.480 & 1.239 & 1.040 & 0.886 & 0.751 & 0.733 \\
5.8 & 1.661 & 1.364 & 1.164 & 0.977 & 0.824 & 0.694 & \\
6.8 & 1.567 & 1.298 & 1.090 & 0.917 & 0.772 & 0.649 & \\
7.8 & 1.475 & 1.221 & 1.024 & 0.859 & 0.721 & 0.606 & \\
8.8 & 1.388 & 1.147 & 0.961 & 0.804 & 0.674 & 0.565 & \\
9.8 & 1.305 & 1.076 & 0.900 & 0.753 & 0.628 & 0.526 & \\
10.8 & 1.227 & 1.009 & 0.844 & 0.704 & 0.585 & 0.490 & \\
11.8 & 1.152 & 0.947 & 0.791 & 0.658 & 0.547 & 0.456 & \\
12.8 & 1.083 & 0.888 & 0.740 & 0.615 & 0.511 & 0.425 & \\
\hline
\end{tabular}

* Side Graphite Reflectors Removed 
Table 26: Measured boron-10 dose using the borated (SN\#446) and the non-borated ion chambers and Equation (3.22)

\begin{tabular}{cccccccc}
\hline $\begin{array}{c}\text { Depth } \\
(\mathrm{cm})\end{array}$ & $0-\mathrm{cm}$ & $1.0-\mathrm{cm}$ & $2.0-\mathrm{cm}$ & $3.0-\mathrm{cm}$ & $4.0-\mathrm{cm}$ & $5.0-\mathrm{cm}$ & $5.0-\mathrm{cm}_{\text {NSGR }}$ \\
\hline 1.0 & 0.087 & 0.081 & 0.080 & 0.076 & 0.075 & 0.076 & 0.057 \\
2.0 & 0.104 & 0.100 & 0.101 & 0.100 & 0.099 & 0.100 & 0.075 \\
3.0 & 0.116 & 0.118 & 0.118 & 0.119 & 0.117 & 0.117 & 0.089 \\
4.0 & 0.129 & 0.126 & 0.128 & 0.127 & 0.125 & 0.125 & 0.097 \\
5.0 & 0.135 & 0.130 & 0.132 & 0.131 & 0.128 & 0.127 & 0.098 \\
5.8 & 0.134 & 0.127 & 0.125 & 0.128 & 0.123 & 0.111 & \\
6.8 & 0.128 & 0.118 & 0.119 & 0.123 & 0.117 & 0.104 & \\
7.8 & 0.121 & 0.109 & 0.111 & 0.113 & 0.108 & 0.095 & \\
8.8 & 0.110 & 0.099 & 0.100 & 0.102 & 0.097 & 0.084 & \\
9.8 & 0.098 & 0.089 & 0.089 & 0.091 & 0.086 & 0.074 & \\
10.8 & 0.087 & 0.078 & 0.078 & 0.079 & 0.076 & 0.064 & \\
11.8 & 0.076 & 0.067 & 0.067 & 0.069 & 0.065 & 0.052 & \\
12.8 & 0.065 & 0.057 & 0.057 & 0.059 & 0.055 & 0.046 & \\
\hline \multicolumn{7}{c}{ * Side Graphite Reflectors Removed }
\end{tabular}

Table 27: Measured PDE Normalized to $100-\mathrm{ppm}{ }^{10} \mathrm{~B}$ using the borated and non-borated ion chambers and Equation (3.23)

\begin{tabular}{cccccccc}
\hline $\begin{array}{c}\text { Depth } \\
(\mathrm{cm})\end{array}$ & $0-\mathrm{cm}$ & $1.0-\mathrm{cm}$ & $2.0-\mathrm{cm}$ & $3.0-\mathrm{cm}$ & $4.0-\mathrm{cm}$ & $5.0-\mathrm{cm}$ & $5.0-\mathrm{cm} / \mathrm{NSGR}^{*}$ \\
\hline 1.0 & $4.2 \%$ & $4.7 \%$ & $5.5 \%$ & $6.1 \%$ & $7.0 \%$ & $8.3 \%$ & $6.3 \%$ \\
2.0 & $5.1 \%$ & $5.9 \%$ & $7.0 \%$ & $8.1 \%$ & $9.4 \%$ & $11.2 \%$ & $8.4 \%$ \\
3.0 & $5.9 \%$ & $7.2 \%$ & $8.5 \%$ & $10.2 \%$ & $11.8 \%$ & $13.9 \%$ & $10.5 \%$ \\
4.0 & $6.9 \%$ & $8.0 \%$ & $9.7 \%$ & $11.5 \%$ & $13.2 \%$ & $15.6 \%$ & $12.3 \%$ \\
5.0 & $7.6 \%$ & $8.8 \%$ & $10.6 \%$ & $12.6 \%$ & $14.4 \%$ & $16.9 \%$ & $13.4 \%$ \\
5.8 & $8.1 \%$ & $9.3 \%$ & $10.8 \%$ & $13.1 \%$ & $14.9 \%$ & $16.0 \%$ & \\
6.8 & $8.2 \%$ & $9.1 \%$ & $11.0 \%$ & $13.4 \%$ & $15.2 \%$ & $16.0 \%$ & \\
7.8 & $8.2 \%$ & $8.9 \%$ & $10.8 \%$ & $13.2 \%$ & $14.9 \%$ & $15.7 \%$ & \\
8.8 & $7.9 \%$ & $8.7 \%$ & $10.4 \%$ & $12.7 \%$ & $14.4 \%$ & $15.0 \%$ & \\
9.8 & $7.5 \%$ & $8.2 \%$ & $9.9 \%$ & $12.0 \%$ & $13.7 \%$ & $14.0 \%$ & \\
10.8 & $7.1 \%$ & $7.7 \%$ & $9.2 \%$ & $11.3 \%$ & $12.9 \%$ & $13.0 \%$ & \\
11.8 & $6.6 \%$ & $7.1 \%$ & $8.5 \%$ & $10.4 \%$ & $11.9 \%$ & $11.4 \%$ & \\
12.8 & $6.0 \%$ & $6.4 \%$ & $7.7 \%$ & $9.6 \%$ & $10.8 \%$ & $10.9 \%$ & \\
\hline
\end{tabular}

* Side Graphite Reflectors Removed 


\section{APPENDIX C}

\section{RAW MEASUREMENT DATA}




\section{C.1 Measurements using the normal TE ion chamber (SN \# 445)}

Table 28: Non-borated ion chamber measurement data for the simplified BNCEFNT assembly: $5 \mathrm{x} 5 \mathrm{~cm}^{2}$ collimator with no-filter using the $20 \times 20 \mathrm{~cm}^{2}$ standard therapy beam. Measurements made May, 2006.

\begin{tabular}{|c|c|c|c|c|c|c|c|c|c|}
\hline \multirow[b]{3}{*}{$\begin{array}{l}\text { Depth } \\
\text { (cm) }\end{array}$} & \multicolumn{3}{|c|}{ Electrometer: Keithley 617 SN: 507703} & \multicolumn{3}{|c|}{ Ion Chamber SN: 445 (normal) } & \multicolumn{2}{|c|}{ High Voltage $=+400 \mathrm{~V}$} & \multirow[b]{3}{*}{ Notes } \\
\hline & $\begin{array}{l}\text { Cint } / X 1= \\
\text { Off }\end{array}$ & $5.483 E+14$ & $\begin{array}{r}\text { protons/X1 } \\
\text { Monitor }\end{array}$ & Beam & & & & & \\
\hline & $\begin{array}{l}\text { Axis } \\
(\mathrm{cm})\end{array}$ & $\begin{array}{c}\text { Charge } \\
(\mathrm{nC})\end{array}$ & $\begin{array}{l}\text { Units } \\
\text { (MU) }\end{array}$ & $\begin{array}{l}\text { Time } \\
\text { (min) }\end{array}$ & X1 & $\begin{array}{c}\text { X1 } \\
\text { TPCX }\end{array}$ & $\begin{array}{c}\text { Pressure } \\
(\mathrm{mB})\end{array}$ & $\begin{array}{c}\text { Temperature } \\
\left({ }^{\circ} \mathrm{C}\right)\end{array}$ & \\
\hline 1.0 & 0.0 & 8.957 & 0.3022 & 0.95 & 18.09 & 1.027 & 988.7 & 23.5 & $22^{\circ} \mathrm{IC}$ holder \\
\hline 2.0 & 0.0 & 8.940 & 0.3020 & 0.96 & 18.08 & 1.027 & 988.7 & 23.5 & \\
\hline 3.0 & 0.0 & 8.576 & 0.3016 & 0.95 & 18.05 & 1.027 & 988.7 & 23.4 & \\
\hline 4.0 & 0.0 & 8.113 & 0.3009 & 0.95 & 18.00 & 1.027 & 988.7 & 23.4 & \\
\hline 5.0 & 0.0 & 7.664 & 0.3011 & 0.95 & 18.02 & 1.027 & 988.5 & 23.5 & \\
\hline 1.5 & 0.0 & 8.953 & 0.3015 & 0.94 & 18.04 & 1.027 & 988.5 & 23.5 & \\
\hline 1.5 & 1.0 & 8.940 & 0.3013 & 0.94 & 18.03 & 1.027 & 988.5 & 23.4 & \\
\hline 1.5 & 2.0 & 9.001 & 0.3021 & 0.94 & 18.08 & 1.027 & 988.5 & 23.4 & \\
\hline 1.5 & 2.5 & 8.785 & 0.3009 & 0.94 & 18.00 & 1.027 & 988.5 & 23.4 & \\
\hline 1.5 & 3.0 & 6.554 & 0.3003 & 0.96 & 18.07 & 1.028 & 988.5 & 23.4 & \\
\hline 1.5 & -1.0 & 9.030 & 0.3016 & 0.96 & 18.07 & 1.027 & 988.5 & 23.4 & \\
\hline 1.5 & -2.0 & 8.513 & 0.3010 & 0.96 & 18.04 & 1.028 & 988.5 & 23.4 & \\
\hline 1.5 & -2.5 & 6.040 & 0.3016 & 0.96 & 18.00 & 1.028 & 988.5 & 23.4 & \\
\hline 3.0 & 1.0 & 8.499 & 0.3001 & 0.96 & 18.05 & 1.028 & 988.5 & 23.4 & \\
\hline 3.0 & 2.0 & 8.548 & 0.3021 & 0.97 & 18.07 & 1.028 & 988.5 & 23.4 & \\
\hline 3.0 & 2.5 & 8.379 & 0.3022 & 0.96 & 18.07 & 1.028 & 988.5 & 23.4 & \\
\hline 3.0 & 3.0 & 6.445 & 0.3021 & 0.96 & 18.07 & 1.028 & 988.5 & 23.5 & \\
\hline 3.0 & -1.0 & 8.492 & 0.3015 & 0.96 & 18.03 & 1.028 & 988.5 & 23.5 & \\
\hline 3.0 & -2.0 & 7.908 & 0.2992 & 0.95 & 17.89 & 1.028 & 988.5 & 23.5 & \\
\hline 3.0 & -2.5 & 5.733 & 0.3004 & 0.96 & 17.97 & 1.028 & 988.5 & 23.5 & \\
\hline 3.0 & -3.0 & 3.842 & 0.2993 & 0.95 & 17.89 & 1.028 & 988.5 & 23.5 & \\
\hline 5.8 & 0.0 & 10.016 & 0.4207 & 1.34 & 25.14 & 1.029 & 983.6 & 22.84 & Perpendicular \\
\hline 5.8 & 0.0 & 10.045 & 0.4216 & 1.34 & 25.19 & 1.029 & 983.6 & 22.84 & IC holder \\
\hline 6.8 & 0.0 & 9.461 & 0.4209 & 1.34 & 25.14 & 1.029 & 983.6 & 22.84 & \\
\hline 6.8 & 0.0 & 9.479 & 0.4220 & 1.34 & 25.21 & 1.029 & 983.6 & 22.84 & \\
\hline 7.8 & 0.0 & 8.874 & 0.4195 & 1.38 & 25.02 & 1.031 & 983.6 & 22.84 & \\
\hline 7.8 & 0.0 & 8.895 & 0.4207 & 1.38 & 25.09 & 1.031 & 983.6 & 22.84 & \\
\hline 8.8 & 0.0 & 8.364 & 0.4201 & 1.33 & 25.05 & 1.031 & 983.6 & 22.84 & \\
\hline 8.8 & 0.0 & 8.366 & 0.4203 & 1.33 & 25.02 & 1.032 & 983.6 & 22.84 & \\
\hline 9.8 & 0.0 & 7.883 & 0.4210 & 1.33 & 25.08 & 1.032 & 983.6 & 22.84 & \\
\hline 9.8 & 0.0 & 7.881 & 0.4211 & 1.33 & 25.08 & 1.032 & 983.6 & 22.84 & \\
\hline 10.8 & 0.0 & 7.396 & 0.4203 & 1.36 & 25.03 & 1.032 & 983.6 & 22.84 & \\
\hline 11.8 & 0.0 & 6.960 & 0.4212 & 1.36 & 25.07 & 1.033 & 983.6 & 22.84 & \\
\hline 12.8 & 0.0 & 6.530 & 0.4204 & 1.36 & 25.02 & 1.033 & 983.6 & 22.84 & \\
\hline 8.8 & 0.0 & 8.391 & 0.4212 & 1.38 & 25.07 & 1.033 & 983.6 & 22.84 & \\
\hline 8.8 & 1.0 & 8.415 & 0.4216 & 1.38 & 25.08 & 1.033 & 983.6 & 22.84 & \\
\hline 8.8 & 2.0 & 8.276 & 0.4207 & 1.37 & 25.02 & 1.034 & 983.6 & 22.84 & \\
\hline 8.8 & 2.5 & 7.908 & 0.4216 & 1.33 & 25.08 & 1.034 & 983.0 & 22.84 & \\
\hline 8.8 & 3.0 & 6.033 & 0.4212 & 1.36 & 25.06 & 1.033 & 983.5 & 22.84 & \\
\hline 8.8 & 3.5 & 4.244 & 0.4209 & 1.32 & 25.05 & 1.033 & 983.5 & 22.84 & \\
\hline 8.8 & -1.0 & 8.364 & 0.4210 & 1.37 & 25.06 & 1.033 & 983.5 & 23.20 & \\
\hline 8.8 & -2.0 & 8.043 & 0.4219 & 1.35 & 25.08 & 1.034 & 983.5 & 23.20 & \\
\hline 8.8 & -2.5 & 6.520 & 0.4212 & 1.38 & 25.04 & 1.034 & 983.5 & 23.20 & \\
\hline 8.8 & -3.0 & 7.407 & 0.7018 & 2.29 & 41.72 & 1.034 & 983.5 & 23.20 & \\
\hline
\end{tabular}


Table 29: Non-borated ion chamber measurement data for the simplified BNCEFNT assembly: $5 \mathrm{x} 5 \mathrm{~cm}^{2}$ collimator with $1.0-\mathrm{cm}$ tungsten filter using the $20 \times 20 \mathrm{~cm}^{2}$ standard therapy beam. Measurements made May, 2006.

\begin{tabular}{|c|c|c|c|c|c|c|c|c|c|}
\hline \multirow[b]{3}{*}{$\begin{array}{l}\text { Depth } \\
(\mathrm{cm})\end{array}$} & \multicolumn{3}{|c|}{ Electrometer: Keithley 617 SN: 507703} & \multicolumn{3}{|c|}{ Ion Chamber SN: 445 (normal) } & \multicolumn{2}{|c|}{ High Voltage $=+400 \mathrm{~V}$} & \multirow[b]{3}{*}{ Notes } \\
\hline & $\begin{array}{l}\text { Cint } / X 1= \\
\text { Off }\end{array}$ & $5.483 E+14$ & $\begin{array}{l}\text { protons/X1 } \\
\text { Monitor }\end{array}$ & Beam & & & & & \\
\hline & $\begin{array}{l}\text { Axis } \\
(\mathrm{cm})\end{array}$ & $\begin{array}{c}\text { Charge } \\
(\mathrm{nC})\end{array}$ & $\begin{array}{l}\text { Units } \\
\text { (MU) }\end{array}$ & $\begin{array}{l}\text { Time } \\
\text { (min) }\end{array}$ & X1 & $\begin{array}{c}\text { X1 } \\
\text { TPCX }\end{array}$ & $\begin{array}{c}\text { Pressure } \\
(\mathrm{mB})\end{array}$ & $\begin{array}{c}\text { Temperature } \\
\left({ }^{\circ} \mathrm{C}\right)\end{array}$ & \\
\hline 1.0 & 0.0 & 7.433 & 0.2991 & 0.96 & 17.88 & 1.029 & 988.4 & 23.50 & $22^{\circ} \mathrm{IC}$ holder \\
\hline 2.0 & 0.0 & 7.404 & 0.3001 & 0.97 & 17.94 & 1.029 & 988.4 & 23.50 & \\
\hline 3.0 & 0.0 & 7.052 & 0.2998 & 0.96 & 17.92 & 1.029 & 988.4 & 23.36 & \\
\hline 4.0 & 0.0 & 6.777 & 0.3002 & 0.96 & 17.94 & 1.029 & 988.4 & 23.36 & \\
\hline 5.0 & 0.0 & 6.389 & 0.3002 & 0.97 & 17.94 & 1.029 & 988.4 & 23.36 & \\
\hline 1.5 & 0.0 & 7.507 & 0.3006 & 0.96 & 17.96 & 1.029 & 988.4 & 23.36 & \\
\hline 1.5 & 2.5 & 7.260 & 0.2997 & 0.96 & 17.91 & 1.029 & 988.3 & 23.36 & \\
\hline 1.5 & 3.0 & 5.525 & 0.2995 & 0.96 & 17.89 & 1.029 & 988.4 & 23.36 & \\
\hline 1.5 & -2.5 & 5.209 & 0.2994 & 0.97 & 17.88 & 1.029 & 988.4 & 23.36 & \\
\hline 1.5 & -3.0 & 3.663 & 0.2990 & 0.96 & 17.91 & 1.029 & 988.4 & 23.36 & \\
\hline 5.8 & 0.0 & 9.907 & 0.5070 & 1.63 & 29.83 & 1.034 & 983.5 & 23.20 & Perpendicular \\
\hline 6.8 & 0.0 & 9.336 & 0.5017 & 1.63 & 29.84 & 1.034 & 983.5 & 22.98 & IC holder \\
\hline 7.8 & 0.0 & 8.760 & 0.5005 & 1.63 & 29.77 & 1.034 & 983.5 & 22.98 & \\
\hline 8.8 & 0.0 & 8.243 & 0.5014 & 1.63 & 29.81 & 1.034 & 983.5 & 22.98 & \\
\hline 9.8 & 0.0 & 7.729 & 0.5011 & 1.63 & 29.80 & 1.034 & 983.5 & 22.98 & \\
\hline 10.8 & 0.0 & 7.252 & 0.5013 & 1.63 & 29.81 & 1.034 & 983.5 & 22.98 & \\
\hline 11.8 & 0.0 & 6.803 & 0.5013 & 1.64 & 29.81 & 1.034 & 983.5 & 22.98 & \\
\hline 12.8 & 0.0 & 6.386 & 0.5019 & 1.64 & 29.82 & 1.035 & 983.5 & 22.98 & \\
\hline 8.8 & 1.0 & 8.216 & 0.5003 & 1.64 & 29.82 & 1.035 & 983.5 & 22.98 & \\
\hline 8.8 & 2.0 & 8.084 & 0.5019 & 1.64 & 29.81 & 1.035 & 983.5 & 22.98 & \\
\hline 8.8 & 2.5 & 7.780 & 0.5011 & 1.63 & 29.76 & 1.035 & 983.5 & 22.98 & \\
\hline 8.8 & 3.0 & 9.928 & 0.7998 & 2.61 & 47.52 & 1.035 & 983.5 & 22.98 & \\
\hline
\end{tabular}

Table 30: Non-borated ion chamber measurement data for the simplified BNCEFNT assembly: $5 \times 5 \mathrm{~cm}^{2}$ collimator with $2.0-\mathrm{cm}$ tungsten filter using the $20 \times 20 \mathrm{~cm}^{2}$ standard therapy beam. Measurements made May, 2006.

\begin{tabular}{|c|c|c|c|c|c|c|c|c|c|}
\hline \multirow[b]{2}{*}{$\begin{array}{l}\text { Depth } \\
(\mathrm{cm})\end{array}$} & \multicolumn{3}{|c|}{ Electrometer: Keithley 617 SN: 507703} & \multicolumn{3}{|c|}{ Ion Chamber SN: 445 (normal) } & \multicolumn{2}{|c|}{ High Voltage $=+400 \mathrm{~V}$} & \multirow[b]{2}{*}{ Notes } \\
\hline & $\begin{array}{l}\text { Cint } / \times 1= \\
\text { Off } \\
\text { Axis } \\
(\mathrm{cm})\end{array}$ & $\begin{array}{c}5.483 E+14 \\
\text { Charge } \\
(\mathrm{nC})\end{array}$ & $\begin{array}{c}\text { protons/X1 } \\
\text { Monitor } \\
\text { Units } \\
\text { (MU) }\end{array}$ & $\begin{array}{l}\text { Beam } \\
\text { Time } \\
\text { (min) }\end{array}$ & X1 & $\begin{array}{c}\text { X1 } \\
\text { TPCX }\end{array}$ & $\begin{array}{c}\text { Pressure } \\
(\mathrm{mB})\end{array}$ & $\begin{array}{c}\text { Temperature } \\
\left({ }^{\circ} \mathrm{C}\right)\end{array}$ & \\
\hline 1.0 & 0.0 & 8.435 & 0.4008 & 1.25 & 23.93 & 1.029 & 988.4 & 23.36 & $22^{\circ} \mathrm{IC}$ holder \\
\hline 2.0 & 0.0 & 7.310 & 0.3501 & 1.13 & 20.91 & 1.029 & 988.4 & 23.36 & \\
\hline 3.0 & 0.0 & 6.965 & 0.3503 & 1.13 & 20.92 & 1.029 & 988.4 & 23.36 & \\
\hline 4.0 & 0.0 & 6.631 & 0.3500 & 1.12 & 20.90 & 1.029 & 988.4 & 23.36 & \\
\hline 5.0 & 0.0 & 6.248 & 0.3506 & 1.13 & 20.93 & 1.029 & 988.4 & 23.36 & \\
\hline 3.0 & 2.5 & 6.688 & 0.3510 & 1.12 & 20.96 & 1.029 & 988.4 & 23.36 & \\
\hline 3.0 & 3.0 & 5.715 & 0.3710 & 1.19 & 22.15 & 1.030 & 988.4 & 23.36 & \\
\hline 3.0 & -2.5 & 4.924 & 0.3509 & 1.12 & 20.95 & 1.030 & 988.4 & 23.36 & \\
\hline 3.0 & -3.0 & 3.884 & 0.3719 & 1.19 & 22.20 & 1.030 & 988.4 & 23.36 & \\
\hline 5.8 & 0.0 & 13.360 & 0.8012 & 2.60 & 47.60 & 1.035 & 983.5 & 22.98 & Perpendicular \\
\hline 6.8 & 0.0 & 7.833 & 0.5014 & 1.62 & 29.79 & 1.035 & 983.5 & 22.98 & IC holder \\
\hline 7.8 & 0.0 & 7.352 & 0.5009 & 1.62 & 29.75 & 1.035 & 983.5 & 22.98 & \\
\hline 8.8 & 0.0 & 7.591 & 0.5510 & 1.78 & 32.75 & 1.035 & 983.5 & 22.98 & \\
\hline 9.8 & 0.0 & 7.757 & 0.6016 & 1.94 & 35.73 & 1.035 & 983.5 & 22.98 & \\
\hline 10.8 & 0.0 & 7.266 & 0.6010 & 1.94 & 35.69 & 1.035 & 983.5 & 22.98 & \\
\hline 11.8 & 0.0 & 6.813 & 0.6013 & 1.96 & 35.71 & 1.036 & 983.5 & 22.98 & \\
\hline 12.8 & 0.0 & 6.911 & 0.6517 & 2.11 & 38.68 & 1.036 & 983.5 & 22.98 & \\
\hline 8.8 & 1.0 & 7.544 & 0.5501 & 2.11 & 38.68 & 1.036 & 983.5 & 22.98 & \\
\hline 8.8 & 2.0 & 8.081 & 0.6090 & 1.93 & 35.66 & 1.036 & 983.5 & 22.98 & \\
\hline 8.8 & 2.5 & 7.783 & 0.6016 & 1.93 & 35.69 & 1.036 & 983.5 & 22.98 & \\
\hline 8.8 & 3.0 & 6.346 & 0.6022 & 1.94 & 35.72 & 1.036 & 983.5 & 22.98 & \\
\hline
\end{tabular}


Table 31: Non-borated ion chamber measurement data for the simplified BNCEFNT assembly: $5 \times 5 \mathrm{~cm}^{2}$ collimator with $3.0-\mathrm{cm}$ tungsten filter using the $20 \times 20 \mathrm{~cm}^{2}$ standard therapy beam. Measurements made May, 2006.

\begin{tabular}{|c|c|c|c|c|c|c|c|c|c|}
\hline \multirow[b]{3}{*}{$\begin{array}{l}\text { Depth } \\
(\mathrm{cm})\end{array}$} & \multicolumn{2}{|c|}{ Electrometer: Keithley 617} & SN: 507703 & \multicolumn{3}{|c|}{ Ion Chamber SN: 445 (normal) } & \multicolumn{2}{|c|}{ High Voltage $=+400 \mathrm{~V}$} & \multirow[b]{3}{*}{ Notes } \\
\hline & $\begin{array}{l}\text { Cint } / X 1= \\
\text { Off }\end{array}$ & $5.483 E+14$ & $\begin{array}{l}\text { protons/X1 } \\
\text { Monitor }\end{array}$ & Beam & & & & & \\
\hline & $\begin{array}{l}\text { Axis } \\
(\mathrm{cm})\end{array}$ & $\begin{array}{c}\text { Charge } \\
(\mathrm{nC})\end{array}$ & $\begin{array}{l}\text { Units } \\
(\mathrm{MU})\end{array}$ & $\begin{array}{l}\text { Time } \\
(\min )\end{array}$ & $\mathrm{X} 1$ & $\begin{array}{c}\text { X1 } \\
\text { TPCX }\end{array}$ & $\begin{array}{c}\text { Pressure } \\
(\mathrm{mB})\end{array}$ & $\begin{array}{c}\text { Temperature } \\
\left({ }^{\circ} \mathrm{C}\right)\end{array}$ & \\
\hline 1.0 & 0.0 & 5.371 & 0.3001 & 0.96 & 17.91 & 1.030 & 988.4 & 23.36 & $22^{\circ}$ IC holder \\
\hline 2.0 & 0.0 & 7.085 & 0.4009 & 1.28 & 23.93 & 1.030 & 988.4 & 23.36 & \\
\hline 3.0 & 0.0 & 6.720 & 0.4006 & 1.27 & 23.90 & 1.030 & 988.4 & 23.36 & \\
\hline 4.0 & 0.0 & 6.402 & 0.4013 & 1.27 & 23.93 & 1.030 & 988.4 & 23.36 & \\
\hline 5.0 & 0.0 & 6.001 & 0.4011 & 1.27 & 23.93 & 1.030 & 988.4 & 23.36 & \\
\hline 1.5 & 0.0 & 7.167 & 0.4004 & 1.27 & 23.88 & 1.030 & 988.4 & 23.36 & \\
\hline 1.5 & 2.5 & 6.821 & 0.4012 & 1.27 & 23.93 & 1.031 & 988.4 & 23.36 & \\
\hline 1.5 & 3.0 & 5.464 & 0.4009 & 1.27 & 23.91 & 1.031 & 988.4 & 23.36 & \\
\hline 1.5 & -2.5 & 5.225 & 0.4011 & 1.27 & 23.92 & 1.031 & 988.4 & 23.36 & \\
\hline 1.5 & -3.0 & 3.985 & 0.4011 & 1.27 & 23.92 & 1.031 & 988.4 & 23.36 & Perpendicular \\
\hline 5.8 & 0.0 & 8.436 & 0.6019 & 1.96 & 35.69 & 1.037 & 984.1 & 22.98 & IC holder \\
\hline 6.8 & 0.0 & 7.898 & 0.6007 & 1.94 & 35.63 & 1.037 & 984.1 & 22.98 & \\
\hline 7.8 & 0.0 & 7.403 & 0.6011 & 1.94 & 35.64 & 1.037 & 984.0 & 22.98 & \\
\hline 8.8 & 0.0 & 6.945 & 0.6024 & 1.94 & 35.73 & 1.037 & 984.1 & 22.98 & \\
\hline 9.8 & 0.0 & 5.014 & 0.4659 & 1.97 & 35.73 & 1.037 & 984.1 & 22.98 & \\
\hline 10.8 & 0.0 & 6.727 & 0.6213 & 1.97 & 36.85 & 1.037 & 984.2 & 22.98 & \\
\hline 11.8 & 0.0 & 6.560 & 0.6498 & 2.12 & 38.54 & 1.037 & 984.2 & 22.98 & \\
\hline 12.8 & 0.0 & 6.437 & 0.6816 & 2.22 & 40.42 & 1.037 & 984.2 & 22.98 & \\
\hline 8.8 & 0.0 & 6.186 & 0.7014 & 2.27 & 41.60 & 1.037 & 984.2 & 22.98 & \\
\hline
\end{tabular}

Table 32: Non-borated ion chamber measurement data for the simplified BNCEFNT assembly: $5 \times 5 \mathrm{~cm}^{2}$ collimator with $4.0-\mathrm{cm}$ tungsten filter using the $20 \times 20 \mathrm{~cm}^{2}$ standard therapy beam. Measurements made May, 2006.

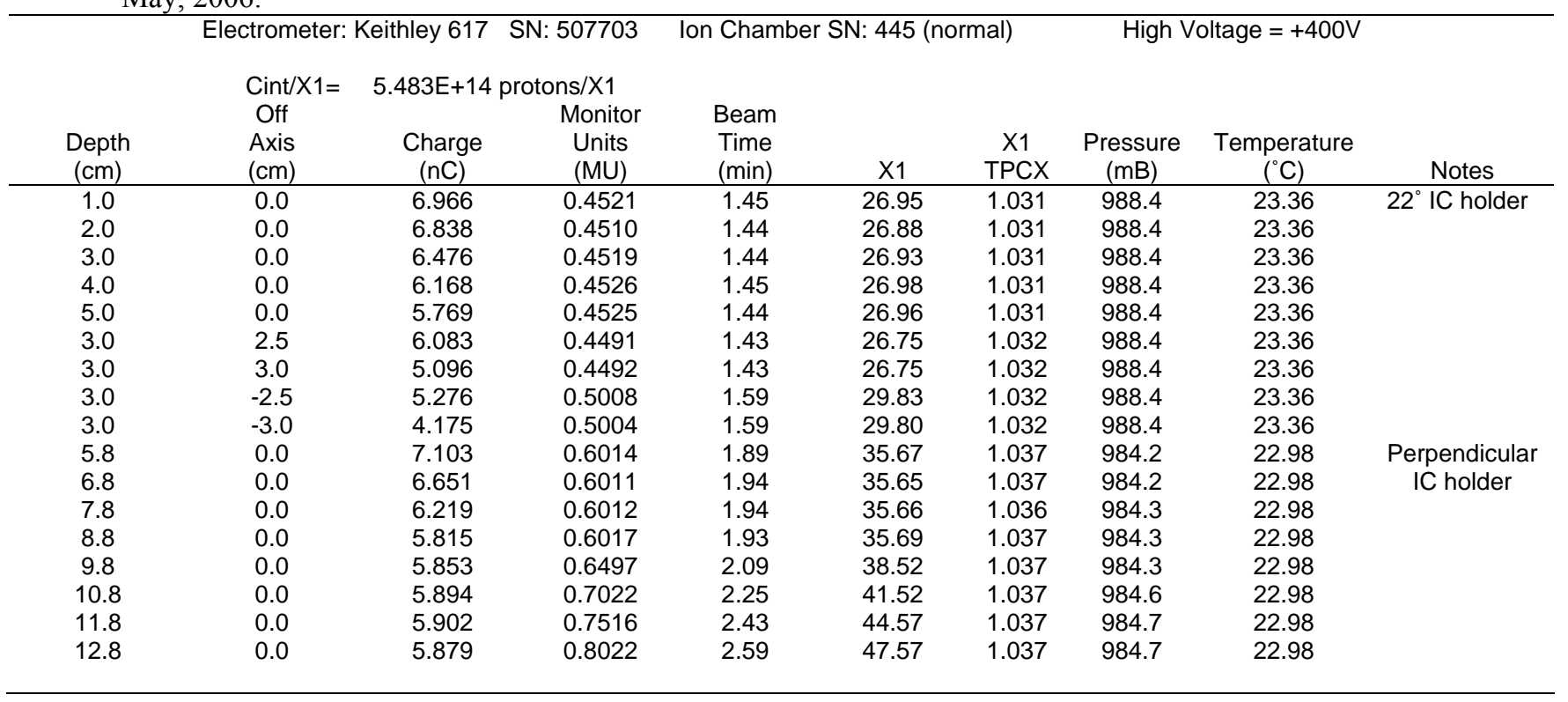


Table 33: Non-borated ion chamber measurement data for the simplified BNCEFNT assembly: $5 \times 5 \mathrm{~cm}^{2}$ collimator with $5.0-\mathrm{cm}$ tungsten filter using the $20 \times 20 \mathrm{~cm}^{2}$ standard therapy beam. Measurements made May, 2006.

\begin{tabular}{|c|c|c|c|c|c|c|c|c|c|}
\hline \multirow[b]{2}{*}{$\begin{array}{l}\text { Depth } \\
(\mathrm{cm})\end{array}$} & \multicolumn{3}{|c|}{ Electrometer: Keithley 617 SN: 507703} & \multicolumn{3}{|c|}{ Ion Chamber SN: 445 (normal) } & \multicolumn{2}{|c|}{ High Voltage $=+400 \mathrm{~V}$} & \multirow[b]{2}{*}{ Notes } \\
\hline & $\begin{array}{l}\text { Cint } / \times 1= \\
\text { Off } \\
\text { Axis } \\
\text { (cm) }\end{array}$ & $\begin{array}{c}5.483 \mathrm{E}+14 \\
\text { Charge } \\
(\mathrm{nC})\end{array}$ & $\begin{array}{c}\text { protons/X1 } \\
\text { Monitor } \\
\text { Units } \\
\text { (MU) }\end{array}$ & $\begin{array}{l}\text { Beam } \\
\text { Time } \\
\text { (min) }\end{array}$ & $\mathrm{X} 1$ & $\begin{array}{c}\text { X1 } \\
\text { TPCX }\end{array}$ & $\begin{array}{c}\text { Pressure } \\
(\mathrm{mB})\end{array}$ & $\begin{array}{c}\text { Temperature } \\
\left({ }^{\circ} \mathrm{C}\right)\end{array}$ & \\
\hline 1.0 & 0.0 & 6.581 & 0.5002 & 1.58 & 29.21 & 1.032 & 988.4 & 23.36 & $22^{\circ}$ IC holder \\
\hline 2.0 & 0.0 & 6.446 & 0.5002 & 1.58 & 29.78 & 1.033 & 988.4 & 23.36 & \\
\hline 3.0 & 0.0 & 5.476 & 0.4494 & 1.42 & 26.76 & 1.033 & 988.4 & 23.36 & \\
\hline 4.0 & 0.0 & 5.787 & 0.5010 & 1.42 & 26.76 & 1.033 & 988.4 & 23.36 & \\
\hline 5.0 & 0.0 & 5.401 & 0.5003 & 1.58 & 29.82 & 1.033 & 988.4 & 23.36 & \\
\hline 1.5 & 0.0 & 6.571 & 0.5006 & 1.57 & 29.78 & 1.033 & 988.4 & 23.36 & \\
\hline 1.5 & 1.0 & 6.528 & 0.5007 & 1.58 & 29.80 & 1.033 & 988.4 & 23.36 & \\
\hline 1.5 & 2.0 & 6.384 & 0.5012 & 1.58 & 29.79 & 1.033 & 988.3 & 23.36 & \\
\hline 1.5 & 2.5 & 6.138 & 0.5005 & 1.58 & 29.81 & 1.033 & 988.3 & 23.36 & \\
\hline 1.5 & 3.0 & 5.120 & 0.5020 & 1.59 & 29.85 & 1.034 & 987.9 & 23.36 & \\
\hline 1.5 & -1.0 & 6.496 & 0.5016 & 1.58 & 29.82 & 1.034 & 987.9 & 23.36 & \\
\hline 1.5 & -2.0 & 6.021 & 0.5017 & 1.58 & 29.83 & 1.034 & 987.9 & 23.36 & \\
\hline 1.5 & -2.5 & 4.934 & 0.5018 & 1.58 & 29.83 & 1.034 & 987.8 & 23.36 & \\
\hline 1.5 & -3.0 & 4.758 & 0.6006 & 1.89 & 35.70 & 1.034 & 987.8 & 23.36 & \\
\hline 3.0 & 1.0 & 5.492 & 0.4506 & 1.42 & 26.78 & 1.034 & 987.8 & 23.36 & \\
\hline 3.0 & 2.0 & 5.989 & 0.5019 & 1.58 & 29.82 & 1.035 & 987.8 & 23.36 & \\
\hline 3.0 & 2.5 & 5.781 & 0.5012 & 1.60 & 29.78 & 1.035 & 987.8 & 23.36 & \\
\hline 3.0 & 3.0 & 4.918 & 0.5016 & 1.58 & 29.80 & 1.035 & 987.9 & 23.36 & \\
\hline 3.0 & -1.0 & 6.038 & 0.5012 & 1.59 & 29.76 & 1.035 & 987.9 & 23.36 & \\
\hline 3.0 & -2.0 & 5.584 & 0.5018 & 1.60 & 29.80 & 1.035 & 987.9 & 23.36 & \\
\hline 3.0 & -2.5 & 4.776 & 0.5209 & 1.66 & 30.93 & 1.035 & 987.8 & 23.36 & \\
\hline 3.0 & -3.0 & 4.106 & 0.5512 & 1.74 & 32.73 & 1.036 & 987.8 & 23.36 & Perpendicular \\
\hline 5.8 & 0.0 & 6.981 & 0.7006 & 2.19 & 54.54 & 1.037 & 984.8 & 22.98 & IC holder \\
\hline 6.8 & 0.0 & 6.525 & 0.7002 & 2.25 & 41.50 & 1.037 & 984.8 & 22.98 & \\
\hline 7.8 & 0.0 & 6.087 & 0.7003 & 2.25 & 41.51 & 1.037 & 984.8 & 22.98 & \\
\hline 8.8 & 0.0 & 5.839 & 0.7202 & 2.31 & 42.68 & 1.037 & 984.8 & 22.98 & \\
\hline 9.8 & 0.0 & 6.043 & 0.8001 & 2.59 & 47.39 & 1.038 & 984.8 & 22.98 & \\
\hline 10.8 & 0.0 & 5.782 & 0.8223 & 2.65 & 48.72 & 1.038 & 984.8 & 22.98 & \\
\hline 11.8 & 0.0 & 5.903 & 0.9013 & 2.91 & 53.39 & 1.038 & 984.8 & 22.98 & \\
\hline 12.8 & 0.0 & 5.490 & 0.9001 & 2.90 & 53.31 & 1.038 & 985.0 & 22.98 & \\
\hline 8.8 & 1.0 & 6.061 & 0.7506 & 2.49 & 44.51 & 1.037 & 985.5 & 22.98 & \\
\hline 8.8 & 1.5 & 6.239 & 0.7799 & 2.59 & 46.27 & 1.036 & 985.5 & 22.98 & \\
\hline 8.8 & 2.0 & 6.128 & 0.7811 & 2.58 & 46.34 & 1.036 & 985.7 & 22.98 & \\
\hline 8.8 & 2.5 & 5.888 & 0.7804 & 2.58 & 46.29 & 1.036 & 985.7 & 22.98 & \\
\hline 8.8 & 3.0 & 5.162 & 0.8007 & 2.65 & 47.50 & 1.036 & 986.0 & 22.98 & \\
\hline 8.8 & -1.0 & 6.006 & 0.7513 & 2.50 & 44.57 & 1.036 & 986.0 & 22.98 & \\
\hline 8.8 & -1.5 & 5.911 & 0.7516 & 2.48 & 44.57 & 1.037 & 986.0 & 22.98 & \\
\hline 8.8 & -2.0 & 6.102 & 0.8024 & 2.65 & 47.59 & 1.036 & 986.0 & 22.98 & \\
\hline 8.8 & -2.5 & 5.395 & 0.8019 & 2.65 & 47.56 & 1.037 & 986.0 & 22.98 & \\
\hline 8.8 & -3.0 & 4.398 & 0.8015 & 2.66 & 47.53 & 1.037 & 986.0 & 22.98 & \\
\hline 1.0 & 0.0 & 6.492 & 0.5004 & 1.55 & 29.71 & 1.033 & 987.8 & 23.36 & Graphite \\
\hline 2.0 & 0.0 & 6.408 & 0.5007 & 1.59 & 29.73 & 1.033 & 987.8 & 23.36 & reflector on \\
\hline 3.0 & 0.0 & 6.058 & 0.4998 & 1.58 & 29.67 & 1.033 & 987.8 & 23.36 & both sides \\
\hline 4.0 & 0.0 & 5.666 & 0.5006 & 1.58 & 29.73 & 1.033 & 987.8 & 23.36 & removed \\
\hline 5.0 & 0.0 & 5.503 & 0.5219 & 1.65 & 30.98 & 1.033 & 987.8 & 23.36 & \\
\hline
\end{tabular}




\section{C.2 Measurements using the borated TE ion chamber (SN \# 446)}

Table 34: Borated ion chamber measurement data for the simplified BNCEFNT assembly: $5 \times 5 \mathrm{~cm}^{2}$ collimator with no-filter using the $20 \times 20 \mathrm{~cm}^{2}$ standard therapy beam. Measurements made May, 2006.

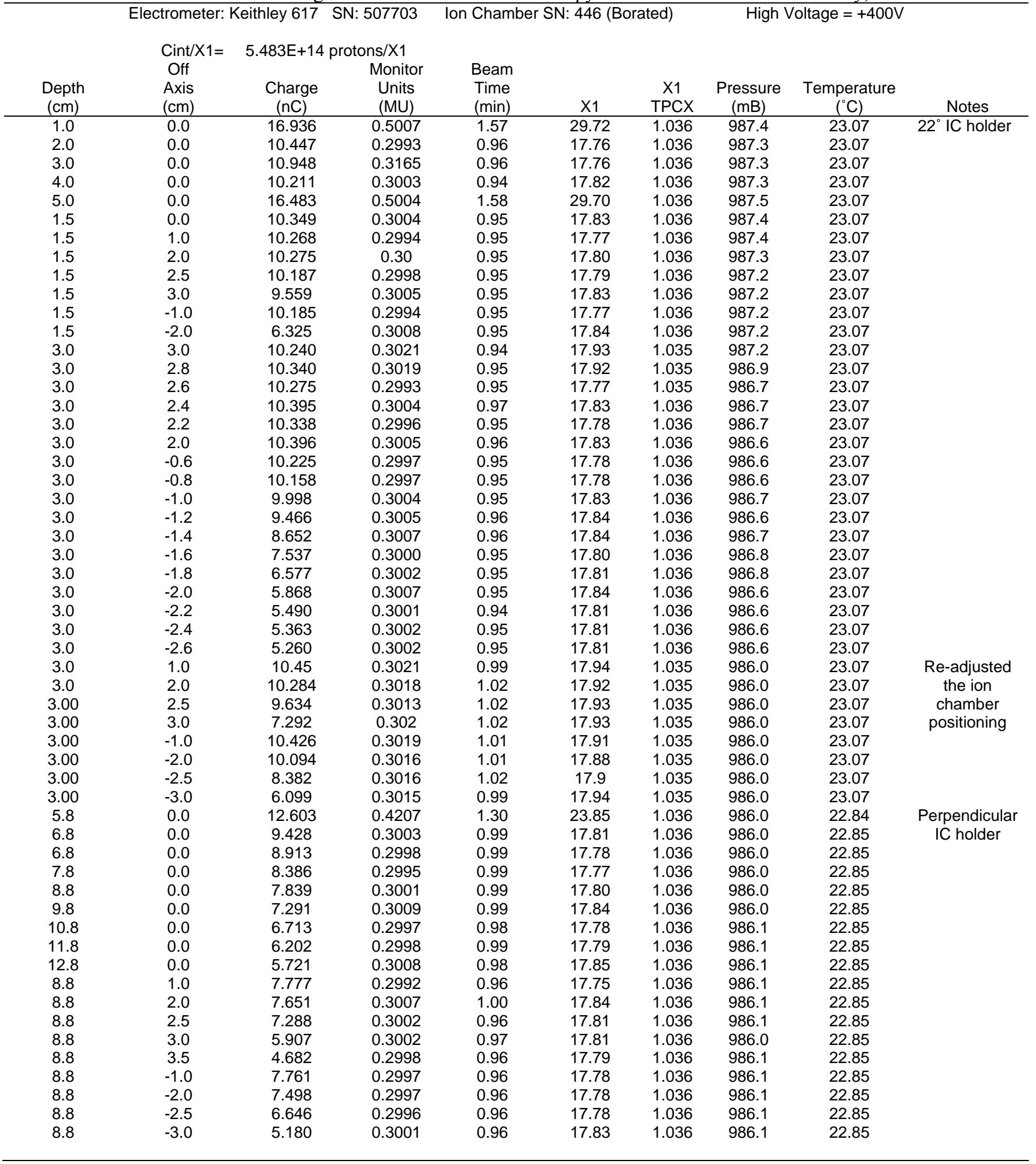


Table 35: Borated ion chamber measurement data for the simplified BNCEFNT assembly: $5 \times 5 \mathrm{~cm}^{2}$ collimator with $1.0-\mathrm{cm}$ tungsten filter using the $20 \times 20 \mathrm{~cm}^{2}$ standard therapy beam. Measurements made May, 2006.

\begin{tabular}{|c|c|c|c|c|c|c|c|c|c|}
\hline \multirow[b]{3}{*}{$\begin{array}{l}\text { Depth } \\
(\mathrm{cm})\end{array}$} & \multicolumn{2}{|c|}{ Electrometer: Keithley 617} & SN: 507703 & \multicolumn{3}{|c|}{ Ion Chamber SN: 446 (Borated) } & \multicolumn{2}{|c|}{ High Voltage $=+400 \mathrm{~V}$} & \multirow[b]{3}{*}{ Notes } \\
\hline & $\begin{array}{l}\text { Cint } / \times 1= \\
\text { Off }\end{array}$ & 5.483E+14 & $\begin{array}{r}\text { protons/X1 } \\
\text { Monitor }\end{array}$ & Beam & & & & & \\
\hline & $\begin{array}{l}\text { Axis } \\
(\mathrm{cm})\end{array}$ & $\begin{array}{c}\text { Charge } \\
(\mathrm{nC})\end{array}$ & $\begin{array}{l}\text { Units } \\
(\mathrm{MU}) \\
\end{array}$ & $\begin{array}{l}\text { Time } \\
\text { (min) }\end{array}$ & X1 & $\begin{array}{c}\mathrm{X} 1 \\
\text { TPCX }\end{array}$ & $\begin{array}{c}\text { Pressure } \\
(\mathrm{mB})\end{array}$ & $\begin{array}{c}\text { Temperature } \\
\left({ }^{\circ} \mathrm{C}\right)\end{array}$ & \\
\hline 1.0 & 0.0 & 8.660 & 0.3002 & 1.01 & 17.88 & 1.035 & 986.0 & 23.07 & $22^{\circ} \mathrm{IC}$ holder \\
\hline 2.0 & 0.0 & 9.014 & 0.3010 & 1.01 & 17.88 & 1.035 & 986.0 & 23.07 & \\
\hline 3.0 & 0.0 & 8.991 & 0.2999 & 1.00 & 17.80 & 1.035 & 986.0 & 23.07 & \\
\hline 4.0 & 0.0 & 8.938 & 0.3019 & 1.01 & 17.93 & 1.035 & 986.0 & 23.07 & \\
\hline 5.0 & 0.0 & 8.634 & 0.3013 & 1.01 & 17.89 & 1.035 & 985.9 & 23.07 & \\
\hline 1.5 & 0.0 & 8.961 & 0.3027 & 1.02 & 17.97 & 1.035 & 985.9 & 23.07 & \\
\hline 1.5 & -2.5 & 8.084 & 0.3024 & 1.02 & 17.96 & 1.035 & 986.0 & 23.07 & \\
\hline 1.5 & -3.0 & 6.049 & 0.3020 & 1.02 & 17.93 & 1.035 & 986.0 & 23.07 & \\
\hline 1.5 & 2.5 & 7.227 & 0.3021 & 1.02 & 17.94 & 1.035 & 986.0 & 23.07 & \\
\hline 1.5 & 3.0 & 5.296 & 0.3020 & 1.02 & 17.93 & 1.035 & 986.0 & 23.07 & \\
\hline 5.8 & 0.0 & 8.059 & 0.3000 & 0.96 & 17.8 & 1.036 & 986.1 & 22.85 & Perpendicular \\
\hline 6.8 & 0.0 & 7.609 & 0.2992 & 0.96 & 17.75 & 1.036 & 986.1 & 22.82 & IC holder \\
\hline 7.8 & 0.0 & 7.124 & 0.2995 & 0.95 & 17.77 & 1.036 & 986.3 & 22.82 & \\
\hline 8.8 & 0.0 & 6.626 & 0.2993 & 0.96 & 17.76 & 1.036 & 986.2 & 22.82 & \\
\hline 9.8 & 0.0 & 6.152 & 0.3006 & 0.97 & 17.84 & 1.036 & 986.1 & 22.82 & \\
\hline 10.8 & 0.0 & 5.656 & 0.3001 & 0.96 & 17.8 & 1.036 & 986.2 & 22.82 & \\
\hline 11.8 & 0.0 & 5.180 & 0.2992 & 0.99 & 17.75 & 1.036 & 986.2 & 22.82 & \\
\hline 12.8 & 0.0 & 4.759 & 0.3005 & 0.99 & 17.83 & 1.036 & 986.2 & 22.82 & \\
\hline 8.8 & 1.0 & 6.426 & 0.2992 & 0.99 & 17.76 & 1.036 & 986.3 & 22.82 & \\
\hline 8.8 & 2.0 & 4.864 & 0.3000 & 0.99 & 17.8 & 1.036 & 986.4 & 22.82 & \\
\hline 8.8 & 2.5 & 4.144 & 0.2994 & 0.99 & 17.77 & 1.036 & 986.5 & 22.82 & \\
\hline 8.8 & 3.0 & 3.920 & 0.2999 & 0.98 & 17.79 & 1.036 & 986.3 & 22.82 & \\
\hline 8.8 & 3.0 & 6.537 & 0.5005 & 1.65 & 29.69 & 1.036 & 986.4 & 22.82 & \\
\hline
\end{tabular}

Table 36: Borated ion chamber measurement data for the simplified BNCEFNT assembly: $5 \times 5 \mathrm{~cm}^{2}$ collimator with $2.0-\mathrm{cm}$ tungsten filter using the $20 \times 20 \mathrm{~cm}^{2}$ standard therapy beam. Measurements made May, 2006.

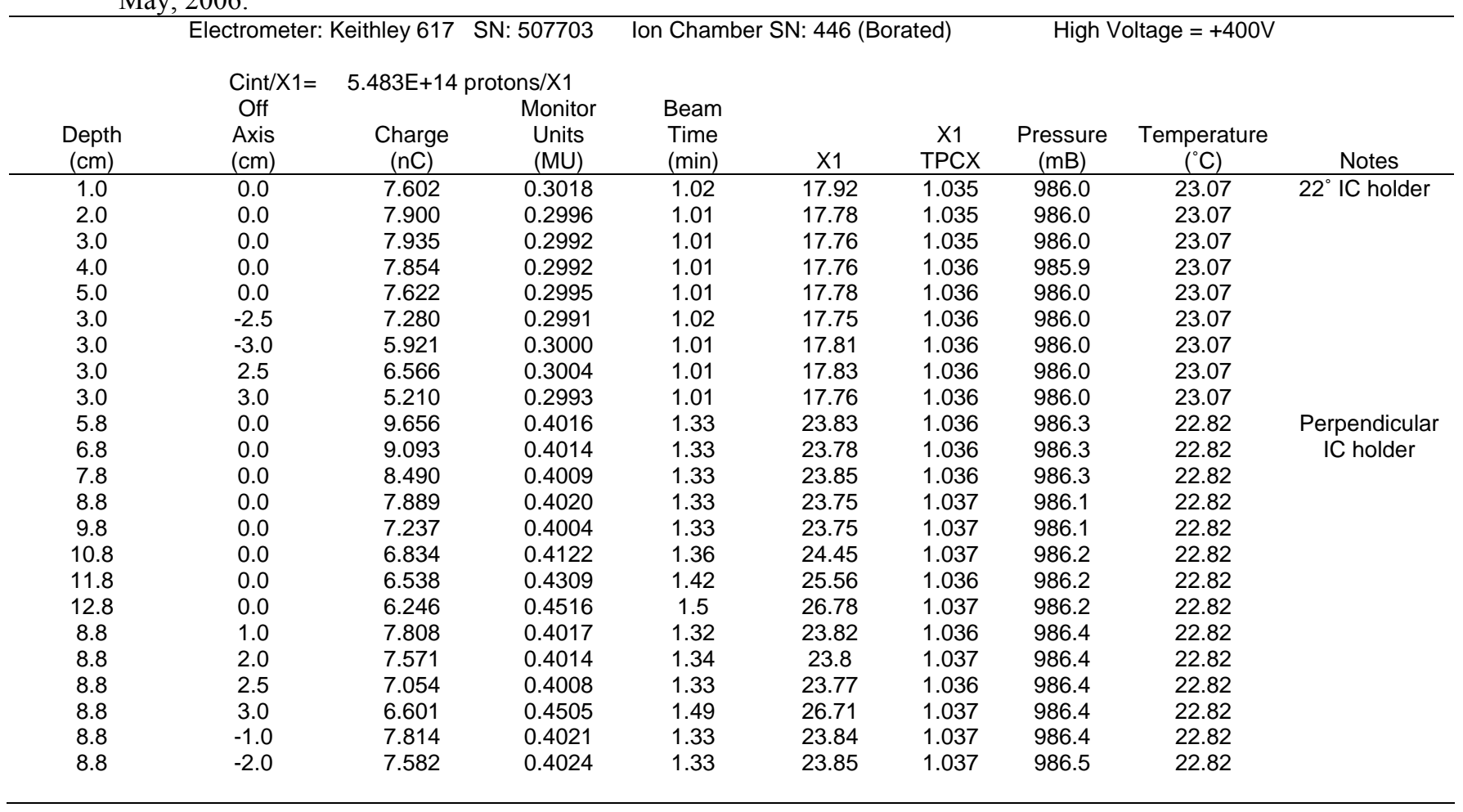


Table 37: Borated ion chamber measurement data for the simplified BNCEFNT assembly: $5 \times 5 \mathrm{~cm}^{2}$ collimator with $3.0-\mathrm{cm}$ tungsten filter using the $20 \times 20 \mathrm{~cm}^{2}$ standard therapy beam. Measurements made May, 2006.

\begin{tabular}{|c|c|c|c|c|c|c|c|c|c|}
\hline \multirow[b]{3}{*}{$\begin{array}{l}\text { Depth } \\
\text { (cm) }\end{array}$} & \multicolumn{2}{|c|}{ Electrometer: Keithley 617} & SN: 507703 & \multicolumn{3}{|c|}{ Ion Chamber SN: 446 (Borated) } & \multicolumn{2}{|c|}{ High Voltage $=+400 \mathrm{~V}$} & \multirow[b]{3}{*}{ Notes } \\
\hline & $\begin{array}{l}\text { Cint } / \times 1= \\
\text { Off }\end{array}$ & $5.483 E+14$ & $\begin{array}{r}\text { protons/X1 } \\
\text { Monitor }\end{array}$ & Beam & & & & & \\
\hline & $\begin{array}{l}\text { Axis } \\
(\mathrm{cm})\end{array}$ & $\begin{array}{l}\text { Charge } \\
(\mathrm{nC})\end{array}$ & $\begin{array}{l}\text { Units } \\
\text { (MU) }\end{array}$ & $\begin{array}{l}\text { Time } \\
\text { (min) }\end{array}$ & $\mathrm{X} 1$ & $\begin{array}{c}\text { X1 } \\
\text { TPCX }\end{array}$ & $\begin{array}{c}\text { Pressure } \\
(\mathrm{mB})\end{array}$ & $\begin{array}{c}\text { Temperature } \\
\left({ }^{\circ} \mathrm{C}\right)\end{array}$ & \\
\hline 1.0 & 0.0 & 6.580 & 0.3002 & 0.99 & 17.82 & 1.036 & 986.0 & 23.07 & $22^{\circ}$ IC holder \\
\hline 2.0 & 0.0 & 6.980 & 0.3000 & 1.01 & 17.78 & 1.036 & 986.0 & 23.07 & \\
\hline 3.0 & 0.0 & 7.082 & 0.2996 & 1.01 & 17.75 & 1.036 & 986.0 & 23.07 & \\
\hline 4.0 & 0.0 & 6.996 & 0.2992 & 1.01 & 17.78 & 1.036 & 985.6 & 23.07 & \\
\hline 5.0 & 0.0 & 6.797 & 0.2997 & 1.01 & 17.78 & 1.036 & 985.6 & 23.07 & \\
\hline 1.5 & 0.0 & 6.859 & 0.3001 & 1.01 & 17.80 & 1.036 & 985.6 & 23.07 & \\
\hline 1.5 & -2.5 & 6.072 & 0.2993 & 1.00 & 17.75 & 1.036 & 985.6 & 23.07 & \\
\hline 1.5 & -3.0 & 4.890 & 0.3003 & 1.01 & 17.81 & 1.036 & 985.6 & 23.07 & \\
\hline 1.5 & 2.5 & 5.646 & 0.2994 & 1.00 & 17.76 & 1.036 & 985.6 & 23.07 & \\
\hline 1.5 & 3.0 & 4.493 & 0.3003 & 1.00 & 17.81 & 1.036 & 985.6 & 23.07 & Perpendicular \\
\hline 5.8 & 0.0 & 13.035 & 0.6003 & 1.93 & 36.02 & 1.025 & 988.5 & 23.05 & IC holder \\
\hline 6.8 & 0.0 & 8.238 & 0.4015 & 1.26 & 24.09 & 1.024 & 988.6 & 23.05 & \\
\hline 7.8 & 0.0 & 7.667 & 0.4014 & 1.26 & 24.08 & 1.025 & 988.6 & 23.05 & \\
\hline 8.8 & 0.0 & 7.075 & 0.4007 & 1.26 & 24.04 & 1.025 & 988.6 & 23.05 & \\
\hline 9.8 & 0.0 & 6.491 & 0.4007 & 1.25 & 24.04 & 1.025 & 988.5 & 23.05 & \\
\hline 10.8 & 0.0 & 5.926 & 0.4006 & 1.25 & 24.03 & 1.025 & 988.6 & 23.05 & \\
\hline 11.8 & 0.0 & 6.074 & 0.4504 & 1.41 & 27.02 & 1.025 & 988.7 & 23.05 & \\
\hline 12.8 & 0.0 & 6.143 & 0.5014 & 1.58 & 30.07 & 1.025 & 988.8 & 23.05 & \\
\hline
\end{tabular}

Table 38: Borated ion chamber measurement data for the simplified BNCEFNT assembly: $5 \times 5 \mathrm{~cm}^{2}$ collimator with $4.0-\mathrm{cm}$ tungsten filter using the $20 \times 20 \mathrm{~cm}^{2}$ standard therapy beam. Measurements made May, 2006.

\begin{tabular}{|c|c|c|c|c|c|c|c|c|c|}
\hline \multirow[b]{2}{*}{$\begin{array}{l}\text { Depth } \\
(\mathrm{cm})\end{array}$} & \multicolumn{3}{|c|}{ Electrometer: Keithley 617 SN: 507703} & \multicolumn{3}{|c|}{ Ion Chamber SN: 446 (Borated) } & \multicolumn{2}{|c|}{ High Voltage $=+400 \mathrm{~V}$} & \multirow[b]{2}{*}{ Notes } \\
\hline & $\begin{array}{l}\text { Cint } / \times 1= \\
\text { Off } \\
\text { Axis } \\
\text { (cm) }\end{array}$ & $\begin{array}{c}5.483 E+14 \\
\text { Charge } \\
(\mathrm{nC})\end{array}$ & $\begin{array}{c}\text { protons/X1 } \\
\text { Monitor } \\
\text { Units } \\
\text { (MU) }\end{array}$ & $\begin{array}{c}\text { Beam } \\
\text { Time } \\
\text { (min) }\end{array}$ & $\mathrm{X} 1$ & $\begin{array}{c}\mathrm{X} 1 \\
\mathrm{TPCX}\end{array}$ & $\begin{array}{c}\text { Pressure } \\
(\mathrm{mB})\end{array}$ & $\begin{array}{c}\text { Temperature } \\
\left({ }^{\circ} \mathrm{C}\right)\end{array}$ & \\
\hline 1.0 & 0.0 & 5.855 & 0.3003 & 1.01 & 17.82 & 1.036 & 985.6 & 23.07 & $22^{\circ} \mathrm{IC}$ holder \\
\hline 2.0 & 0.0 & 6.238 & 0.2998 & 1.01 & 17.79 & 1.036 & 985.9 & 23.07 & \\
\hline 3.0 & 0.0 & 6.345 & 0.2992 & 1.01 & 17.75 & 1.036 & 985.9 & 23.07 & \\
\hline 4.0 & 0.0 & 6.327 & 0.3007 & 1.01 & 17.84 & 1.036 & 985.9 & 23.07 & \\
\hline 5.0 & 0.0 & 6.114 & 0.2997 & 1.01 & 17.78 & 1.036 & 985.9 & 23.07 & \\
\hline 3.0 & -2.5 & 5.770 & 0.2994 & 1.00 & 17.76 & 1.037 & 985.5 & 23.07 & \\
\hline 3.0 & -3.0 & 4.903 & 0.2993 & 1.01 & 17.75 & 1.037 & 985.5 & 23.07 & \\
\hline 3.0 & 2.5 & 5.371 & 0.3003 & 1.01 & 17.82 & 1.037 & 985.5 & 23.07 & \\
\hline 3.0 & 3.0 & 4.519 & 0.3000 & 1.00 & 17.80 & 1.037 & 985.5 & 23.07 & \\
\hline 5.8 & 0.0 & 9.654 & 0.5013 & 1.57 & 30.06 & 1.025 & 988.8 & 23.05 & Perpendicular \\
\hline 6.8 & 0.0 & 9.116 & 0.5012 & 1.59 & 30.05 & 1.025 & 988.7 & 23.05 & IC holder \\
\hline 7.8 & 0.0 & 8.451 & 0.5008 & 1.57 & 30.02 & 1.025 & 988.7 & 23.05 & \\
\hline 8.8 & 0.0 & 7.772 & 0.5006 & 1.56 & 30.01 & 1.025 & 988.7 & 23.05 & \\
\hline 9.8 & 0.0 & 7.119 & 0.5017 & 1.56 & 30.08 & 1.025 & 988.7 & 23.05 & \\
\hline 10.8 & 0.0 & 6.469 & 0.5006 & 1.55 & 30.01 & 1.025 & 988.7 & 23.05 & \\
\hline 11.8 & 0.0 & 6.461 & 0.5516 & 1.72 & 33.05 & 1.026 & 988.7 & 23.05 & \\
\hline 12.8 & 0.0 & 6.378 & 0.6020 & 1.88 & 36.07 & 1.026 & 988.7 & 23.05 & \\
\hline
\end{tabular}


Table 39: Borated ion chamber measurement data for the simplified BNCEFNT assembly: $5 \times 5 \mathrm{~cm}^{2}$ collimator with $5.0-\mathrm{cm}$ tungsten filter using the $20 \times 20 \mathrm{~cm}^{2}$ standard therapy beam. Measurements made May, 2006.

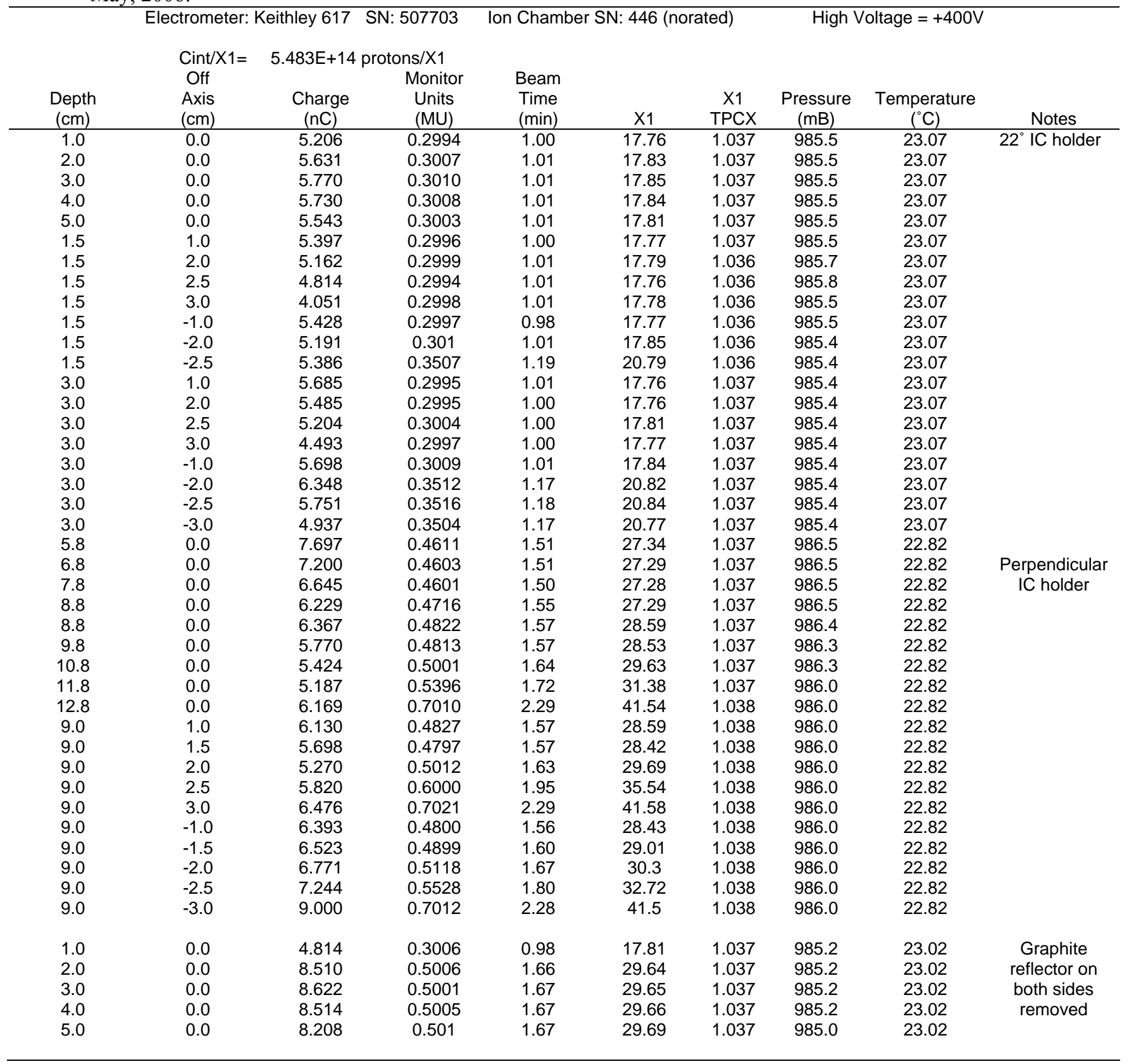


C.3 Comparison of neutron spectra before and after $5.0-\mathrm{cm}$ tungsten filter in the simplified BNCEFNT assembly

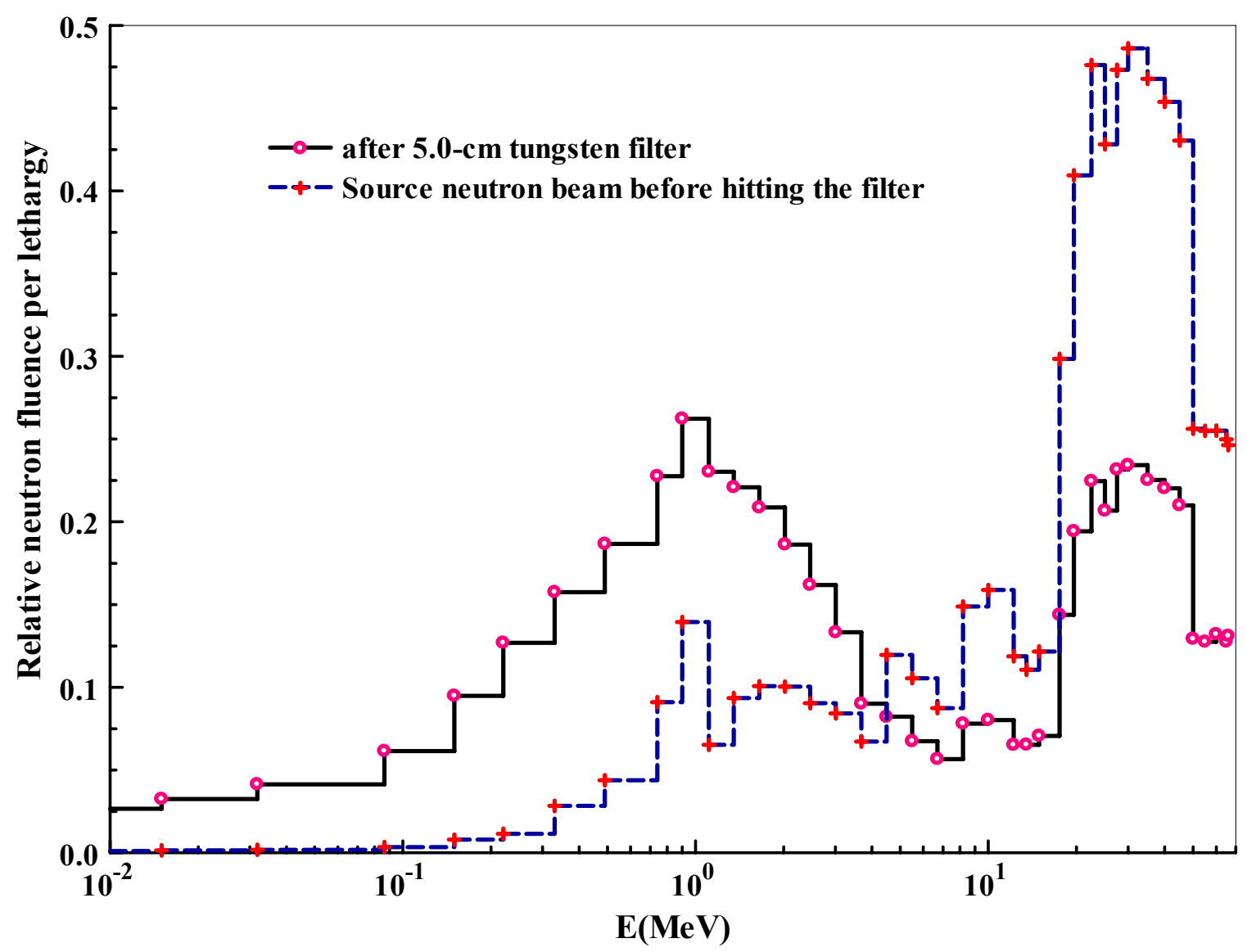

Figure 65: Comparison of source neutron spectrum and neutron spectrum after 5.0-cm tungsten filter in the simplified BNCEFNT assembly (lethargy). 


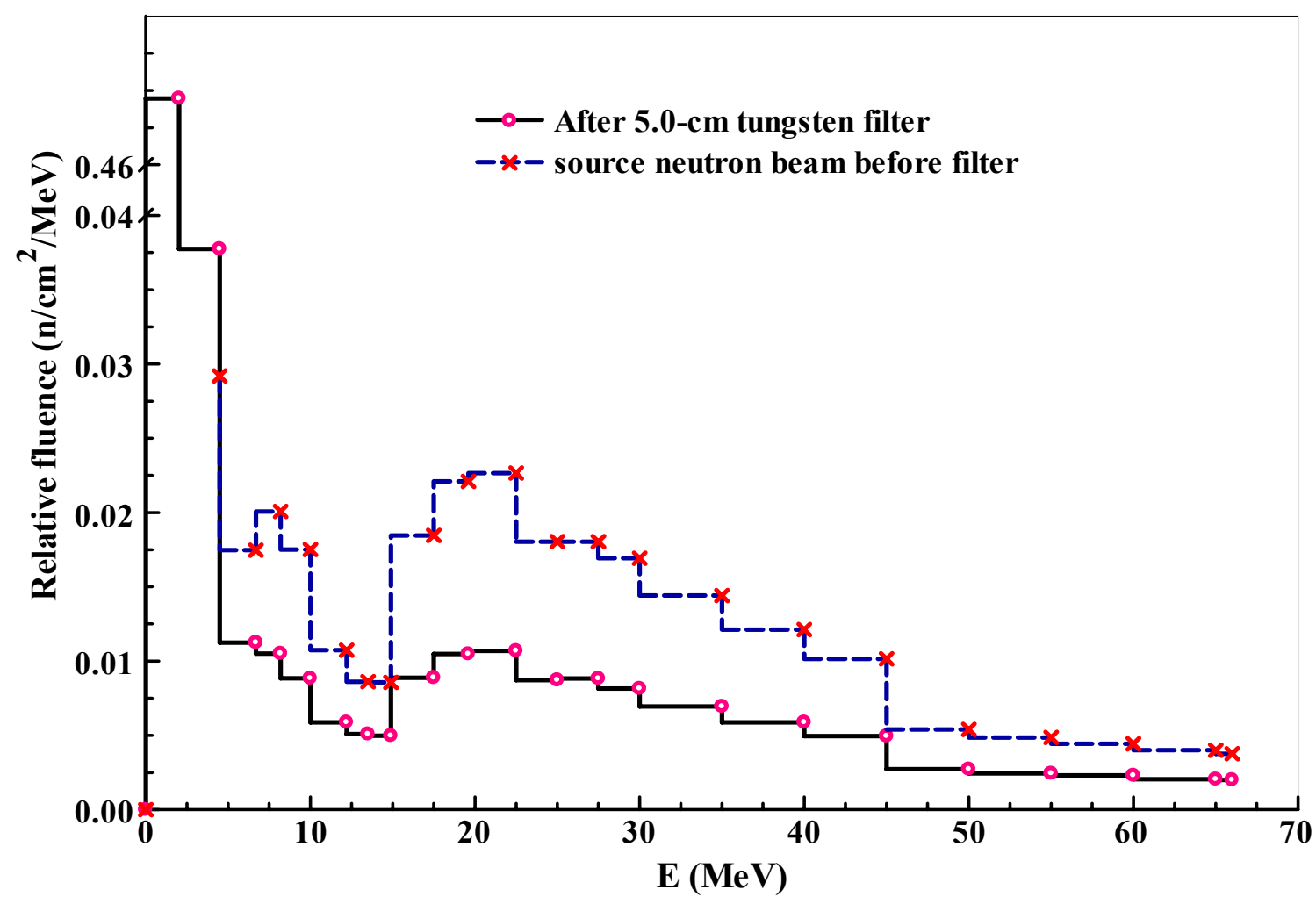

Figure 66: Comparison of source neutron spectrum and neutron spectrum after 5.0-cm tungsten filter in the simplified BNCEFNT assembly (linear). Notice that the energy intervals are not evenly divided, and the area under the curve represents the fraction of neutron fluence in each energy group. 
APPENDIX D

SELECTED MCNPX AND MCNP5 INPUT FILES 


\section{D1. MCNPX input file}

\section{D1.1 Neutron source calculation model}

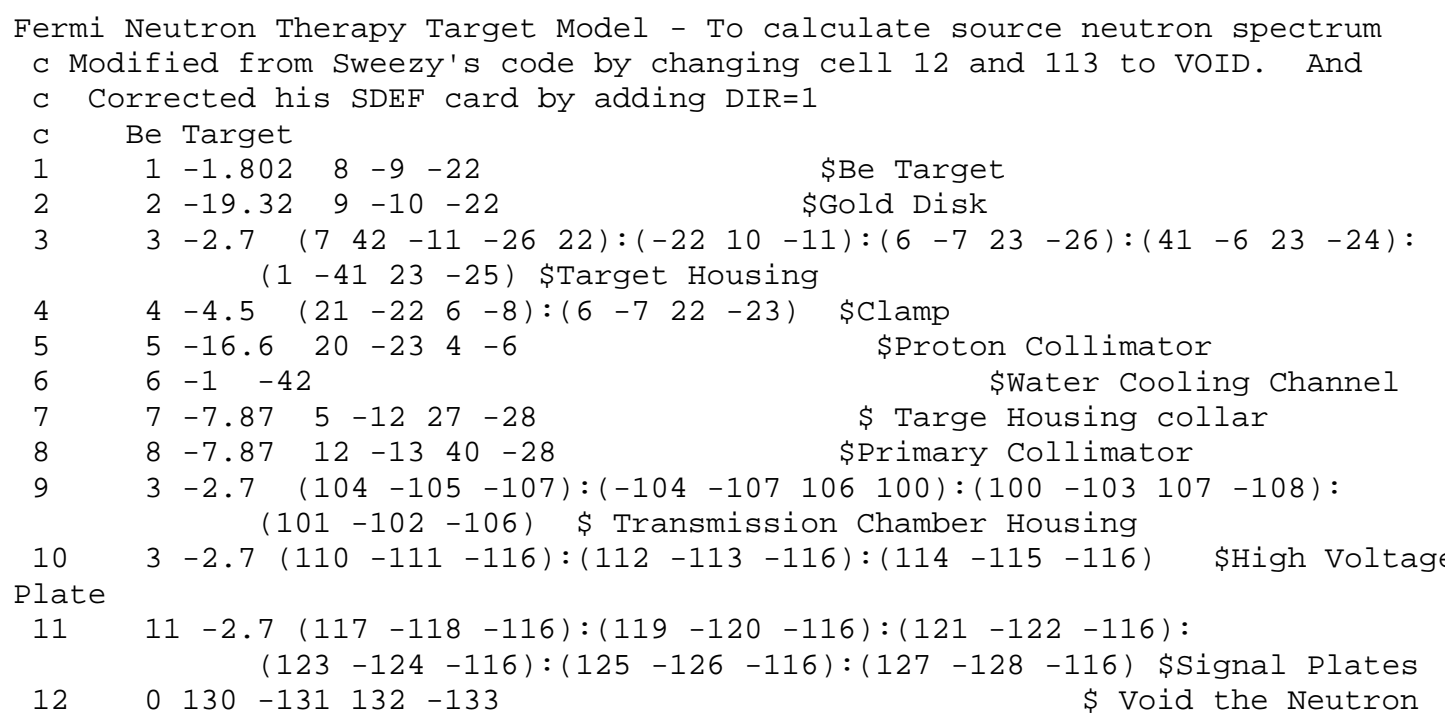
Entrance

$\mathrm{C}$

c Area's of Vacuum or Air tbat are inside of a part

$100 \quad 0 \quad(1-4-23):\left(\begin{array}{lll}4 & -6 & -20\end{array}\right):\left(\begin{array}{lll}6 & -8 & -21\end{array}\right) \quad$ \$Vacuum Chamber Before Target

$108100-0.001293\left(\begin{array}{llll}-22 & 11 & -12\end{array}\right):\left(\begin{array}{lll}12 & -13 & -40\end{array}\right):\left(\begin{array}{lll}100 & -101 & -106\end{array}\right)$ \$Air in Primary

C

$109 \quad 100-0.001293 \quad 102 \quad-104 \quad-106 \quad \# 10 \quad \# 11$

$112100-0.001293 \quad(105-130-132)$

\$Air in Neutron

Entrance

$113 \odot(130-131-132) \quad$ \$Neutron Entrance Port set to

void

C Area's of Vacuum or Air that are outside of a part

$203100-0.001293\left(\begin{array}{llll}11 & -12 & 22 & -27\end{array}\right):\left(\begin{array}{llll}-27 & 26 & -11 & 6\end{array}\right):\left(\begin{array}{lllll}-6 & -27 & 24 & 3\end{array}\right):$

$\left(\begin{array}{llll}-3 & 24 & 41 & -25\end{array}\right):\left(\begin{array}{llll}25 & -3 & 1 & -27\end{array}\right):\left(\begin{array}{llll}1 & -5 & 27 & -28\end{array}\right)$ \$Air Around

Tar Note change the last -28 to incorporate a larger radius

$212100-0.001293\left(\begin{array}{llllll}132 & -130 & 105 & -133\end{array}\right):\left(\begin{array}{lllll}-105 & 103 & 107 & -133\end{array}\right)$ :

$\left(\begin{array}{llll}-103 & 100 & 108 & -133\end{array}\right):\left(\begin{array}{llll}-100 & 1 & 28 & -133\end{array}\right)$ \$Air outside of

Target

c

$100 \odot \odot-1: 131: 133$

$\begin{array}{lllll}1 & \text { pz } & -3.9243 \text { \$Target Housing Flange Upsteam Face (3) } \\ 2 & \text { pz } & -3.3655 \text { \$Target Housing slope point (not used) } \\ 3 & \text { pz } & -3.1115 \text { \$Target Housing slope point (not used) } \\ 4 & \text { pz } & -2.16408 \text { \$Proton Collimator Front Face (5) } \\ 5 & \text { pz } & -1.82118 \text { \$Target Housing Colliar Front Face (7) } \\ 6 & \text { pz } & -1.7018 \text { \$Target Housing Front Face } & \text { (3) } \\ 7 & \text { pz } & -1.3843 \text { \$Clamp (4) Downstream Face } & (4) \\ 8 & \text { pz } & -1.1049 \text { \$Target Upstream Face } & (1) \\ 9 & \text { pz } & 1.1049 \text { \$Target Downstream Face } & \text { (1) } \\ 10 & \text { pz } & 1.1557 \text { \$Gold Disk (2) Downstream Face }\end{array}$




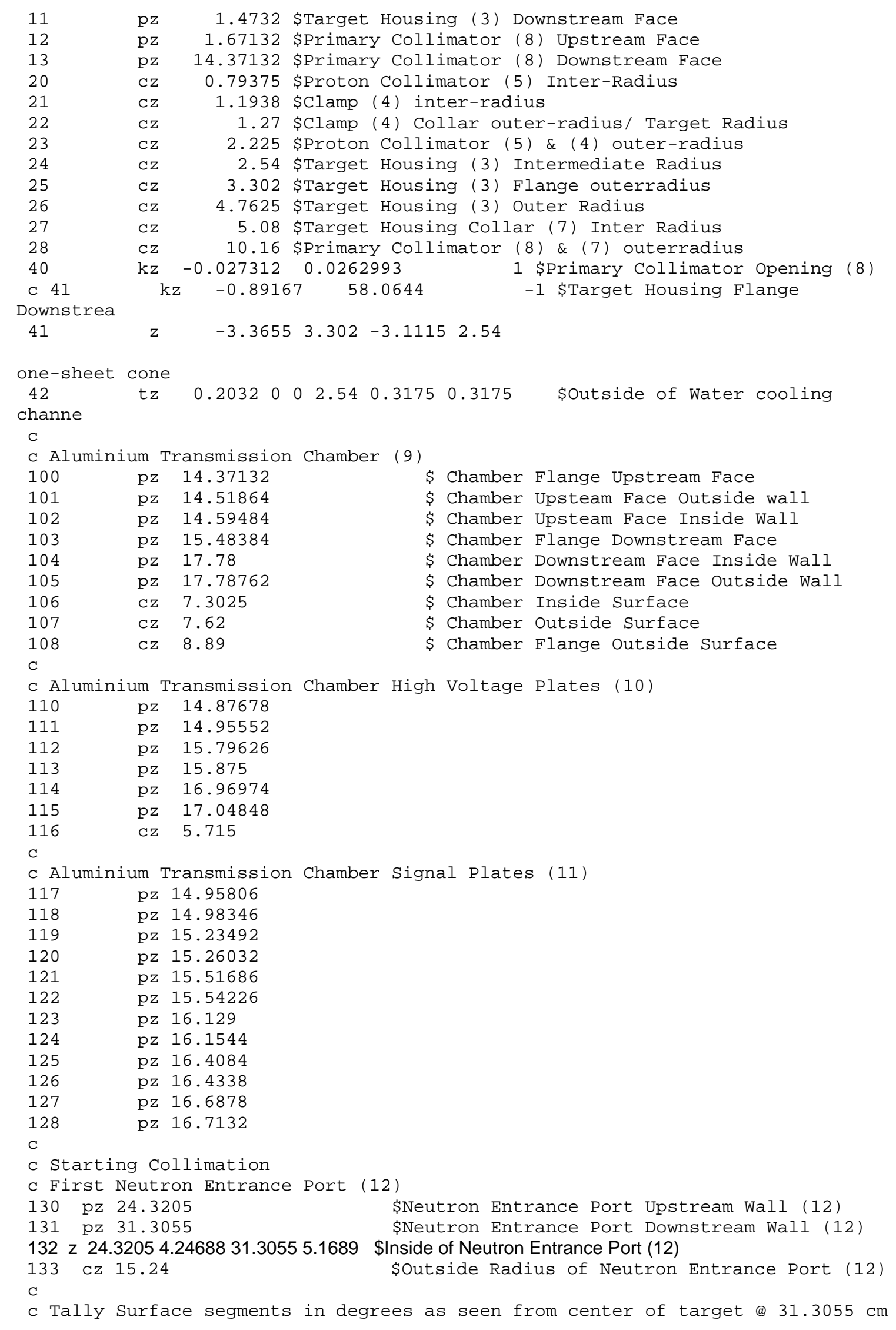




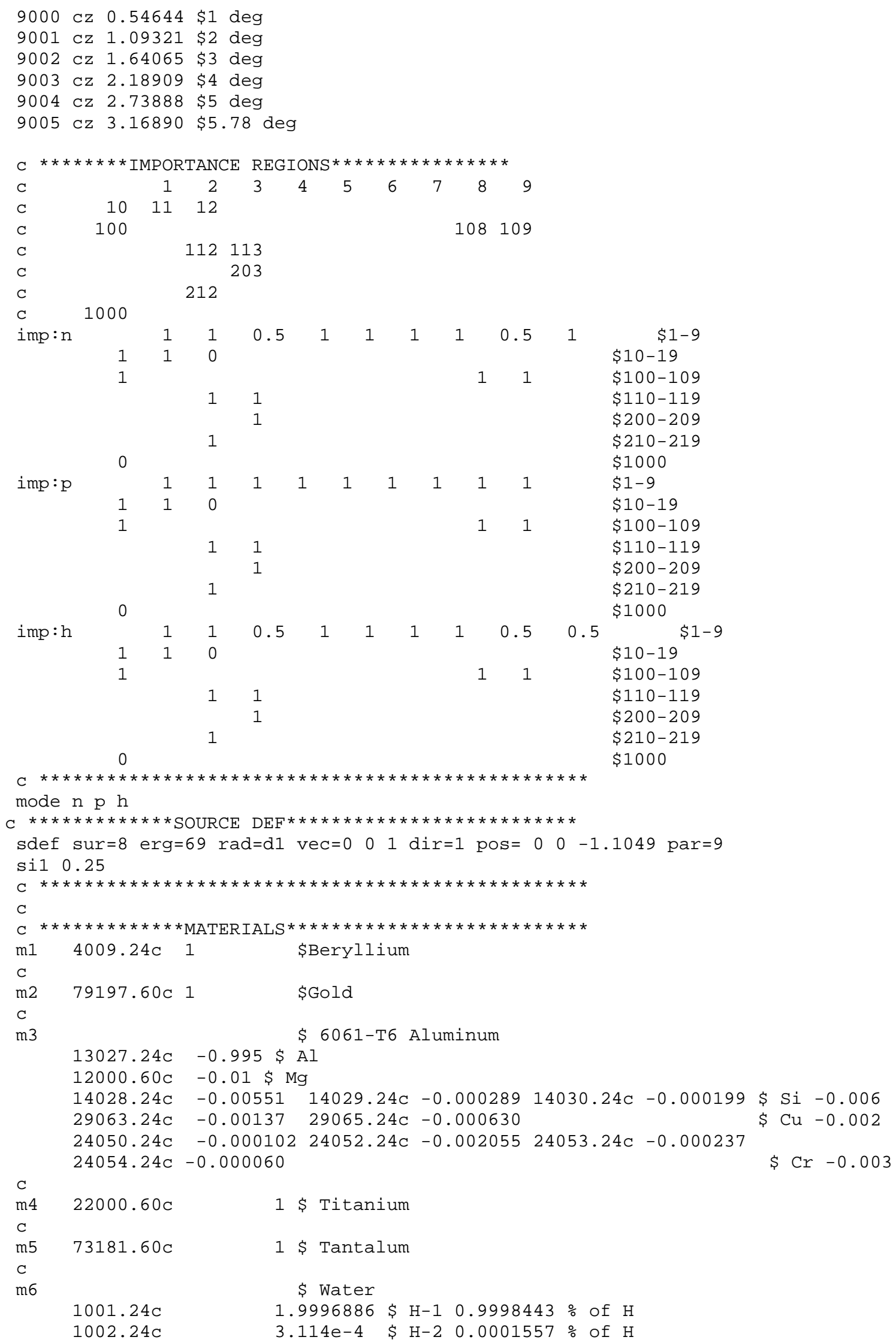




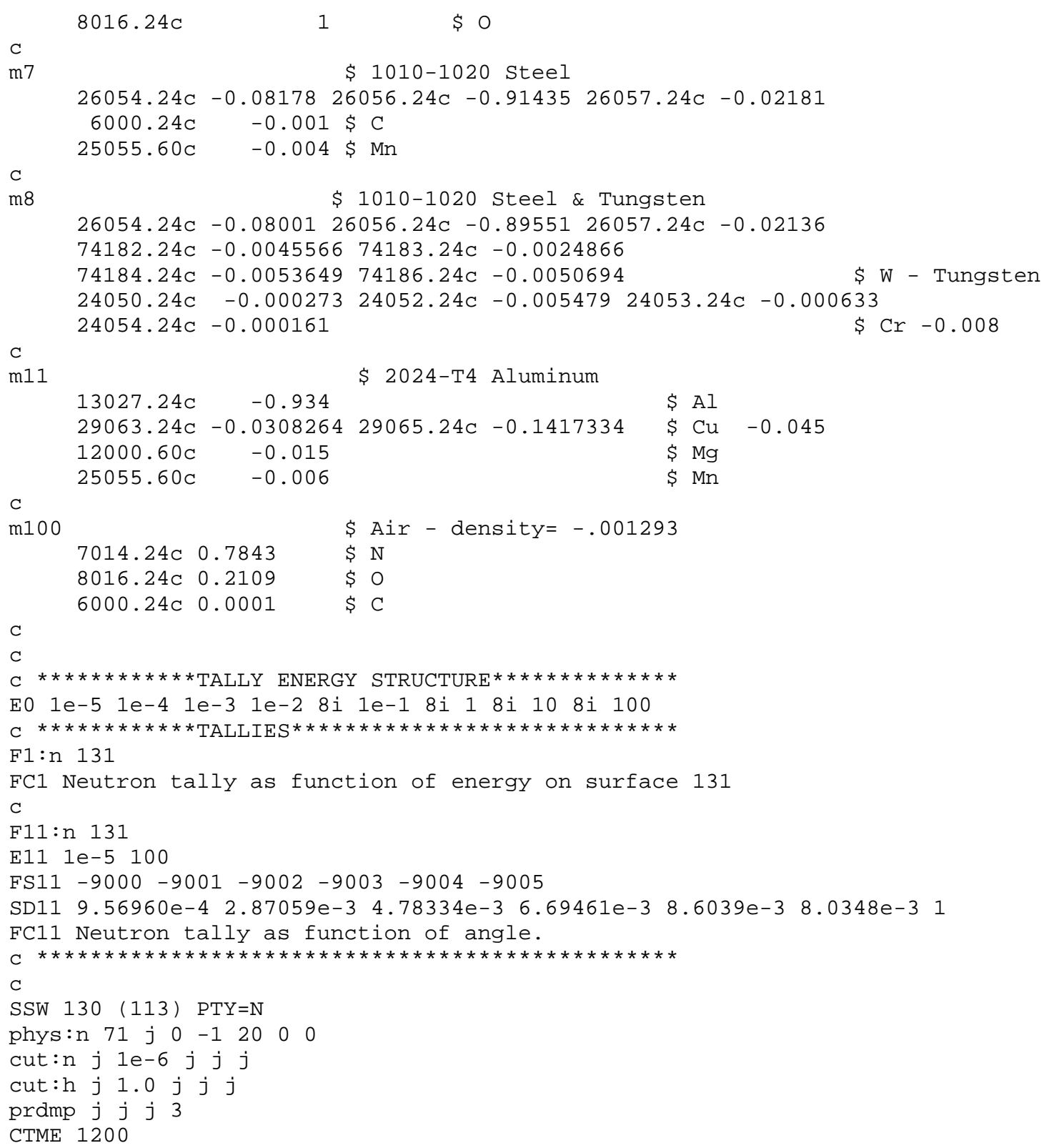




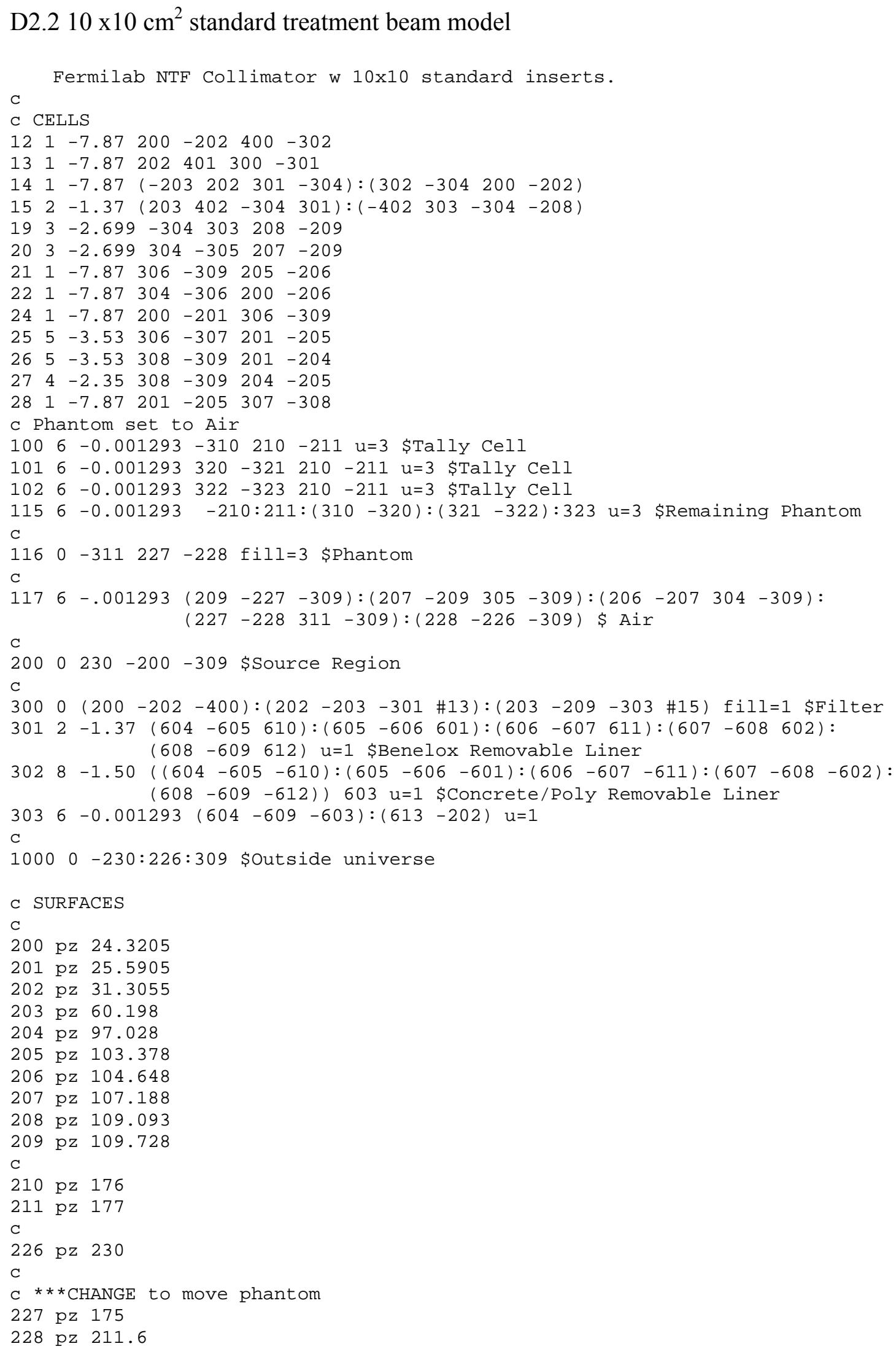




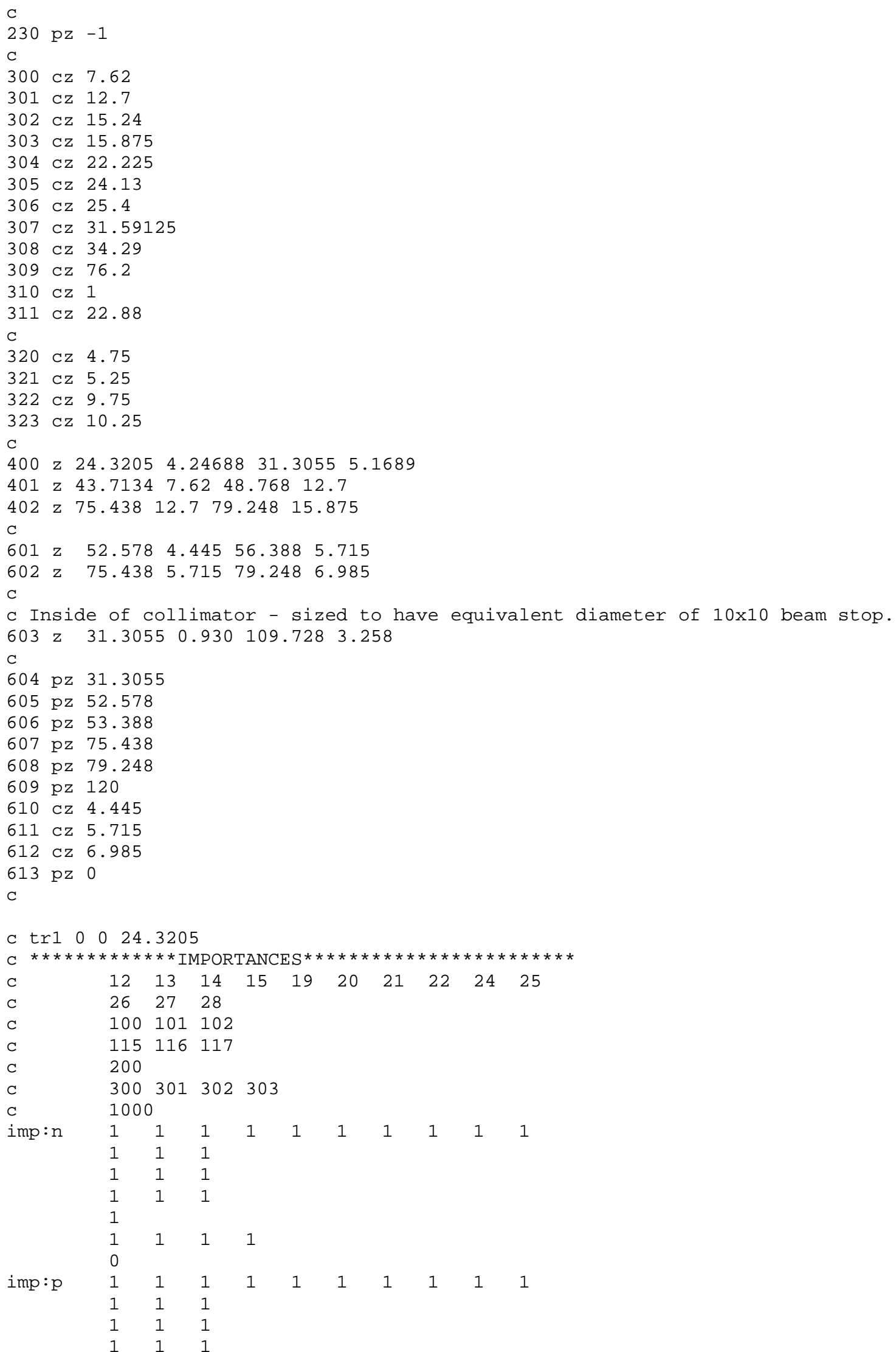




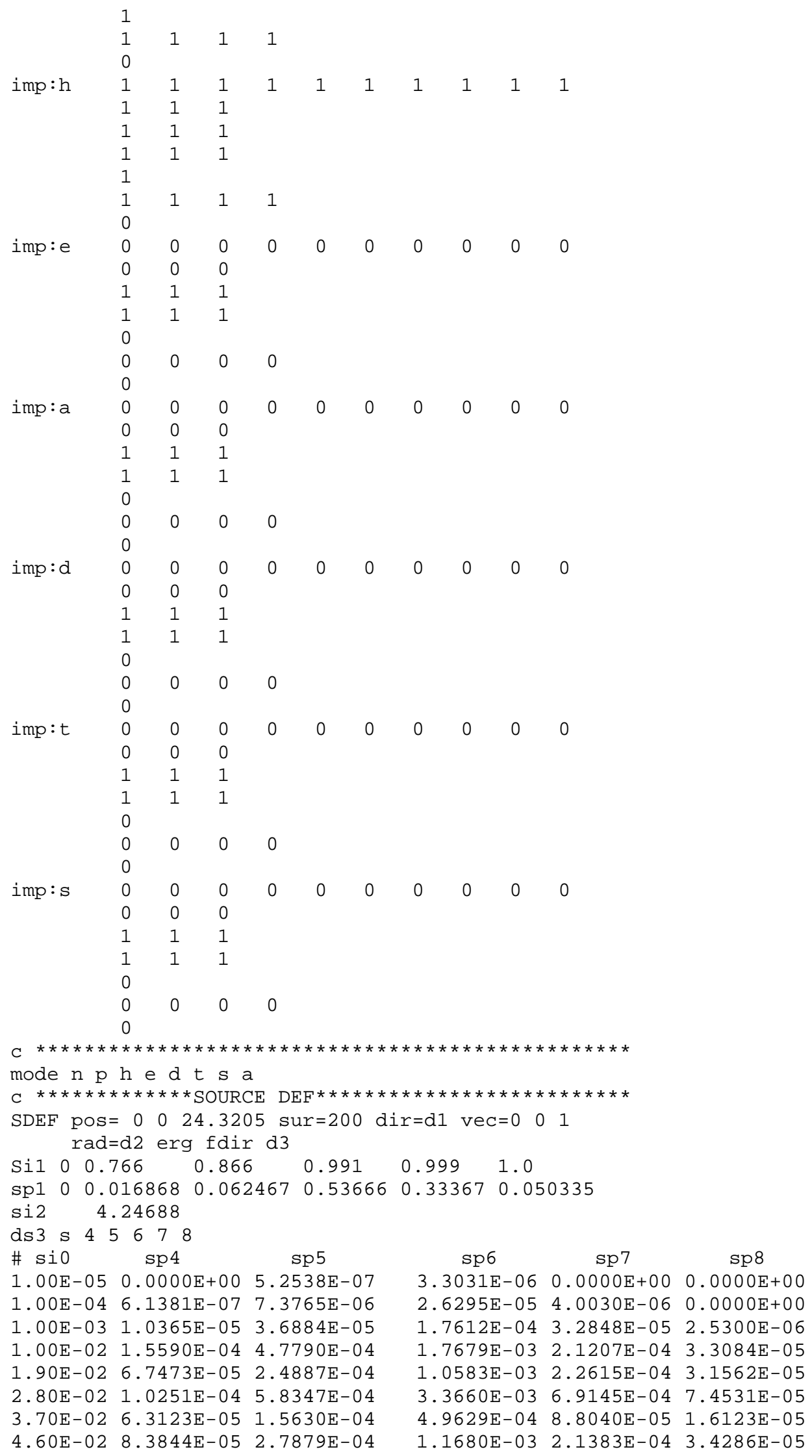


5. 50E-๑2 8. 2559E-๑5 2.8929E-๑4 6. 40E-02 1.0318E-04 3.6976E-@4 7.30E-02 1.3553E-04 5.5712E-04 8. 20E- -2 1.6422E- -4 3. $3229 \mathrm{E}-04$ 9.10E-02 6.7815E-05 2.0296E-04 1. $00 \mathrm{E}-01$ 7.3264E-05 2.0604E-04 1.90E-01 1.2515E-03 3.8771E-03 2. 80E-01 9.5044E-०4 3.1914E-०3 3. $70 \mathrm{E}-01$ 1.2152E-03 4.1743E-०3 4.6०E-01 9.5745E-๑4 3. $0331 \mathrm{E}-03$ 5.50E-01 9.5612E-๑4 3.3023E-०3 6. 4०E-01 1.2117E- 03 4. $0752 \mathrm{E}-03$ 7. 30E-01 8.7505E-04 3.2507E- 03 8. 20E-01 7.5467E-04 2.4727E-03 9.10E-01 6.1951E-๑4 2.2228E- 03 $1.00 \mathrm{E}+0 \odot$ 4.9143E- 04 2.1497E- 03 1. $90 \mathrm{E}+\odot \odot 3.1760 \mathrm{E}-\odot 3 \quad 1.2211 \mathrm{E}-02$ 2. $80 \mathrm{E}+\odot \odot 1.2372 \mathrm{E}-\odot 3 \quad 5.0355 \mathrm{E}-\odot 3$ $3.70 \mathrm{E}+0 \odot$ 5.6907E-๑4 2.3749E-०3 4. $60 \mathrm{E}+\odot \odot \quad 3.3170 \mathrm{E}-\odot 4 \quad 1.4425 \mathrm{E}-\odot 3$ $5.50 \mathrm{E}+0 \odot$ 1.8680E-๑4 9.1799E- 04 $6.40 \mathrm{E}+0 \odot$ 1. 4347E- $\odot 4 \quad 6.1411 \mathrm{E}-\odot 4$ $7.30 \mathrm{E}+0 \odot \quad 8.8363 \mathrm{E}-05 \quad 4.7921 \mathrm{E}-\odot 4$ 8. $20 \mathrm{E}+0 \odot \quad 7.6872 \mathrm{E}-05 \quad 3.5122 \mathrm{E}-04$ $9.10 \mathrm{E}+0 \odot$ 5.6953E- 05 2.8812E-๑4 1. $00 \mathrm{E}+01$ 5.3195E- $\odot 5$ 2.5295E- 04 $1.38 \mathrm{E}+01$ 1.7216E- $04 \quad 7.1528 \mathrm{E}-04$ 1. $75 \mathrm{E}+01$ 1. $0850 \mathrm{E}-\odot 4$ 5.8977E- $\odot 4$ 2.13E+01 9.0139E-05 4.4138E-04 $2.50 \mathrm{E}+01$ 3.5289E- 05 2.7924E- 04 $2.88 \mathrm{E}+01 \quad 3.2220 \mathrm{E}-05 \quad 2.1634 \mathrm{E}-04$ 3. $25 \mathrm{E}+01$ 2.4549E-05 1.6724E-04 $3.63 \mathrm{E}+012.4549 \mathrm{E}-05$ 1.2888E- 04 4. $0 \odot \mathrm{E}+01$ 1.6877E- $\odot 5$ 1.1814E- $\odot 4$ 4.38E+01 2.3014E-05 8.7455E-05 4. $75 \mathrm{E}+01$ 9.2058E-06 6.9043E- 05 $5.13 \mathrm{E}+01 \quad 6.1372 \mathrm{E}-06 \quad 6.9043 \mathrm{E}-05$ $5.50 \mathrm{E}+01$ 7.6715E-06 3.8357E-05 $5.88 \mathrm{E}+01$ 1.5343E- 06 1.8412E- $\odot 5$ $6.25 \mathrm{E}+01$ 1.5343E-06 1.3809E-05 $6.63 \mathrm{E}+01$ 1.5343E- 06 $0.0000 \mathrm{E}+0 \odot$ 7. $.0 \mathrm{E}+01 \quad 0.000 \odot \mathrm{E}+\odot \odot \quad \odot .00 \odot \odot \mathrm{E}+\odot \odot$ C SSR OLD 130 NEW 200

C sdef erg $=d 2$ dir $=d 3$ vec $=\odot \odot 1$ pos $=\odot \odot \odot$ par $=1$

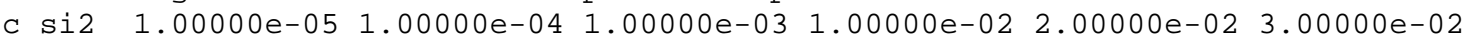

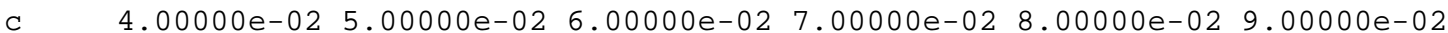

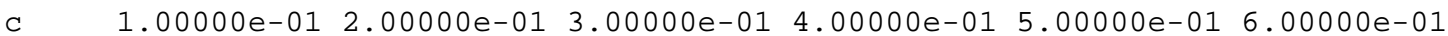

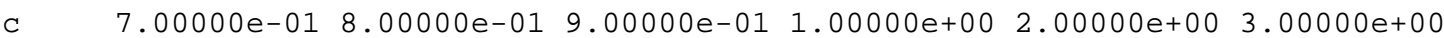

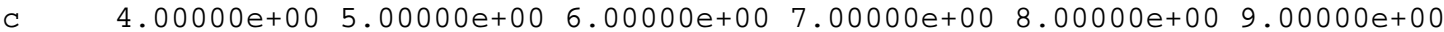

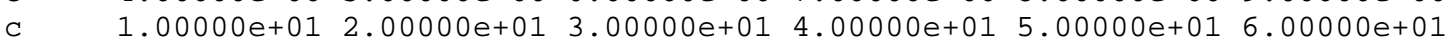
c $\quad 7.00000 \mathrm{e}+01$

c sp2 $0.00000 \mathrm{e}+00 \quad 1.15826 \mathrm{e}-07 \quad 9.56867 \mathrm{e}-07 \quad 8.15276 \mathrm{e}-06 \quad 6.54268 \mathrm{e}-06 \quad 2.91185 \mathrm{e}-05$ c $\quad 3.59253 \mathrm{e}-06 \quad 7.84624 \mathrm{e}-06 \quad 7.55651 \mathrm{e}-06 \quad 1.61060 \mathrm{e}-05 \quad 1.28825 \mathrm{e}-05 \quad 1.48511 \mathrm{e}-05$ c $\quad 5.70329 \mathrm{e}-06 \quad 1.55085 \mathrm{e}-04 \quad 1.48989 \mathrm{e}-04 \quad 2.13710 \mathrm{e}-04 \quad 1.14516 \mathrm{e}-04 \quad 1.38239 \mathrm{e}-04$ c $\quad 2.00873 e-041.08475 e-04 \quad 9.69866 e-051.07365 e-04 \quad 5.23179 e-04 \quad 1.98955 e-04$ c $\quad 1.05525 \mathrm{e}-04 \quad 6.76163 \mathrm{e}-05 \quad 5.34447 \mathrm{e}-05 \quad 4.83748 \mathrm{e}-05 \quad 3.89503 \mathrm{e}-05 \quad 4.02425 \mathrm{e}-05$ c $\quad 4.04447 \mathrm{e}-05 \quad 3.07750 \mathrm{e}-04 \quad 3.44128 \mathrm{e}-04 \quad 2.34320 \mathrm{e}-04 \quad 1.54216 \mathrm{e}-04 \quad 7.21327 \mathrm{e}-05$ c $\quad 1.09715 \mathrm{e}-05$

$\begin{array}{llllllll}\text { C } \mathrm{si3} & -1 & .984808 & .996195 & .997564 & .998630 & .999391 & .999848\end{array}$

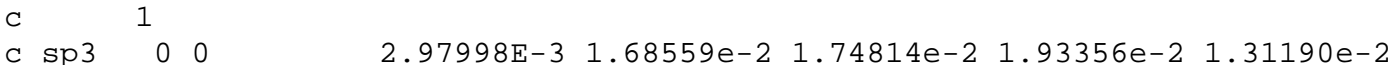

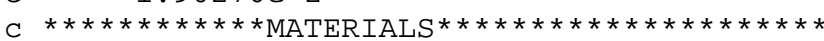




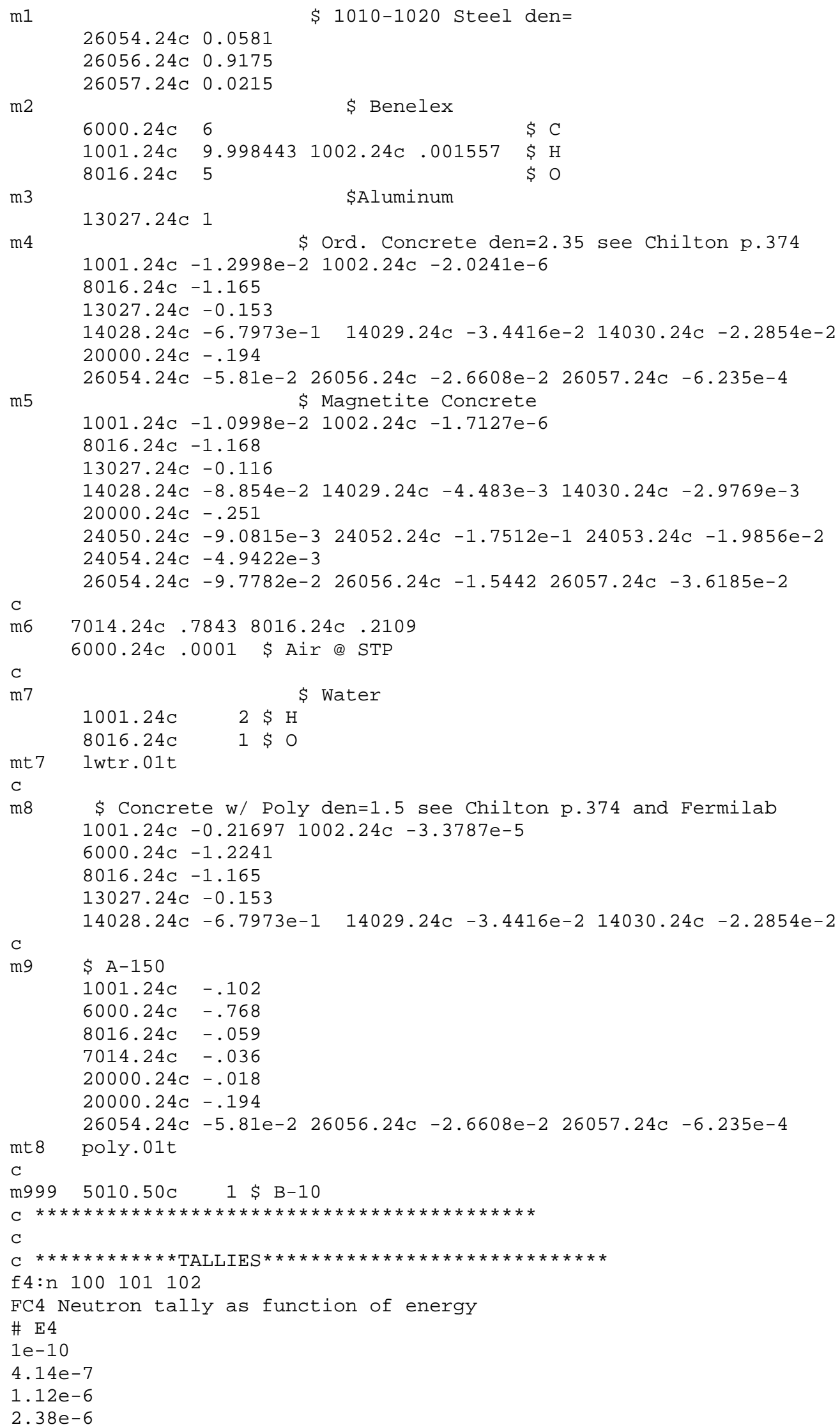




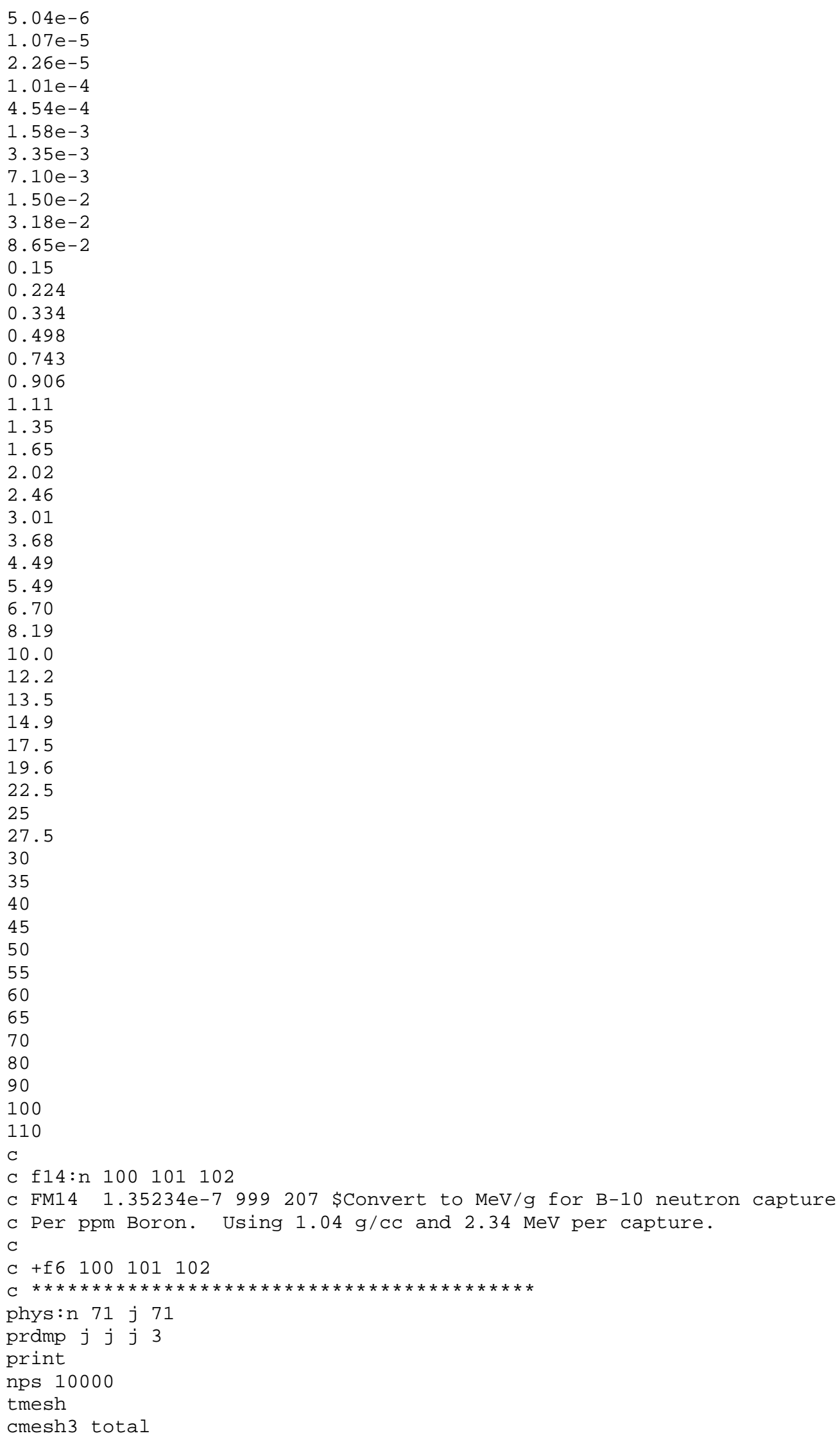




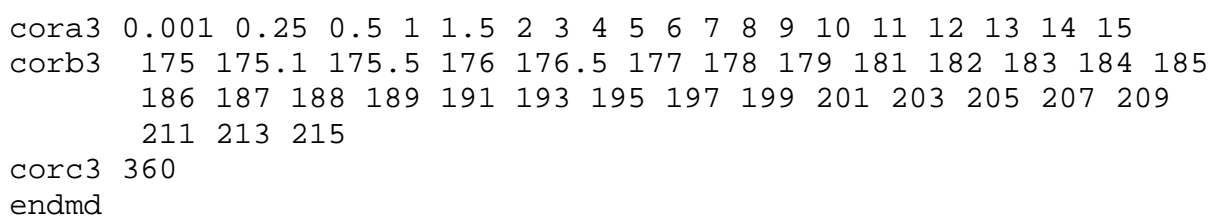

\section{D1.3 Response matrix calculations}

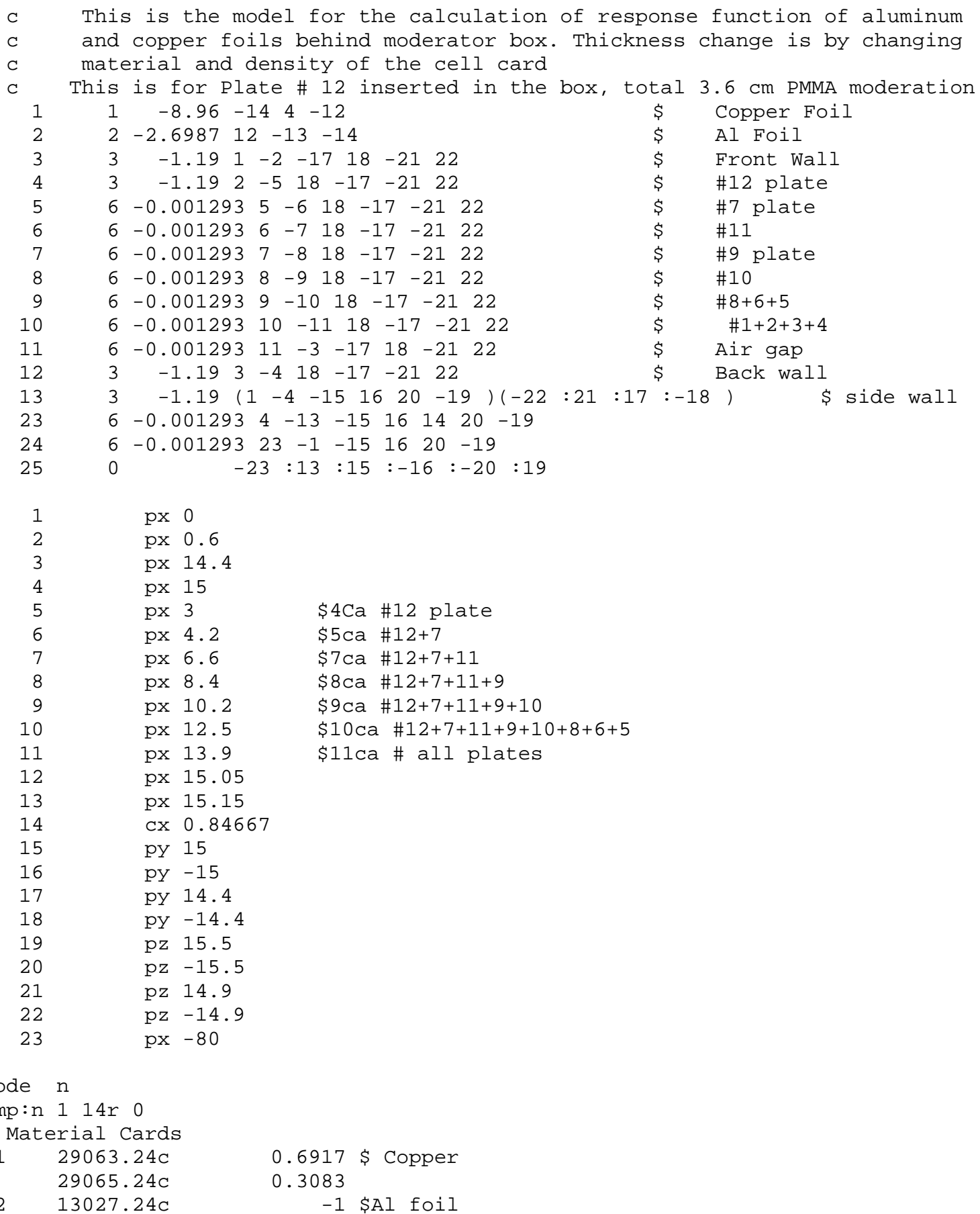




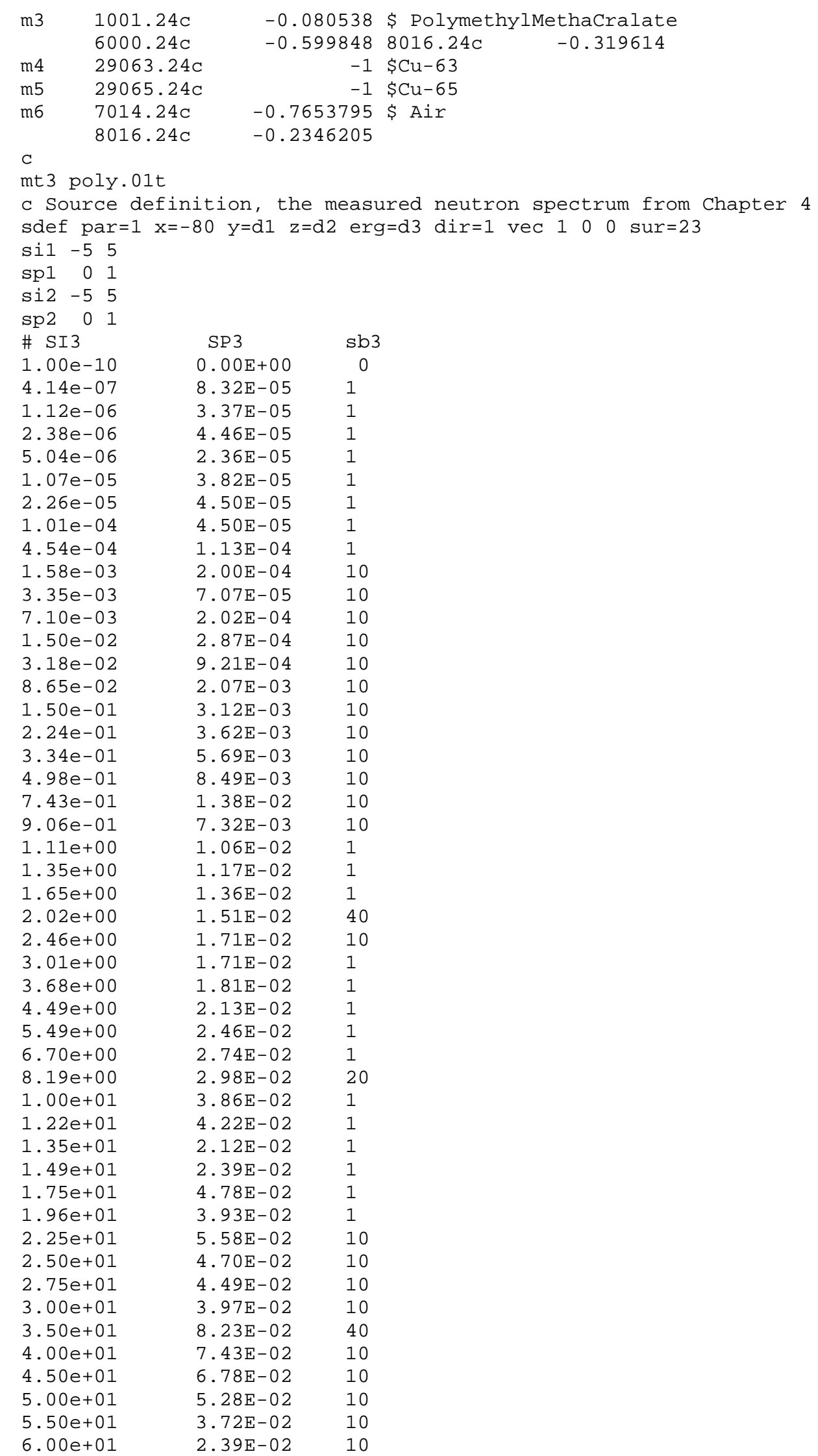




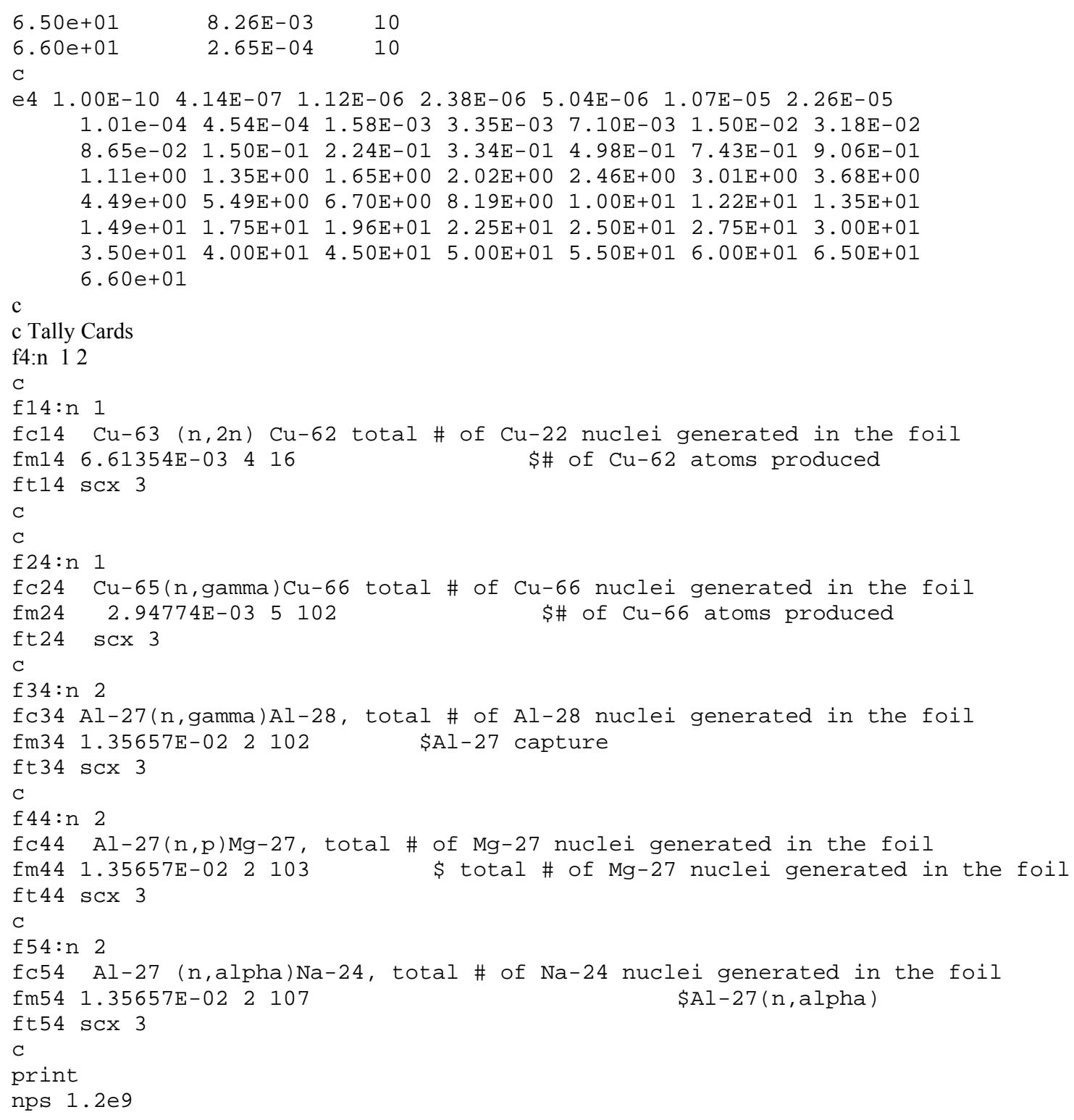




\section{D2. MCNP5 input files}

D2.1 Depth-dose and PDE calculation for the BNCEFNT assembly

C BNCEFNT assembly: 10-cm thick tungsten collimator with $5.64-\mathrm{cm}$ diameter

C $\quad 5.0-\mathrm{cm}$ thick tungsten filter; steel filter holder.

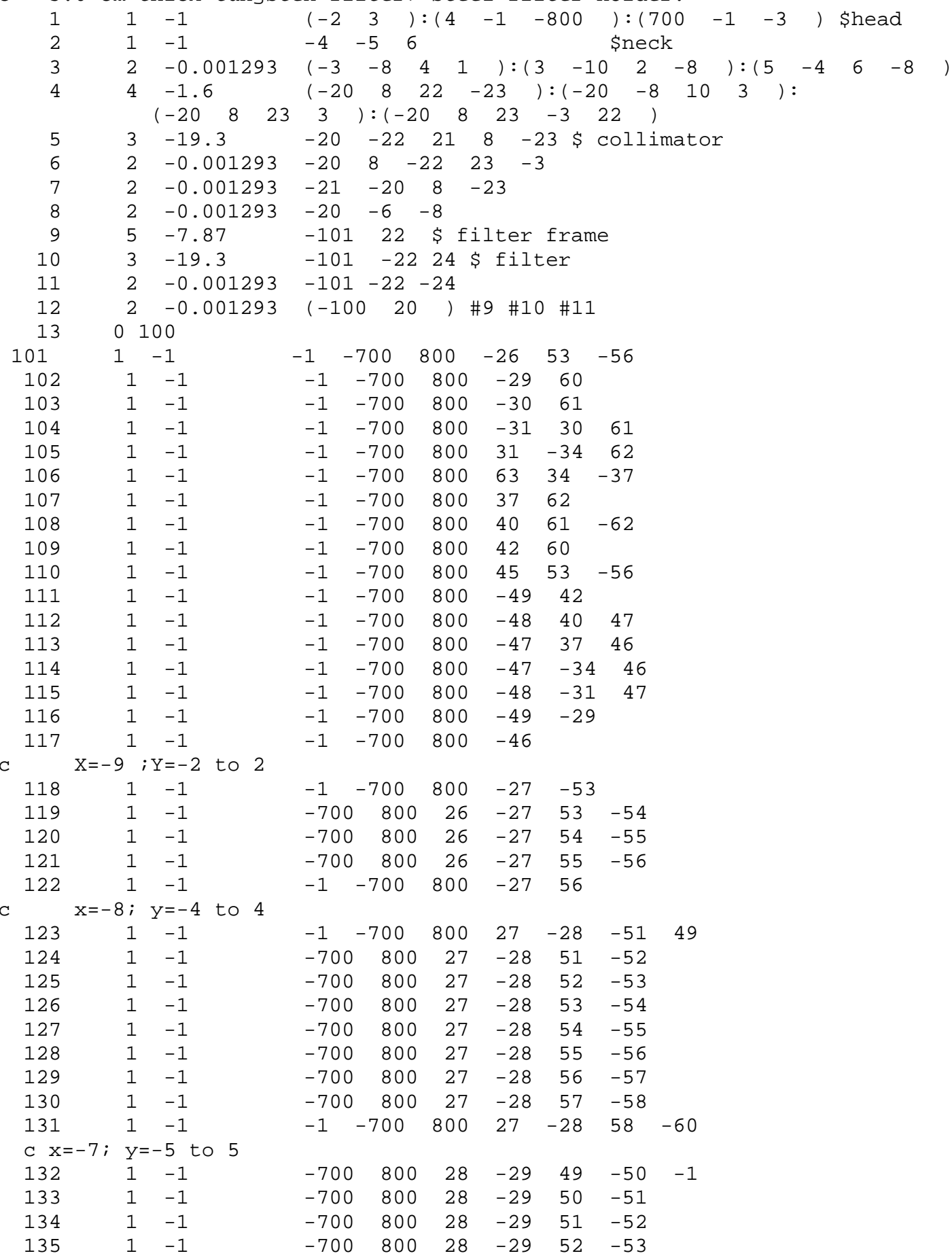




\begin{tabular}{|c|c|c|c|c|c|c|c|c|}
\hline 136 & 1 & -1 & -700 & 800 & 28 & -29 & 53 & -54 \\
\hline 137 & 1 & -1 & -700 & 800 & 28 & -29 & 54 & -55 \\
\hline 138 & 1 & -1 & -700 & 800 & 28 & -29 & 55 & -56 \\
\hline 139 & 1 & -1 & -700 & 800 & 28 & -29 & 56 & -57 \\
\hline 140 & 1 & -1 & $-70 \odot$ & $80 \odot$ & 28 & -29 & 57 & -58 \\
\hline 141 & 1 & -1 & -700 & $80 \odot$ & 28 & -29 & 58 & -59 \\
\hline 142 & 1 & -1 & -700 & 800 & 28 & -29 & 59 & -60 \\
\hline$c x=$ & & $6 t$ & & & & & & \\
\hline 143 & 1 & -1 & -700 & 800 & 29 & -30 & 48 & -49 \\
\hline 144 & 1 & -1 & -700 & 800 & 29 & -30 & 49 & -50 \\
\hline 145 & 1 & -1 & -700 & $80 \odot$ & 29 & -30 & 50 & -51 \\
\hline 146 & 1 & -1 & -700 & 800 & 29 & -30 & 51 & -52 \\
\hline 147 & 1 & -1 & -700 & $80 \odot$ & 29 & -30 & 52 & -53 \\
\hline 148 & 1 & -1 & -700 & $80 \odot$ & 29 & -30 & 53 & -54 \\
\hline 149 & 1 & -1 & -700 & 800 & 29 & -30 & 54 & -55 \\
\hline 150 & 1 & -1 & -700 & 800 & 29 & -30 & 55 & -56 \\
\hline 151 & 1 & -1 & -700 & $80 \odot$ & 29 & -30 & 56 & -57 \\
\hline 152 & 1 & -1 & -700 & $80 \odot$ & 29 & -30 & 57 & -58 \\
\hline 153 & 1 & -1 & -700 & 800 & 29 & -30 & 58 & -59 \\
\hline 154 & 1 & -1 & -700 & $80 \odot$ & 29 & -30 & 59 & -60 \\
\hline 155 & 1 & -1 & -700 & 800 & 29 & -30 & 60 & -61 \\
\hline$c x=$ & & $6 t$ & & & & & & \\
\hline 156 & 1 & -1 & -700 & 800 & 30 & -31 & 48 & -49 \\
\hline 157 & 1 & -1 & -700 & $80 \odot$ & 30 & -31 & 49 & -50 \\
\hline 158 & 1 & -1 & -700 & $80 \odot$ & 30 & -31 & 50 & -51 \\
\hline 159 & 1 & -1 & -700 & 800 & 30 & -31 & 51 & -52 \\
\hline 160 & 1 & -1 & $-70 \odot$ & $80 \odot$ & 30 & -31 & 52 & -53 \\
\hline 161 & 1 & -1 & -700 & 800 & 30 & -31 & 53 & -54 \\
\hline 162 & 1 & -1 & -700 & 800 & 30 & -31 & 54 & -55 \\
\hline 163 & 1 & -1 & -700 & 800 & 30 & -31 & 55 & -56 \\
\hline 164 & 1 & -1 & -700 & $80 \odot$ & 30 & -31 & 56 & -57 \\
\hline 165 & 1 & -1 & $-70 \odot$ & $80 \odot$ & 30 & -31 & 57 & -58 \\
\hline 166 & 1 & -1 & -700 & 800 & 30 & -31 & 58 & -59 \\
\hline 167 & 1 & -1 & $-70 \odot$ & $80 \odot$ & 30 & -31 & 59 & -60 \\
\hline 168 & 1 & -1 & -700 & 800 & 30 & -31 & 60 & -61 \\
\hline$c x=$ & $y=$ & $7 \mathrm{t}$ & & & & & & \\
\hline 169 & 1 & -1 & -700 & 800 & 31 & -32 & 47 & -48 \\
\hline 170 & 1 & -1 & -700 & 800 & 31 & -32 & 48 & -49 \\
\hline 171 & 1 & -1 & -700 & 800 & 31 & -32 & 49 & -50 \\
\hline 172 & 1 & -1 & $-70 \odot$ & $80 \odot$ & 31 & -32 & 50 & -51 \\
\hline 173 & 1 & -1 & -700 & $80 \odot$ & 31 & -32 & 51 & -52 \\
\hline 174 & 1 & -1 & -700 & 800 & 31 & -32 & 52 & -53 \\
\hline 175 & 1 & -1 & $-70 \odot$ & $80 \odot$ & 31 & -32 & 53 & -54 \\
\hline 176 & 1 & -1 & -700 & 800 & 31 & -32 & 54 & -55 \\
\hline 177 & 1 & -1 & $-70 \odot$ & $80 \odot$ & 31 & -32 & 55 & -56 \\
\hline 178 & 1 & -1 & -700 & 800 & 31 & -32 & 56 & -57 \\
\hline 179 & 1 & -1 & $-70 \odot$ & $80 \odot$ & 31 & -32 & 57 & -58 \\
\hline 180 & 1 & -1 & $-70 \odot$ & $80 \odot$ & 31 & -32 & 58 & -59 \\
\hline 181 & 1 & -1 & -700 & 800 & 31 & -32 & 59 & -60 \\
\hline 182 & 1 & -1 & $-70 \odot$ & 800 & 31 & -32 & 60 & -61 \\
\hline 183 & 1 & -1 & -700 & 800 & 31 & -32 & 61 & -62 \\
\hline$c x=$ & & $7 t$ & & & & & & \\
\hline 184 & 1 & -1 & -700 & 800 & 32 & -33 & 47 & -48 \\
\hline 185 & 1 & -1 & -700 & 800 & 32 & -33 & 48 & -49 \\
\hline 186 & 1 & -1 & -700 & 800 & 32 & -33 & 49 & -50 \\
\hline 187 & 1 & -1 & $-70 \odot$ & $80 \odot$ & 32 & -33 & 50 & -51 \\
\hline 188 & 1 & -1 & -700 & 800 & 32 & -33 & 51 & -52 \\
\hline 189 & 1 & -1 & -700 & 800 & 32 & -33 & 52 & -53 \\
\hline 190 & 1 & -1 & -700 & 800 & 32 & -33 & 53 & -54 \\
\hline 191 & 1 & -1 & -700 & 800 & 32 & -33 & 54 & -55 \\
\hline 192 & 1 & -1 & -700 & 800 & 32 & -33 & 55 & -56 \\
\hline 193 & 1 & -1 & -700 & 800 & 32 & -33 & 56 & -57 \\
\hline 194 & 1 & -1 & $-70 \odot$ & 800 & 32 & -33 & 57 & -58 \\
\hline
\end{tabular}




\begin{tabular}{|c|c|c|c|c|c|c|c|c|}
\hline 195 & 1 & -1 & -700 & 800 & 32 & -33 & 58 & -59 \\
\hline 196 & 1 & -1 & -700 & 800 & 32 & -33 & 59 & -60 \\
\hline 197 & 1 & -1 & $-70 \odot$ & $80 \odot$ & 32 & -33 & 60 & -61 \\
\hline 198 & 1 & -1 & -700 & 800 & 32 & -33 & 61 & -62 \\
\hline \multicolumn{9}{|c|}{ c $x=-2 ; y=-7$ to 7} \\
\hline 199 & 1 & -1 & -700 & $80 \odot$ & 33 & -34 & 47 & -48 \\
\hline 200 & 1 & -1 & -700 & 800 & 33 & -34 & 48 & -49 \\
\hline 201 & 1 & -1 & -700 & 800 & 33 & -34 & 49 & -50 \\
\hline 202 & 1 & -1 & -700 & 800 & 33 & -34 & 50 & -51 \\
\hline 203 & 1 & -1 & $-70 \odot$ & $80 \odot$ & 33 & -34 & 51 & -52 \\
\hline 204 & 1 & -1 & -700 & 800 & 33 & -34 & 52 & -53 \\
\hline 205 & 1 & -1 & -700 & 800 & 33 & -34 & 53 & -54 \\
\hline 206 & 1 & -1 & -700 & 800 & 33 & -34 & 54 & -55 \\
\hline 207 & 1 & -1 & -700 & 800 & 33 & -34 & 55 & -56 \\
\hline 208 & 1 & -1 & -700 & 800 & 33 & -34 & 56 & -57 \\
\hline 209 & 1 & -1 & -700 & 800 & 33 & -34 & 57 & -58 \\
\hline 210 & 1 & -1 & -700 & 800 & 33 & -34 & 58 & -59 \\
\hline 211 & 1 & -1 & -700 & 800 & 33 & -34 & 59 & -60 \\
\hline 212 & 1 & -1 & -700 & 800 & 33 & -34 & 60 & -61 \\
\hline 213 & 1 & -1 & -700 & 800 & 33 & -34 & 61 & -62 \\
\hline \multicolumn{9}{|c|}{$c x=-1 ; y=-8$ to 8} \\
\hline 214 & 1 & -1 & -700 & 800 & 34 & -35 & 46 & -47 \\
\hline 215 & 1 & -1 & -700 & $80 \odot$ & 34 & -35 & 47 & -48 \\
\hline 216 & 1 & -1 & -700 & 800 & 34 & -35 & 48 & -49 \\
\hline 217 & 1 & -1 & -700 & 800 & 34 & -35 & 49 & -50 \\
\hline 218 & 1 & -1 & -700 & 800 & 34 & -35 & 50 & -51 \\
\hline 219 & 1 & -1 & -700 & 800 & 34 & -35 & 51 & -52 \\
\hline 220 & 1 & -1 & -700 & 800 & 34 & -35 & 52 & -53 \\
\hline 221 & 1 & -1 & -700 & 800 & 34 & -35 & 53 & -54 \\
\hline 222 & 1 & -1 & -700 & 800 & 34 & -35 & 54 & -55 \\
\hline 223 & 1 & -1 & -700 & 800 & 34 & -35 & 55 & -56 \\
\hline 224 & 1 & -1 & -700 & 800 & 34 & -35 & 56 & -57 \\
\hline 225 & 1 & -1 & -700 & 800 & 34 & -35 & 57 & -58 \\
\hline 226 & 1 & -1 & -700 & 800 & 34 & -35 & 58 & -59 \\
\hline 227 & 1 & -1 & -700 & 800 & 34 & -35 & 59 & -60 \\
\hline 228 & 1 & -1 & -700 & 800 & 34 & -35 & 60 & -61 \\
\hline 229 & 1 & -1 & -700 & 800 & 34 & -35 & 61 & -62 \\
\hline 230 & 1 & -1 & -700 & 800 & 34 & -35 & 62 & -63 \\
\hline \multicolumn{9}{|c|}{$c x=0 ; y=-8$ to 8} \\
\hline 231 & 1 & -1 & -700 & 800 & 35 & -36 & 46 & -47 \\
\hline 232 & 1 & -1 & -700 & 800 & 35 & -36 & 47 & -48 \\
\hline 233 & 1 & -1 & -700 & 800 & 35 & -36 & 48 & -49 \\
\hline 234 & 1 & -1 & -700 & 800 & 35 & -36 & 49 & -50 \\
\hline 235 & 1 & -1 & -700 & 800 & 35 & -36 & 50 & -51 \\
\hline 236 & 1 & -1 & $-70 \odot$ & 800 & 35 & -36 & 51 & -52 \\
\hline 237 & 1 & -1 & -700 & 800 & 35 & -36 & 52 & -53 \\
\hline 238 & 1 & -1 & -700 & 800 & 35 & -36 & 53 & -54 \\
\hline 239 & 1 & -1 & -700 & 800 & 35 & -36 & 54 & -55 \\
\hline 240 & 1 & -1 & -700 & 800 & 35 & -36 & 55 & -56 \\
\hline 241 & 1 & -1 & -700 & 800 & 35 & -36 & 56 & -57 \\
\hline 242 & 1 & -1 & -700 & 800 & 35 & -36 & 57 & -58 \\
\hline 243 & 1 & -1 & -700 & 800 & 35 & -36 & 58 & -59 \\
\hline 244 & 1 & -1 & -700 & 800 & 35 & -36 & 59 & -60 \\
\hline 245 & 1 & -1 & -700 & 800 & 35 & -36 & 60 & -61 \\
\hline 246 & 1 & -1 & -700 & 800 & 35 & -36 & 61 & -62 \\
\hline 247 & 1 & -1 & -700 & 800 & 35 & -36 & 62 & -63 \\
\hline \multicolumn{9}{|l|}{$x=1$} \\
\hline 248 & 1 & -1 & -700 & 800 & 36 & -37 & 46 & -47 \\
\hline 249 & 1 & -1 & -700 & 800 & 36 & -37 & 47 & -48 \\
\hline 250 & 1 & -1 & -700 & 800 & 36 & -37 & 48 & -49 \\
\hline 251 & 1 & -1 & $-7 \odot \odot$ & $80 \odot$ & 36 & -37 & 49 & -50 \\
\hline 252 & 1 & -1 & -700 & 800 & 36 & -37 & 50 & -51 \\
\hline 253 & 1 & -1 & -700 & 800 & 36 & -37 & 51 & -52 \\
\hline
\end{tabular}




\begin{tabular}{|c|c|c|c|c|c|c|c|c|}
\hline 254 & 1 & -1 & -700 & 800 & 36 & -37 & 52 & -53 \\
\hline 255 & 1 & -1 & -700 & 800 & 36 & -37 & 53 & -54 \\
\hline 256 & 1 & -1 & $-70 \odot$ & 800 & 36 & -37 & 54 & -55 \\
\hline 257 & 1 & -1 & -700 & 800 & 36 & -37 & 55 & -56 \\
\hline 258 & 1 & -1 & -700 & 800 & 36 & -37 & 56 & -57 \\
\hline 259 & 1 & -1 & $-7 \odot \odot$ & $80 \odot$ & 36 & -37 & 57 & -58 \\
\hline 260 & 1 & -1 & -700 & 800 & 36 & -37 & 58 & -59 \\
\hline 261 & 1 & -1 & -700 & 800 & 36 & -37 & 59 & -60 \\
\hline 262 & 1 & -1 & -700 & 800 & 36 & -37 & 60 & -61 \\
\hline 263 & 1 & -1 & -700 & 800 & 36 & -37 & 61 & -62 \\
\hline 264 & 1 & -1 & -700 & 800 & 36 & -37 & 62 & -63 \\
\hline$c \quad x=2$ & $y=-8$ & to 8 & & & & & & \\
\hline 265 & 1 & -1 & -700 & 800 & 37 & -38 & 47 & -48 \\
\hline 266 & 1 & -1 & -700 & 800 & 37 & -38 & 48 & -49 \\
\hline 267 & 1 & -1 & -700 & 800 & 37 & -38 & 49 & -50 \\
\hline 268 & 1 & -1 & -700 & 800 & 37 & -38 & 50 & -51 \\
\hline 269 & 1 & -1 & -700 & 800 & 37 & -38 & 51 & -52 \\
\hline 270 & 1 & -1 & -700 & 800 & 37 & -38 & 52 & -53 \\
\hline 271 & 1 & -1 & -700 & 800 & 37 & -38 & 53 & -54 \\
\hline 272 & 1 & -1 & -700 & 800 & 37 & -38 & 54 & -55 \\
\hline 273 & 1 & -1 & -700 & 800 & 37 & -38 & 55 & -56 \\
\hline 274 & 1 & -1 & -700 & 800 & 37 & -38 & 56 & -57 \\
\hline 275 & 1 & -1 & -700 & 800 & 37 & -38 & 57 & -58 \\
\hline 276 & 1 & -1 & -700 & 800 & 37 & -38 & 58 & -59 \\
\hline 277 & 1 & -1 & -700 & 800 & 37 & -38 & 59 & -60 \\
\hline 278 & 1 & -1 & -700 & 800 & 37 & -38 & 60 & -61 \\
\hline 279 & 1 & -1 & -700 & 800 & 37 & -38 & 61 & -62 \\
\hline$c x=3$ & $y=-8$ & to 8 & & & & & & \\
\hline 280 & 1 & -1 & -700 & 800 & 38 & -39 & 47 & -48 \\
\hline 281 & 1 & -1 & -700 & 800 & 38 & -39 & 48 & -49 \\
\hline 282 & 1 & -1 & -700 & 800 & 38 & -39 & 49 & -50 \\
\hline 283 & 1 & -1 & -700 & 800 & 38 & -39 & 50 & -51 \\
\hline 284 & 1 & -1 & -700 & 800 & 38 & -39 & 51 & -52 \\
\hline 285 & 1 & -1 & -700 & 800 & 38 & -39 & 52 & -53 \\
\hline 286 & 1 & -1 & -700 & 800 & 38 & -39 & 53 & -54 \\
\hline 287 & 1 & -1 & -700 & 800 & 38 & -39 & 54 & -55 \\
\hline 288 & 1 & -1 & -700 & 800 & 38 & -39 & 55 & -56 \\
\hline 289 & 1 & -1 & -700 & 800 & 38 & -39 & 56 & -57 \\
\hline 290 & 1 & -1 & -700 & 800 & 38 & -39 & 57 & -58 \\
\hline 291 & 1 & -1 & -700 & 800 & 38 & -39 & 58 & -59 \\
\hline 292 & 1 & -1 & -700 & 800 & 38 & -39 & 59 & -60 \\
\hline 293 & 1 & -1 & -700 & 800 & 38 & -39 & 60 & -61 \\
\hline 294 & 1 & -1 & -700 & 800 & 38 & -39 & 61 & -62 \\
\hline$c x=$ & $y=$ & -7 to & & & & & & \\
\hline 295 & 1 & -1 & -700 & 800 & 39 & -40 & 47 & -48 \\
\hline 296 & 1 & -1 & -700 & 800 & 39 & -40 & 48 & -49 \\
\hline 297 & 1 & -1 & -700 & 800 & 39 & -40 & 49 & -50 \\
\hline 298 & 1 & -1 & -700 & 800 & 39 & -40 & 50 & -51 \\
\hline 299 & 1 & -1 & -700 & 800 & 39 & -40 & 51 & -52 \\
\hline 300 & 1 & -1 & -700 & 800 & 39 & -40 & 52 & -53 \\
\hline 301 & 1 & -1 & $-7 \odot \odot$ & $80 \odot$ & 39 & -40 & 53 & -54 \\
\hline $3 \odot 2$ & 1 & -1 & -700 & 800 & 39 & -40 & 54 & -55 \\
\hline 303 & 1 & -1 & -700 & 800 & 39 & -40 & 55 & -56 \\
\hline 304 & 1 & -1 & -700 & 800 & 39 & -40 & 56 & -57 \\
\hline 305 & 1 & -1 & -700 & 800 & 39 & -40 & 57 & -58 \\
\hline 306 & 1 & -1 & -700 & 800 & 39 & -40 & 58 & -59 \\
\hline 307 & 1 & -1 & -700 & 800 & 39 & -40 & 59 & -60 \\
\hline 308 & 1 & -1 & -700 & 800 & 39 & -40 & 60 & -61 \\
\hline 309 & 1 & -1 & -700 & 800 & 39 & -40 & 61 & -62 \\
\hline c $x=5$ & $y=-6$ & to 6 & & & & & & \\
\hline 310 & 1 & -1 & -700 & 800 & 40 & -41 & 48 & -49 \\
\hline 311 & 1 & -1 & -700 & 800 & 40 & -41 & 49 & -50 \\
\hline 312 & 1 & -1 & -700 & 800 & 40 & -41 & 50 & -51 \\
\hline
\end{tabular}




\begin{tabular}{|c|c|c|c|c|c|c|c|c|c|c|c|c|}
\hline 313 & 1 & -1 & & -700 & $80 \odot$ & 40 & -41 & 51 & -52 & & & \\
\hline 314 & 1 & -1 & & -700 & 800 & 40 & -41 & 52 & -53 & & & \\
\hline 315 & 1 & -1 & & -700 & 800 & 40 & -41 & 53 & -54 & & & \\
\hline 316 & 1 & -1 & & -700 & 800 & 40 & -41 & 54 & -55 & & & \\
\hline 317 & 1 & -1 & & -700 & 800 & 40 & -41 & 55 & -56 & & & \\
\hline 318 & 1 & -1 & & -700 & 800 & 40 & -41 & 56 & -57 & & & \\
\hline 319 & 1 & -1 & & -700 & 800 & 40 & -41 & 57 & -58 & & & \\
\hline 320 & 1 & -1 & & -700 & 800 & 40 & -41 & 58 & -59 & & & \\
\hline 321 & 1 & -1 & & -700 & 800 & 40 & -41 & 59 & -60 & & & \\
\hline 322 & 1 & -1 & & -700 & 800 & 40 & -41 & 60 & -61 & & & \\
\hline c $\quad x=$ & $; y=-$ & b to & 6 & & & & & & & & & \\
\hline 323 & 1 & -1 & & -700 & 800 & 41 & -42 & 48 & -49 & -1 & & \\
\hline 324 & 1 & -1 & & -700 & 800 & 41 & -42 & 49 & -50 & & & \\
\hline 325 & 1 & -1 & & -700 & 800 & 41 & -42 & 50 & -51 & & & \\
\hline 326 & 1 & -1 & & -700 & 800 & 41 & -42 & 51 & -52 & & & \\
\hline 327 & 1 & -1 & & -700 & 800 & 41 & -42 & 52 & -53 & & & \\
\hline 328 & 1 & -1 & & -700 & 800 & 41 & -42 & 53 & -54 & & & \\
\hline 329 & 1 & -1 & & -700 & 800 & 41 & -42 & 54 & -55 & & & \\
\hline 330 & 1 & -1 & & -700 & 800 & 41 & -42 & 55 & -56 & & & \\
\hline 331 & 1 & -1 & & -700 & 800 & 41 & -42 & 56 & -57 & & & \\
\hline 332 & 1 & -1 & & -700 & 800 & 41 & -42 & 57 & -58 & & & \\
\hline 333 & 1 & -1 & & -700 & 800 & 41 & -42 & 58 & -59 & & & \\
\hline 334 & 1 & -1 & & -700 & 800 & 41 & -42 & 59 & -60 & & & \\
\hline 335 & 1 & -1 & & -700 & 800 & 41 & -42 & 60 & -61 & -1 & & \\
\hline c $x=7$ & $; y=-5$ & 5 to & 5 & & & & & & & & & \\
\hline 336 & 1 & -1 & & -700 & $80 \odot$ & 42 & -43 & 49 & -50 & -1 & & \\
\hline 337 & 1 & -1 & & -700 & 800 & 42 & -43 & 50 & -51 & & & \\
\hline 338 & 1 & -1 & & -700 & 800 & 42 & -43 & 51 & -52 & & & \\
\hline 339 & 1 & -1 & & -700 & 800 & 42 & -43 & 52 & -53 & & & \\
\hline 340 & 1 & -1 & & -700 & 800 & 42 & -43 & 53 & -54 & & & \\
\hline 341 & 1 & -1 & & -700 & 800 & 42 & -43 & 54 & -55 & & & \\
\hline 342 & 1 & -1 & & -700 & 800 & 42 & -43 & 55 & -56 & & & \\
\hline 343 & 1 & -1 & & -700 & 800 & 42 & -43 & 56 & -57 & & & \\
\hline 344 & 1 & -1 & & -700 & 800 & 42 & -43 & 57 & -58 & & & \\
\hline 345 & 1 & -1 & & -700 & 800 & 42 & -43 & 58 & -59 & & & \\
\hline 346 & 1 & -1 & & -700 & 800 & 42 & -43 & 59 & -60 & -1 & & \\
\hline$c \quad x=8$ & $; y=-3$ & 3 to & 3 & & & & & & & & & \\
\hline 347 & 1 & -1 & & -1 & -700 & 800 & -51 & 43 & -44 & & & \\
\hline 348 & 1 & -1 & & $-70 \odot$ & 800 & 43 & -44 & 51 & -52 & & & \\
\hline 349 & 1 & -1 & & -700 & 800 & 43 & -44 & 52 & -53 & & & \\
\hline 350 & 1 & -1 & & -700 & 800 & 43 & -44 & 53 & -54 & & & \\
\hline 351 & 1 & -1 & & -700 & 800 & 43 & -44 & 54 & -55 & & & \\
\hline 352 & 1 & -1 & & -700 & 800 & 43 & -44 & 55 & -56 & & & \\
\hline 353 & 1 & -1 & & -700 & 800 & 43 & -44 & 56 & -57 & & & \\
\hline 354 & 1 & -1 & & -700 & 800 & 43 & -44 & 57 & -58 & & & \\
\hline 355 & 1 & -1 & & -1 & -700 & 800 & 43 & 58 & -44 & & & \\
\hline 356 & 1 & -1 & & -1 & -700 & 800 & 44 & -53 & & & & \\
\hline 357 & 1 & -1 & & $-70 \odot$ & 800 & 44 & -45 & 53 & -54 & & & \\
\hline 358 & 1 & -1 & & -700 & 800 & 44 & -45 & 54 & -55 & & & \\
\hline 359 & 1 & -1 & & -700 & 800 & 44 & -45 & 55 & -56 & & & \\
\hline 360 & 1 & -1 & & -1 & $-7 \odot \odot$ & $80 \odot$ & 44 & 56 & & & & \\
\hline \multirow[t]{2}{*}{1} & & $s q$ & \multicolumn{2}{|r|}{$\odot .0106$} & \multicolumn{2}{|c|}{$\odot .0133$} & \multicolumn{3}{|c|}{$\odot .0 \odot 45$} & & $\odot$ & $\odot$ \\
\hline & & & $\odot$ & & -1 & & $\odot$ & & $\Theta$ & & -1 & \\
\hline \multirow[t]{2}{*}{2} & & $\mathrm{sq}$ & & ๑. 0115 & 0.0 & 9145 & & 0.11 & & & $\odot$ & $\odot$ \\
\hline & & & $\odot$ & & -1 & & $\odot$ & & $\odot$ & & 4.7 & \\
\hline 3 & & $p z$ & & 5.8 & & & & & & & & \\
\hline 4 & & $p z$ & & -11 & & & & & & & & \\
\hline \multirow[t]{2}{*}{5} & & sq & & 0.04 & & 029 & & & $\odot$ & & $\odot$ & $\odot$ \\
\hline & & & $\odot$ & & -1 & & $\odot$ & & $\odot$ & & $\odot$ & \\
\hline 6 & & $p z$ & & -17 & & & & & & & & \\
\hline 8 & & $C Z$ & & 10 & & & & & & & & \\
\hline 10 & & $\mathrm{sq}$ & & $\odot .0098$ & 0.0 & อ०98 & & $\odot . \odot$ & & & $\odot$ & $\odot$ \\
\hline
\end{tabular}




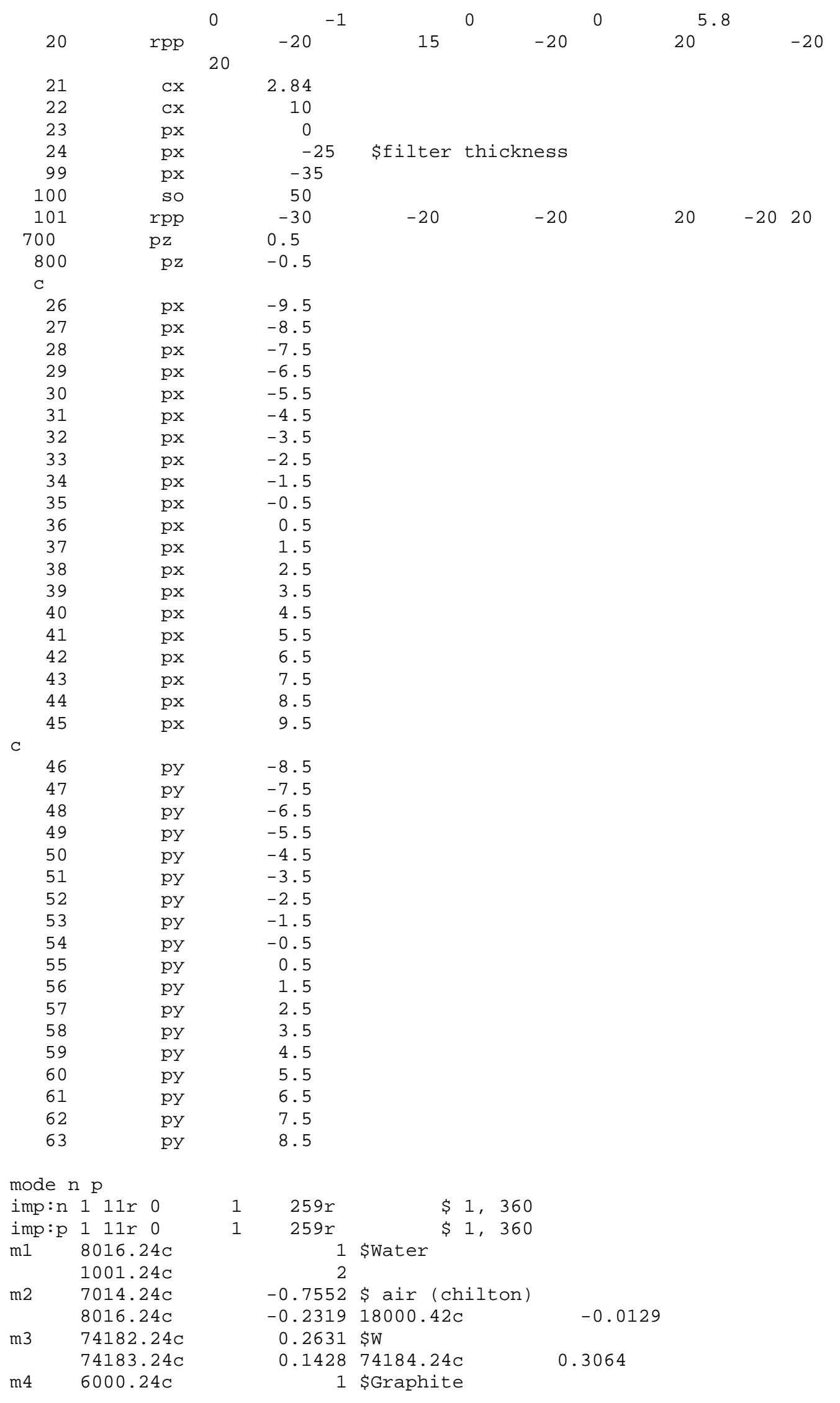




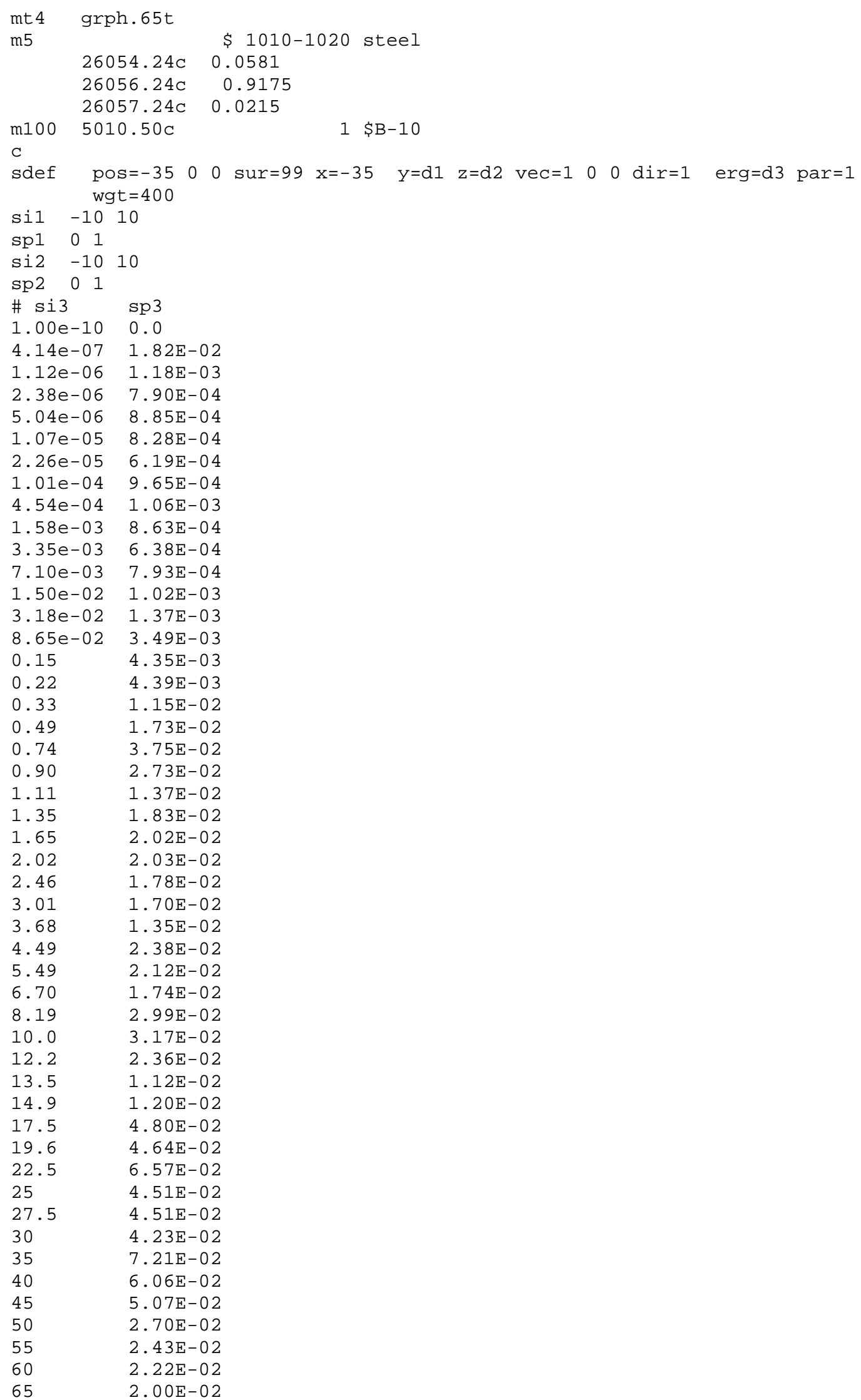




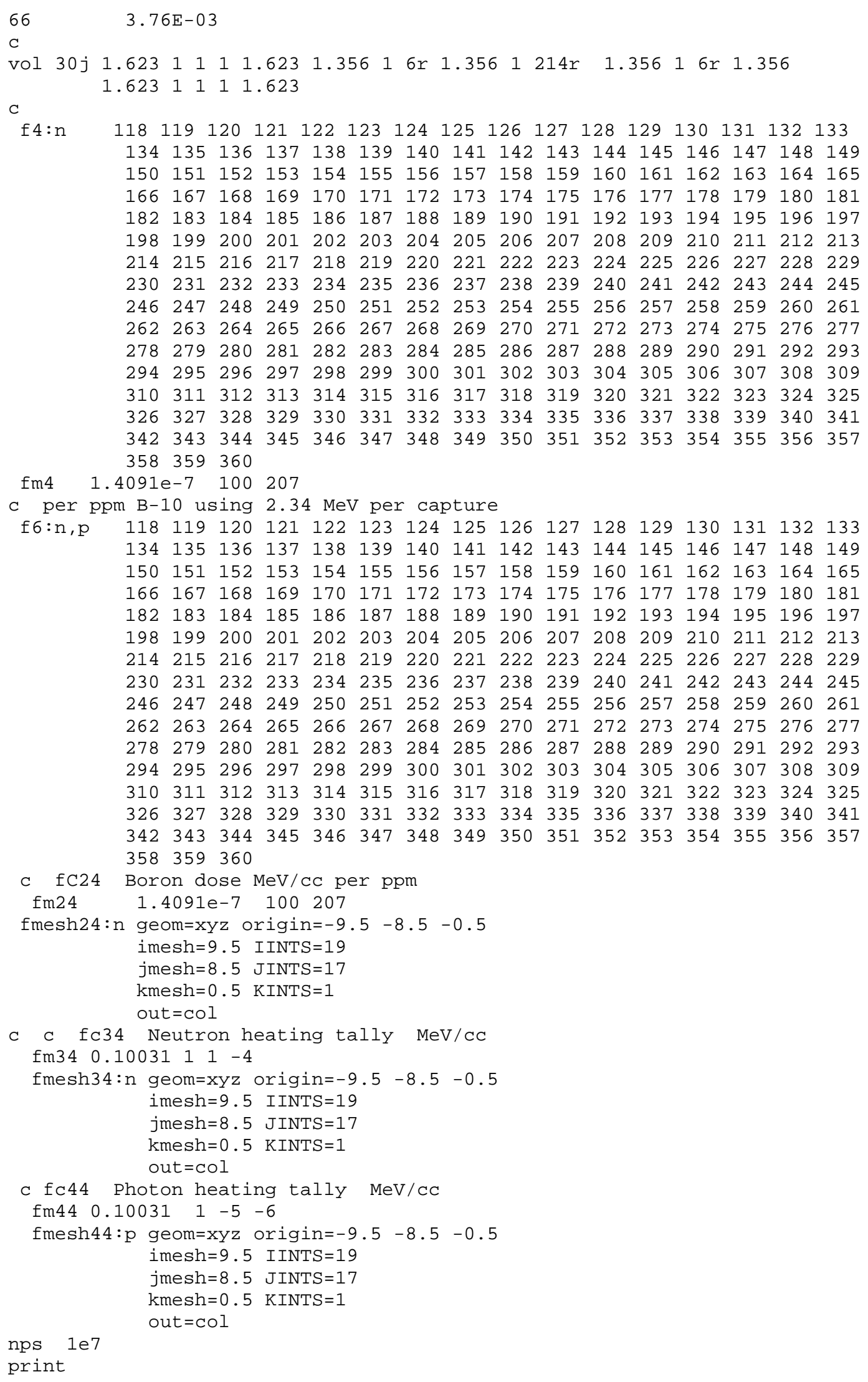


D2.2 Activation calculation in the tungsten filter and lead collimator of the simplified BNCEFNT assembly

c Collimator: $10 \mathrm{~cm} \mathrm{Pb;} \mathrm{filter:} 5 \mathrm{~cm} \mathrm{~W}$

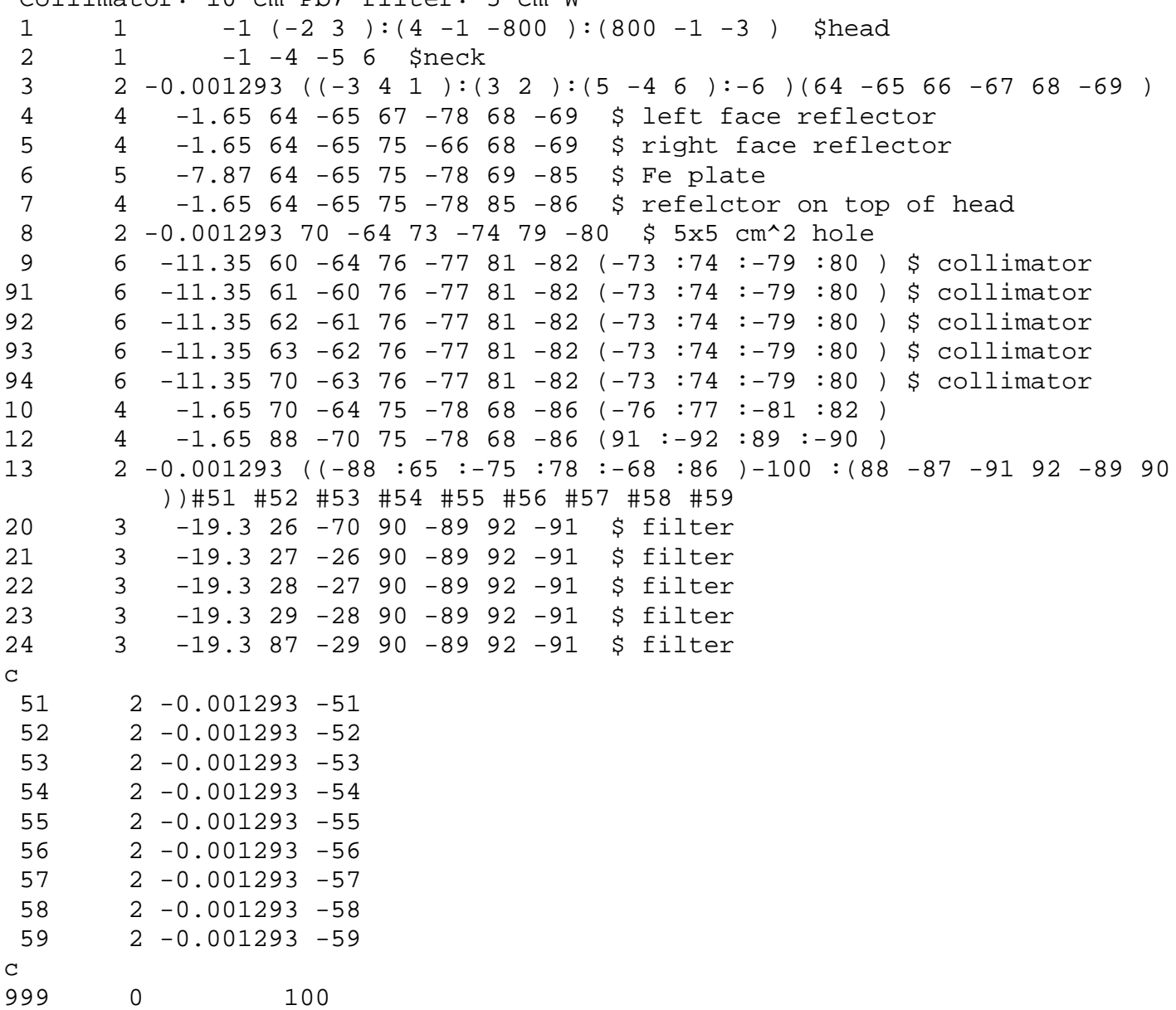

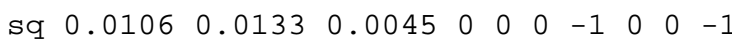

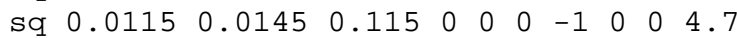

pz 5.8

pz -11

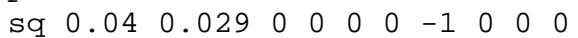

pz -17

so 150

pz 0.5

pz $-\odot .5$

800

$\mathrm{px}-21$

$\mathrm{px}-22$

$\mathrm{px}-23$

$\mathrm{px}-24$

$\mathrm{px}-5.5$

$\mathrm{px}-4.5$

$\mathrm{px}-3.5$

px -2.5

px -1.5

px -0.5

px 0.5 


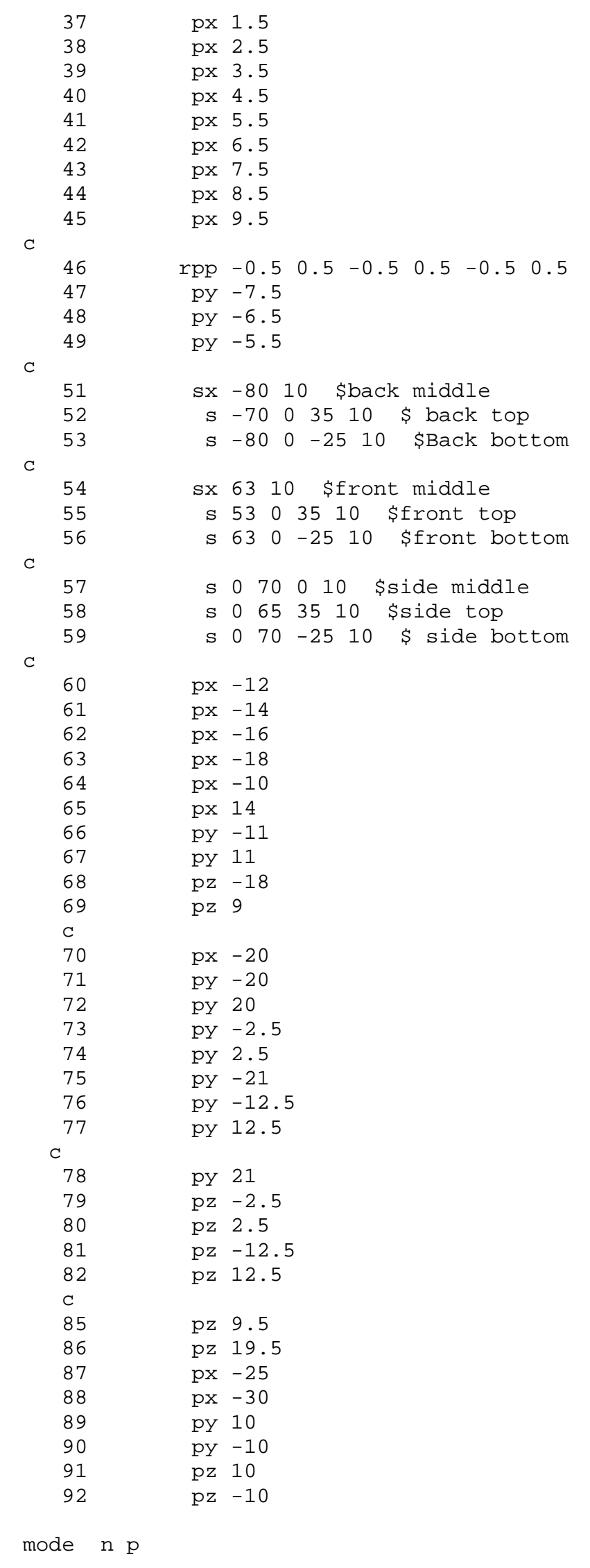




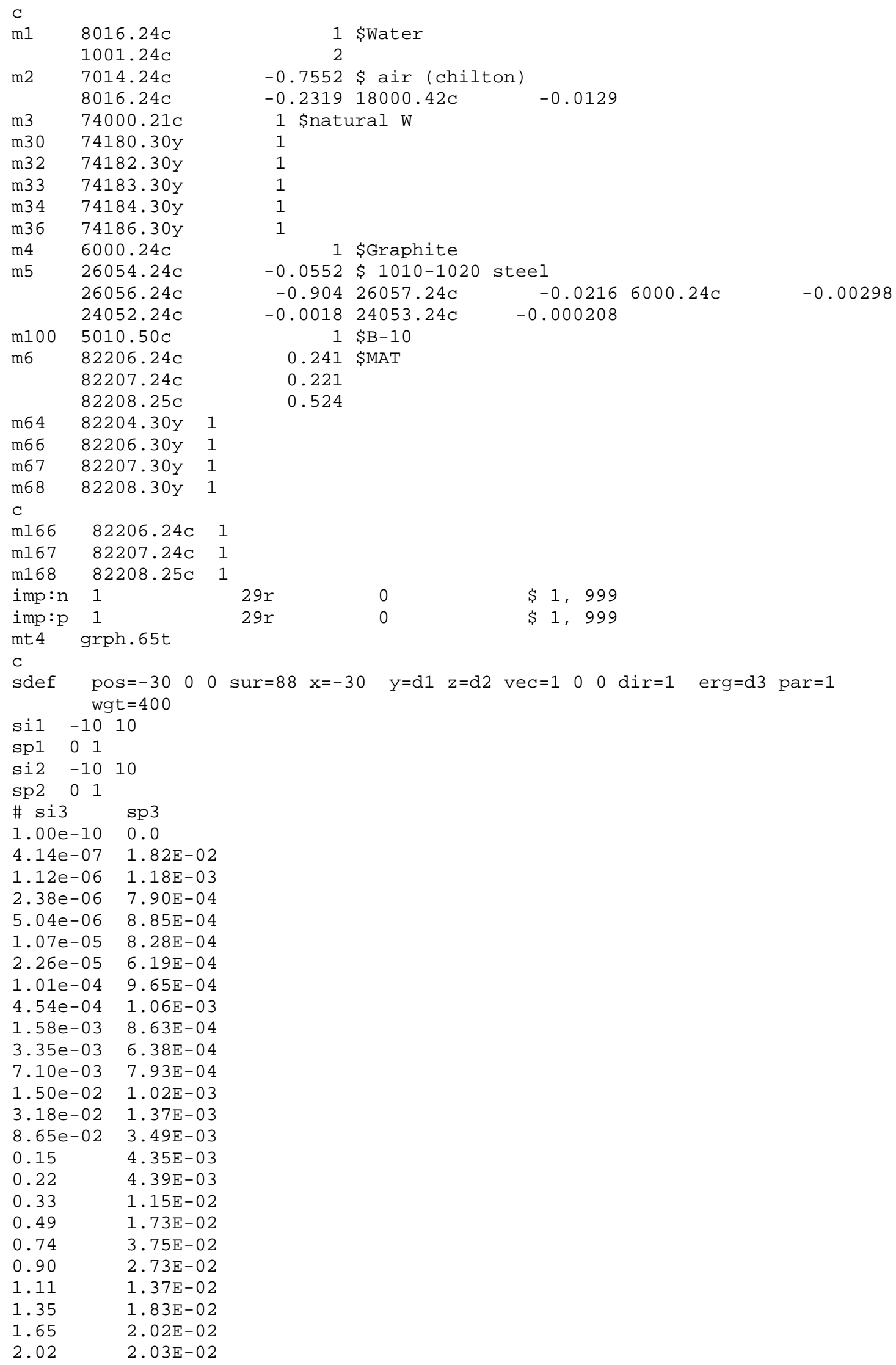




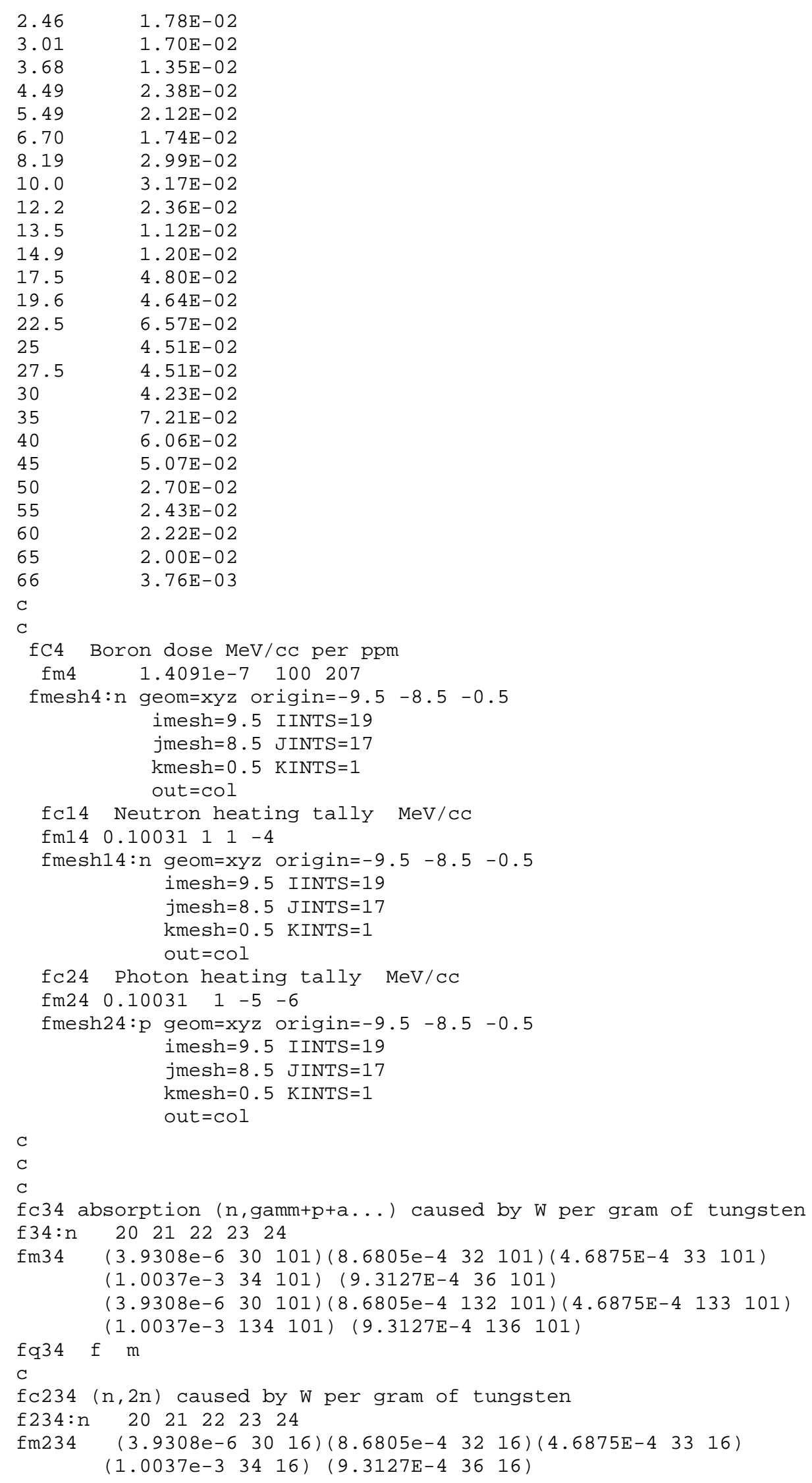




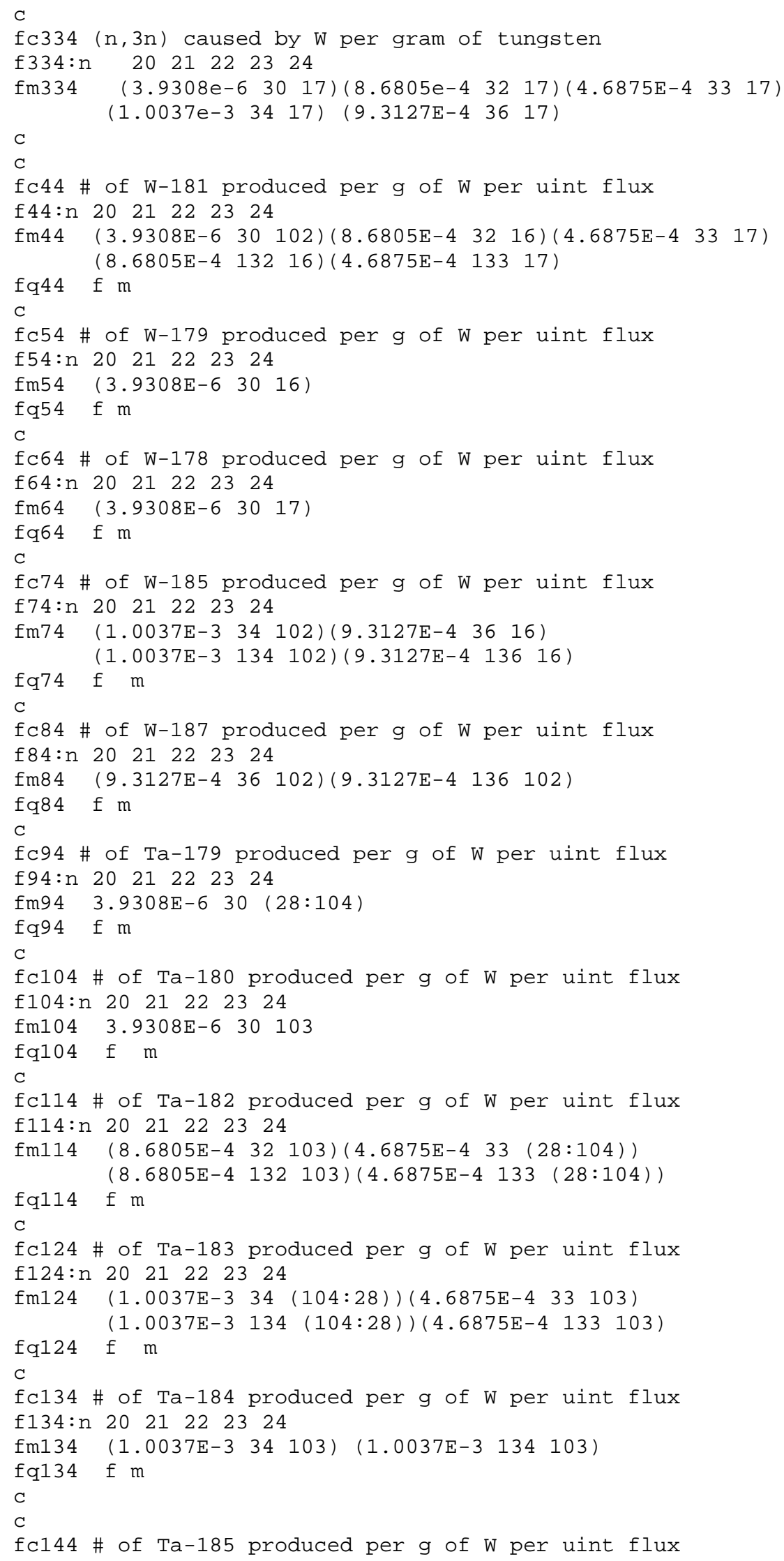


f144:n $20 \quad 2122 \quad 23 \quad 24$

fm144 (9.3127E-4 $36(28: 104))(9.3127 E-4136(28: 104))$

fq144 $f$ m

c

fc154 \# of Ta-186 produced per $g$ of $W$ per uint flux

f154:n $20 \quad 2122 \quad 2324$

fm154 (1.0037E-3 36 103)(1.0037E-3 136 103)

$\mathrm{fq} 154 \mathrm{f} m$

c

fc164 \# of Hf-178m produced per $g$ of $W$ per uint flux

f164:n $20 \quad 2122 \quad 2324$

fm164 (8.6805E-4 32 22) (8.6805E-4 132 22)

fq164 $f \mathrm{~m}$

c

fc174 \# of Hf-179m produced per $g$ of $W$ per uint flux

f174:n $20 \quad 2122 \quad 2324$

fm174 (4.6875E-4 $33 \quad 22)\left(\begin{array}{llll}4.6875 E-4 & 133 & 22\end{array}\right)$

$\mathrm{fq} 174$ f $\mathrm{m}$

c

fc184 \# of Hf-181 produced per $g$ of $W$ per uint flux

f184:n $20 \quad 2122 \quad 23 \quad 24$

fm184 (1.0037E-3 34 107)(1.0037E-3 134 107)

$\mathrm{fq} 184 \mathrm{f} \mathrm{m}$

$\mathrm{C}$

fc194 \# of Hf-182/183 produced per $g$ of $W$ per uint flux

f194:n $202122 \quad 2324$

fm194 (9.3127E-4 $36(22)(107))(9.3127 \mathrm{E}-4136$ (22) (107))

$\mathrm{fq} 194 \mathrm{f} \mathrm{m}$

c

fc404 absorption $(n, g a m m+p+a \ldots)$ caused by $P b$ per gram of tungsten

f404:n $\quad 991929394$

fm404 (4.0689e-5 $64-2)\left(\begin{array}{llll}7.0044 e-4 & 66 & -2\end{array}\right)\left(\begin{array}{lll}6.4231 E-4 & 67 & -2\end{array}\right)$

$(1.5229 \mathrm{e}-368-2)(7.0044 \mathrm{e}-4 \quad 166-2)(6.4231 \mathrm{E}-4 \quad 167-2)$ $(1.5229 \mathrm{e}-3 \quad 168-2)$

$\mathrm{fq} 404 \mathrm{f} \mathrm{m}$

$\mathrm{C}$

fc414 $(n, 2 n)$ caused by $\mathrm{Pb}$ per gram of tungsten

f414:n $\quad 991929394$

fm414 (4.0689e-5 64 16)( $7.0044 \mathrm{e}-4 \quad 66$ 16)( $\left(\begin{array}{lll}6.4231 \mathrm{E}-4 & 67 & 16\end{array}\right)$

$(1.5229 \mathrm{e}-368$ 16)( $7.0044 \mathrm{e}-4$ 166 16)(6.4231E-4 167 16)

$(1.5229 \mathrm{e}-3 \quad 16816)$

$\mathrm{fq} 414$ f $m$

C

fc424 $(n, 3 n)$ caused by $P b$ per gram of tungsten

$\mathrm{f} 424: \mathrm{n} \quad 991929394$

fm424 (4.0689e-5 64 17)( $7.0044 \mathrm{e}-4 \quad 66$ 17)( $\left.\begin{array}{lllll}6.4231 \mathrm{E}-4 & 67 & 17\end{array}\right)$

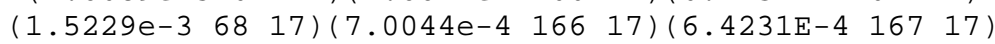
$(1.5229 \mathrm{e}-3 \quad 16817)$

$\mathrm{fq} 424 \mathrm{f} \mathrm{m}$

C

fc434 \# of $\mathrm{Pb}-202$ produced per $\mathrm{g}$ of $\mathrm{Pb}$ per uint flux

f434:n 991929394

fm434 $4.0689 \mathrm{e}-5 \quad 6417$

$\mathrm{fq434} f \mathrm{~m}$

C

fc444 \# of $\mathrm{Pb}-203$ produced per $\mathrm{g}$ of $\mathrm{Pb}$ per uint flux

f444:n 991929394

fm444 (4.0689e-5 6416$)$

$\mathrm{fq} 444 \mathrm{f} \mathrm{m}$

C

fc454 \# of $\mathrm{Pb}-204 \mathrm{~m}$ produced per $\mathrm{g}$ of $\mathrm{Pb}$ per uint flux

f454:n 991929394

fm454 $4.0689 \mathrm{e}-5644$ 


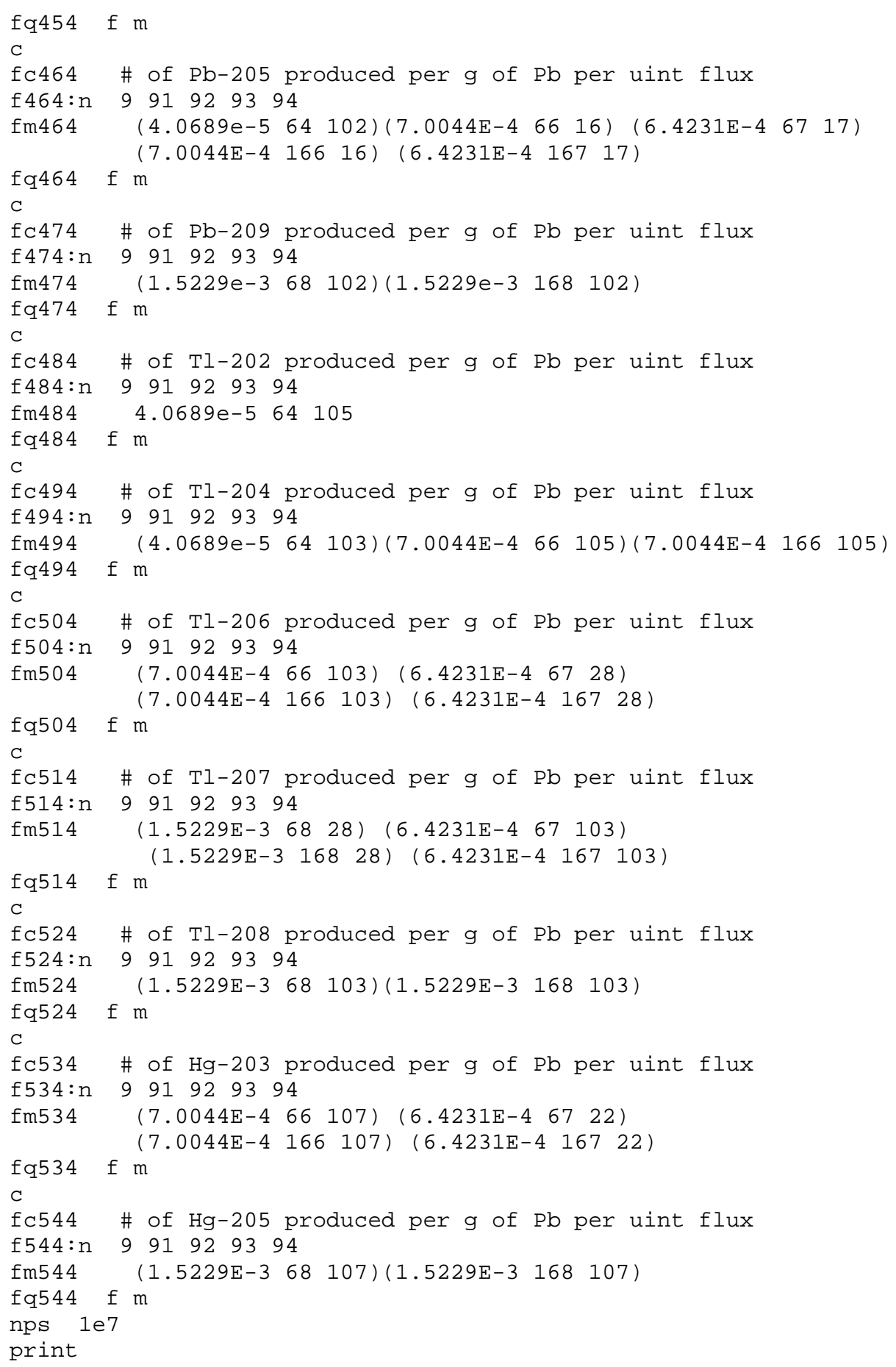


D2.3 Calculation of dose rate due to $1 \mathrm{~Bq}$ of activation products $\left({ }^{187} \mathrm{~W}\right)$ in the filter

C Collimator: $10 \mathrm{~cm} \mathrm{~Pb}$; filter: $5-\mathrm{cm}$ thick $20 \times 20 \mathrm{~cm} \wedge 2 \mathrm{~W}$

C Dose rate due to $1 \mathrm{~Bq}$ of $\mathrm{W}-187$ distributed in tungsten filter

C

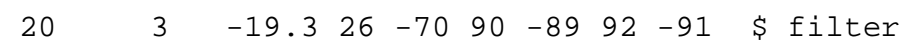

$\begin{array}{llllllllll}21 & 3 & -19.3 & 27 & -26 & 90 & -89 & 92 & -91 & \$ \text { filter }\end{array}$

$\begin{array}{llllllllll}22 & 3 & -19.3 & 28 & -27 & 90 & -89 & 92 & -91 & \$ \text { filter }\end{array}$

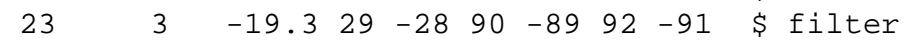

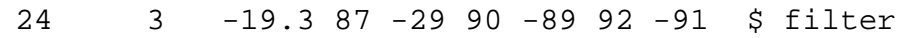

C

$51 \quad 2-0.001293-51$

$52 \quad 2-0.001293-52$

$53 \quad 2-0.001293-53$

$54 \quad 2-0.001293-54$

$55 \quad 2-0.001293-55$

$56 \quad 2-0.001293-56$

$57 \quad 2-0.001293-57$

$58 \quad 2-0.001293-58$

$59 \quad 2-0.001293-59$

$60 \quad 6 \quad-11.3593-94 \quad \$ 1 / 4^{\prime \prime}$ lead sheet cover

612 - 2.001293 (94 -100) \#51 \#52 \#53 \#54 \#55 \#56 \#57 \#58 \#59 C

$999 \quad 0 \quad 100$

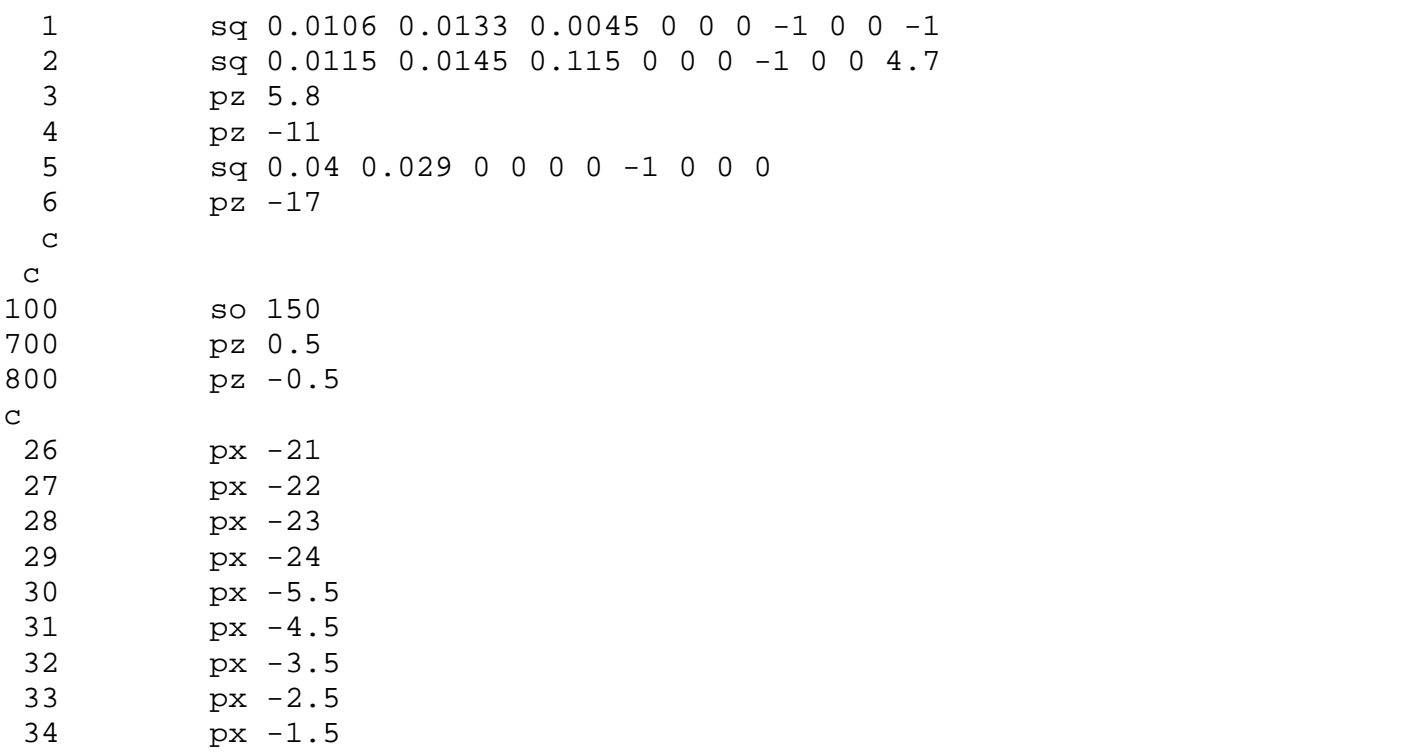




\begin{tabular}{|c|c|c|}
\hline 35 & $\mathrm{px}$ & -0.5 \\
\hline 36 & $\mathrm{px}$ & 0.5 \\
\hline 37 & $\mathrm{px}$ & 1.5 \\
\hline 38 & $\mathrm{px}$ & 2.5 \\
\hline 39 & $\mathrm{px}$ & 3.5 \\
\hline $4 \odot$ & $\mathrm{px}$ & 4.5 \\
\hline 41 & $\mathrm{px}$ & 5.5 \\
\hline 42 & $\mathrm{px}$ & 6.5 \\
\hline 43 & $\mathrm{px}$ & 7.5 \\
\hline 44 & $\mathrm{px}$ & 8.5 \\
\hline 45 & $\mathrm{px}$ & 9.5 \\
\hline \multicolumn{3}{|r|}{$\cos$} \\
\hline 46 & rpp & $\begin{array}{llllll}-0.5 & 0.5 & -0.5 & 0.5 & -0.5 & 0.5\end{array}$ \\
\hline 47 & py & -7.5 \\
\hline 48 & py & -6.5 \\
\hline 49 & py & -5.5 \\
\hline \multicolumn{3}{|c|}{ 然 } \\
\hline 51 & sx & -8010 \$back middle \\
\hline 52 & $\mathrm{~s}$ & $-70 \odot 3510 \quad \$$ back top \\
\hline 53 & $\mathrm{~s}$ & $-80 \odot-2510 \quad$ \$Back bottom \\
\hline \multicolumn{3}{|r|}{ a } \\
\hline 54 & sx & 6310 \$front middle \\
\hline 55 & $\mathrm{~s}$ & $53 \odot 3510 \quad$ \$front top \\
\hline 56 & $\mathrm{~s}$ & $\begin{array}{lllll}63 & 0 & -25 & 10 & \text { \$front bottom }\end{array}$ \\
\hline \multicolumn{3}{|r|}{ 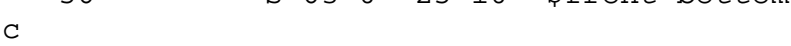 } \\
\hline 57 & $\mathrm{~s}$ & $\odot 70 \odot 10$ \$side middle \\
\hline 58 & $\mathrm{~s}$ & ๑ $653510 \quad$ \$side top \\
\hline 59 & $\mathrm{~s}$ & $\odot 70-2510 \quad \$$ side bottom \\
\hline \multicolumn{3}{|r|}{ 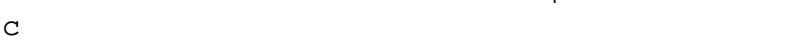 } \\
\hline 60 & $\mathrm{px}$ & -12 \\
\hline 61 & $\mathrm{px}$ & -14 \\
\hline 62 & $\mathrm{px}$ & -16 \\
\hline 63 & $\mathrm{px}$ & -18 \\
\hline 64 & $\mathrm{px}$ & -10 \\
\hline 65 & $p x$ & 14 \\
\hline 66 & py & -11 \\
\hline 67 & py & 11 \\
\hline 68 & $\mathrm{pz}$ & -18 \\
\hline 69 & $\mathrm{pz}$ & 9 \\
\hline \multicolumn{3}{|l|}{ c } \\
\hline 70 & $p x$ & -20 \\
\hline 71 & py & -20 \\
\hline 72 & py & 20 \\
\hline 73 & py & -2.5 \\
\hline 74 & py & 2.5 \\
\hline 75 & py & -21 \\
\hline 76 & py & -12.5 \\
\hline 77 & py & 12.5 \\
\hline \multicolumn{3}{|c|}{ py 12.0} \\
\hline 78 & py & 21 \\
\hline 79 & $\mathrm{pz}$ & -2.5 \\
\hline 80 & $\mathrm{pz}$ & 2.5 \\
\hline 81 & $\mathrm{pz}$ & -12.5 \\
\hline 82 & $\mathrm{pz}$ & 12.5 \\
\hline \multicolumn{3}{|l|}{ c } \\
\hline 85 & $\mathrm{pz}$ & 9.5 \\
\hline 86 & $\mathrm{pz}$ & 19.5 \\
\hline 87 & $\mathrm{px}$ & -25 \\
\hline 88 & $p x$ & -30 \\
\hline 89 & py & 10 \\
\hline 90 & py & -10 \\
\hline 91 & $\mathrm{pz}$ & 10 \\
\hline 92 & $\mathrm{pz}$ & -10 \\
\hline
\end{tabular}




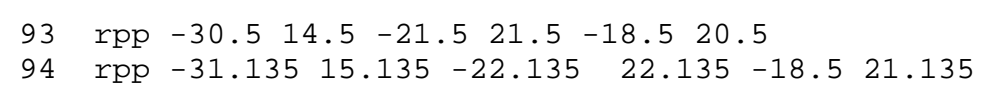

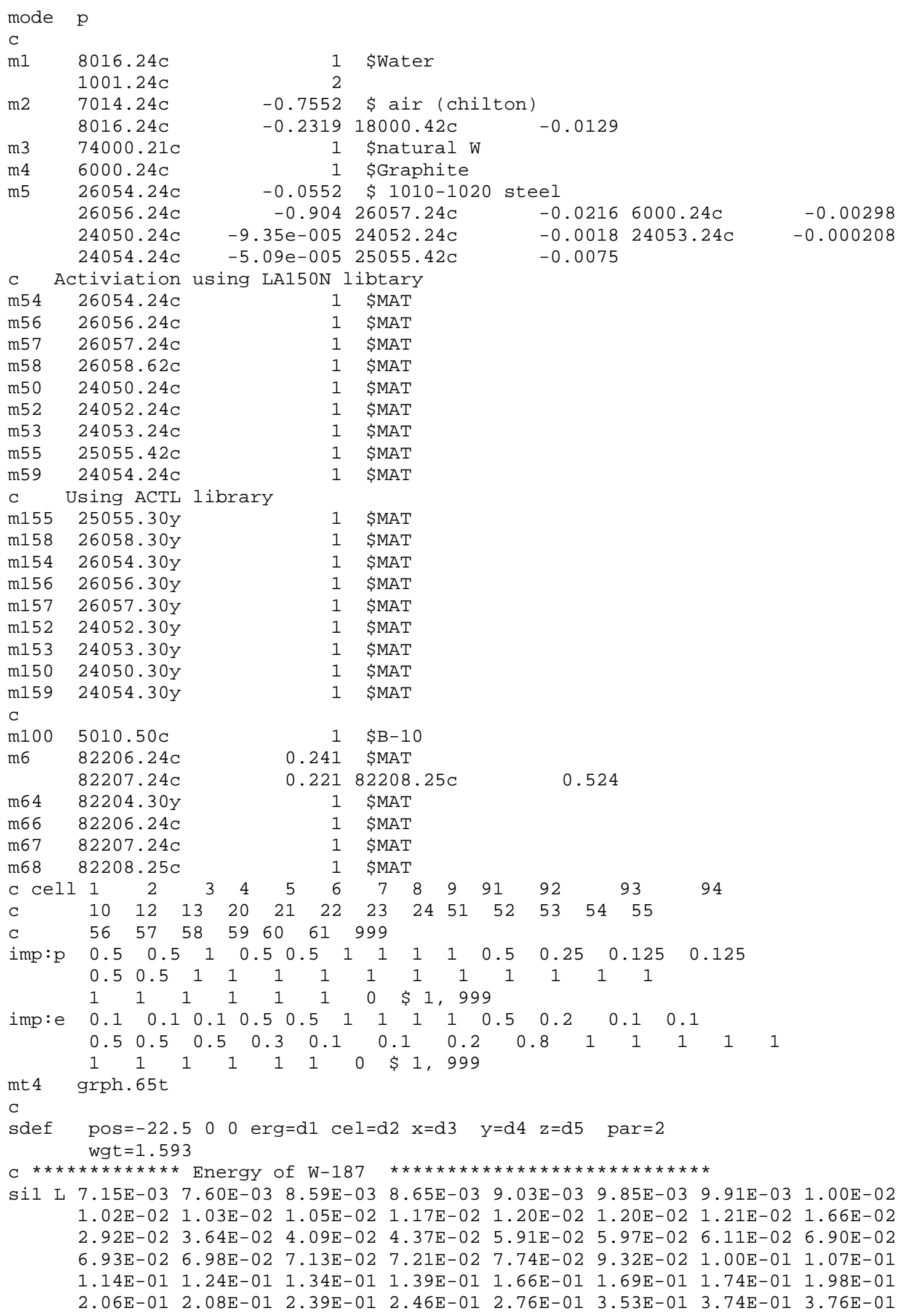


4.55E-01 4.80E-01 4.84E-01 4.93E-01 5.12E-01 5.52E-01 5.65E-01 5.74E-01 5.76E-01 5.79E-01 5.89E-01 6.13E-01 6.18E-01 6.26E-01 6.39E-01 6.47E-01 6.82E-01 6.86E-01 6.93E-01 7.30E-01 7.45E-01 7.67E-01 7.73E-01 8.17E-01

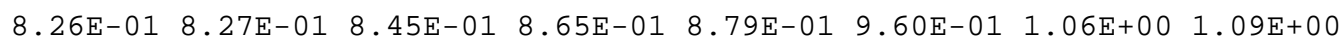

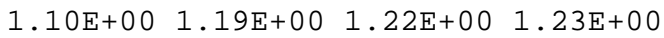

sp1 D 2.63E-05 6.28E-03 1.75E-02 1.57E-01 2.77E-03 2.04E-03 2.06E-03 1.31E-01

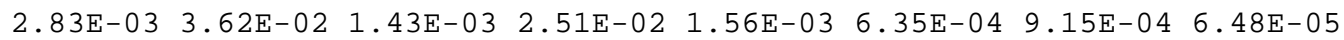
4.07E-05 6.70E-05 1.85E-05 1.85E-05 6.17E-05 7.58E-02 1.31E-01 1.49E-02 2.87E-02 6.87E-04 1.13E-02 1.19E-01 7.41E-05 6.48E-05 9.63E-05 2.73E-04 8.24E-@4 2.78E-05 9.45E-02 4.63E-05 9.26E-06 2.78E-05 4.63E-06 $1.85 E-05$ 1.53E-03 7.41E-06 9.26E-04 1.28E-03 2.22E-05 1.67E-05 2.78E-05 3.70E-05 3.15E-04 2.34E-01 1.85E-๑4 2.78E-@4 6.92E-@3 5.45E-02 1.30E-๑4 5.56E-@6 7.13E-05 1.02E-05 1.31E-03 2.22E-05 6.73E-02 1.17E-02 3.43E-05 8.33E-06 7.41E-05 2.93E-01 1.39E-05 1.85E-04 3.19E-03 1.67E-05 4.42E-02 1.06E-04 2.50E-๑6 2.50E-๑6 2.59E-@6 3.60E-๑3 $1.52 \mathrm{E}-03 \quad 1.42 \mathrm{E}-05 \quad 2.41 \mathrm{E}-06 \quad 9.26 \mathrm{E}-07$ 7. 41E-07 2.32E-06 1.85E-07 1.42E-05

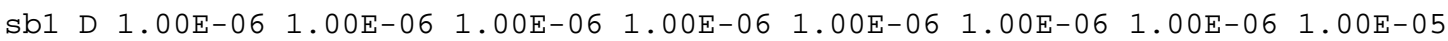
1.00E-05 1.00E-05 1.00E-05 1.00E-05 1.00E-05 1.00E-05 1.00E-05 1.00E-05

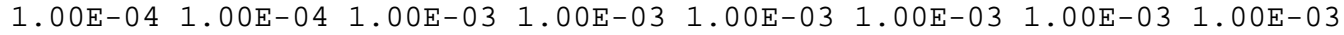

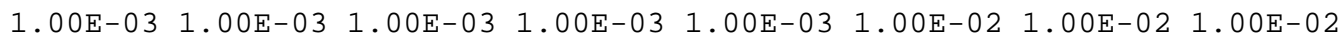
1. $00 \mathrm{E}-01$ 1.00E-01 1.00E-01 1.00E-01 1.00E-01 1.00E-01 1.00E-01 5.00E-01

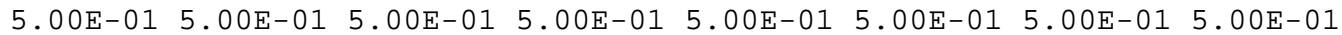

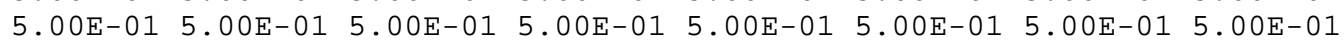
5.

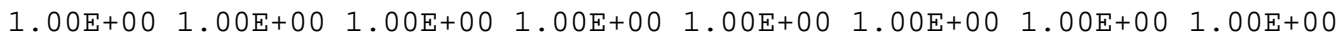

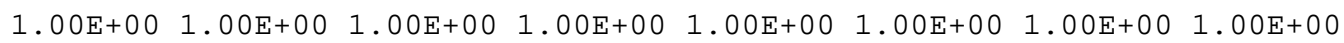

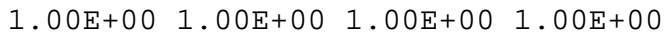

c activity fraction in cells

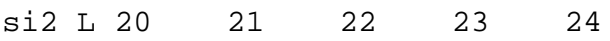

sp2 D $\odot .249 \quad 0.168 \quad 0.161 \quad 0.181 \quad 0.241$

$\mathrm{C}$

si3 - $25-20$

sp3 01

si4 -1010

sp4 $\odot 1$

si5 -1010

sp5 01

$\mathrm{C}$

e4 $\quad 0.01 \quad 0.015 \quad 0.02 \quad 0.03 \quad 0.04 \quad 0.05 \quad 0.06 \quad 0.07 \quad 0.08 \quad 0.1 \quad 0.15 \quad 0.2 \quad 0.25 \quad 0.3 \quad 0.35$ $\begin{array}{lllllllllllllllllllll}0.4 & 0.45 & 0.5 & 0.55 & 0.6 & 0.65 & 0.7 & 0.8 & 1.0 & 1.4 & 1.8 & 2.2 & 2.6 & 2.8\end{array}$

f4:p $51 \quad 54 \quad 57$

fq4 e $f$

C

fc14 Photon Flux-to-Dose Rate Conversion Factors ANSI/ANS"C6.1.1"C1977

f14:p $51 \quad 54 \quad 57$

fq14 f e

c

c Photon Flux-to-Dose Rate Conversion Factors ANSI/ANS"C6.1.1"C1977

C $(\mathrm{rem} / \mathrm{hr}) /\left(\mathrm{p} / \mathrm{cm}^{\wedge} 2 / \mathrm{s}\right)$

\# DE14 DF14

1. $00 \mathrm{E}-02 \quad 3.96 \mathrm{E}-06$

3. $\odot \odot \mathrm{E}-02 \quad 5.82 \mathrm{E}-07$

$5.00 \mathrm{E}-02 \quad 2.90 \mathrm{E}-07$

7. $00 \mathrm{E}-02 \quad 2.58 \mathrm{E}-07$

$1.00 \mathrm{E}-01 \quad 2.83 \mathrm{E}-07$

1. $50 \mathrm{E}-01 \quad 3.79 \mathrm{E}-07$

2. $00 \mathrm{E}-01$ 5.01E-07

2. 50E-01 6.31E-07

3. $00 \mathrm{E}-01 \quad 7.59 \mathrm{E}-07$

3.50E-01 8.78E-07

4. $00 \mathrm{E}-01 \quad 9.85 \mathrm{E}-07$

4. 50E-01 1.08E-06 


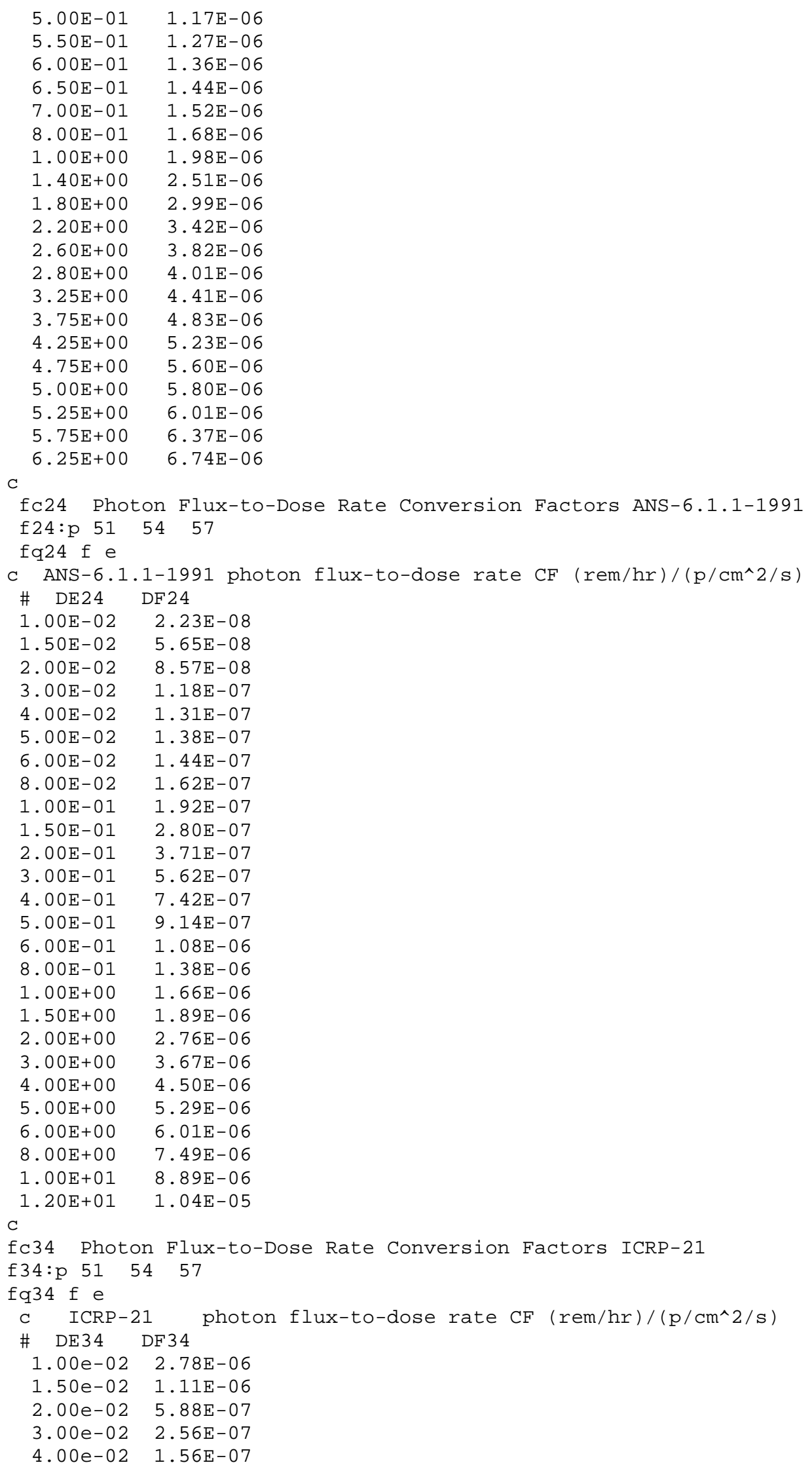




$$
\begin{aligned}
& \text { 5. } 00 \mathrm{e}-\odot 2 \text { 1.20E- } 07 \\
& \text { 6.00e-02 1.11E-07 } \\
& \text { 8.00e-02 1.20E-07 } \\
& 1.00 \mathrm{e}-01 \text { 1.47E-07 } \\
& 1.50 \mathrm{e}-01 \quad 2.38 \mathrm{E}-07 \\
& 2.00 \mathrm{e}-01 \quad 3.45 \mathrm{E}-07 \\
& \text { 3. } 0 \odot \mathrm{e}-01 \text { 5.56E- } 07 \\
& \text { 4. } 00 \mathrm{e}-01 \text { 7.69E-07 } \\
& \text { 5. } 00 \mathrm{e}-01 \text { 9.09E-07 } \\
& \text { 6. } 00 \mathrm{e}-01 \text { 1.14E-06 } \\
& \text { 8. } 00 \mathrm{e}-01 \text { 1.47E-06 } \\
& 1.0 \odot \mathrm{e}+0 \odot \quad 1.79 \mathrm{E}-06 \\
& 1.50 \mathrm{e}+\odot \odot \quad 2.44 \mathrm{E}-06 \\
& \text { 2. } 00 \mathrm{e}+0 \odot \quad 3.03 \mathrm{E}-06 \\
& \text { 3. } \odot \odot \mathrm{e}+\odot \odot \text { 4. } . \odot \mathrm{E}-\odot 6 \\
& 4.00 \mathrm{e}+00 \text { 4.76E- } 06 \\
& 5.00 \mathrm{e}+\odot \odot \quad 5.56 \mathrm{E}-\odot 6 \\
& 6.00 \mathrm{e}+0 \odot \quad 6.25 \mathrm{E}-06 \\
& 8.00 \mathrm{e}+00 \text { 7.69E-06 }
\end{aligned}
$$

fc44 Photon Flux-to-Dose Rate Conversion Factors ICRP-21 rem/hr/Bq $\mathrm{f} 44: \mathrm{p} 51 \quad 54 \quad 57$

fq44 $f$ e

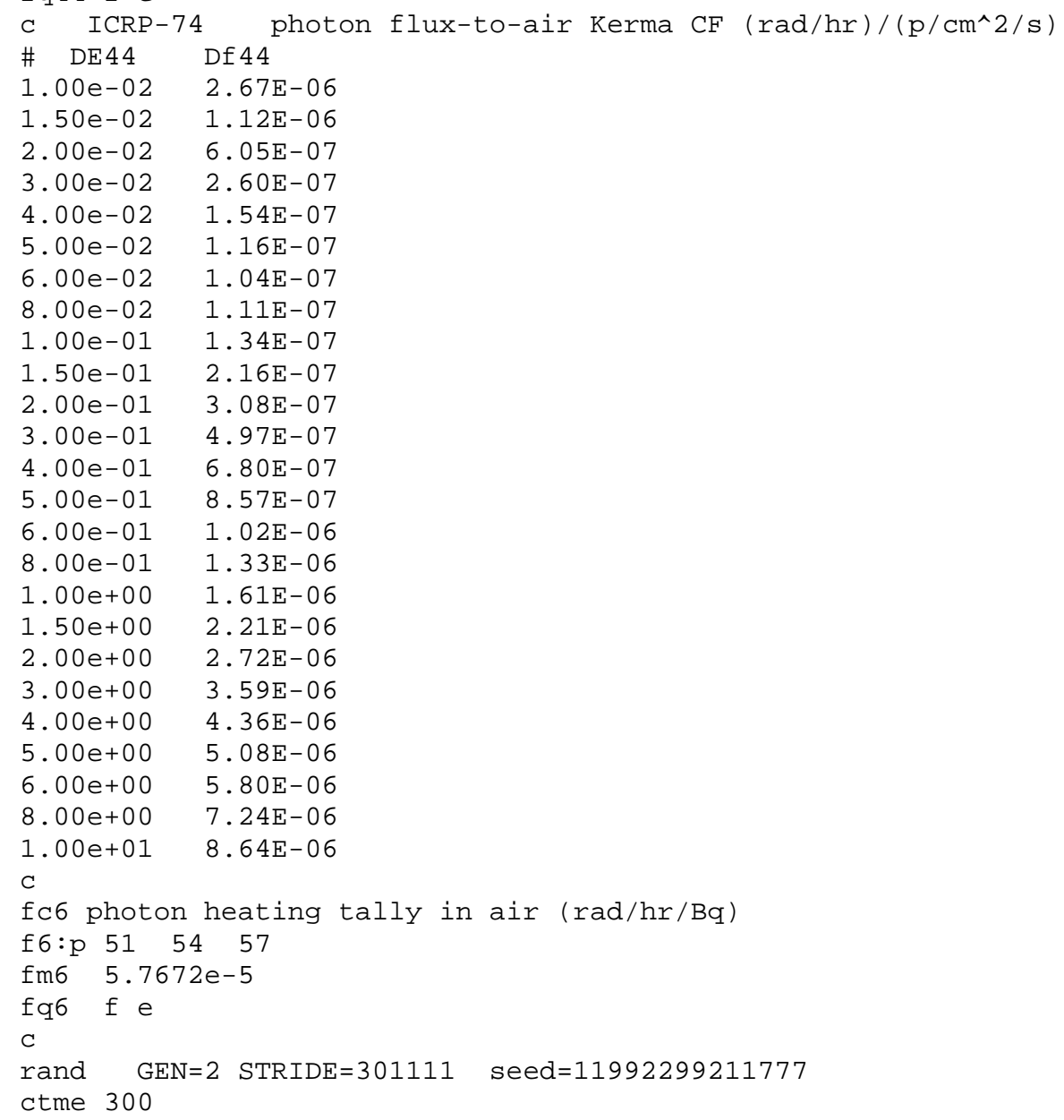


D2.4 HPGe detector (GEM-15190-P) efficiency calculation

c This file models the GEM-15190-P HPGe detector (SN: 33-TP30846)

c The dead layer on top of the crystal is much thicker than specified in the

c manual, the distance between the crystal and Al can is also adjusted

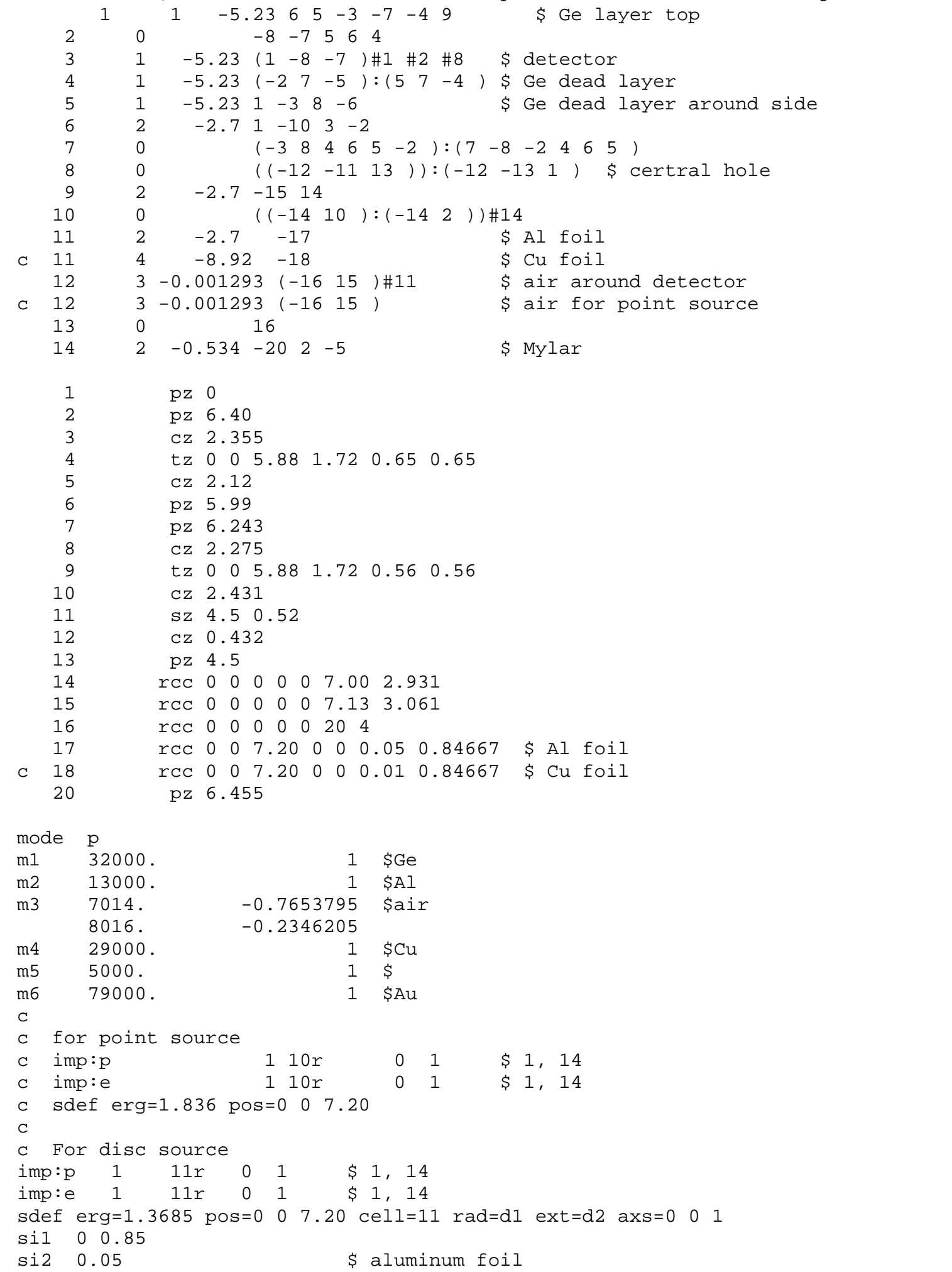


C si2 $0.01 \quad \$$ copper foil

e8 $\odot 1999 i 2.0$

f8:p 3

c ft8 geb $9.374 \mathrm{e}-4 \quad 5.202 \mathrm{e}-4 \quad 0.75967$ nps 1 e 7 


\section{REFERENCES}

[1] J. Bruce, R. C. Anderson, F. T. PharmD, M.J. Kahn, R. McKenna, and .Macdonald, Glioblastoma Multiforme, http://www.emedicine.com/med/topic2692.htm (last visited June 7, 2006)

[2] K.K. Herfarth, S.Gutwein, and Debus J. Postoperative radiotherapy of astrocytomas. Seminars in Surgical Oncology, 20:13-23, 2001

[3] M. Catterall, H.J.G. Bloom, D.V. Ash, L. Walsh, A. Richardson, D. Uttley, N. Gowing, P. Lewis, and B. Chaucer, Fast neutrons compared with megavoltage Xrays in the treatment of patients with supratentorial gioblastoma: A controlled pilot study. Int. J. Radiation Oncology Bio. Phys., 6:261-266,1980.

[4] F.M. Waterman,F.T. Kuchnir, L.S. Skaggs, D.K. Bewley, B.C. Page, and F.H. Attix. The use of 10B to enhance the tumor dose in fast-neutron therapy. Phys. Med. Biol., 23(4):592-602,1978.

[5] W.H. Sweet. The use of nuclear disintegrations in the diagnosis and treatment of brain tumor. N. Engl. J. Med., 245:875-878, 1951.

[6] L.E.. Farr, W.H. Sweet, J.S. Robertson, C.G. Foster, H.G Locksley, D.L. Sutherland, M.L. Mendelsohn and E.E Stickley, Neutron Capture Therapy with Boron in the Treatment of Globlastoma Multiforme, AM J. Roentgenol 71:279-291,1954.

[7] IAEA-TECDOC-1223, Current status of neutron capture therapy, International Atomic Energy Agency, May 2001.

[8] P. M. Busse, O. K. Harling, M. R. Palmer, W.S. Kiger III, J. Kaplan, I. Kaplan, C, F. Chuang, J. T. Goorley, K. J Riley, T. H. Newton, G. A. Santa Cruz, X-Q. Lu and R. G. Zamenhof, "A critical examination of the results from the Harvard-MIT NCT program phase I clinical trial of neutron capture therapy for intracranial disease," $J$. Neuro-Oncol 62 pp. 111-121, 2003.

[9] W. S. Kiger III, X. Q. Lu, O. K. Harling, K. J. Riley, P. J. Binns, J. Kaplan, H. Patel, R. G. Zamenhof, Y. Shibata, I. D. Kaplan, P. M. Busse, M. R. Palmer, "Preliminary treatment planning and dosimetry for a clinical trial of neutron capture therapy using fission converter epithermal neutron beam," Appl. Radiat. Isot. 61 pp 1075-1081, 2004. 
[10] Y. Nakagawa, K. Pooh, T. Kobayashi and T. Kageji, Clinical review of the Japanese experience with boron neutron capture therapy and a proposed strategy using epithermal neutron beams, J. Neuro-Oncol., 62, pp87-99, 2003

[11] T. Yamamoto, A. Matsumura, K. Nakai, Y. Shibata, K. Endo, F. Sakurai, T. Kishi, H. Kumada, K. Yamamoto and Y. Torii, Current clinical results of Tsukuba BNCT trial, Appl. Rad. Isot. 61: pp 1089-1093, 2004

[12] IAEA-TECDOC-1223, Current status of neutron capture therapy, International Atomic Energy Agency (IAEA), May 2001.

[13] Chanana, A.D., Capala, J., Chadha, M., Coderre, J.A., Diaz, A.Z., Elowitz, E.H., Iwai, J., Joel, D.D., Liu, H.B., Ma, R., Pendzick, N., Peress, N.S., Shady, M.S., Slatkin, D.N., Tyson, G.W. and Wielopolski, L., Boron neutron capture therapy for glioblastoma multiforme: Interim results from the phase I/II dose-escalation studies. Neurosurgery 44, pp. 1182-1193, 1999.

[14] J.A. Coderre, J.W. Hopewell, J.C. Turcotte, K.J. Riley, P.J. Binns, W.S. Kiger III, and O.K. Harling, Tolerance of normal haman brain to boron neutron capture therapy, Appl. Rad. Isot. 61, pp 1083-1087, 2004.

[15] Coderre, J. A., Makar, M.S., Micca, P. L., Nawrocky M.M., Liu, H.B., Joel, D.D., Slatkin, D.N., Amols, H.I., Derivation of relative biological effectiveness for the high-let radiations produced during boron neutron capture irradiations of 9L rat gliosarcomar in vitro and in vivo. Int. J. Radiat. Oncol. Biol. Phys. 27: 1121-1129, 1993.

[16] Morris, G.M., et al., Response of the central nervous system to boron neutron capture irradiation: evaluation using rat spinal cord model, Radiother. Oncl. 32 (1994), pp.249-255.

[17] Coderre, J.A. and Morris, G.M., 1999. The radiation biology of boron neutron capture therapy. Radiat. Res. 151, pp. 1-18.

[18] Coderre, J.A., Turcotte, J.C., Riley, K.J., Binns, P.J., Harling, O.K. and Kiger III, W.S., 2003. Boron neutron capture therapy: cellular targeting of high linear energy transfer radiation. Technol. Cancer Res. Treatment 2, pp. 355-375.

[19] T. Kageji, S. Nagahiro, Y. Mizobuchi, H. Toi, Y. Nakagawa and H. Kumada, Radiation injury of boron neutron capture therapy using mixed epithermal- and 
thermal neutron beams in patients with malignant glioma, Appl. Rad. Isot. 61. PP. 1063-1067, 2004.

[20] Palmer, M.R., Goorley, J. T., Kiger, III W. S., Busse, P. M., Riley K. J., Harling, O. K., Zamenhof, R. G., Treatment planning and dosimetry for the Harvard-MIT phaseI clinical trial of cranial neutron capture therapy. Int. J. Radiat. Oncol. Biol. Phys. 53: 1361-1379, 2002.

[21] Ono, K. Masunaga, S. Kinashi, Y., Takagaki, M., Kobayashi, T. Imahori Y., Ueda, S., Oda, Y., The dose planning of BNCT for brain tumors. In : Mishima, Y. (ed) Cancer Neutron Capture Therapy. Plenum Press, New York, pp 563-569. 1996.

[22] Hideghety, K., Sauerwein, W., deVries, M., Grochulla, F., Goetz, C., Haselsberger, K., Paquis, P., Heimans, J., Wolbers, J., Moss, R., Huiskamp, R., StecherRasmussen, F., Rassow, J., Garbe, S., Frankhauser, H., Gabel, D., Report on the first patient group of the European Phase I trial (EORTC Protocol 11961) at the High Flux Reactor Petten. In: Hawthorn, F.M., Shelley, K., Wiersema, R.J. (eds) Frontiers in Neutron Capture Therapy. Kluver Academic/Plenum Publishers, New York, pp 105-111, 2001.

[23] Busse, P.M., Zamenhof, R.G., Harling, O.K., Kaplan, I., Kaplan, J., Chuang, C.F., Goorley, J.T., Kigger III, W.S., Riley, K.J., Tang, L., Solares, G.R., Palmer, M.R., The Harvard-MIT BNCT program: overview of the clinical trials and translational research. In: Hawthorn, F.M., Shelley, K., Wiersema, R.J. (eds) Frontiers in Neutron Capture Therapy. Kluver Academic/Plenum Publishers, New York, pp 3760, 2001.

[24] Busse, P.M., Zamenhof, R.G., Madoc-Jones, H., Solares, G., Kiger III, W.S., Riley K. J., Chuang, C. F., Rogers, G., Harling O.K., Clinical follow-up of patients with melanoma of the etremity treated in a phase I boron neutron capture therapy protocol. In: Larsson, B., Crawford, J. Weinreich, R. (eds) Advances in Neutron Capture Therapy. Elsevier, Amsterdam, pp 60-64, 1997.

[25] Chadha, M., Capla, J., Coderre, J. A., Elowitz, E.H., Iwai, J., Joel, D.D., Liu, H.B., Wielopolski, L., Chanana, A. D. Boron neutron capture therapy (BNCT) for glioblastoma multiforme (GBM) using epithermal neutron beam at the Brookhaven National Laboratory. Int. J. Radiat. Oncol. Boil. Phys. 40: 829-843, 1998.

[26] Coderre, J.A., Chanana, A.D., Joel, D.D., Elowitz, E.H., Micca, P.L., Nawrocky, M.M., Chadha, M., Gebbers J.O., Shady, M., Peress, N.S., Slatkin, D.N., Biodistribution of boronophenylalanine in patients with glioblastoma multiforme: 
boron concentration correlates with tumor cellularity. Radiat. Res. 149: 163-170, 1998.

[27] Elowitz, E.H., Bergland, R.M., Coderre, J.A., Joel, D.D., Chadha, M., Chanana, A.D., Biodistribution of p-boronophenylalanine in patients with glioblastoma multiforme for use in boron neutron capture therapy. Neurosurgery. 42: 463-469, 1998.

[28] Kiger III, W.S., Palmer, M.R., Riley, K.J., Zamenhof, R.G., and Busse, P. M. A pharmacokinetic model for the concentration of ${ }^{10} \mathrm{~B}$ in blood after boronophenylalanine-fructose administration in humans. Radiat. Res. 155, 611-618, 2001 .

[29] Kiger III, W.S., Palmer, M.R., Riley, K.J., Zamenhof, R.G., and Busse, P. M. Pharmacokinetic modeling for boronophenylalanine-fructose mediated neutron capture therapy: ${ }^{10} \mathrm{~B}$ concentration predictions and dosimetric consequences. $J$. Neuro-Oncology 62: 171-186, 2003.

[30] J. Chadwick. Possible existence of a neutron. Nature, 129:312, 1932.

[31] J.H. Lawrence, P.C. Abersold, and E.O. Lawrence, Comparative effects of x-rays and neutrons on normal and tumor tissue. Proc. Natl. Acad. Sci. USA, 22(9):543557,1936 .

[32] R.S. Stone. Neutron therapy and specific ionization. Am. J. Roentgenol, 59:771785,1948 .

[33] D.K. Bewley, J.F. Fowler and R.L. Morgan, et al. Brit. J. Radiol. 36:107-15 (1963).

[34] M. Catterall, D. Bewley, Fast neutron in the treatment of Cancer, P. 5. London: Academic Press. PP. 394 (1979).

[35] A. J. Lennox and P.L. Petti, Hadronic Radiotherapy,P. 5-6, Fermilab-pub-94/204, 1994.

[36] Nuclear data for neutron therapy: Status and future needs. Technical Report IAEATECDOC-992, International Atomic Energy Agency (IAEA), Vienna, Austria, Decmber 1997. 
[37] K.R. Saroja, J. Mansell, F.R. Hendrickson, L. Cohen and A. Lennox, Failure of accelerated neutron therapy to control high grade astrocytomas, Int. J. Radiation Oncology Biol. Phys. 27:1295-97, 1989.

[38] Catteral, M., Bloom,H. J. G., Ash, D. V., Walsh, L.,Richardson, A., Uttley, D., Gowing, N. F. C., Lews, P., Chaucer, B., Fast neutrons compared with megavolt Xrays in the treatment of patients with supratentorial glioblastoma: a controlled pilot study, Int. J. Radiation Oncology Biol. Phys. Vol. 6, pp. 261-266, 1980.

[39] Buchholz, T.A., Laramore G. E., Stelzer K. J., Risler, R, Wootton, P and Griffin, T.W., Boron neutron capture enhanced radiotherapy for malignant gliomas and other tumors, J. Neuro-Oncol., 33:171-178, 1997.

[40] Nigg, D.W., Hartwell, J. K., Wemple, C.A.; Risler, R., Hartwell, J.K., Harker, Y.D., Venhuizen, J.R., and Risler. Spectral characterization of the University of Washington fast neutron therapy facility using activation foil technique. Transactions of the American Nuclear Society,V77, 1997, P351-2

[41] Nigg, D.W. ,Wemple, C.A.; Risler, R., Hartwell, J.K.; Harker, Y.D.; Laramore, G.E. Modification of the University of Washington Neutron Radiotherapy Facility for optimization of neutron capture enhanced fast-neutron therapy. Med. Phys, v 27, n 2, Feb. 2000, p 359-67.

[42] Nigg, D.W., Wemple, C.A.; Risler, R., Hartwell, J.K.; Harker, Y.D.; Laramore, G.E. Improved neutron sources for neutron capture enhanced fast neutron therapy. Transactions of the American Nuclear Society, V.82,2000, Pp116-17.

[43] R.L. Maughan, W. E. Powers and H.G. Blosser, A super conducting cyclotron for neutron radiation therapy, Med. Phys, v 21, n 6, June. 1994, pp 779-85.

[44] Maughan, R.L., Kota, C., and Yudelev, M. A microdosimetric study of the dose enhancement in a fast neutron beam due to boron neutron capture. Physics in Medicine and Biology, v 38, n 12, Dec. 1993, p 1957-61.

[45] C. Kota, R.L. Maughan, J. Burmeister, and J.D. Forman. A modified fast neutron therapy beam for boron neutron capture enhanced fast neutron therapy (BNCEFNT). In Borje Larsson, John Crawford, and Regin Weinreich, editors, Advances in Neutron Capture Therapy, Volume I. Elsevier, New York, 1997. 
[46] J. Burmeister, M. Yudelev, C. Kota, and R. L. Maughan. Boron neutron capture enhancement of fast neutron radiotherapy utilizing a moderated fast neutron beam. Med. Phys, Vol. 32, No. 3, pp. 666-672, March 2005.

[47] J.P. Pignol, P. Cuendet, N. Brassart et al., Combined use of FLUKA and MCNP-4A for the Monte Carlo simulation of the dosimetry of ${ }^{10}$ Boron neutron capture enhancement of fast neutron. Med. Phys. 25 (1998), pp. 885-891.

[48] Jean-Philippe Pignol, Philippe Paquis, Pascal Cuendet, David Gibon, Cheikh M'Bake Diop and Roland Sabattier, Beam collimation and bolusing material optimizations for 10boron neutron capture enhancement of fast neutron (BNCEFN): definition of the optimum irradiation technique, Int. J. Radiation Oncology Biol. Phys, Volume 43, Issue 5, 15 March 1999, Pages 1151-1159.

[49] I. Rosenberg and M.Awschalom. Characterization of a p(66)Be(49) neutron therapy beam I: Center axis depth dose and off-axis ratios. Med. Phys., 8:105-107,1981.

[50] M.Awschalom and I. Rosenberg, Fermilab Cancer Therapy Facility, Neutron Beam Calibration and Treatment Planning, Fermilab Technical Memo TM-0834, 1978

[51] Katja M. Langen. Microdosimetric Investigations at Fast Neutron Therapy facility at Fermilab. PhD thesis, University of Wisconsin-Madison, 1997.

[52] Laurie S. Waters, editor. MCNPX User's Manual, Version 2.1.5. Los Alamos National Laboratory, 1999. LA-UR-99-6058.

[53] J. E. Sweezy, Development of a Boron Neutron Capture Enhanced Fast Neutron Therapy Beam. PhD. Thesis, Georgia Institute of Technology, 2002.

[54] Standard Imaging, Inc., 7601 Murphy Drive, Middleton, Wisconsin 53562-2532. phone: 800-261-4446, Fax: 608-831-2202, Internet: http://www.standardimaging.com/ (last visited: October, 2005).

[55] AAPM Report No. 7. Protocol for neutron beam dosimetry. Technical report, American Association of Physicists in Medicine, Madison, WI,1980.

[56] G.M. Hale and P.G. Young. ENDF/B-VI version 1, material 525 B-10 (neutron), 1991. 5-B-10 LANL EVAL-NOV89. 
[57] J. E. Sweezy, A. Lennox, and N.E. Hertel, Paired Tissue Equivalent Ionization Chambers for Boron Enhancement Fast Neutron Therapy, $10^{\text {th }}$ International Congression Neutron Capture Therapy, NCT Essen 2002, September 8-11, 2002, Essen, Germany.

[58] J. A. Grundl, D. M. Gilliam, N.D. Dudey, and R.J. Popek, Measurement of absolute fission rates, Nuclear Technology, Vol 25, pp.273-257, 1975

[59] V.R. CUPPS, A.J. Elwyn, A. J. Lennox, and T. Kroc, "Fermilab NTF Neutron Beam Energy Spectrum by Foil Activation," Proceedings of the 44th Annual Meeting of the Radiation Research Society, Chicago, April 14-17, p. 114,Radiation Research Society, (1996)

[60] M.A. Ross, P. M. Deluca Jr., D.T. L. Jones, A. Lennox and R. L. Maughan, Calculated Fluence Spectra At Neutron Therapy Facilities, Radiation Protection Dosimetry, v 70, n 1-4, 1997, p 481-4

[61] D. T. L. Jones, J. E. Symons, and T. J. Fulcher, Neutron Fluence and Kerma spectra of a p(66)Be(40) Clinical Source, Med. Phys. 19 (5), 1285, 1992.

[62] M. B. CHADWICK, P. G YOUNG, et. al., "Cross Section Evaluations to $150 \mathrm{MeV}$ for Accelerator-Driven Systems and Implementation in MCNPX", Nucl Sci. Eng, 131 3, 293 (1999).

[63] J. K. Tuli, Nuclear Wallet Cards, National Nuclear data Center, January, 2000.

[64] D.C. Kocher. Radioactive Decay Data Tables, A Handbook of Decay Data for Application to Radiation Dosimetry and Radiological Assessments. Oak Ridge, Tennessee. Oak Ridge National Laboratory Technical Information Center, U.S. Department of Energy. 1981.

[65] Z. Wang, B. Kahn and J. Valentine, "Efficiency calculation and coincidence summing correction of a germanium detector by Monte-Carlo simulation", 2001 IEEE Nuclear Science Symposium Conference Record (Cat. No.01CH37310), 2002, pt. 2, p 1037-41 vol.2

[66] R. B. Firestone, V. S. Shirley, editor, and C. M Baglin, S. Y. Frank Chu, and J. Zipkin, assistant editor, Table of Isotopes, Eighth edition, Vol. 1. P. 52. John Wiley \& Sons, Inc., 1996. 
[67] M. REGINATTO, The "Few-Channel" Unfolding Programs in the UMG Package: MXD_FC33, GRV_FC33 and IQU_FC33, UMG package, Version3.3-release

[68] M. Rehinatto and P. Goldhagen, MAXED, A computer Code for the Deconvolution of Multisphere Neutron Spectrometer Data Using the Maximum Entropy Method, Environmental Measurements Laboratory, USDOE Report EML 595 (1998).

Available at http://www.eml.doe.gov/publications/reports/(last accessed June, 2006).

[69] M. Rehinatto and P. Goldhagen, MAXED, A computer Code for the Deconvolution of Multisphere Neutron Spectrometer Data Using the Maximum Entropy Method, Health Phys. 77, 579 (1999).

[70] M. Rehinatto and P. Goldhagen, and S. Neumann, Spectrum unfolding, sensitivity analysis and propagation of uncertainties with maximum entropy deconvolution code MAXED, Nucl. Instr. And Meth. A 476, 242 (2202).

[71] RSVP phantom ${ }^{\mathrm{TM}}$ Manual, available on-line (last accessed June,2006) at http://www.phantomlab.com/pdf/RSVP_phantom_manual_1299.pdf

[72] White Rock Science. BodyBuilder, www.whiterockscience.com/wrs.html (Accessed May 18, 2005).

[73] Van Riper, K.A. White Rock Science Tools for Geometry Modeling. Transactions of the American Nuclear Society, Volume 91, 2004.

[73] R. C. Little and R. E. Seamon, "Dosimetry/Activation Cross Sections for MCNP,'Los Alamos National Laboratory internal memorandum, March 13, 1984 (available on-line http://wwwxdiv.lanl.gov/PROJECTS/DATA/nuclear/pdf/dosimetry.pdf).

[75] Rad toolbox V 1.0.0, available on line at http://ordose.ornl.gov/downloads.html (last visit June 3, 2006).

[76] International Commission on Radiological Protection, ICRP Publication 38: Radionuclide Transformations: Energy and Intensity of Emissions, 1984.

[77] ANS-6.1.1 Working Group, M. E. Battat (Chairman), "American National Standard Neutron and Gamma-Ray Flux-to-Dose Rate Factors," ANSI/ANS-6.1.1-1977 (N666), American Nuclear Society, LaGrange Park, Illinois (1977). 
[78] ICRP Committee 3 Task Group, P. Grande and M. C. O'Riordan, chairmen, "Data forProtection Against Ionizing Radiation from External Sources: Supplement to ICRPPublication 15," ICRP-21, International Commission on Radiological Protection, Pergamon Press (April 1971).

[79] ICRP publication 74: Conversion Coefficients for use in Radiological Protection against External Radiation, Annals of the ICRP, Volume 26 No. 3/4 (1996) Pergamon.

[80] D. Biswas, "Rad-in Tissue versus Rad-in-Air"- A look at the Difference and its Effect on 12-Rad Zone Analysis, WSRC-MS-2002-00472, Available electronically at http://sti.srs.gov/fulltext/ms2002472/ms2002472.html (last accessed May,2006) 